\title{
UAB
}

Universitat Autònoma de Barcelona

Facultat de Ciències

Departament de Química

\section{Flexible Approach to Stemona Alkaloids: Total Syntheses of (-)-Stemospironine and Three New Diastereoisomeric Analogs}

\section{TESI DOCTORAL}

Programa de Doctorat en Química

Núria Bardají Valls

2013

Dirigida per:

Dra. Marta Figueredo i Galimany Dr. Félix Busqué Sánchez 

Memòria presentada per aspirar al grau de Doctor per Núria Bardají Valls

Núria Bardají Valls

Vist i plau 

INDEX 

INDEX

Reagent and Solvent Acronyms 1

Formula Index 5

1.1. Introduction 15

1.1.1. Stemona alkaloids. Natural sources and properties ............................. 15

1.1.2. Structural classification ............................................................. 18

1.1.3. Synthetic precedents ..................................................................... 20

1.1.4. Retrosynthetic analysis and previous work of the group ....................... 28

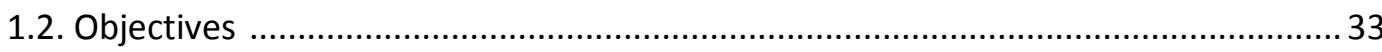

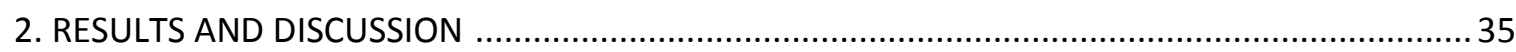

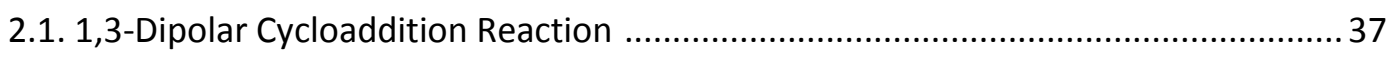

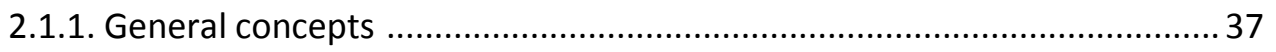

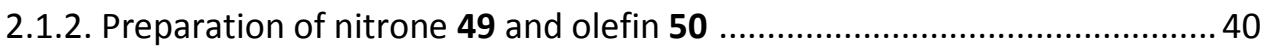

2.1.3. 1,3-Cycloaddition reaction of nitrone 49 to olefin 50 ..........................42

2.2. Construction of the pyrrolo[1,2-a]azepinone core. Synthesis of intermediate $52 \ldots 44$

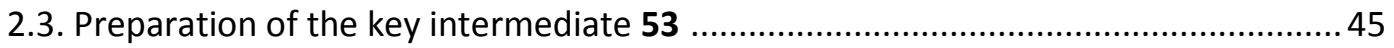

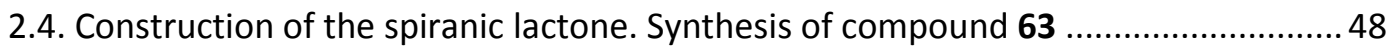

2.5. Construction of the "eastern" lactone. Synthesis of bislactone 106 ......................53

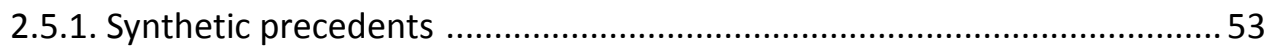

2.5.2. New strategy for the construction of the eastern lactone .......................56

2.6. Syntheses of two new diastereoisomeric analogs of stemospironine .....................58

2.6.1. Hydrogenation of the carbon-carbon double bonds of bislactones 106 and 107 61

2.6.2. Reduction of the lactam functionality in $\mathbf{1 1 5}$ and $\mathbf{1 1 8}$ 66

2.6.3. Attempt to epimerize 11-epi-stemospironine, $\mathbf{1 2 0}$ 71

2.7. New approach to the synthesis of (-)-stemospironine 72

2.7.1. Construction of the spiranic lactone. Synthesis of $\mathbf{1 2 6}$ 72 
2.7.2. Hydrogenation of the double bond and methylation. Synthesis of $\mathbf{1 2 8} \ldots 80$

2.7.3. Construction of the east-side lactone. Syntheses of 146 and $147 \ldots \ldots \ldots . . .83$

2.7.4. Hydrogenation of the eastern lactone. Syntheses of $\mathbf{1 1 4}$ and $\mathbf{1 1 7} \ldots \ldots \ldots . . .85$

2.7.5. Reduction of the lactam functionality. Syntheses of (-)-stemospironine

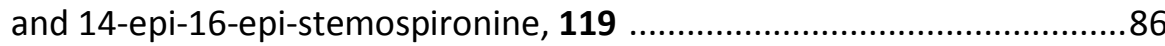

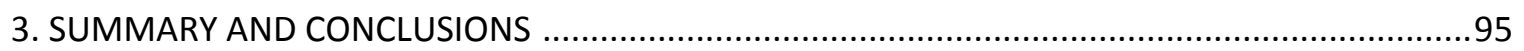

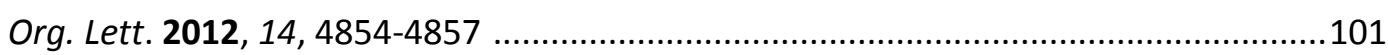

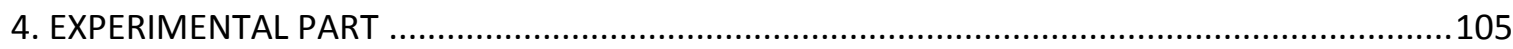

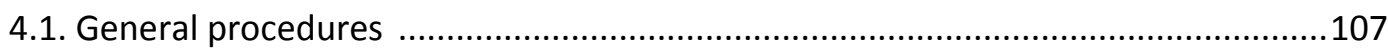

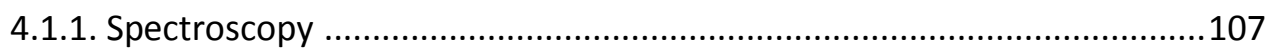

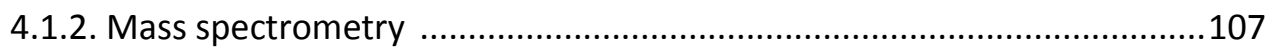

4.1.3. Chromatography ..........................................................................107

4.1.4. Optical rotatory power ......................................................................108

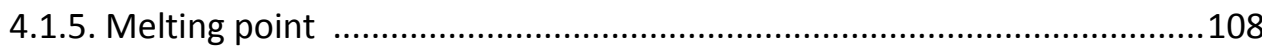

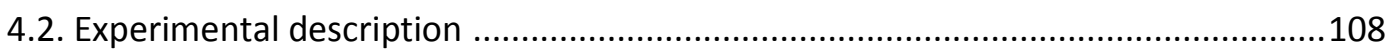

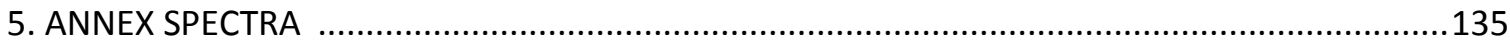

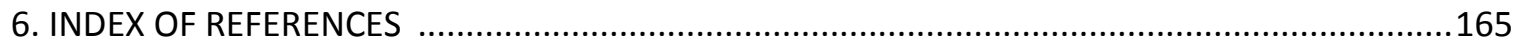


Reagent and Solvent Acronyms 



\begin{tabular}{|c|c|}
\hline DCC & $N, N^{\prime}$-dicyclohexylcarbodiimide \\
\hline DIAD & diisopropyl azodicarboxylate \\
\hline DIBAL-H & diisobutylaluminium hydride \\
\hline DIPT & diisopropyl tartarate \\
\hline DMAP & 4-dimethylaminopyridine \\
\hline DMD & dimethyldioxirane \\
\hline DME & dimethoxyethane \\
\hline DMF & dimethylformamide \\
\hline DMPI & Dess-Martin periodinane \\
\hline DMPU & $N, N^{\prime}$-dimethylpropylene urea \\
\hline DMS & dimethyl sulfide \\
\hline DMSO & dimethyl sulfoxide \\
\hline EDTA & ethylenediaminetetraacetic acid \\
\hline HMPA & hexamethylphosphoramide \\
\hline Im & imidazole \\
\hline LiHMDS & lithium bis(trimethylsilyl)amide \\
\hline MEM & methoxyethoxymethyl \\
\hline Ms & mesylate \\
\hline NCS & $\mathrm{N}$-chlorosuccinimide \\
\hline TBA & tetrabutylammonium \\
\hline TBDPS & ${ }^{t}$ butyldiphenylsilyl \\
\hline TEMPO & (2,2,6,6-tetramethylpiperidin-1-yl)oxyl \\
\hline TFA & trifluoroacetic acid \\
\hline TFMD & (trifluoromethyl)methyldioxirane \\
\hline THF & tetrahydrofuran \\
\hline TIPS-OTf & triisopropylsilyl trifluoromethanesulfonate \\
\hline TMEDA & $N, N, N^{\prime}, N^{\prime}$-tetramethylethylenediamine \\
\hline TMS & trimethylsilyl \\
\hline
\end{tabular}



Formula Index 



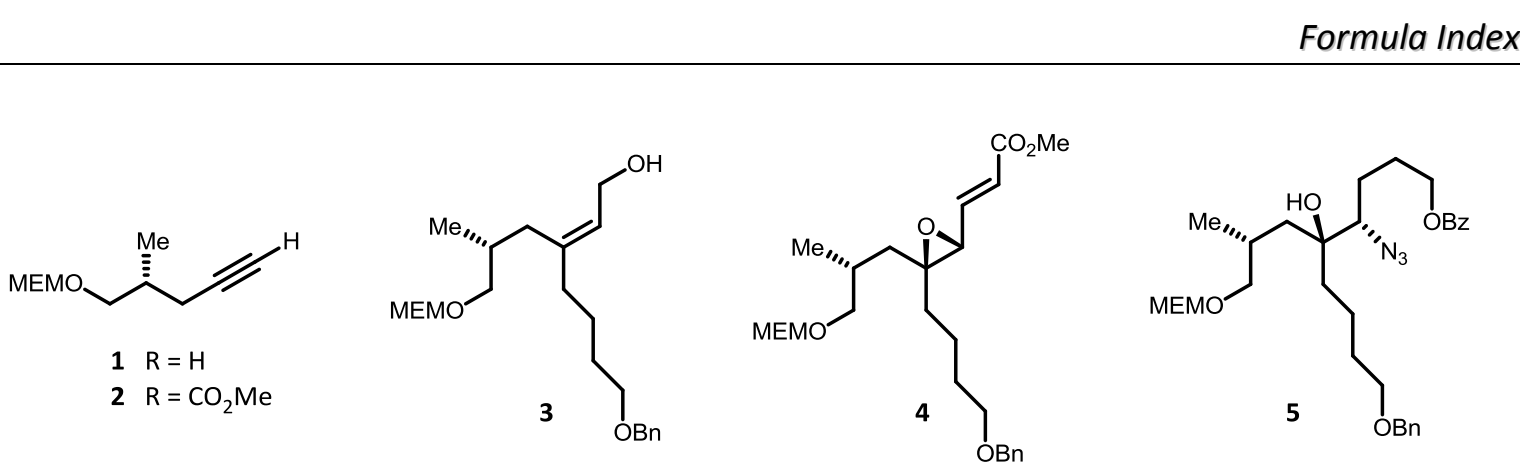

$$
\begin{aligned}
& \text { 蛏 }
\end{aligned}
$$

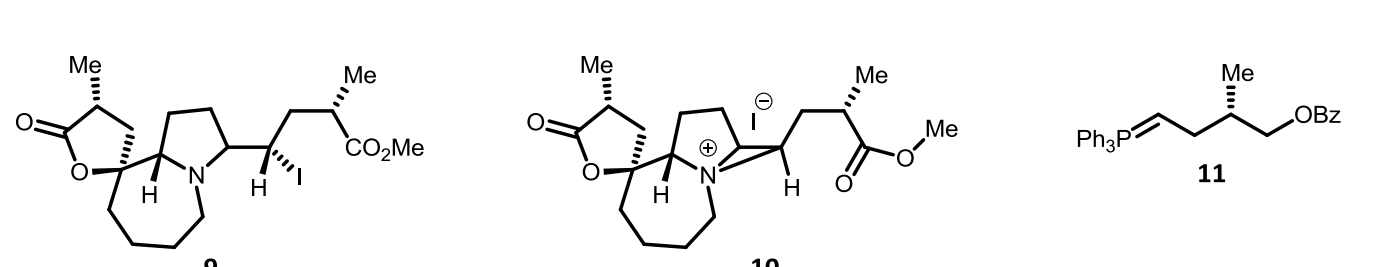

$$
\begin{aligned}
& 20 \text {. }
\end{aligned}
$$

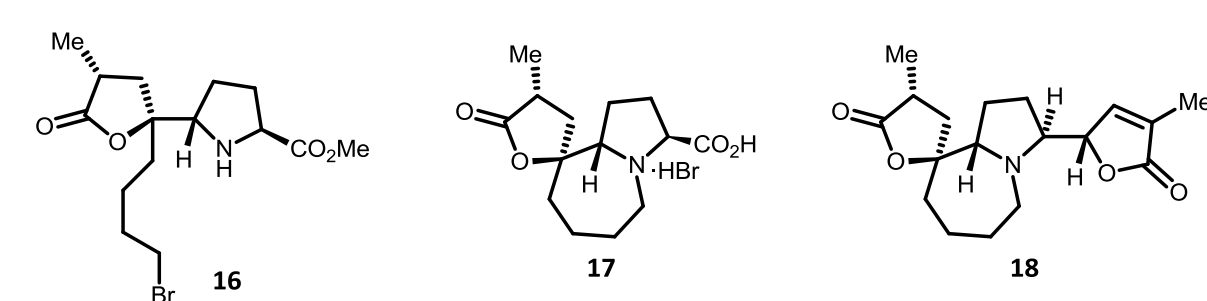

$$
\begin{aligned}
& \text { - } \\
& \text { ane wre } y
\end{aligned}
$$


<smiles>COC[C@@H](C)C/C(=C/CO)C(CCCOCc1ccccc1)OC</smiles>

26<smiles>COCCC[C@@H](N)C(O)(C[C@@H](C)COC)C(CCCOCc1ccccc1)OC</smiles>

29

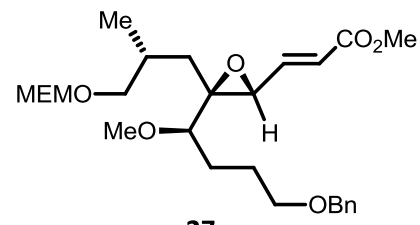

27

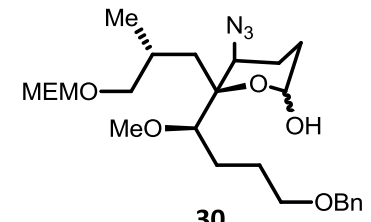

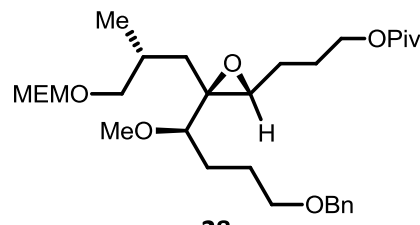

28

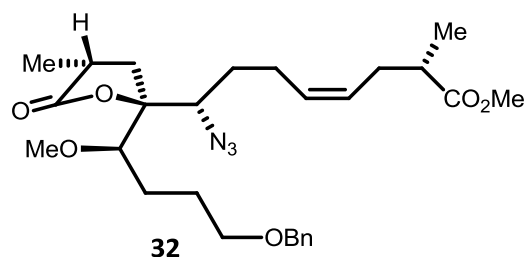<smiles>COC(=O)OCC(C)CCPP</smiles>

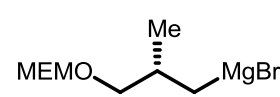

35<smiles></smiles>

36<smiles>COC(CCCOCc1ccccc1)C(O)(C[C@@H](C)CO)[C@H](N)CC/C=C/C[C@@H](C)CO</smiles>

31

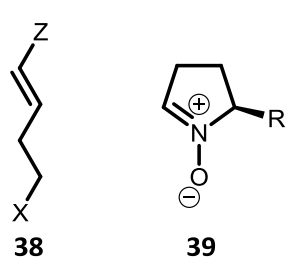<smiles>OCC1CCCN1</smiles>

40<smiles>OCC1CCCN1O[Ge]</smiles><smiles>Br[Mg]CCC1OCCO1</smiles>

45<smiles>CCOC(=O)C1CCC(=O)N1</smiles>

42

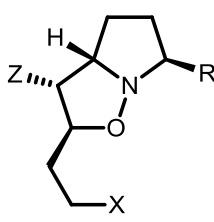

37

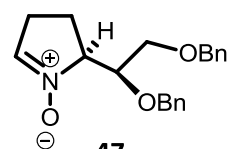

47<smiles>OCC1CCC=N1</smiles>

43

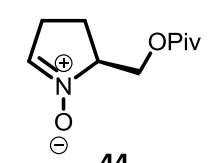

44<smiles>COC(=O)C=CCCCC(C)=O</smiles>

50

51<smiles>[O-]N1CCCC1CO[PbH]([O-])c1ccccc1</smiles>

48

53

52

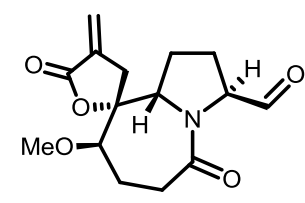

56

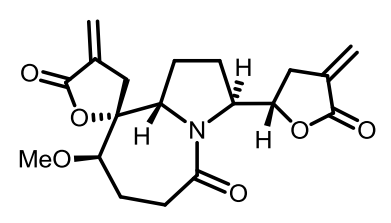

57

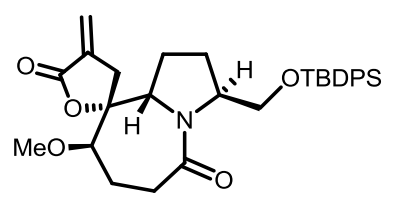

55

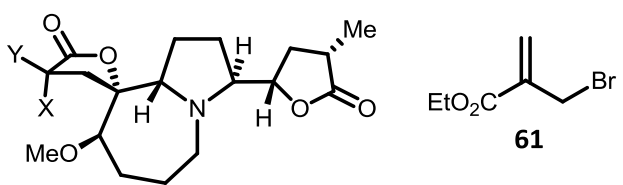

(-)-stemonidine, $\mathrm{X}=\mathrm{H}, \mathrm{Y}=\mathrm{Me}$

60, (-)-11-epi-stemonidine, $X=M e, Y=H$ 


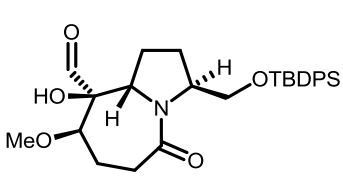

62

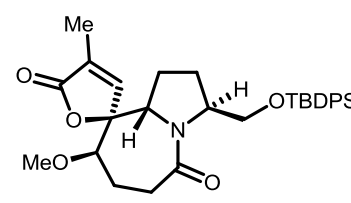

63

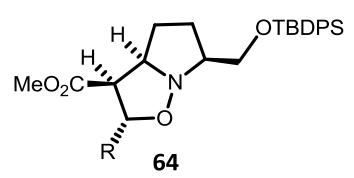

$\mathbf{R}=\mathrm{CH}_{2} \mathrm{CH}_{2} \mathrm{CO}_{2} \mathrm{Me}$

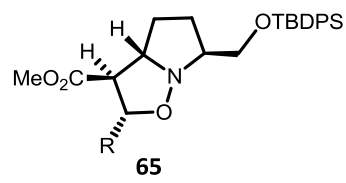

$\mathbf{R}=\mathrm{CH}_{2} \mathrm{CH}_{2} \mathrm{CO}_{2} \mathrm{Me}$

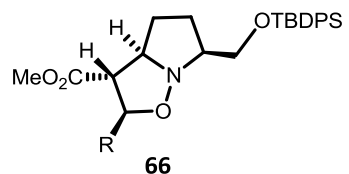

$\mathbf{R}=\mathrm{CH}_{2} \mathrm{CH}_{2} \mathrm{CO}_{2} \mathrm{Me}$<smiles>O=C(O)C1CCCN1</smiles>

67

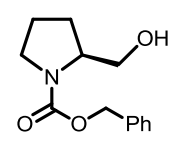

68

$\|_{69}$<smiles>COC(=O)CCCC(C(=O)OC)S(=O)O</smiles>

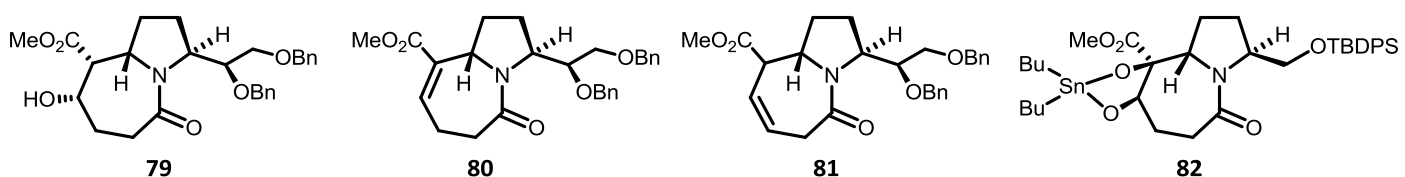

79

80

81

82

OtBd

83

84

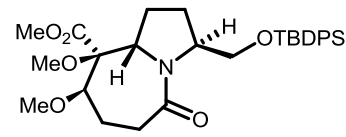

85

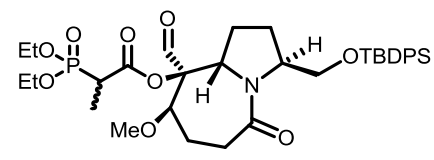

86 $\underbrace{\text { EtO-III }}_{\mathbf{8 7}}$
$\left.\right|_{\mathrm{EtO}} ^{\text {EtO }}$

88<smiles>[R]CC(=O)O</smiles>

89

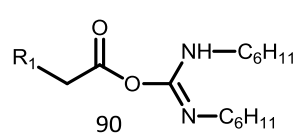<smiles>[X]C(=O)N1CCCC1C(O)CO</smiles><smiles>[R]CC(=O)O[R20]</smiles><smiles>[R]C=C=O</smiles><smiles>[X]C(C)(C)N1CCCC1C1CO1</smiles>

95<smiles>[R]C([R5])C(=O)O</smiles>

96

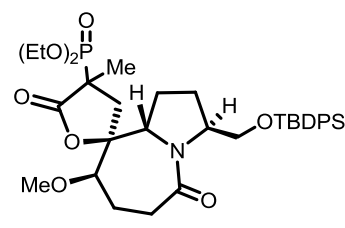

93

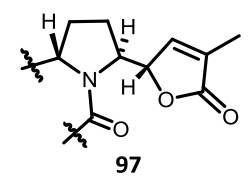

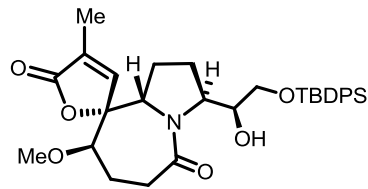

99<smiles>COC1CCC(=O)N2[C@@H]([C@@H](O)CO)CC[C@]23C=C(C)C(=O)O[C@]13C</smiles>

102

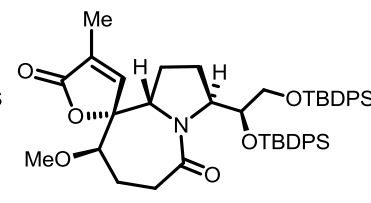

100
101

103 
<smiles>COC1CCC(=O)N2[C@@H](CO)CC[C@@]23C=C(C)C(=O)O[C@]13C</smiles>

104<smiles>C=C1C[C@H]([C@H]2CC[C@]3(C=C(C)C(=O)O3)[C@H]2C)OC(=O)CCC1OC</smiles>

107

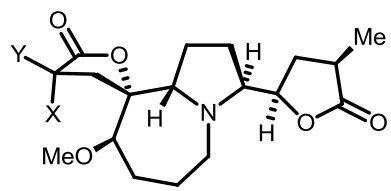

110, $X=H, Y=M e$

111, $X=M e, Y=H$

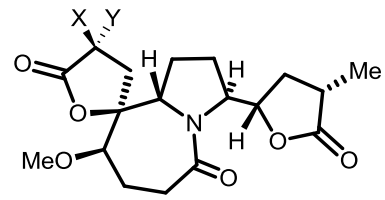

114, $\mathrm{X}=\mathrm{H}, \mathrm{Y}=\mathrm{Me}$

115, $X=M e, Y=H$

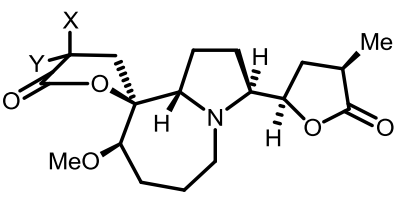

119, $\mathrm{X}=\mathrm{H}, \mathrm{Y}=\mathrm{Me}$

120, $X=M e, Y=H$

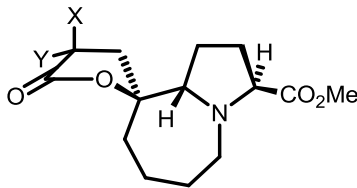

123, $\mathrm{X}=\mathrm{H}, \mathrm{Y}=\mathrm{Me}$

124, $X=M e, Y=H$

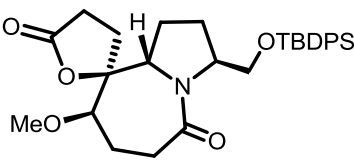

127

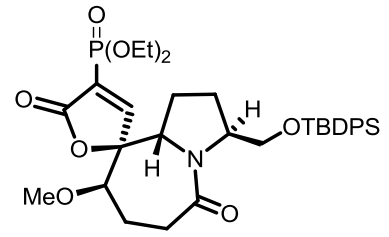

130

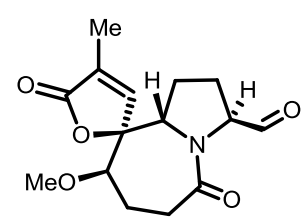

105

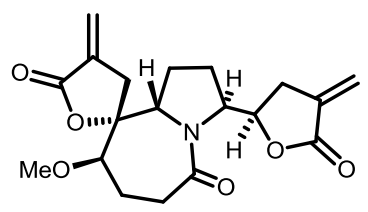

108

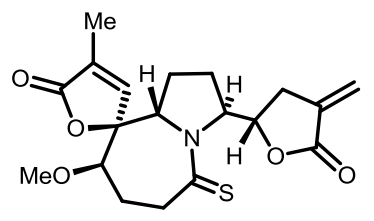

112

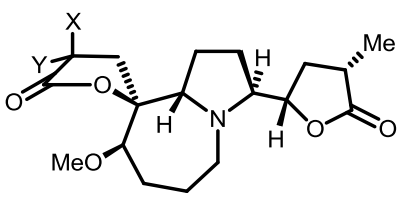

(-)-stemospironine, $\mathrm{X}=\mathrm{H}, \mathrm{Y}=\mathrm{Me}$ 116, $X=M e, Y=H$<smiles>[Y6]C1C[C@]23CCC([C@H]4C[C@H](C)C(=O)O4)N2C(=S)CCC(OC)[C@]3(C)OC1=O</smiles>

121

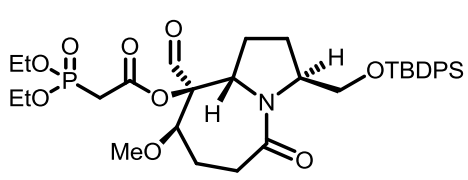

125

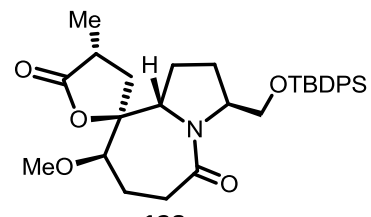

128

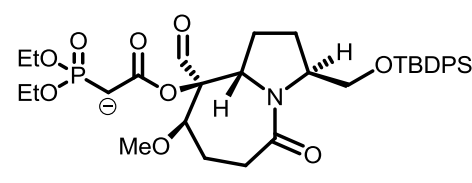

131

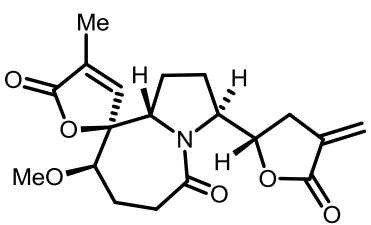

106

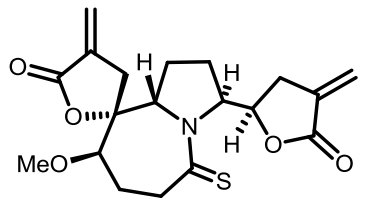

109

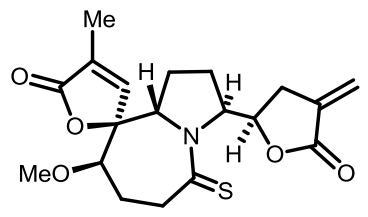

113

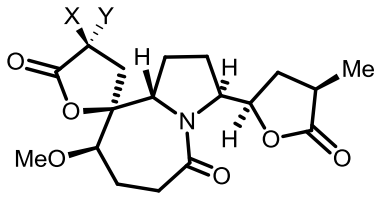

117, $X=H, Y=M e$

118, $X=M e, Y=H$

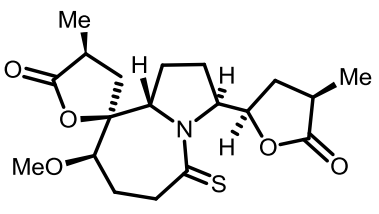

122

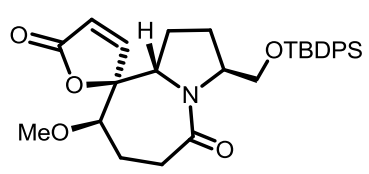

126

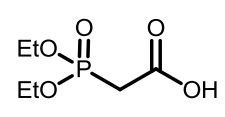

129

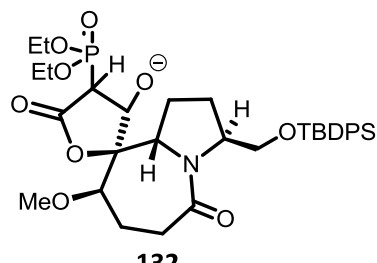

132 


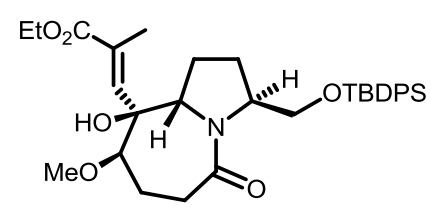

133

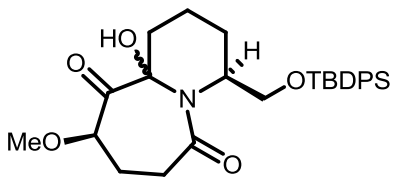

136<smiles>CCO[P+](=O)C1=CC(C)(C)OC1=O</smiles>

139<smiles>CO[C@H]1CCC(=O)N2C(CO)CC[C@@]23C[C@H](C)C(=O)O[C@]13C</smiles>

144

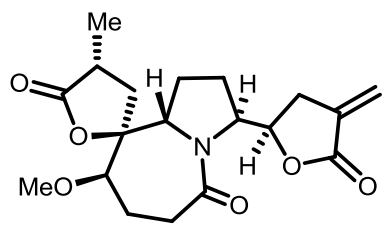

147

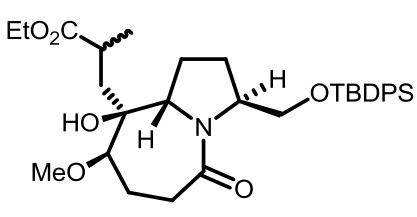

134

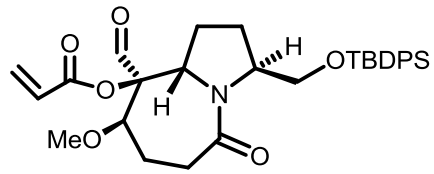

137<smiles>CCOC1C(=O)OC(C)(C)C1[Po]([O-])OCC</smiles><smiles>CC1(C)C=CC(=O)O1</smiles>

142

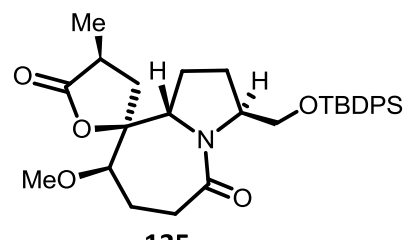

135

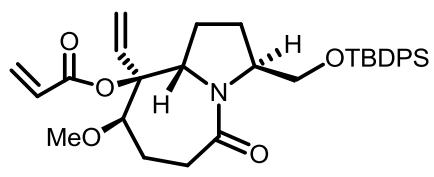

138

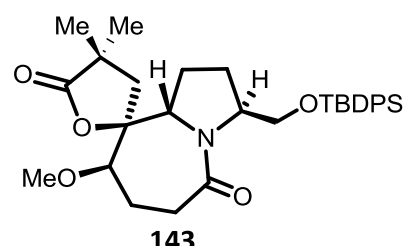

145

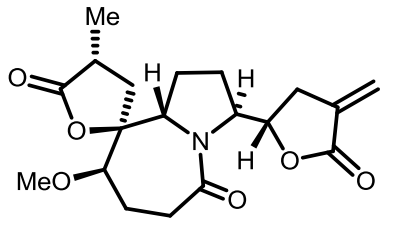

146
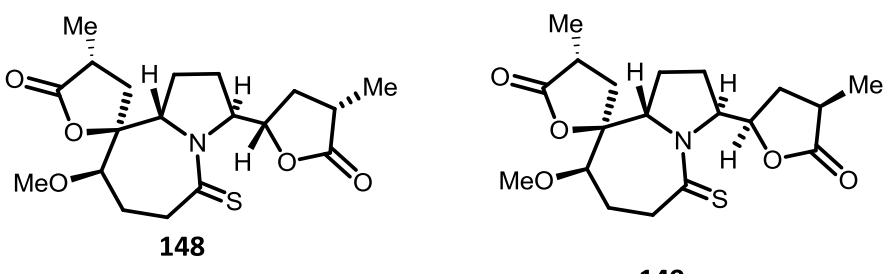

1. Introduction and Objectives 



\subsection{INTRODUCTION}

\subsubsection{Stemona alkaloids. Natural sources and properties}

Throughout history, folk medicine from all civilizations has found in Nature all kind of plants that provided remedies against a great variety of diseases. The deep knowledge of plant curative properties acquired by this medicine has motivated the scientific community towards the isolation and characterization of their bioactive components in order to develop new drugs.

The extracts of several plants of the Stemonaceae family have long been used in China, Japan, and other Asian countries for the treatment of respiratory disorders, such as bronchitis and tuberculosis, as antihelmintics and also as domestic insecticides. ${ }^{1}$ The Stemonaceae family consists of three genera, being Stemona the most representative of them (Figure 1). Three of its species, S. Tuberosa, S. Japonica and S. Sessilifolia, are officially listed in the 2000 Edition of Chinese Pharmacopoeia as medicinal herbs. Significant constituents of these species are a series of structurally related secondary metabolites, named Stemona alkaloids, that may be responsible for their medicinal and antiparasitic properties, although studies on the specific biological activities of individual members of this alkaloid family are quite limited. ${ }^{2}$

Kingdom: Plantae

Division: Magnoliophyta

Class: Liliopsida

Order: Dioscoreales

Family: Stemonaceae

Genera: Stemona: contains 34 species located in Asia and Australia

Croomia: contains 3 species located in North America and Japan

Stichoneuron: contains 2 species located in the west of Asia

Figure 1. Taxonomy tree of the Stemonaceae family.

\footnotetext{
${ }^{1}$ (a) Pilli, R. A.; de Oliveira, M. C. F. Nat. Prod. Rep. 2000, 17, 117-127; (b) Pilli, R. A.; Rosso, G. B.; de Oliveira, M. C. F.; in: The Alkaloids (Ed.: G.A. Cordell), Elsevier, New York, 2005, 62, 77-173; (c) Greger, H.; Planta Med. 2006, 72, 99-113; (d) Pilli, R. A.; Rosso, G. B.; de Oliveira, M. C. F.; Nat. Prod. Rep. 2010, 27, 1908-1937.

${ }^{2}$ Figueredo, M.; Alibés, R. Eur. J. Org. Chem. 2009, 2421-2435.
} 
The marketing of mixtures of dry roots from the species S. japonica, S. tuberosa and $S$. sessilifolia, commonly known as Bai $\mathrm{Bu}$, and their use as infusion is an extended practice in the oriental medicine. ${ }^{3}$ Moreover, there is a huge amount of patents for the use of the extracts of these plants in a wide range of fields, such as biodegradable insecticides to control plagues, ${ }^{4}$ detergent formulation, ${ }^{5}$ shampoo, ${ }^{6}$ insect repellent, ${ }^{7}$ drugs for the treatment against asthma ${ }^{8}$ and tuberculosis, ${ }^{9}$ among others.

Tuberostemonine was the first Stemona alkaloid to have its biological activity tested (Figure 2), ${ }^{1}$ showing activity against the helminth Angiostrongylos cantonensis (responsible for meningitis), Dipylidium caninum (canine intestinal parasite) and Fasciola hepatica (parasite that infects herbivorous vertebrate animals). Its activity on the neuromuscular transmission in crayfish (model to study the interaction of drugs in the mammalian central nervous system) revealed that tuberostemonine depressed glutamate-induced responses at similar levels of those of established glutamate inhibitors. ${ }^{10}$ The insecticide activity of stemonine, stemospironine and stemofoline was also tested, revealing positive results against the silk worm larvae. ${ }^{11}$

Didehydrostemofoline, which has an unsaturated $n$-butenyl side chain, showed high insecticidal activity against the larvae of Spodoptera littoralis, ${ }^{12}$ whereas stemofoline, characterized by a saturated n-butyl side chain, revealed less insecticidal properties. Furthermore, didehydrostemofoline exhibits nanomolar activity against different carcinoma cell lines and possesses potent in vivo anti-oxytocin activity (decreases uterine contractions). ${ }^{13}$

\footnotetext{
${ }^{3}$ There are several webpages where the use and marketing of products containing extracts of these plants are described.

${ }^{4}$ Shenging, F.Z. CN 102643134 A 20120822; Liren, Z.; Yuebin, Z. CN 1054349 A 19910111; (c) Maoxuan, L.; Guangyu, Y. CN 1308871 A 20010822; (d) Changan, W.; Zhaoming, W. CN 1120890 A 19960424.

${ }^{5}$ Ahaoli, C. CN 1129733 A 19960828.

${ }^{6}$ (a) Xianliang, H. CN 1247893 A 20000322; (b) Minqui, D.; Jihua, X.; Chengjing, W. CN 1301533 A 20010704.

7 (a) Shenging, Z. CN 102640765 A 20120822; (b) Shuili, X. CN 1186604 A 19980708.

${ }^{8}$ (a) Shenging, F. Z. CN 102614434 A 20120801; (b) Quingyun, M.; Yingchun, C. CN 102552773 A 20120711; (c) Hongbo, Z.; Xiaming, Z. CN 102526662 A 20120704.

${ }^{9}$ (a) Junrui, M. CN 1265315 A 20000906; (b) Lisheng, S. CN 102579928 A 20120718; (c) Yanke, L. CN 102166304 B 20120425

${ }^{10}$ Shinozaki, H.; Ishida, M. Brain Res. 1985, 334, 33-40.

${ }^{11}$ Sakata, K.; Aoki, K.; Chang, C.-F.; Sakurai, A.; Tamura, S.; Murakoshi, S. Agric. Biol. Chem. 1978, 42, 457-463.

${ }^{12}$ Brem, B.; Seger, C.; Pacher, T.; Hofer, O.; Vajrodaya, S.; Greger. H. J. Agric. Food Chem. 2002, 50, 6383-6388.

${ }^{13}$ (a) Sekine, T.; Ikegami, F.; Fukasawa, N.; Kashiwagi, Y.; Aizawa, T.; Fujii, Y.; Ruangrungsi, N.; Murakoshi, I. J. Chem. Soc. Perkin Trans. 1, 1995, 391-393; (b) Tip-Pyang, S.; Tangpraprutgul, P.; Wiboonpun, N.; Veerachato, G.; Phuwapraisirisan, P.; Sup-Udompol, B. ACGC Chem. Res. Commun. 2000, 12, 31-35.
} 


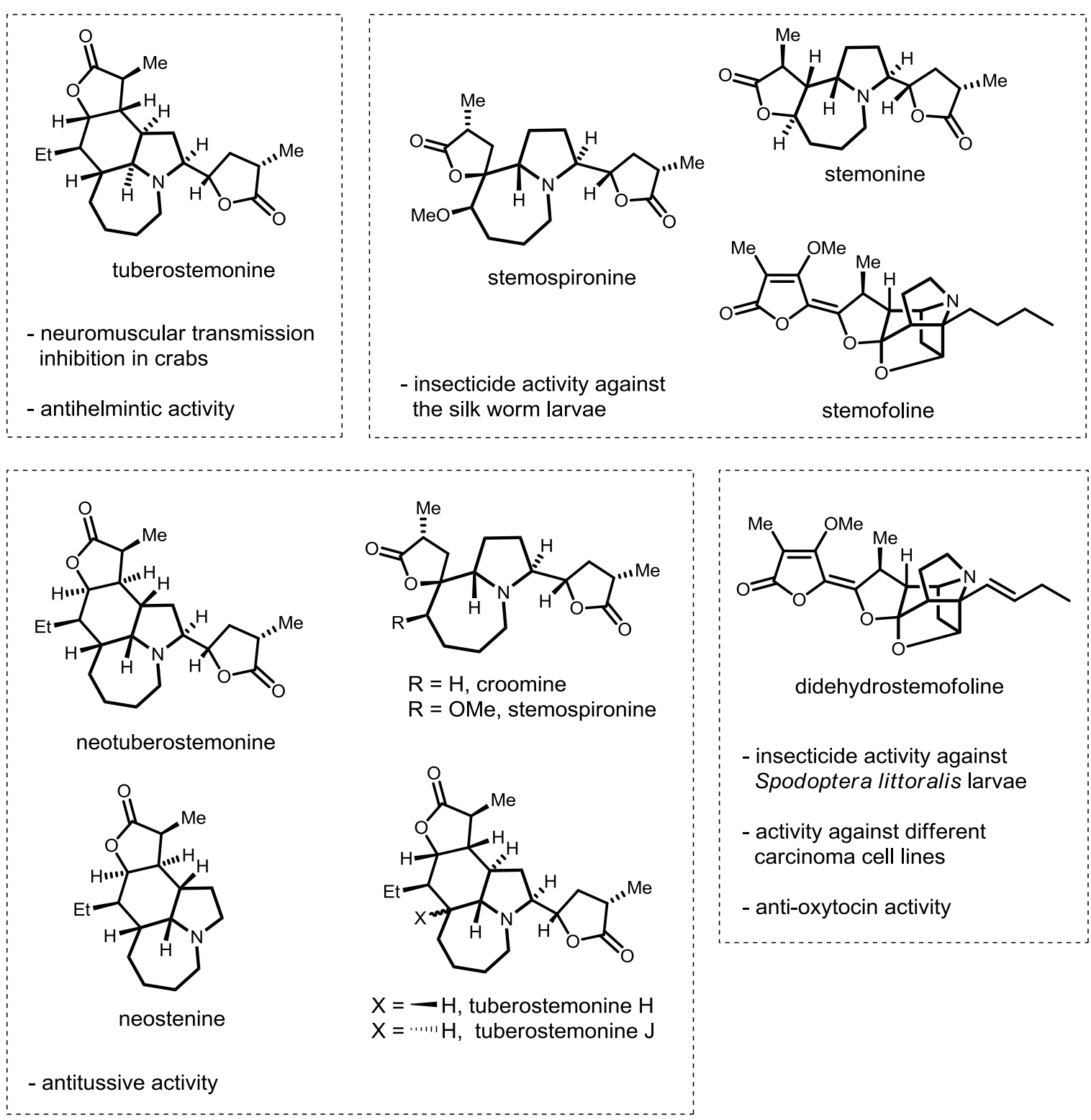

Figure 2. Biological activity of some Stemona alkaloids.

On the other hand, croomine, stemospironine, neostenine, tuberostemonine J, tuberostemonine $\mathrm{H}$ and neotuberostemonine were examined for antitussive activity in guinea pig after cough induction. It was demonstrated that all these compounds showed significant antitussive activities, although they do not act on the same sites of cough reflex. Further studies on structure-activity relationship with seven related compounds revealed that the saturated tricyclic pyrrolobenzazepine nucleus of tuberostemonine (stenine group) is the prerequisite for antitussive activity. ${ }^{14}$

${ }^{14}$ (a) Chung, H.-S.; Hon, P.-M.; Lin, G.; But, P. P.-H.; Dong, H. Planta Med. 2003, 69, 914; (b) Xu, Y. T.; Shaw, P. C.; Jiang, R. W.; Hon, P. M.; Chan, Y. M.; But, P. P. J. Ethnopharmacol. 2010, 128, 679-684; (c) Yang, X. Z.; Zhu, J. Y.; Tang, C. P.; Ke, C. Q.; Lin, G.; Cheng, T. Y.; Rudd, J. A.; Ye, Y. Planta Med. 2009, 75, 174-177; (d) Wang, W.; Wang, X.; Sun, H.; Dong, 
In preliminary anti-tumor tests, crude extracts of plants of the genera Stemona were investigated for their effect on medullary thyroid carcinoma cells and $\mathrm{S}$. tuberosa extracts showed an enhancement of apoptosis. ${ }^{15}$

\subsubsection{Structural classification}

All the Stemona alkaloids are polycyclic and most of them possess a central pyrrolo[1,2a]azepine system as a characteristic structural feature, although a few contain a pyrido[1,2$a$ ]azepine core instead. The majority also incorporate at least one $\alpha$-methyl- $\gamma$-butyrolactone substructure, which can be linked to the azabicyclic core in a spiro or fused manner or as a substituent. Considering their structural diversity, Pilli and co-workers classified the Stemona alkaloids into eight groups (Figure 3). ${ }^{1 a, b, d}$ The stenine, stemoamide, tuberostemospironine, stemonamine, parvistemoline and stemofoline groups present the characteristic pyrrolo[1,2a]azepine core, whereas the stemocurtisine group displays the less usual pyrido[1,2-a]azepine nucleus, and a further, miscellaneous group includes those alkaloids which do not display the structural motifs mentioned before, or are the sole representative of a new group.

W.; Zhang, A. Fitoterapia, 2012, 83, 1699-1705; (e) Lin, L.-G.; Leung, H. P.-H.; Zhu, J.-Y.; Tang, C.-P.; Ke, C.-Q.; Rudd, J. A.; Ye, Y. Tetrahedron, 2008, 64, 10155-10161; (f) But, P. P.-H; Shaw, P.-C.; Jiang, R.-W.; Xu, Y.-T. Adv. Bot. Res. 2012, $62,1-33$.

${ }^{15}$ Rinner, B.; Siegl, V.; Pürstner, P.; Efferth, T.; Brem, B.; Greger, H.; Pfragner, R. Anticancer Res. 2004, 24, 495-500. 


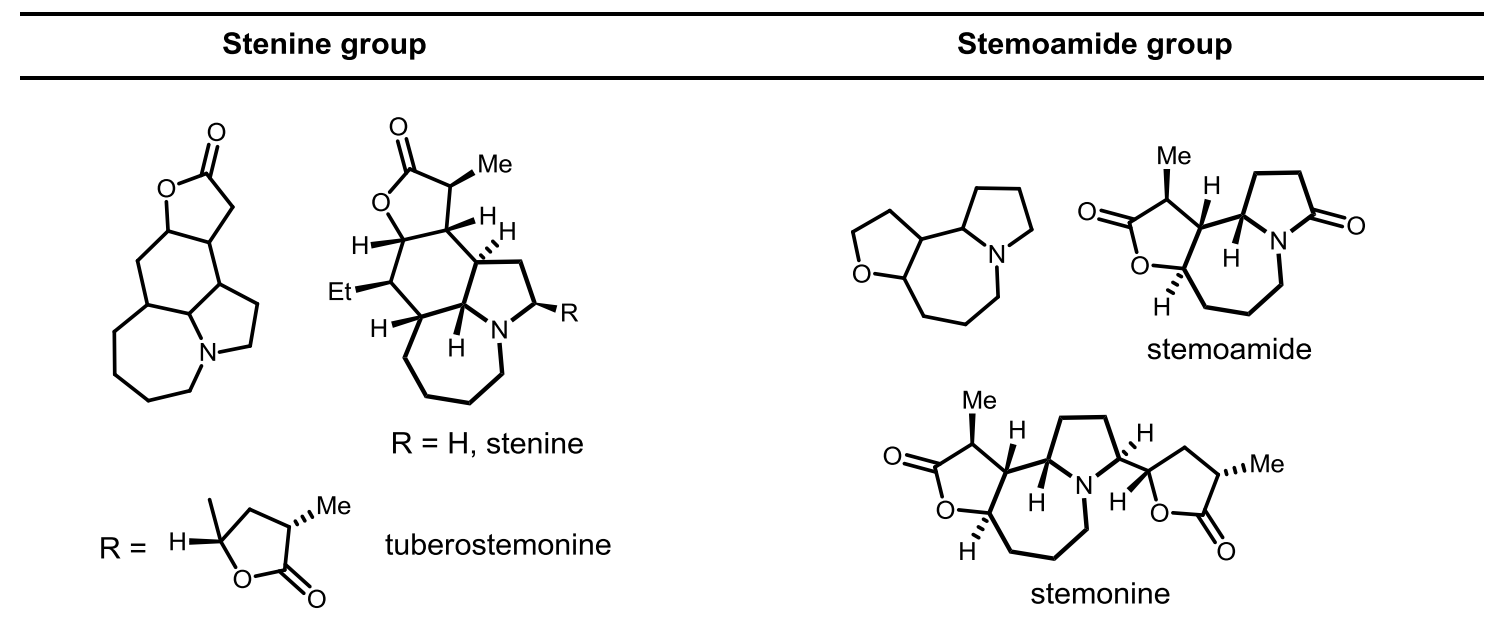

Tuberostemospironine group ${ }^{\mathrm{a}}$

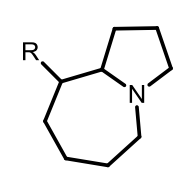

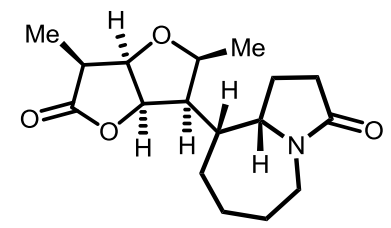

parvistemoline
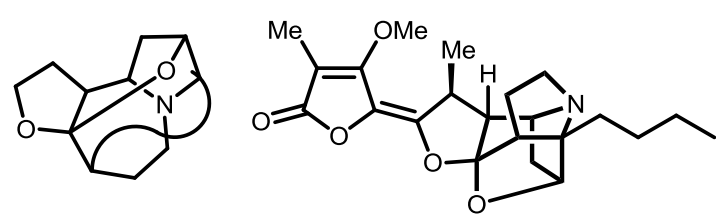

stemofoline

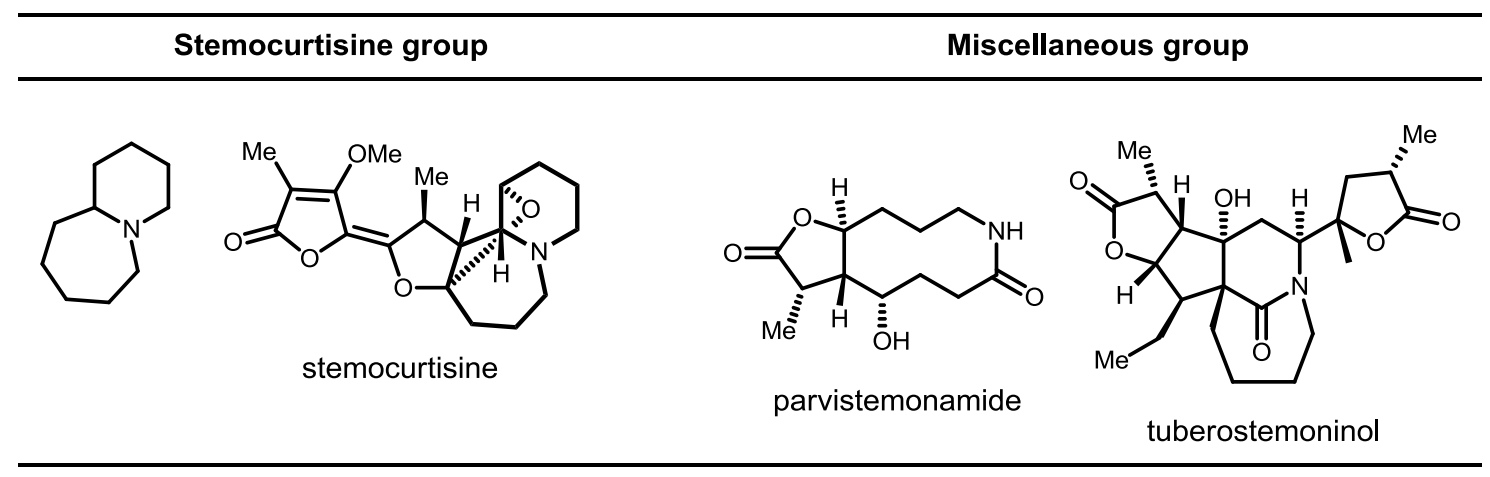

a) For better comprehension, the nomenclature used in the Introduction and Results and Discussion sections is intended to keep fixed numbers in equivalent carbon atoms of related compounds.

Figure 3. Representative members and characteristic structural features of the Stemona alkaloid groups according to Pilli's classification. ${ }^{1 \mathrm{a}, \mathrm{b}, \mathrm{d}}$ 
Recently, Greger has suggested a new classification based on biosynthetic connections. It consists of three skeletal types, differing in the carbon chains attached to $C_{9}$ of the pyrroloazepine core (Figure 4). ${ }^{1 \mathrm{c}}$ In the stichoneurine- and protostemonine-types these chains usually contain eight carbon atoms forming a terminal lactone ring, but differ among each other in the branching pattern. In the croomine-type, by contrast, the chain consists only of four carbon atoms forming a lactone ring directly attached to $C_{9}$ in a spiro system.

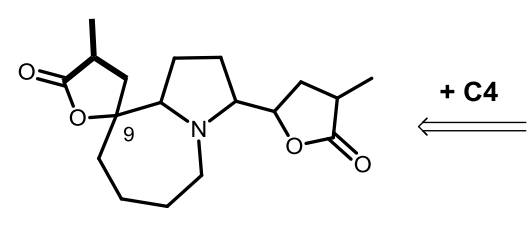

Croomine-type alkaloids<smiles>CC1CC(C2CCC3CCCCCN32)OC1=O</smiles>

$+\mathrm{C8}$
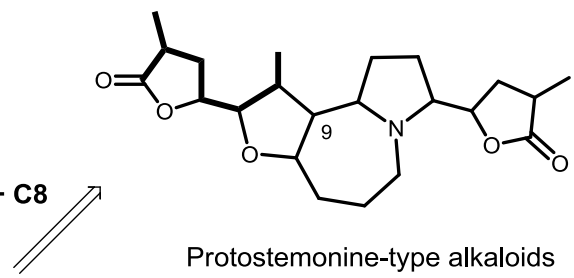

Protostemonine-type alkaloids

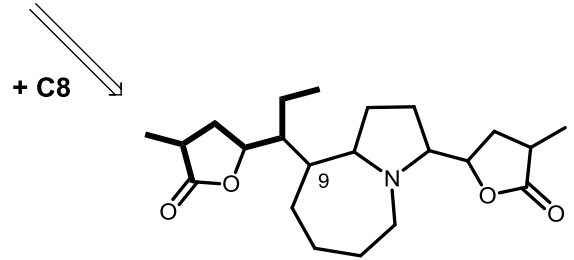

Stichoneurine-type alkaloids

Figure 4. Greger's classification of the Stemona alkaloids. ${ }^{1 \mathrm{c}}$

To date, around one hundred Stemona alkaloids are known, but, in the literature, there is a continuous flow of new reports describing the isolation of previously unknown members of the family. The structural elucidation of 30 of them has been established by X-ray diffraction analysis, whereas the rest has been determined by NMR studies, mass spectrometry, IR spectroscopy and/or by chemical correlation. ${ }^{1,2}$

\subsubsection{Synthetic precedents}

The challenging molecular architectures of the Stemona alkaloids have motivated the development of new strategies for the construction of their azabicyclic core. ${ }^{16}$ However, only a

\footnotetext{
${ }^{16}$ (a) Xiang, L.; Kozikowski, A. P. Synlett 1990, 279-281; (b) Wipf, P.; Kim, Y. Tetrahedron Lett. 1992, 33, 5477-5480; (c) Beddoes, R. L.; Davies, M. P. H.; Thomas, E. J. J. Chem. Soc., Chem. Commun. 1992, 538-540; (d) Martin, S. F.; Corbett, J. W. Synthesis 1992, 01/02, 55-57; (e) Morimoto, Y.; Nishida, K.; Hayashi, Y.; Shirahama, H. Tetrahedron Lett. 1993, 34, 5773-5776; (f) Morimoto, Y.; Iwahashi, M. Synlett 1995, 1221-1222; (g) Wipf, P.; Goldstein, D. M. Tetrahedron Lett. 1996, 37, 739-742; (h) Martin, S. F.; Bur, S. K. Tetrahedron Lett. 1997, 38, 7641-7644; (i) Rigby, J. H.; Laurent, S.; Cavezza, A.; Heeg, M. J. J. Org. Chem. 1998, 63, 5587-5591; (j) Wipf, P.; Li, W. J. Org. Chem. 1999, 64, 4576-4577; (k) Pearson, W. H.; Hutta, D. A.; Fang, W.-K. J. Org. Chem. 2000, 65, 8326-8332; (I) Jung, S. H.; Lee, J. E.; Joo, H. J.; Kim, S.
} 
few total syntheses have been published and they are still limited to a quite small number of targets. So far, 40 total syntheses have been completed, ${ }^{17-38} 22$ of which furnished the targeted alkaloid with high enantiomeric excess (Figure 5).

H.; Koh, H. Y. Bull. Korean Chem. Soc. 2000, 21, 159-160; (m) Pearson, W. H.; Walavalkar, R. Tetrahedron 2001, 57, 5081-5089; (n) Hinmnan, M. M.; Heathcock, C. H. J. Org. Chem. 2001, 66, 7751-7756; (o) Velázquez, F.; Olivo, H. F. Org. Lett. 2002, 4, 3175-3178; (p) Booker-Milburn, K. I.; Hirst, P.; Charamant, J. P. H.; Taylor, L. H. J. Angew. Chem. Int. Ed. 2003, 42, 1642-1644; (q) Lindsay, K. B.; Pyne, S. G. Synlett 2004, 779-782; (r) Cid, P.; Closa, M.; de March, P.; Figueredo, M.; Font, J.; Sanfeliu, E.; Soria, A. Eur. J. Org. Chem. 2004, 4215-4233; (s) Roberts, E.; Samçon, J. P.; Sweeney, J. B. Org. Lett. 2005, 7, 2075-2078; (t) Alibés, R.; Blanco, P.; Casas, E.; Closa, M.; de March, P.; Figueredo, M.; Font, J.; Sanfeliu, E.; Álvarez-Larena, A. J. Org. Chem. 2005, 70, 3157-3167; (u) Gu, P.; Zhao Y.-M.; Tu, Y. Q.; Ma, Y.; Zhang, F. Org. Lett. 2006, 8, 5271-5273; (v) Antoline, J. E.; Hsung, R. P.; Huang, J.; Song, Z.; Li, G. Org. Lett. 2007, 9, 1275-1278; (w) Zhu, L.; Lauchli, R.; Loo, M.; Shea, K. J. Org. Lett. 2007, 9, 2269-2271; (x) Frankowski, K. J.; Neuenswander, B.; Aubé, J. J. Comb. Chem. 2008, 10, 721-725; (y) Yaji, K.; Shindo, M. Tetrahedron Lett. 2010, 51, 5469-5472; (z) Burrell, A.; Watson, L.; Martin, N. G.; Oram, N.; Coldham, I. Org. Biomol. Chem. 2010, 8, 4530-4532; (aa) Dietz, J.; Martin, S. F. Tetrahedron Lett. 2011, 52, 2048-2050; (ab) Bates, R. W.; Sridhar, S. J. Org. Chem. 2011, 76, 5026-5035.

${ }^{17-38}$ Total syntheses:

${ }^{17}$ (+)-Croomine: (a) Williams, D. R.; Brown, D. L.; Benbow, J. W. J. Am. Chem. Soc. 1989, 111, 1923-1925; (b) Martin, S. F.; Barr, K. J. J. Am. Chem. Soc. 1996, 118, 3299-3300; (c) Martin, S. F.; Barr, K. J.; Smith, D. W.; Bur, S. K. J. Am. Chem. Soc. 1999, 121, 6990-6997.

${ }^{18}$ (士)-Stenine: (a) Chen, C. Y.; Hart, D. J. J. Org. Chem. 1990, 55, 6236-6240; (b) Chen, C. Y.; Hart, D. J. J. Org. Chem. 1993, 58, 3840-3849; (c) Ginn, J. D.; Padwa, A. Org. Lett. 2002, 4, 1515-1517; (d) Golden, J. E.; Aubé, J. Angew. Chem. Int. Ed. 2002, 41, 4316-4318; (e) Zeng, Y.; Aubé, J. J. Am. Chem. Soc. 2005, 127, 15712-15713; (f) Frankowski, K. J.; Golden, J. E.; Zeng, Y.; Lei, Y.; Aubé, J. J. Am. Chem. Soc. 2008, 130, 6018-6024.

${ }^{19}$ (-)-Stenine: (a) Wipf, P.; Kim, Y.; Goldstein, D. M. J. Am. Chem. Soc. 1995, 117, 11106-11112;(b) Morimoto, Y.; Iwahashi, M.; Nishida, K.; Hayashi, Y.; Shirahama, H. Angew. Chem. Int. Ed. Engl. 1996, 35, 904-906; (c) Morimoto, Y.; Iwahashi, M.; Kinoshita, T.; Nishida, K. Chem. Eur. J. 2001, 7, 4107-4116; (d) Chen, J.; Chen, J.; Xie, Y.; Zhang, H. Angew. Chem. Int. Ed. 2012, 51, 1024-1027; (e) Fujioka, H.; Nakahara, K.; Kotoku, N.; Ohba, Y.; Nagatomi, Y.; Wang, T.-L.; Sawama, Y.; Murai, K.; Hirano, K.; Oki, T.; Wakamatsu, S.; Kita, Y. Chem. Eur. J. 2012, 18, 13861-13870.

${ }^{20}$ (士)-Stemoamide: (a) Kohno, Y.; Narasaka, K. Bull. Chem. Soc. Jpn. 1996, 69, 2063-2070; (b) Jacobi, P. A.; Lee, K. J. Am. Chem. Soc. 1997, 119, 3409-3410; (c) Jacobi, P. A.; Lee, K. J. Am. Chem. Soc. 2000, 122, 4295-4303; (d) Bogliotti, N.; Dalko, P. I.; Cossy, J. J. Org. Chem. 2006, 71, 9528-9531; (e) Bates, R. W.; Sridhar, S. Synlett. 2009, 12, 1979-1981; (f) Wang, Y.; Zhu, L.; Zhang, Y.; Hong, R. Angew. Chem. Int. Ed. 2011, 50, 2787-2790.

${ }^{21}$ (-)-Stemoamide: (a) Williams, D. R.; Reddy, J. P.; Amato, G. S. Tetrahedron Lett. 1994, 35, 6417-6420; (b) Kinoshita, A.; Mori, M. J. Org. Chem. 1996, 61, 8356-8357; (c) Kinoshita, A.; Mori, M. Heterocycles 1997, 46, 287-299; (d) see ref. 20c; (e) Gurjar, M. K.; Reddy, D. S. Tetrahedron Lett. 2002, 43, 295-298; (f) Sibi, M. P.; Subramanian, T. Synlett 2004, 1211-1214; (g) Olivo, H. F.; Tovar-Miranda, R.; Barragán, E. J. Org. Chem. 2006, 71, 3287-3290; (h) Torssell, S.; Wanngren, E.; Somfai, P.; J. Org. Chem. 2007, 72, 4246-4249; (i) Honda, T.; Matsukawa, T.; Takahashi, K. Org. Biomol. Chem. 2011, 9, 673-675.

${ }^{22}$ (+)-Stemoamide: Bogliotti, N.; Dalko, P. I.; Cossy, J. Synlett. 2006, 2664-2666.

${ }^{23}$ (-)-9,10-epi-Stemoamide: Khim, S.-K.; Schultz, A. G. J. Org. Chem. 2004, 69, 7734-7736.

${ }^{24}( \pm)-9,10$-epi-Stemoamide: see ref. 20d.

${ }^{25}$ (士)-Isostemofoline: Kende, A. S.; Smalley, Jr T. L.; Huang, H. J. Am. Chem. Soc. 1999, 121, 7431-7432.

${ }^{26}$ ( \pm )-Stemonamide and ( \pm )-isostemonamide: (a) Kende, A. S.; Hernando, J. I. M.; Milbank, J. B. J. Org. Lett. 2001, 3, 2505-2508; (b) Kende, A. S.; Hernando, J. I. M.; Milbank, J. B. J. Tetrahedron 2002, 58, 61-74; (c) Taniguchi, T.; Tanabe, O.; Muraoka, O.; Ishibashi, H. Org. Lett. 2008, 10, 197-199; (d) Taniguchi, T.; Ishibashi, H. Tetrahedron 2008, 64, 87738779; (e) Chen, Z.-H.; Zhang, Y.; Chen, Z; Tu, Y.; Zhang, F. Chem. Comm. 2011, 47, 1836-1838; (f) Chen, Z.; Chen, Z.; Zhang, Y.-Q.; Tu, Y.-Q.; Zhang, F.-M. J. Org. Chem. 2011, 76, 10173-10186.

${ }^{27}$ (-)-Stemospironine: (a) Williams, D. R.; Fromhold, M. G.; Earley, J. D. Org. Lett. 2001, 3, 2721-2724; (b) Bardají, N.; Sánchez-Izquierdo, F.; Alibés, R.; Font, J.; Busqué, F.; Figueredo, M. Org. Lett. 2012, 14, 4854-4857.

${ }^{28}$ (-)-Tuberostemonine: (a) Wipf, P.; Rector, S. R.; Takahashi, H. J. Am. Chem. Soc. 2002, 124, 14848-14849; (b) Wipf, P.; Spencer, S. R. J. Am. Chem. Soc. 2005, 127, 225-235.

${ }^{29}$ (-)-Stemonine: Williams, D. R.; Shamim, K.; Reddy, J. P.; Amato, G. S.; Shaw, S. M. Org. Lett. 2003, 5, 3361-3364. 


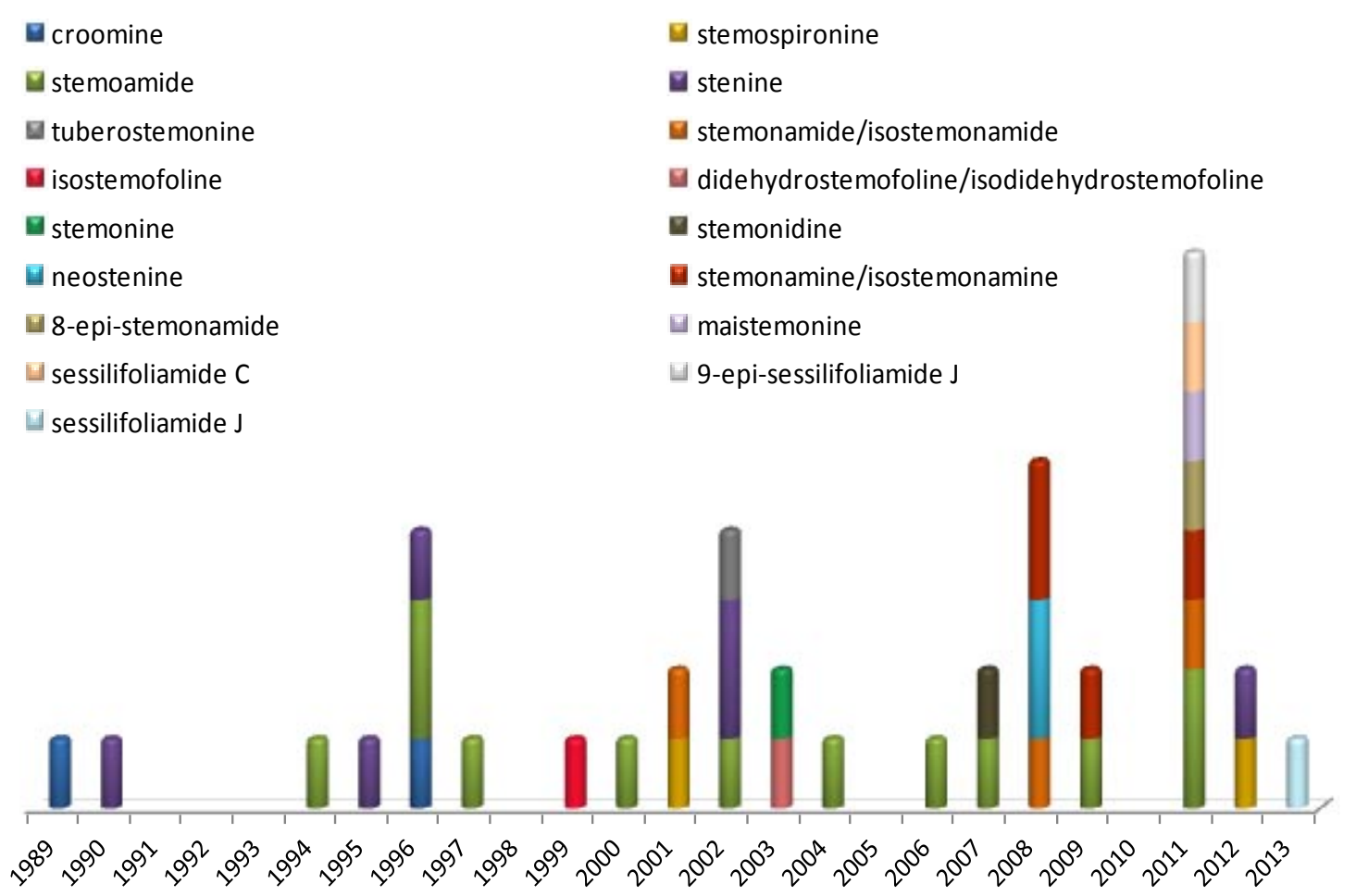

Figure 5. Chronology of the reported total synthesis of Stemona alkaloids.

In most of the published syntheses of these secondary metabolites the central azabicyclodecane core is formed by exo-tet or exo-trig cyclization of a substituted pyrrolidine or azepine, although several authors make use of ring-closing metathesis chemistry or intramolecular cycloaddition processes (Figure 6a). This last methodology is also used to provide the fused lactone ring that is present on several alkaloids of the family.

A detailed study of the reported works reveals a certain parallelism between the approaches developed by different groups. The early syntheses launched different types of strategies, which were later on refined to improve efficiency and/or selectivity, but still relied on

${ }^{30}$ ( \pm )-Didehidrostemofoline (asparagamine A) and (士)-isodidehidrostemofoline: Brüggemann, M.; McDonald, A. I.; Overman, L. E.; Rosen, M. D.; Schwink, L.; Scott, J. P. J. Am. Chem. Soc. 2003, 125, 15284-15285.

${ }^{31}$ (-)-Didehidrotuberostemonine: see ref. 28b.

32 (士)-Neostenine: (a) Lainchbury, M. D.; Medley, M. I.; Taylor, P. M.; Hirst, P.; Dohle, W.; Booker-Milburn, K. I. J. Org. Chem; 2008, 73, 6497-6505; (b) see ref. $18 f$.

${ }^{33}$ ( \pm )-Stemonamine and ( \pm )-isostemonamine: (a) see ref. 26d; (b) Zhao, Y.-M.; Gu, P.; Tu, Y.-Q.; Fan, C.-A.; Zhang, Q. Org. Lett. 2008, 10, 1763-1766; (c) Zhao, Y.-M.; Gu, P.; Zhang, H.-J.; Zhang, Q.-W.; Fan, C.-A.; Tu, Y.-Q.; Zhang, F.-M. J. Org. Chem. 2009, 74, 3211-3213; (d) Chen, Z.-H.; Tu, Y.-Q.; Zhang, S.-Y.; Zhang, F.-M. Org. Lett. 2011, 13, 724-727.

${ }^{34}$ (-)-Sessilifoliamide J: (a) Liu, X.-K.; Ye, J.-L.; Ruan, Y.-P.; Li, Y.-X.; Huang, P.-Q. J. Org. Chem. 2013, 78, 35-41, (b) Tuo, S.; Liu, X.; Huang, P. Chin. J. Chem. 2013, 31, 55-62.

${ }^{35}$ (-)-9-epi-sessilifoliamide J: Tuo, S.-C.; Ye, J.-L.; Wang, A.-E; Huang, S.-Y.; Huang, P.-Q. Org. Lett. 2011, 13, 5270-5273.

${ }^{36}$ (-)-Sessilifoliamide C and (-)-8-epi-stemoamide: Hoye, A. T.; Wipf, P. Org. Lett. 2011, 13, 2634-2637.

${ }^{37}$ ( \pm )-Maistemonine: see ref. 26e-f.

${ }^{38}$ Stemonidine (putative structure): Sánchez-Izquierdo, F.; Blanco, P.; Busqué, F.; Alibés, R.; de March, P.; Figueredo, M.; Font, J.; Parella, T. Org. Lett. 2007, 9, 1769-1772. 
the same retrosynthetic principles. Generally, the lactone rings are formed via intramolecular acyl transfer reactions, iodolactonization processes or vinylogous Mannich reactions with a silyloxyfuran (Figure 6b).

a)

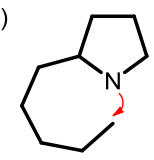

2-substituted pyrrolidine cyclization

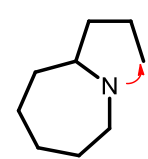

2-substituted azepine cyclization

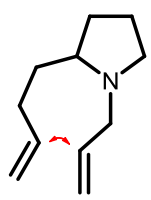

intramolecular metathesis

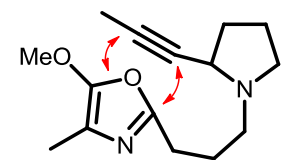

Diels-Alder + retro Diels-Alder

Formation of the azabicyclodecane nucleus

b)

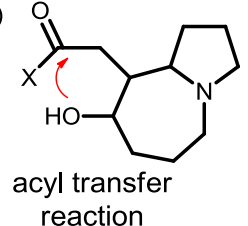

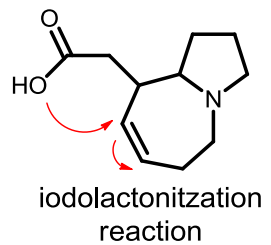

reaction

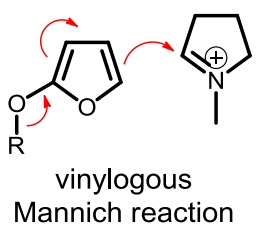

vinylogous
Mannich reaction

Formation of the lactones

Figure 6. Procedures described for the preparation of the azabicyclic core (a) and lactones (b) of Stemona alkaloids.

Due to the high structural complexity of these alkaloids, most of the syntheses published to date are intricate and consist of a high number of steps.

The present thesis is focused on the tuberostemospironine group and, for this reason, all the total syntheses published until now for the alkaloids of this group are summarized below.

In 1989, Williams and co-workers published the first total synthesis of a Stemona alkaloid. ${ }^{17 a}$ In their innovative work, these authors succeeded in completing the preparation of (+)-croomine through an impressive 24 -step linear sequence in $0.5 \%$ overall yield (Scheme 1 ). Their strategy involves the preliminary construction of a branched carbon chain, followed by consecutive ring closures to generate each heterocycle. Thus, the synthesis started with the transformation of (+)-methyl 3-hydroxy-2-methylpropionate, through a four-step sequence and $72 \%$ overall yield, in alkyne 1 which, in turn, was converted to the (Z)-trisubstituted allylic alcohol 3. The relative configurations of $C_{9}$ and $C_{9 a}$ in the alkaloid were established by means of a highly diastereoselective Sharpless epoxidation of 3, providing an epoxyalcohol that, after a two-carbon chain homologation of the corresponding aldehyde, led to epoxide 4 . The west-side lactone A in 7 was constructed after a regioselective opening of 4 with lithium azide (4 to 5), chain homologation (5 to 6 ), deprotection of the 1,4-diol, oxidation and lactonization (6 to 7). The central perhydroazepine ring $B$ was formed through a Staudinger-aza-Wittig reaction and the 
rings $C$ and $D$ were accomplished in a single step by an iodine-induced double cyclization reaction of amine $8{ }^{39}$ This process required the initial formation of the iodoamination product $\mathbf{9}$, and then nucleophilic anchimeric assistance by the vicinal tertiary amine led to the aziridinium intermediate 10, which was captured by the neighboring methyl ester affording (+)-croomine with net retention of configuration at $\mathrm{C}_{14}$.
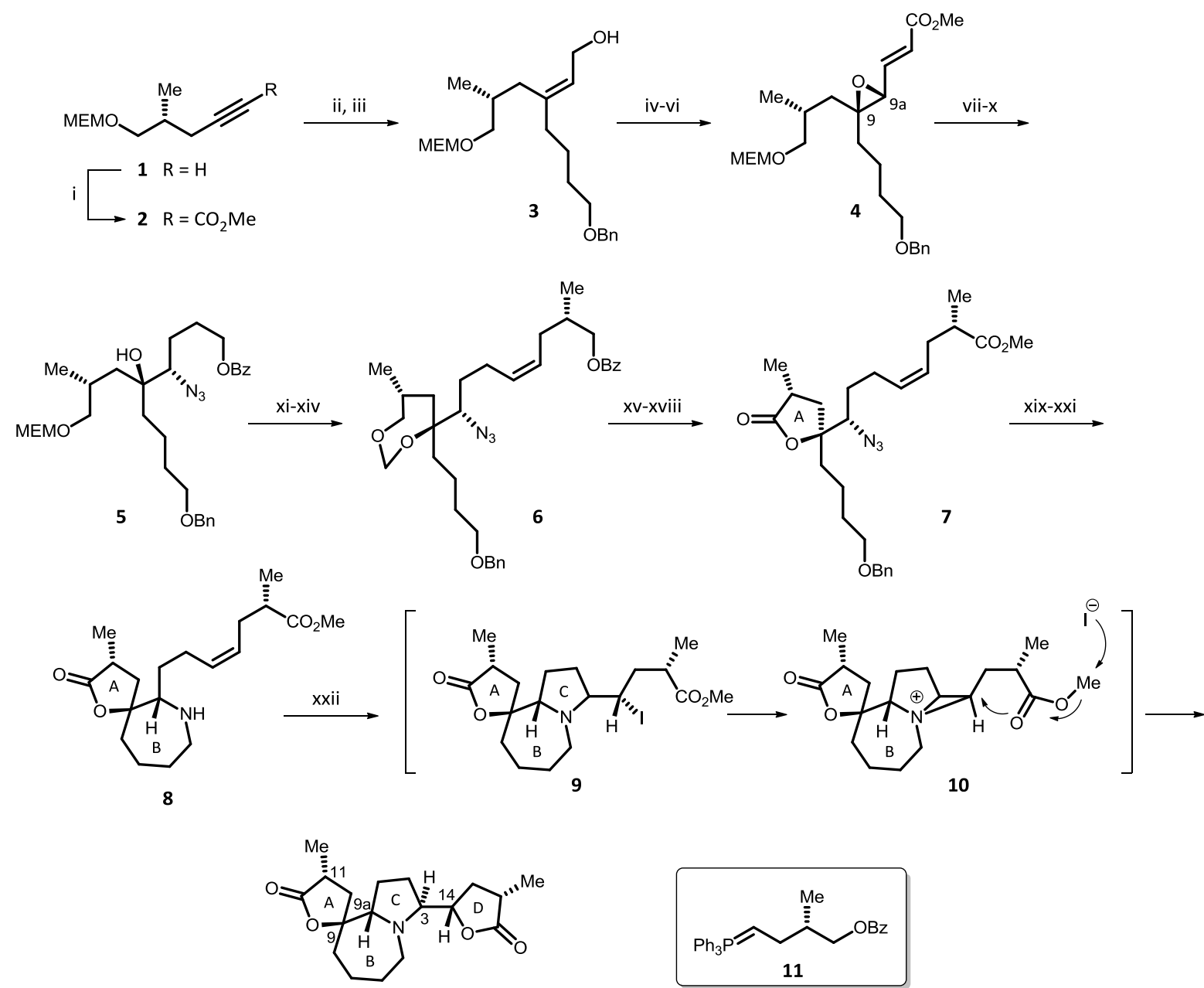

(+)-croomine

Reagents and conditions: (i) $n$ - BuLi, THF, -78 to $0{ }^{\circ} \mathrm{C}$; then, $\mathrm{ClCO}_{2} \mathrm{Me},-78{ }^{\circ} \mathrm{C}(63 \%)$; (ii) $\mathrm{BnO}\left(\mathrm{CH}_{2}\right)_{3} \mathrm{MgBr}, \mathrm{DMS}, \mathrm{CuBr}$, TMEDA, Et ${ }_{2} \mathrm{O},-78{ }^{\circ} \mathrm{C}$ (95\%); (iii) DIBAL-H, $\mathrm{CH}_{2} \mathrm{Cl}_{2},-78{ }^{\circ} \mathrm{C}$ (98\%); (iv) Ti(OiPr) ${ }_{4}$ (cat.), D-DIPT (cat.), ${ }^{t} \mathrm{BuOOH}, \mathrm{MS} 4 \AA \mathrm{A}^{2} \mathrm{CH}_{2} \mathrm{Cl}_{2}$, $-50{ }^{\circ} \mathrm{C}$ (83\%); (v) $(\mathrm{COCl})_{2}, \mathrm{DMSO}, \mathrm{CH}_{2} \mathrm{Cl}_{2}, \mathrm{Et}_{3} \mathrm{~N},-78$ to $0{ }^{\circ} \mathrm{C}$; (vi) $\mathrm{Ph}_{3} \mathrm{P}=\mathrm{CHCO}_{2} \mathrm{Me}, 0{ }^{\circ} \mathrm{C}$ to r.t. (89\%, 2 steps); (vii) $\mathrm{LiBH}_{4}$, $\mathrm{Et}_{2} \mathrm{O}, \mathrm{MeOH}, 0^{\circ} \mathrm{C}$ (81\%); (viii) 5\% Rh/ $\mathrm{Al}_{2} \mathrm{O}_{3}, \mathrm{H}_{2}$, THF (62\%); (ix) $\mathrm{BzCl}, \mathrm{Et}_{3} \mathrm{~N}, \mathrm{CH}_{2} \mathrm{Cl}_{2}, 0^{\circ} \mathrm{C}$ to r.t. (97\%); (x) LiN $\mathrm{L}_{3}, \mathrm{DMPU}, 110$ ${ }^{\circ} \mathrm{C}(94 \%)$; (xi) $\mathrm{BF}_{3} \cdot \mathrm{Et}_{2} \mathrm{O}, \mathrm{CH}_{2} \mathrm{Cl}_{2}, 0{ }^{\circ} \mathrm{C}$ (81\%); (xii) LiOH, THF, aq. MeOH (97\%); (xiii) (COCl) $2, \mathrm{DMSO} \mathrm{CH}_{2} \mathrm{Cl}_{2}, \mathrm{Et}_{3} \mathrm{~N},-78$ to $0{ }^{\circ} \mathrm{C}$ (91\%); (xiv) 11, ${ }^{t} \mathrm{BuOK}, \mathrm{THF},-10{ }^{\circ} \mathrm{C}(70-81 \%)$; (xv) aq. $\mathrm{HBF}_{4}, \mathrm{MeOH}(72 \%)$, (xvi) LiOH, THF, MeOH, $\mathrm{H}_{2} \mathrm{O}, 22{ }^{\circ} \mathrm{C}(86 \%)$; (xvii) Jones' reagent, THF, $0{ }^{\circ} \mathrm{C}$; (xviii) $\mathrm{CH}_{2} \mathrm{~N}_{2}, \mathrm{Et}_{2} \mathrm{O}$ (78\%, 2 steps); (xix) $\mathrm{BCl}_{3}, \mathrm{CH}_{2} \mathrm{Cl}_{2},-78$ to $0^{\circ} \mathrm{C}$; then, $\mathrm{MeOH},-78{ }^{\circ} \mathrm{C}(77 \%)$; (xx) $(\mathrm{COCl})_{2}, \mathrm{DMSO}, \mathrm{CH}_{2} \mathrm{Cl}_{2}, \mathrm{Et}_{3} \mathrm{~N},-78$ to $0{ }^{\circ} \mathrm{C}(92 \%)$; (xxi) $\mathrm{Ph}_{3} \mathrm{P}, \mathrm{THF}, 2{ }^{\circ} \mathrm{C}$; then, $\mathrm{NaBH}_{4}, \mathrm{MeOH}(90 \%)$; (xxii) $\mathrm{I}_{2}, \mathrm{CH}_{2} \mathrm{Cl}_{2}, \mathrm{Et}_{2} \mathrm{O}$, $22{ }^{\circ} \mathrm{C}(25 \%)$.

Scheme 1. Williams' strategy for the synthesis of (+)-croomine. ${ }^{17 a}$

\footnotetext{
${ }^{39}$ Williams, D. R.; Osterhout, M. H.; McGill, J. M. Tetrahedron Lett. 1989, 30, 1331-1334.
} 
Some years later, Martin and co-workers published a new asymmetric synthesis of $(+)-$ croomine, which required only 9 steps and was accomplished in $5 \%$ total yield (Scheme 2). ${ }^{17 \mathrm{~b}}$ In this case, as in most approaches to these alkaloids, the starting material already contained the pyrrolidine unit (ring C). The authors used methyl L-pyroglutamate as the source of chirality of the synthetic process and the key transformation of this approach was the vinylogous Mannich reaction between a silyloxyfuran and a cyclic acyliminium ion generated in situ from a derivative of methyl L-pyroglutamate, to deliver the pyrrolidinyl-lactone system. This transformation, which is also applied to prepare the east-side lactone, produced a very elegant and short synthesis, although its moderate yield and poor stereoselectivity diminished the efficiency of the strategy.<smiles>CC1=CCOC1=O</smiles>

12

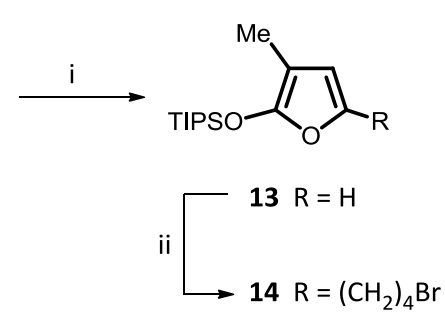

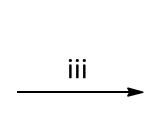

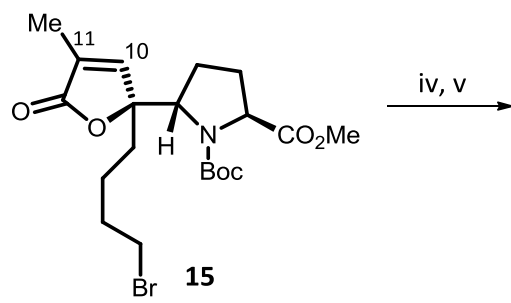

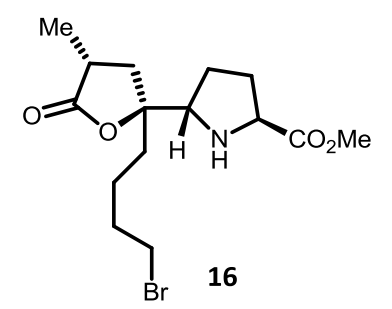

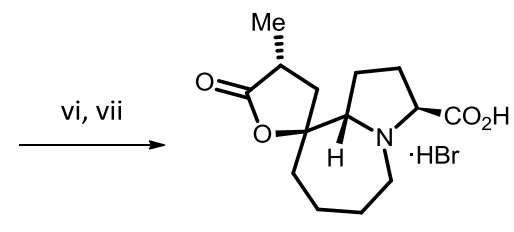

17

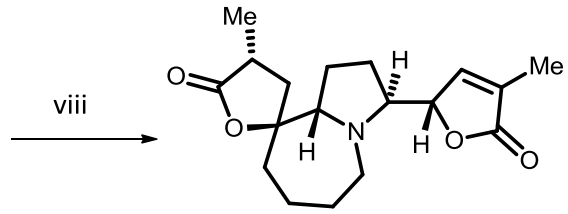

18

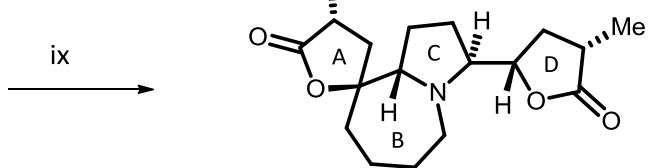

(+)-croomine

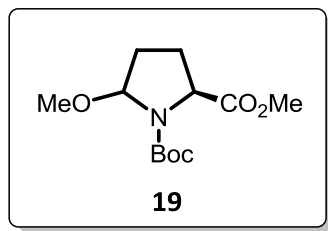

19

Reagents and conditions: (i) TIPS-OTf, $\mathrm{Et}_{3} \mathrm{~N}, \mathrm{CH}_{2} \mathrm{Cl}_{2}, 0{ }^{\circ} \mathrm{C}$ to r.t. (99\%); (ii) $s$-BuLi, TMEDA, THF, $0{ }^{\circ} \mathrm{C}$; then, $\mathrm{BrCH}_{2}\left(\mathrm{CH}_{2}\right)_{2} \mathrm{CH}_{2} \mathrm{Br}$ (83\%); (iii) 19, 5\% TIPS-OTf, $\mathrm{CH}_{2} \mathrm{Cl}_{2}, 0{ }^{\circ} \mathrm{C}$ (32\%); (iv) TFA, $\mathrm{CH}_{2} \mathrm{Cl}_{2}$, r.t.; (v) 3\% Rh/C, $\mathrm{H}_{2}$, EtOAc, EtOH (>96\%, 2 steps); (vi) $\mathrm{N}$-methylmorpholine, DMF, reflux; (vii) $3 \mathrm{M}$ aq. $\mathrm{HBr}, 60^{\circ} \mathrm{C}$ ( $74 \%, 2$ steps); (viii) $\mathrm{POCl}_{3}$, DMF, r.t.; then 13 (32\%); (ix) Pd/C, $\mathrm{H}_{2}, 10 \% \mathrm{HCl} /$ EtOAC (85\%).

Scheme 2. Martin's strategy for the synthesis of (+)-croomine. ${ }^{17 b}$

In 1999 Martin's group disclosed an improved synthesis of the same alkaloid through an analogous route but postponing the hydrogenation of the $\mathrm{C}_{10}-\mathrm{C}_{11}$ double bond (Scheme 3). ${ }^{17 \mathrm{c}}$ The rest of the sequence proceeded according to the same strategy. Thus, the new shorter route 
consisted on deprotecting the former intermediate amine $\mathbf{1 5}$ to obtain pyrrolidine 20 . Intramolecular alkylation of $\mathbf{2 0}$ provided pyrroloazepine $\mathbf{2 1}$ which, after deprotection of the ester and decarboxylation through the corresponding acid chloride, afforded the iminium intermediate that reacted with the silyloxyfuran $\mathbf{1 3}$ to furnish the azatetracyclic compound $\mathbf{2 2}$ and its epimer at $\mathrm{C}_{14}$ as a 2:1 mixture of diastereoisomers. Catalytic hydrogenation of $\mathbf{2 2}$ delivered (+)-croomine as the only isolable product in $3 \%$ overall yield.
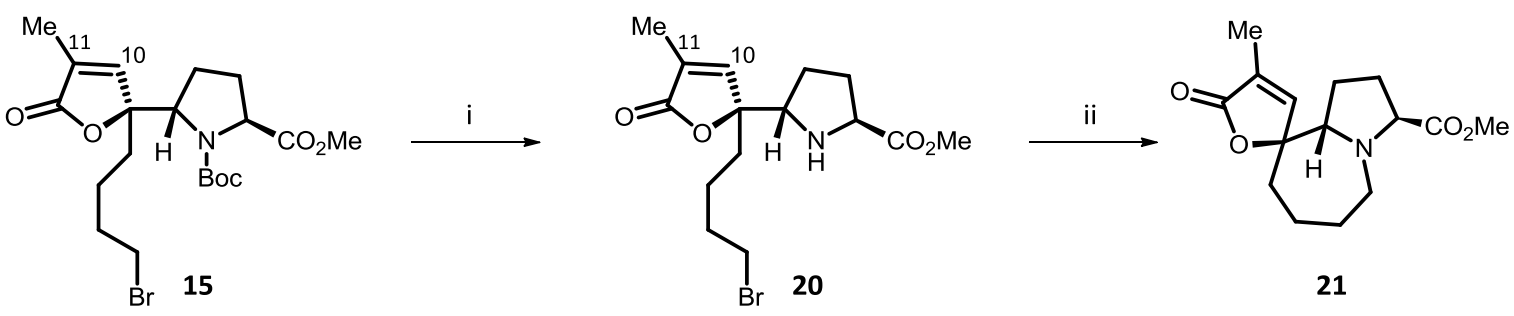

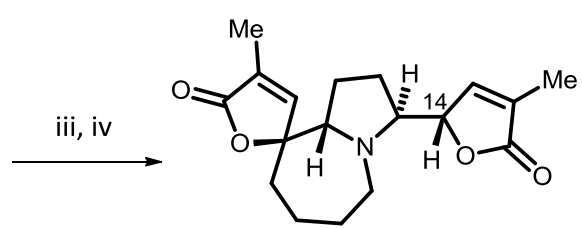

22

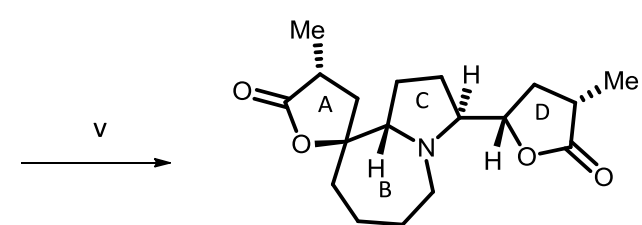

(+)-croomine

Reagents and conditions: (i) TFA, $\mathrm{CH}_{2} \mathrm{Cl}_{2}$, r.t. (quant.); (ii) $\mathrm{N}$-methylmorpholine, DMF, $160{ }^{\circ} \mathrm{C}(51 \%$ ); (iii) $3 \mathrm{M}$ aq. $\mathrm{HBr}, 60$ ${ }^{\circ} \mathrm{C}$; (iv) $\mathrm{POCl}_{3}$, DMF, r.t.; then 13 (26\%); (v) Pd/C, $\mathrm{H}_{2}$, EtOH, $\mathrm{HCl}(81 \%)$.

Scheme 3. Martin's improved strategy for the synthesis of (+)-croomine. ${ }^{17 c}$

The first, and to date unique reported, synthesis of (-)-stemospironine was accomplished by Williams and co-workers in 2001 (Scheme 4). ${ }^{27 a}$ Stemospironine differs from croomine only in the presence of a methoxy group at $\mathrm{C}_{8}$, which adds an extra stereogenic center. The authors used the same strategy developed by them for the total synthesis of croomine, namely the stereoselective construction of a fully functionalized acyclic carbon chain followed by sequential ring closure reactions.

Beginning with the readily available ketone $\mathbf{2 3}$, chirality at $C_{8}$ was introduced via Midland reduction of the conjugated ynone with $(R)$-alpine borane, leading to the $R$ alcohol precursor of 24. After one-carbon homologation, the acetylenic ester underwent a conjugate addition of a cuprate to afford exclusively the $E$ - $\alpha, \beta$-unsaturated ester 25 . Then, removal of the protecting group of the chiral alcohol, followed by methylation and subsequent reduction of the propargylic ester yielded the trisubstituted allylic alcohol $\mathbf{2 6}$, which provided a 4:1 mixture of oxirane isomers using a modified Sharpless asymmetric epoxidation. The major oxirane was oxidized with Dess- 
Martin periodinane, and in situ chain elongation through a Wittig reaction yielded the $E$ unsaturated methyl ester $\mathbf{2 7}$. Hydrogenation, reduction of the ester to the corresponding primary alcohol and protection as pivaloyl ester furnished compound $\mathbf{2 8}$, which was submitted to epoxide opening with lithium azide to obtain the hydroxyazide 29.

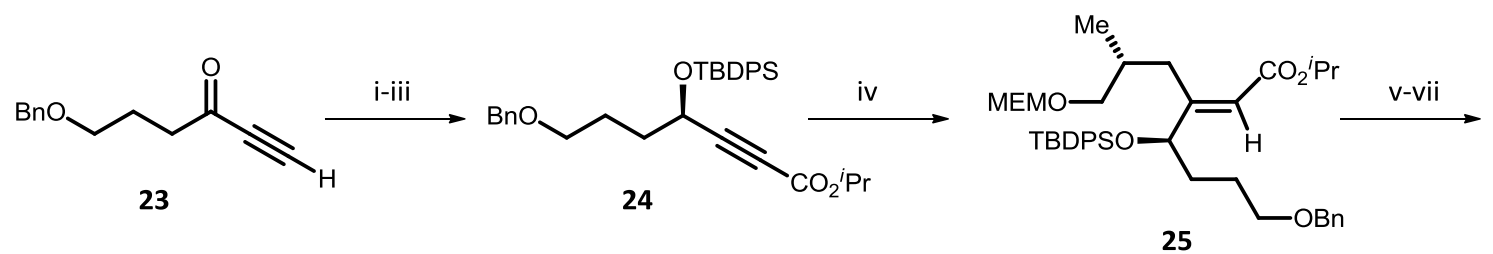

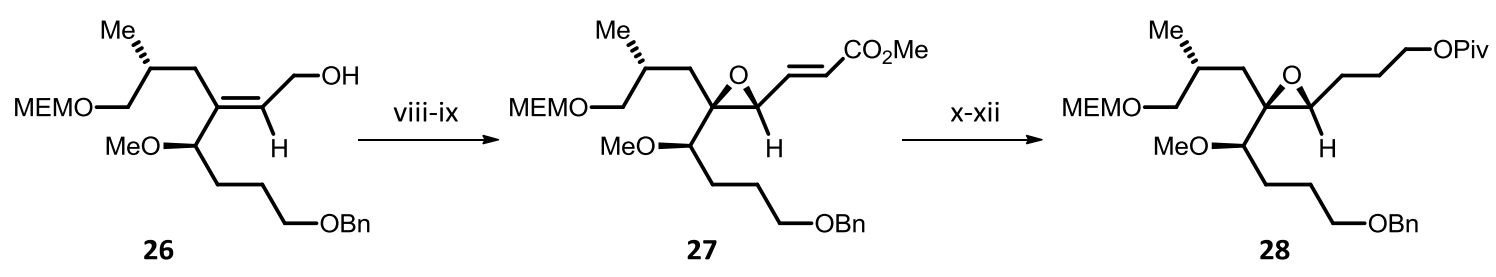

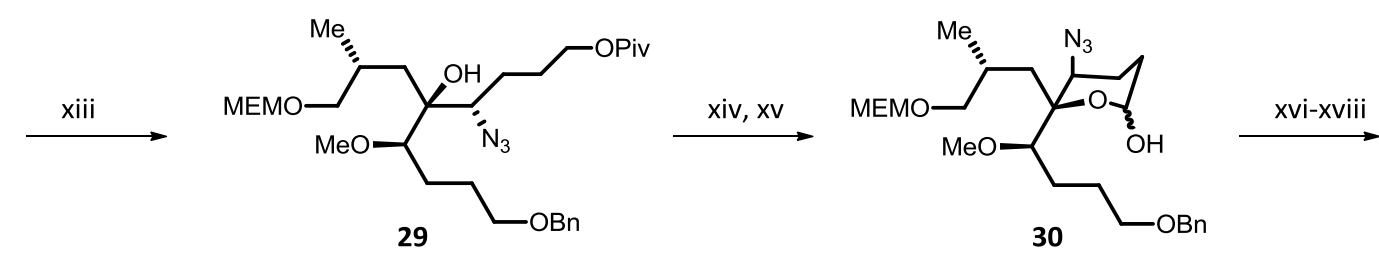<smiles>COC(CCCO)C(O)(C[C@H](C)CO)C(N)C/C=C/C[C@H](C)CO</smiles>

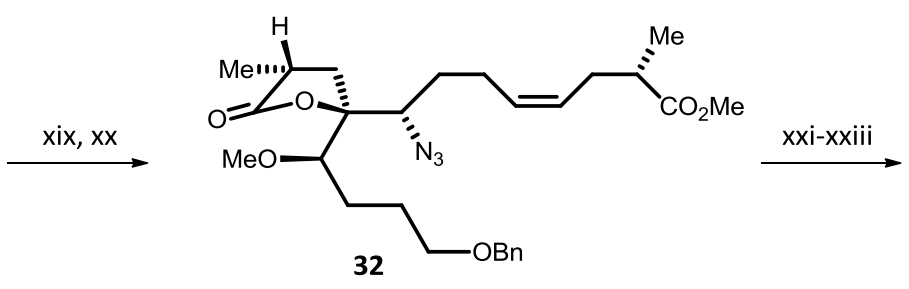

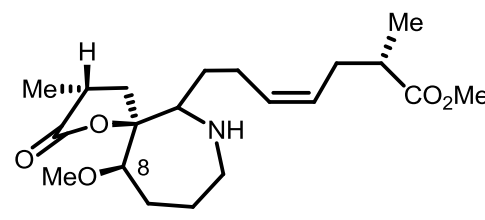

33

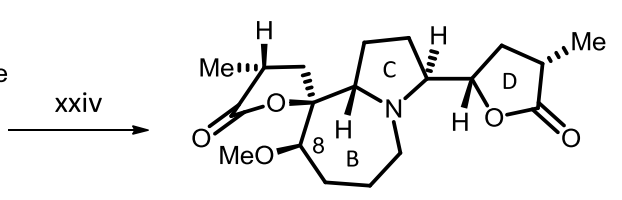

(-)-stemospironine

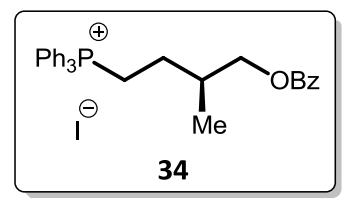

34

Reagents and conditions: (i) (R)-Alpine Borane, THF, $-10{ }^{\circ} \mathrm{C}$ to r.t. $\left(95 \%, 88\right.$, ee); (ii) $\mathrm{TBDPSCl}$, imidazole, $\mathrm{CH}_{2} \mathrm{Cl}_{2}$, r.t. (80\%); (iii) $n$-BuLi, $\mathrm{ClCO}_{2}{ }^{i} \mathrm{Pr}$, THF, $-78{ }^{\circ} \mathrm{C}$ (92\%); (iv) (S)-MEMOCH${ }_{2}\left(\mathrm{CH}_{3}\right) \mathrm{CH}_{2} \mathrm{MgBr}$, 35, CuBr-DMS, THF, $-78{ }^{\circ} \mathrm{C}$ to r.t. (70\%); (v) TBAF, THF, r.t. (90\%); (vi) NaH, Mel, DMF (85\%); (vii) DIBAL-H, $\mathrm{CH}_{2} \mathrm{Cl}_{2},-78{ }^{\circ} \mathrm{C}(92 \%)$; (viii) $\mathrm{Ti}\left(\mathrm{O}^{i} \mathrm{Pr}\right)_{4}, \mathrm{CaH}_{2}, \mathrm{SiO}_{2}$, (-)DIPT, ${ }^{t} \mathrm{BuOOH}, \mathrm{CH}_{2} \mathrm{Cl}_{2},-20{ }^{\circ} \mathrm{C}\left(85-90 \%, 4: 1\right.$ mixture of isomers); (ix) Dess-Martin periodinane, pyridine, $\mathrm{CH}_{2} \mathrm{Cl}_{2},-78{ }^{\circ} \mathrm{C}$; then, $\mathrm{PPh}_{3} \mathrm{CHCO}_{2} \mathrm{CH}_{3}$ (60\%, 2 steps); (x) 5\% Rh/ $\mathrm{Al}_{2} \mathrm{O}_{3}, \mathrm{H}_{2}$, THF (85\%); (xi) $\mathrm{LiBH}_{4}, \mathrm{CH}_{3} \mathrm{OH}, \mathrm{Et}_{2} \mathrm{O}$ (90\%); (xii) PivCl, pyridine, DMAP (91\%); (xiii) $\mathrm{LiN}_{3}, \mathrm{NH}_{4} \mathrm{Cl}, \mathrm{DMPU}, 130{ }^{\circ} \mathrm{C}$ (83\%); (xiv) LiOH, THF, MeOH, $\mathrm{H}_{2} \mathrm{O}$ (94\%); (xv) Swern oxidation (97\%); (xvi) ${ }^{t} \mathrm{BuOK}, 34, \mathrm{THF},-10^{\circ} \mathrm{C}$ (77\%); (xvii) HCl, THF, r.t. (85\%); (xviii) LiOH, THF, $\mathrm{H}_{2} \mathrm{O}$, MeOH (88\%); (xix) Jones' reagent, THF, $-10{ }^{\circ} \mathrm{C}$; (xx) $\mathrm{CH}_{2} \mathrm{~N}_{2}, \mathrm{Et}_{2} \mathrm{O}, 0{ }^{\circ} \mathrm{C}\left(80 \%\right.$, 2 steps); (xxi) $\mathrm{BCl}_{3}, \mathrm{CH}_{2} \mathrm{Cl}_{2},-78{ }^{\circ} \mathrm{C}$ to r.t. (60\%); (xxii) Dess-Martin periodinane, $\mathrm{CH}_{2} \mathrm{Cl}_{2}$ (80\%); (xxiii) $\mathrm{PPh}_{3}$, THF; then, $\mathrm{NaBH}_{4}, \mathrm{MeOH}$, r.t. (60\%); (xxiv) $\mathrm{I}_{2}, \mathrm{CH}_{2} \mathrm{Cl}_{2}$, Et 2 O, r.t. (30\%).

Scheme 4. Williams' strategy for the synthesis of (-)-stemospironine. ${ }^{27 a}$ 
Saponification of the ester followed by a Swern oxidation led to a 3:1 mixture of diastereomeric lactols 30. Then, treatment of this mixture with the triphenylphosphorane derived from 34 provided exclusively the $Z$ alkene, and subsequent removal of the MEM and benzoyl protecting groups yielded triol 31, which was submitted to consecutive Jones' oxidation and treatment with diazomethane, affording the spiranic lactone 32. Cleavage of the benzyl ether was followed by Dess-Martin oxidation to give the crucial azido-aldehyde for the Staudinger-azaWittig process. Once the azepine $\mathbf{3 3}$ was formed, (-)-stemospironine was produced by the iodineinduced double cyclization reaction of $\mathbf{3 3}$, in 24 steps from $\mathbf{2 3}$ and $0.3 \%$ overall yield.

In 2007, our research group described the total synthesis of stemonidine, which will be commented later on. ${ }^{38}$

\subsubsection{Retrosynthetic analysis and previous work of the group}

Some years ago, our research group started a project towards the development of a new methodology for the synthesis of Stemona alkaloids.
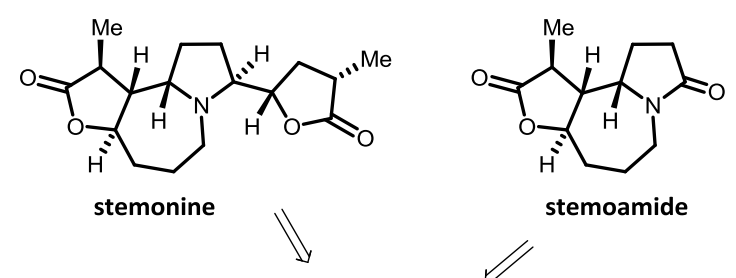

stemoamide
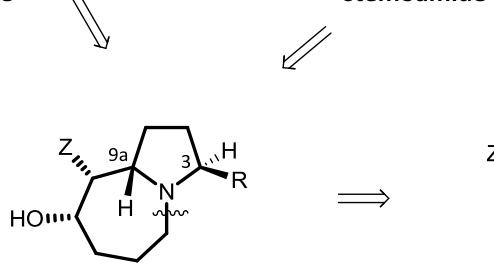

36

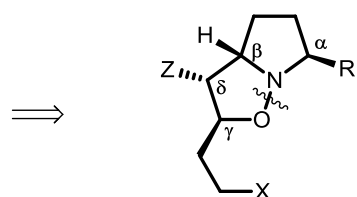

37

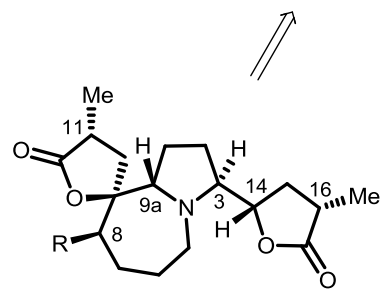

$\mathbf{R}=\mathbf{H}$, croomine

$\mathrm{R}=\mathrm{OMe}$, stemospironine

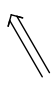

STEMOAMIDE GROUP

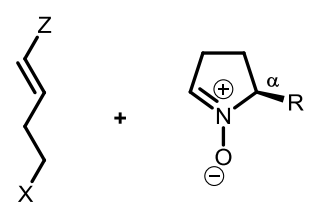

39

Scheme 5. Retrosynthetic analysis for the synthesis of Stemona alkaloids.

In most of the previously published syntheses of these natural products, the characteristic azabicyclic core was generated from an advanced intermediate, generally 
presenting multiple stereocenters and specifically assembled for the particular target. Our strategy consisted on generating the 1-azabicyclo[5.3.0]decane skeleton at an early stage of the sequence and later on incorporating the $\alpha$-methyl- $\gamma$-butyrolactone units and other specific fragments. Such an approach would benefit from flexibility because the same intermediate could be common to various alkaloids, providing molecular diversity (Scheme 5). ${ }^{16 r, t}$

Thus, alkaloids from stemoamide and tuberostemospironine groups could be prepared from amine 36. This amine could in turn be prepared from isoxazolidine $\mathbf{3 7}$ by reductive cleavage of the $\mathrm{N}-\mathrm{O}$ bond and subsequent 7-exo-trig cyclization. Ultimately, compound $\mathbf{3 7}$ would arise from the 1,3-cycloaddition reaction of the cyclic nitrone 39 to olefin 38.

A main advantage of this methodology is the high antifacial selectivity accomplished in the 1,3-dipolar cycloaddition between nitrones such as $\mathbf{3 9}$ and electron-deficient olefins of type 38, delivering isoxazolidine adducts like $\mathbf{3 7}$ with relative trans configuration of the centers $\alpha$ and $\beta$, as required for the targeted alkaloids. The stereogenic center of the nitrone $(\alpha)$, which corresponds to $C_{3}$ on the alkaloids, would remain unchanged throughout the synthesis. In the 1,3-dipolar cycloaddition reaction three new stereocenters $(\beta, \gamma$ and $\delta)$ would be formed. From these, $\beta$ ( $C_{9 a}$ on the alkaloid) would also remain unchanged throughout the synthesis, whereas $\gamma$ and $\delta$, which correspond to $C_{8}$ and $C_{9}$ on the Stemona alkaloids, respectively, would be modified depending on the targeted alkaloid.

The efficient preparation of the starting nitrone in enantiopure form was a crucial step in this approach, because this nitrone is the only source of chirality of our diastereoselective synthetic design. Thus, our research group developed the syntheses of several nitrones synthetically equivalent to $\mathbf{3 9}$ (Scheme 6). Nitrone $\mathbf{4 1}$ was prepared in a single step by oxidation of L-prolinol, 40, using dimethyldioxirane (DMD) as the oxidant, in $32 \%$ yield. ${ }^{40}$ Nitrone $\mathbf{4 4}$ was prepared from L-pyroglutamate, $\mathbf{4 2}$, through the formation of imine $\mathbf{4 3}$, which was oxidized with (trifluoromethyl)methyldioxirane (TFMD). ${ }^{41}$ On the other hand, nitrone 47 was obtained from Dglyceraldehyde, $\mathbf{4 6}$, in 6 steps and $33 \%$ overall yield. ${ }^{16 t, 42}$

\footnotetext{
${ }^{40}$ Closa, M.; de March, P.; Figueredo, M.; Font, J. Tetrahedron Assymetry 1997, 8, 1031-1037.

${ }^{41}$ Busqué, F.; de March, P.; Figueredo, M.; Font, J.; Gallagher, T.; Milán, S. Tetrahedron: Assymetry 2002, 13, 437-445.

${ }^{42}$ Alibés, R.; Blanco, P.; de March, P.; Figueredo, M.; Font, J.; Álvarez-Larena, A.; Piniella, J.F. Tetrahedron Lett. 2003, 44, 523-525.
} 


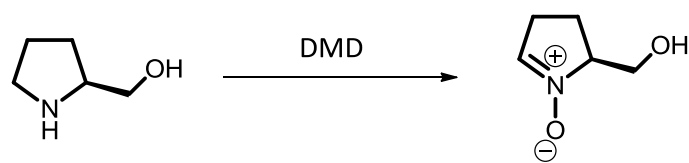

40

41

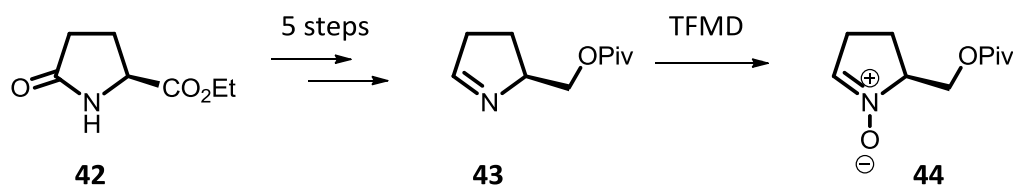

42

43

44

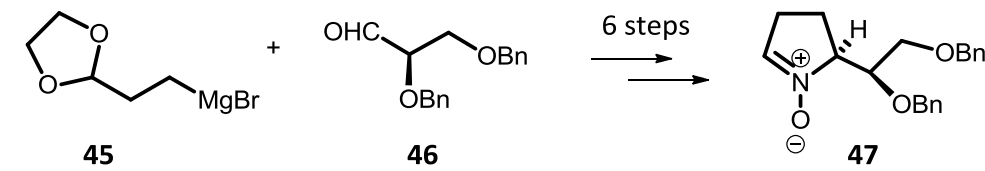

Scheme 6. Synthesis of enantiopure nitrones. ${ }^{16 t, 40,41,42}$

Unfortunately, the two first methodologies proved to be difficult to scale up, essentially because of the problematic preparation of the aforementioned dioxiranes in multigram quantities. On the other hand, nitrone 47 a priori presented the advantage of containing an additional stereocenter and the suitable functionalization for the construction of the east-side lactone present in some of the targeted alkaloids, although it required a longer sequence to be obtained. Furthermore, for reasons that would be discussed later, a first generation synthetic approach starting from nitrone $\mathbf{4 7}$ met with overwhelming difficulties in the installation of the east-side lactone from advanced intermediates. Therefore, additional options for the preparation of a suitable nitrone of type $\mathbf{3 9}$ were needed.

Some years later, our group developed a straightforward and simple procedure to oxidize secondary amines to nitrones using oxone $\left(\mathrm{KHSO}_{5}\right)$ as the sole oxidant. ${ }^{43}$ This methodology was applied to oxidize the TBDPS derivative of prolinol 48 to the pyrroline $N$-oxide 49 , and it was chosen as the most practical way for preparing the required asymmetric nitrone (Scheme 7). Nitrone $\mathbf{4 9}$ was hence visualized as a suitable precursor for the synthesis of Stemona alkaloids.

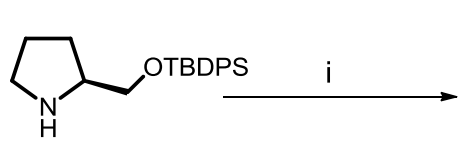

48

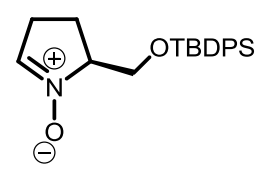

49

Reagents and conditions: (i) oxone, $0.01 \mathrm{M} \mathrm{Na}_{2} \mathrm{EDTA}, \mathrm{NaHCO}_{3}, \mathrm{MeCN}: \mathrm{THF}(4: 1), 0{ }^{\circ} \mathrm{C}, 2 \mathrm{~h}(90 \%)$.

Scheme 7. Synthesis of enantiopure nitrone $\mathbf{4 9}$ using oxone as oxidant.

\footnotetext{
${ }^{43}$ Gella, C.; Ferrer, E.; Alibés, R.; Busqué, F.; de March, P.; Figueredo, M.; Font, J. J. Org. Chem. 2009, 74, 6365-6367.
} 
Our flexible approach towards these Stemona alkaloids has recently culminated with the synthesis of stemonidine, ${ }^{38}$ a member of the tuberostemospironine group isolated from the roots of Stemona tuberosa whose structure was erroneously misassigned as depicted in Scheme $8 .{ }^{44}$
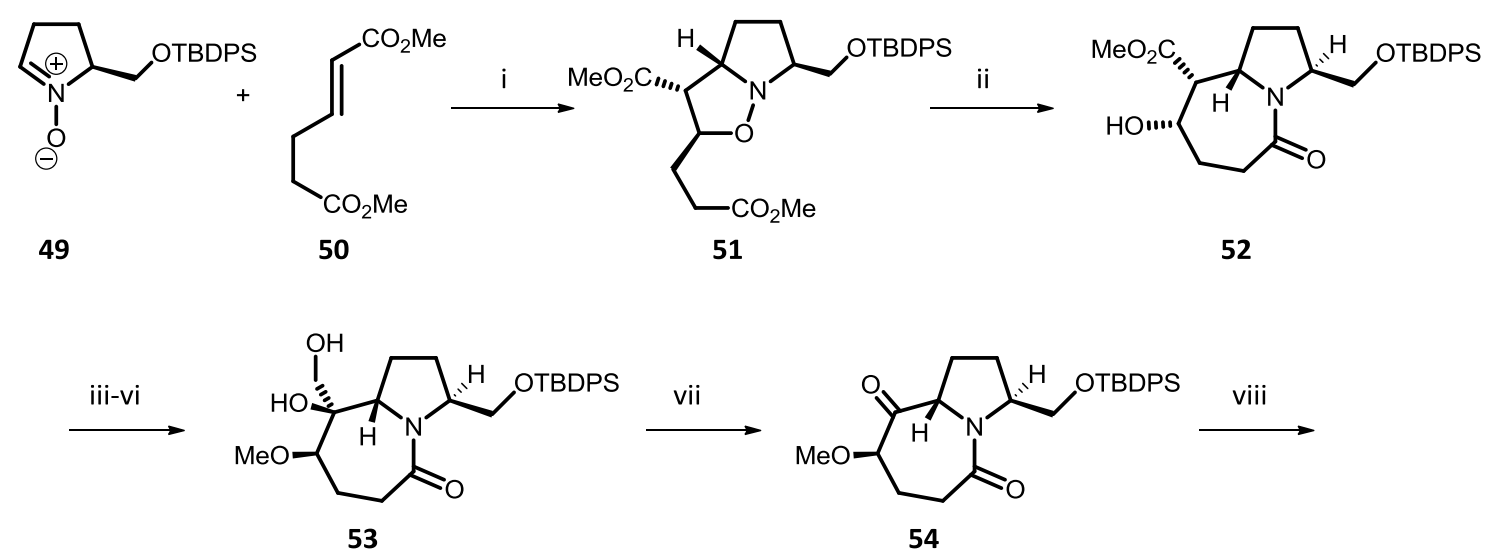

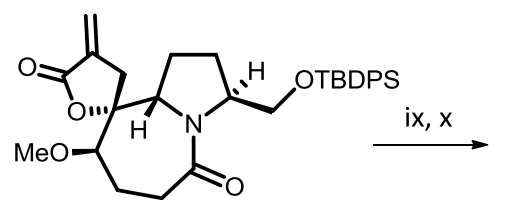

55

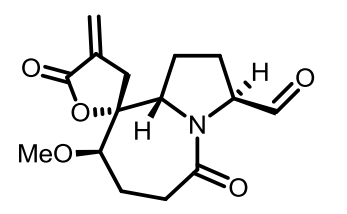

56

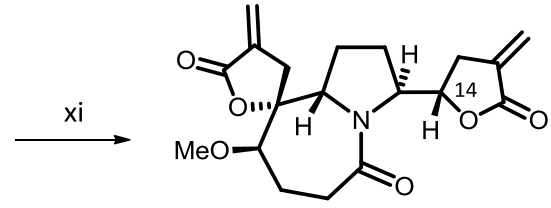

57

$+\mathrm{C}_{14}$ epimer

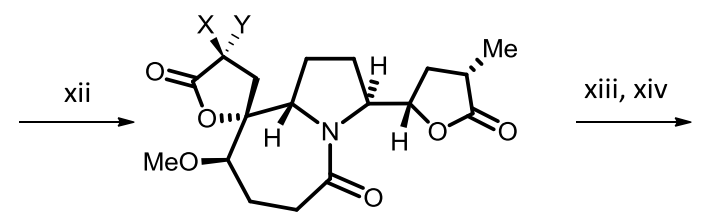

58, $X=M e, Y=H$

59, $X=H, Y=M e$

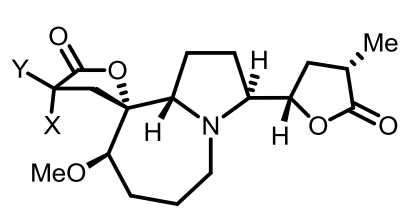

(-)-stemonidine, $X=\mathrm{H}, \mathrm{Y}=\mathrm{Me}$

60, (-)-11-epi-stemonidine, $\mathrm{X}=\mathrm{Me}, \mathrm{Y}=\mathrm{H}$

Reagents and conditions: (i) toluene, reflux (78\%); (ii) $\mathrm{Zn}, \mathrm{AcOH}$; then, aq. $\mathrm{NH}_{3}$; then, toluene, reflux (84\%); (iii) $\mathrm{PPh}_{3}$, DIAD, $\mathrm{PhCO}_{2} \mathrm{H}$, THF (88\%); (iv) $\mathrm{OsO}_{4}, \mathrm{NMO}$, Acetone: $\mathrm{H}_{2} \mathrm{O}, 60{ }^{\circ} \mathrm{C}(92 \%)$; (v) $\mathrm{NaH}$, THF, $0{ }^{\circ} \mathrm{C}$; then, $\mathrm{Me}_{2} \mathrm{SO}_{4}, 0{ }^{\circ} \mathrm{C}$ to r.t.

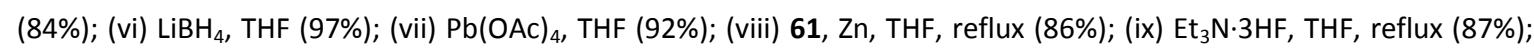
(x) Dess-Martin periodinane, $\mathrm{CH}_{2} \mathrm{Cl}_{2}$ (92\%); (xi) 61, Zn, THF, reflux (37\%); (xii) $\mathrm{H}_{2}$ (6 bar), Pd/C, EtOH: $\mathrm{HCl}(2 \mathrm{M})(9: 1)$ (68\%); (xiii) Lawesson's reagent, THF, reflux; (xiv) Raney-Ni, EtOH, reflux (45\%, 2 steps).

Scheme 8 . Total synthesis of stemonidine. ${ }^{38}$

In 2001, Williams and co-workers completed the first synthesis of (-)-stemospironine, ${ }^{27 a}$ whose structure had been unequivocally established by $\mathrm{X}$-ray analysis, ${ }^{11}$ and found that its

\footnotetext{
${ }^{44}$ (a) Xu, R.; Lu, Y.; Chu, J.; Iwashita, T.; Naoki, H.; Naya, Y.; Nakanishi, K. Tetrahedron 1982, 38, 2667-2670; (b) He, X.; Lin, W.; Xu, R. Huaxue Xuebao 1990, 48, 694-699.
} 
spectral and physical data matched those reported for the natural stemonidine. They also found that the ${ }^{13} \mathrm{C}-\mathrm{NMR}$ spectra of synthetic stemospironine and natural stemonidine were virtually identical, but the authors did not exclude the possibility of the two compounds being spirocyclic diastereoisomers.

In order to shed some light on the controversy of its uncertain structural assignment, our research group first tackled the synthesis of stemonidine (Scheme 8).

The synthetic sequence to stemonidine started with the 1,3-dipolar cycloaddition reaction of the enantiopure nitrone $\mathbf{4 9}$ to the $\alpha, \beta$-unsaturated ester $\mathbf{5 0}$, which furnished isoxazolidine 51. After reductive cleavage of the $\mathrm{N}-\mathrm{O}$ bond and subsequent cyclization, azepinone $\mathbf{5 2}$ was formed. In a few steps, the azepinone $\mathbf{5 2}$ was transformed into the diol $\mathbf{5 3}$, whose oxidative cleavage with lead tetraacetate afforded ketone 54. Treatment of $\mathbf{5 4}$ with acrylate $\mathbf{6 1}$ and zinc rendered the spirolactone $\mathbf{5 5}$ with complete facial selectivity. After removal of the protecting silyl group, Dess-Martin oxidation furnished aldehyde 56. A Reformatsky-type reaction of $\mathbf{5 6}$ with $\mathbf{6 1}$ and zinc produced a roughly 1:1 mixture of bislactone $\mathbf{5 7}$ and its $\mathrm{C}_{14}$ epimer. Then, hydrogenation of $\mathbf{5 7}$ under 6 bar pressure in the presence of $\mathrm{Pd} / \mathrm{C}$ furnished a mixture of azepinones $\mathbf{5 8}$ and $\mathbf{5 9}$ epimeric at $\mathrm{C}_{11}$, which were converted into the corresponding thiolactams, and, finally, treatment with Raney-Ni delivered the corresponding azepines, stemonidine and 11epi-stemonidine, 60.

The spectroscopic data for synthetic stemonidine did not match those of the alkaloid isolated from natural sources and it was thus shown that the putative isolated stemonidine was in fact stemospironine. 


\subsection{OBJECTIVES}

As mentioned above, one of the advantages of our approach is the possibility of synthesizing different Stemona alkaloids from common intermediates. Diol 53 (Scheme 9) was visualized as one of this key intermediates because it should allow the construction of the spiranic lactone present in the tuberostemospironine group alkaloids with either $R$ or $S$ absolute configuration of the spiranic stereocenter, leading the synthesis to stemonidine or stemospironine, respectively.

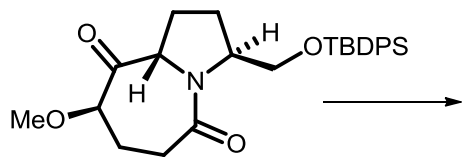

54

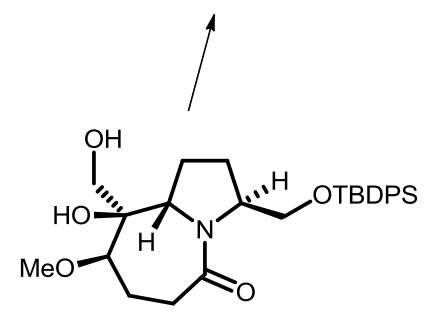

53

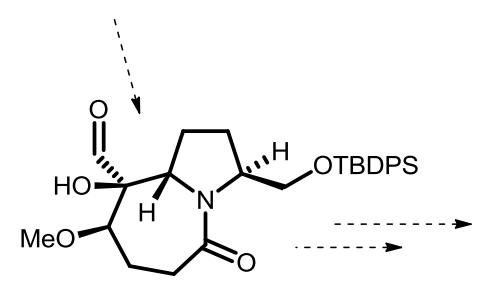

62

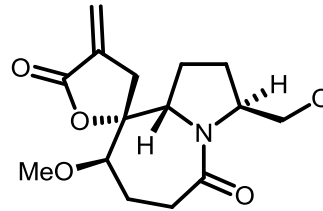

55
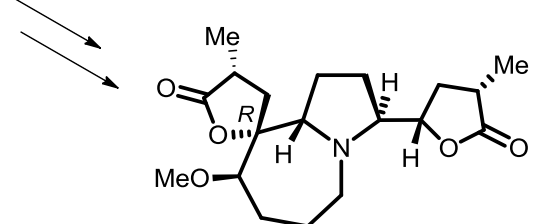

stemonidine

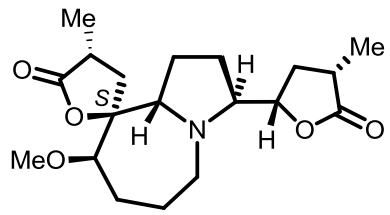

stemospironine

Scheme 9. Synthetic strategy for the putative structure of stemonidine and stemospironine.

Considering the aforementioned precedents, the objectives of the present work were:

- Objective 1. To prepare the key intermediate $\mathbf{5 3}$ by reproducing the methodology previously developed by our research group, which culminated with the synthesis of the putative structure of stemonidine, ${ }^{38}$ trying to improve the yields and scaling up the individual synthetic steps (Scheme 10). 


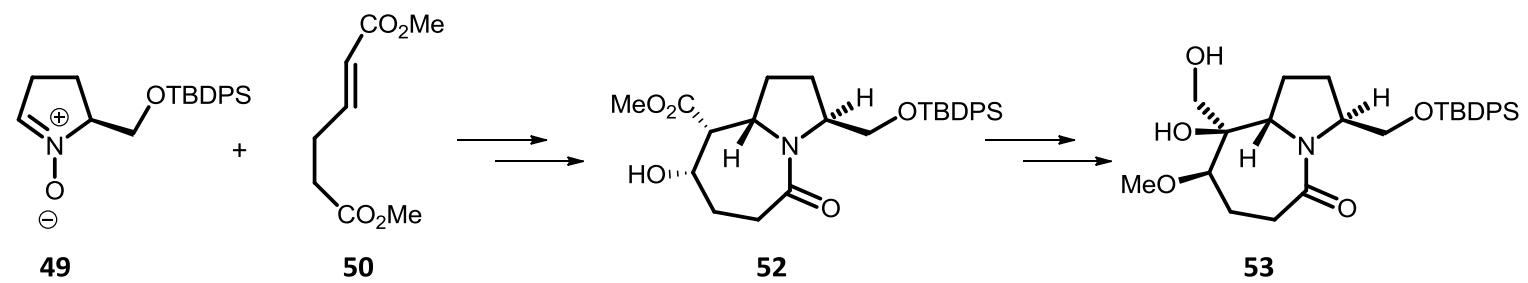

Scheme 10. Synthesis of the key intermediate 53.

- Objective 2: To synthesize (-)-stemospironine and some of its stereoisomers (Scheme 11).

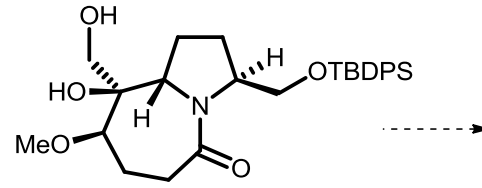

53

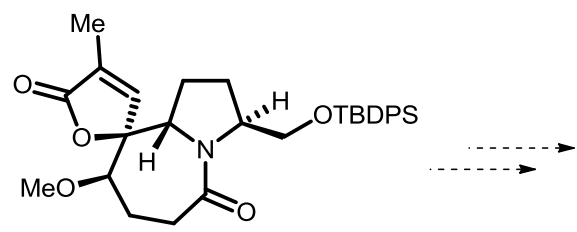

63

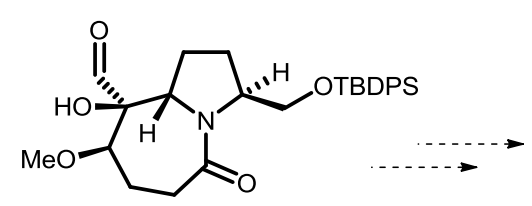

62

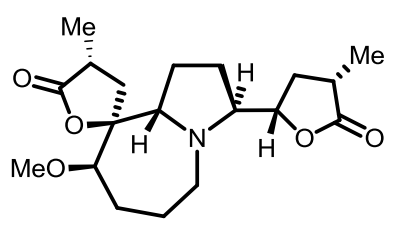

stemospironine

Scheme 11. Proposed synthetic strategy for (-)-stemospironine. 
2. Results and Discussion 



\subsection{1,3-Dipolar Cycloaddition Reaction}

\subsubsection{General concepts}

As it was mentioned in the Introduction, our synthetic approach to Stemona alkaloids starts with a 1,3-dipolar cycloaddition reaction of a 5-substituted 1-pyrroline $\mathrm{N}$-oxide to an electrondeficient olefin (Scheme 5), affording a cycloadduct with two of the stereogenic centers of the targeted alkaloid. Therefore, some basic concepts of this type of reaction will be first introduced and then we will focus on the synthesis and results.

It is generally accepted that the 1,3-dipolar cycloaddition reactions follow an asynchronous concerted mechanism. ${ }^{45}$ Consequently, the dipole-dipolarophile approach takes place in two parallel planes in such a way that a $\pi 4 s+\pi 2 s$ orbital interaction occurs according to Woodward and Hoffmann's symmetry rules. The process can be studied by Fukui's Frontier Molecular Orbital (FMO) theory, with which both the regio- and stereoselectivity can be predicted. ${ }^{46}$ Depending on the dominant HOMO-LUMO interaction, there are 3 different types of 1,3-dipolar cycloadditions (Figure 7). ${ }^{47}$
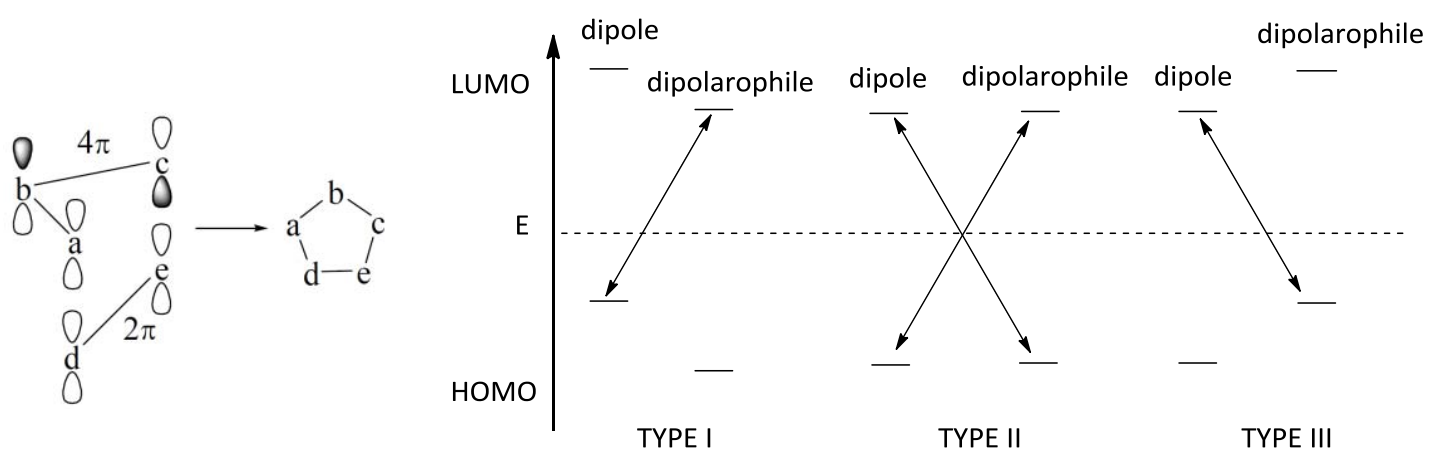

Figure 7. Dipole-dipolarophile interaction and classification of 1,3-dipolar cycloadditions based on the FMO theory.

As nitrones are type II dipoles, the main interaction will depend on the nature of the dipolarophile. Thus, if the dipolarophile contains an electronwithdrawing group, the dominant

\footnotetext{
${ }^{45}$ Houk, K. N.; Firestone, R. A.; Münchausen, L. L.; Mueller, P. H.; Arison, B. H.; García, L. A. J. Am. Chem. Soc. 1985, 107, 7227-7228.

${ }^{46}$ (a) Tufariello, J. J. 1,3-Dipolar Cycloaddition Chemistry, Padwa, A. Ed., John Wiley and Sons, New York, 1984, Vol. 2, Chapter 9; (b) Torsell, K. B. G. Nitrile Oxides, Nitrones, and Nitronates in Organic Synthesis, H. Feuer Ed., V. C. H. Publishers, Inc., New York, 1988; (c) Little, R. C. Comprehensive Organic Chemistry, Trost, B. M. and Fleming, I. Ed., Pergamon Press 1991, Vol. 5, Chapter 3.

${ }^{47}$ Sustmann, R. Pure Appl. Chem. 1974, 40, 569-593.
} 


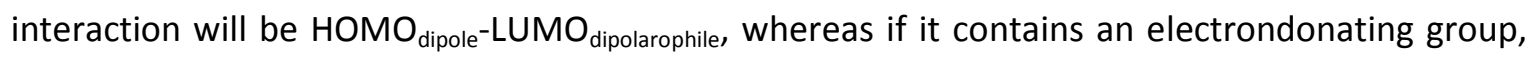
the main interaction will be $\mathrm{HOMO}_{\text {dipolarophile }}-\mathrm{LUMO}_{\text {dipole }}$.

The FMO theory explains the regioselectivity of 1,3-dipolar cycloadditions by considering the different size of the atomic coefficients in the FMO involved on the main interaction. The reaction between a nitrone and an electrondonating substituted dipolarophile will afford a 5substituted isoxazolidine, while the reaction with an electronwithdrawing substituted dipolarophile will furnish a 4-substituted adduct (Figure 8). However, in some cases steric factors may predominate over electronic ones, and there is experimental evidence for the strong tendency of the oxygen atom to bond the more substituted carbon of the dipolarophile.

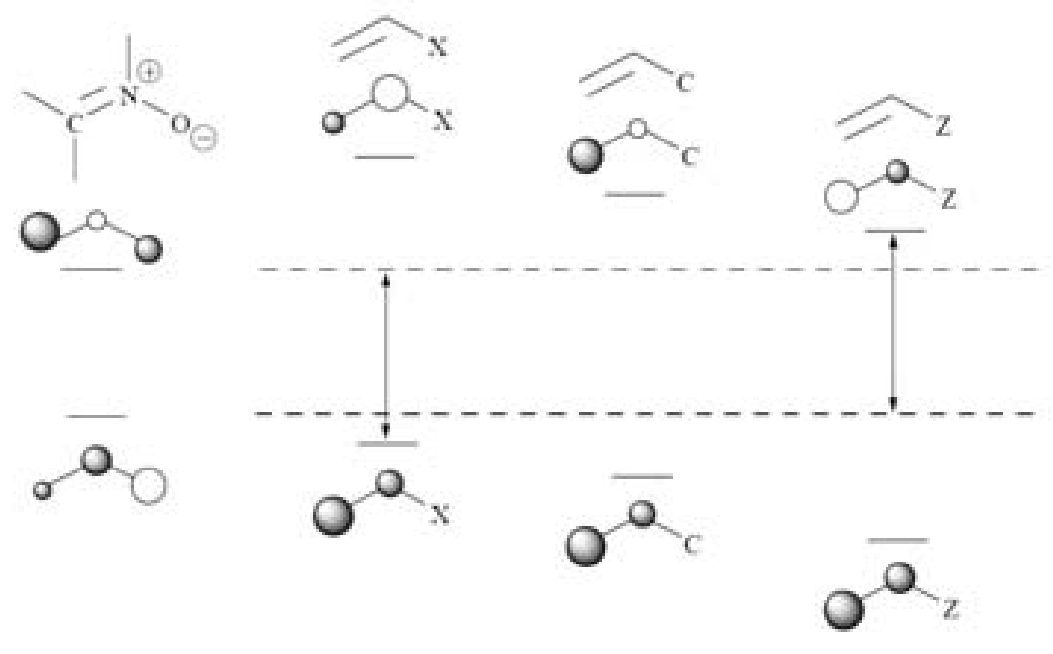

dominant interaction

Figure 8. FMO interactions of a nitrone with different dipolarophiles.

Another factor to consider in a 1,3-dipolar cycloaddition process is the endo/exo stereoselectivity. The dipole-dipolarophile approach can take place in two kinds of transition states (TS), considering the orientation of the substituents of the dipolarophile. When the dipolarophile bears an electronwithdrawing substituent (as the methyl ester group in $\mathbf{5 0}$, Scheme 12), in the endo TS, this substituent is placed towards the dipole, while in the exo TS it is placed outwards the dipole, each approach affording diastereoisomeric cycloadducts. In the case of conjugated olefins, electronic factors favour the TS with the electronwithdrawing group endo oriented, but steric hindrance is also at play. As a general rule, it can be stated that if the 1,2disubstituted alkene has a $Z$ configuration, steric interactions will destabilize the endo TS hence playing against electronic interactions. On the other hand, if the olefin has $E$ configuration, both steric and electronic factors can point to the same or opposite directions.

In addition to the endo/exo selectivity, when the dipole is a chiral substituted nitrone as 49, we also have to consider if the dipolarophile approaches it by the substituent's face (syn 
approach) or by the opposite face (anti approach), being the last one generally preferred. The stereoselectivity of 1,3-dipolar cycloadditions of nitrones has been extensively studied by some groups, ${ }^{48}$ including ours. ${ }^{40,41,42,49}$ In these previous studies, our group used, among others, 5substituted $\mathrm{N}$-oxides as $\mathbf{4 9}$ and different olefins to perform the cycloaddition and, in all cases, the reaction took place with complete antifacial diastereoselectivity through endo or exo approaches in the TS, depending on the trans or cis configuration of the dipolarophile, respectively. ${ }^{40,41,42}$

Taking all the possibilities into account, for the cycloaddition between $\mathbf{4 9}$ and $\mathbf{5 0}$ four possible diastereoisomeric cycloadducts, $51,64,65$ and 66 , can a priori be formed depending on the endo/exo orientation of the dipolarophile and its syn- or antifacial approach to the nitrone.

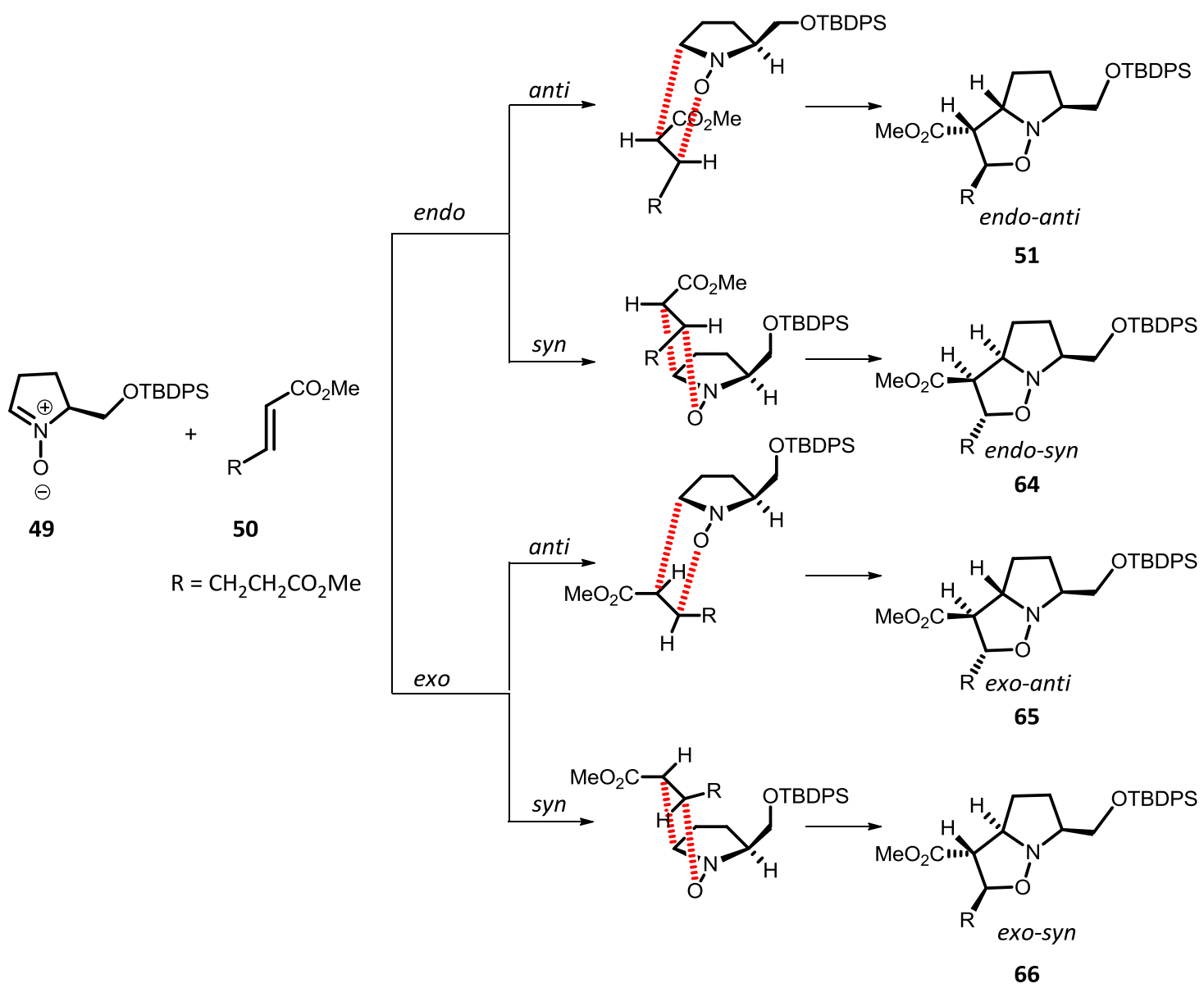

Scheme 12. Transition states and possible adducts of 1,3-dipolar cycloadditions of nitrone 49 and disubstituted alkene $\mathbf{5 0}$.

\footnotetext{
${ }^{48}$ (a) Plate, R.; Hermkens, P. H. H.; Simits, J. M. M.; Ottenheijm, H. C. J. J. Org. Chem. 1986, 51, 309-314; (b) Burdisso, M.; Gandolfi, R.; Grünanger, P. Tetrahedron 1989, 45, 5579-5594; (c) Ali, Sk. A.; Khan, J. H.; Wazeer, M. I. M.; Perzanowski, H. P. Tetrahedron 1989, 45, 5979-5986.

${ }^{49}$ (a) Cid, P.; de March, P.; Figueredo, M.; Font, J.; Milán, S.; Soria, A.; Virgili, A. Tetrahedron 1993, 49, 3857-3870; (b) Alonso-Perarnau, D.; de March, P.; Figueredo, M.; Font, J.; Soria, A. Tetrahedron 1993, 49, 4267-4274; (c) Busqué, F.; de March, P.; Figueredo, M.; Font, J.; Montsalvatje, M.; Álvarez-Larena, A.; Piniella, J. F. J. Org. Chem. 1996, 61, 8578-8585, (d) de March, P.; Figueredo, M.; Font, J.; Heterocycles 1999, 50, 1213-1226.
} 


\subsubsection{Preparation of nitrone 49 and olefin 50}

Nitrone $\mathbf{4 9}$ can be prepared in multigram quantities by oxidation of the corresponding amine 48 (Scheme 13). ${ }^{38,43}$ In order to prepare the amine $\mathbf{4 8}$, we can either use L-prolinol, $\mathbf{4 0}$, as starting material, or L-proline, 67. The route starting from L-proline is economically advantageous, despite it involves four synthetic steps, because the overall yield is very good (70\%) and commercial L-prolinol is much more expensive than L-proline.

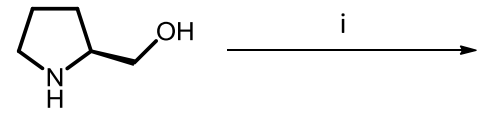

40<smiles>[PbH2]OCC1CCCN1</smiles>

48

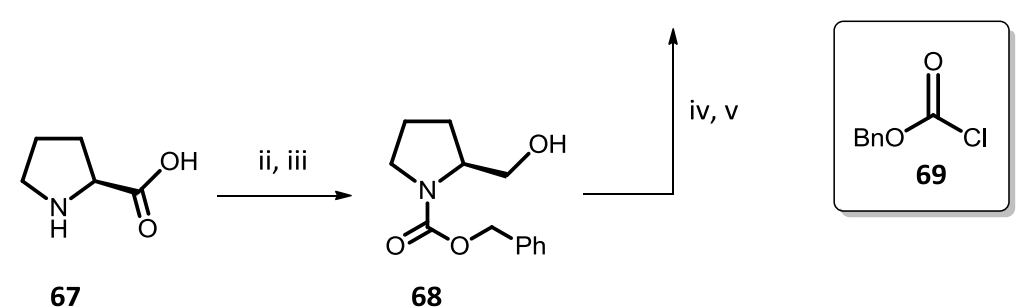

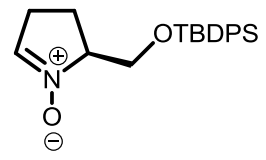

49

Reagents and conditions: (i) TBDPSCl, Imidazole, DMAP, $\mathrm{CH}_{2} \mathrm{Cl}_{2}, 0{ }^{\circ} \mathrm{C}$ to r.t., $16 \mathrm{~h}$ (95\%); (ii) 69, $\mathrm{NaOH} 2 \mathrm{M}, 0{ }^{\circ} \mathrm{C}, 2 \mathrm{~h}$ (97\%); (iii) $\mathrm{BH}_{3} \cdot \mathrm{THF}, \mathrm{THF}, 0{ }^{\circ} \mathrm{C}$ to r.t., $16 \mathrm{~h}$ (93\%); (iv) TBDPSCl, Imidazole, THF, r.t., 16 h (87\%); (v) $\mathrm{HCO}_{2} \mathrm{NH}_{4}, \mathrm{Pd} / \mathrm{C}$, THF:MeOH (2:1), $80^{\circ} \mathrm{C}, 30 \mathrm{~min}(89 \%)$.

Scheme 13. Synthesis of amine 48.

As we mentioned before, nitrone $\mathbf{4 1}$ was previously prepared in one step by treatment of L-prolinol, 40, with dimethyldioxirane in acetone at low temperature (Scheme 14). ${ }^{40}$ Although this straightforward methodology competed favourably with other preparations of related nitrones, difficulties associated with the purification of the nitrone and the scaling-up of the process led us to abandon its use.

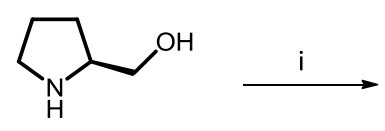

40

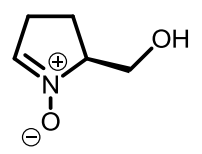

41

Reagents and conditions: (i) DMD, acetone, $-78^{\circ} \mathrm{C}, 30 \mathrm{~min}$; then, toluene, reflux, $6 \mathrm{~h}(32 \%)$.

Scheme 14. Synthesis of nitrone $\mathbf{4 1}$ from L-prolinol $\mathbf{4 0 .}$ 
To avoid these drawbacks, we decided to use oxone for the direct oxidation of an Lprolinol derivative. ${ }^{43}$ After a detailed study, the best result was obtained when the oxidation was carried out starting from the TBDPS derivative of L-prolinol 48 (Scheme 15), with oxone in a mixture of MeCN:THF in the presence of $\mathrm{NaHCO}_{3}$ and EDTA. In that way, a 1.30:1 mixture of nitrones $\mathbf{4 9}$ and $\mathbf{7 0}$ could be prepared in multigram quantities and $90 \%$ combined yield. The optically pure nitrone $\mathbf{4 9}$ was isolated from this mixture and used by our research group for the synthesis of the putative structure of stemonidine. ${ }^{38}$ In the present work, $\mathrm{MeOH}$ was used as solvent instead of the mixture of MeCN:THF while the other conditions remained unchanged, furnishing a 1.34:1 mixture of nitrones $\mathbf{4 9}$ and $\mathbf{7 0}$ in $87 \%$ overall yield. After flash column chromatographic separation, nitrone $\mathbf{4 9}$ was obtained in $48 \%$ yield. It is important to mention that it was possible to scale up the reaction to obtain $10 \mathrm{~g}$ of nitrone 49 in a reproducible manner, without detriment of yield or optical purity.

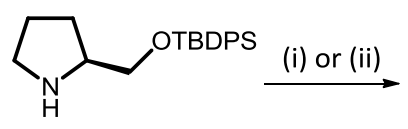

48

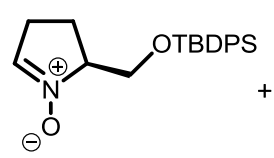

49

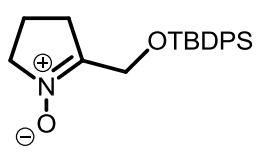

70

Reagents and conditions: (i) oxone, $\mathrm{Na}_{2}$ EDTA $0.01 \mathrm{M}, \mathrm{NaHCO}_{3}, \mathrm{MeCN}: \mathrm{THF}(4: 1), 0{ }^{\circ} \mathrm{C}, 2 \mathrm{~h}$ (90\%); (ii) oxone, $\mathrm{Na}_{2} \mathrm{EDTA}$ $0.01 \mathrm{M}, \mathrm{NaHCO}_{3}, \mathrm{MeOH}, 0{ }^{\circ} \mathrm{C}, 2 \mathrm{~h}(87 \%)$.

Scheme 15. Synthesis of nitrone $\mathbf{4 9}$ from the L-prolinol derivative $\mathbf{4 8 .}$

With the enantiopure nitrone $\mathbf{4 9}$ in hands, olefin $\mathbf{5 0}$ was synthesized also in multigram scale (Scheme 16). This olefin would be used later on as dipolarophile in the 1,3-dipolar cycloaddition to 49.

To prepare alkene $\mathbf{5 0}$ we could start from the commercially available sulfoxide $\mathbf{7 4}$, but in this thesis we prepared it through the sequence outlined below (Scheme 16). Reaction of thiophenol, 71, with methyl bromoacetate, 72, and subsequent oxidation with $\mathrm{NaIO}_{4}$ yielded sulfoxide $74 .^{50}$ The sulfoxide was treated with sodium hydride to afford the corresponding anion, which was subsequently alkylated with methyl 4-bromobutanoate, 76, rendering sulfoxide 75. Without further purification, pyrolysis of $\mathbf{7 5}$ in DME at the reflux temperature yielded olefin $\mathbf{5 0}$ in $45 \%$ overall yield from 71 .

\footnotetext{
${ }^{50}$ Raghavan, S.; Reddy, S. R.; Tony, K.A.; Kumar, C. N.; Varma, A. K.; Nangia, A. J. Org. Chem. 2002, 67, 5838-5841.
} 
<smiles>COC(=O)CBr</smiles>

71<smiles>COC(=O)CSc1ccccc1</smiles>

73

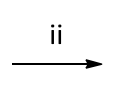<smiles>COC(=O)CS(=O)c1ccccc1</smiles>

74

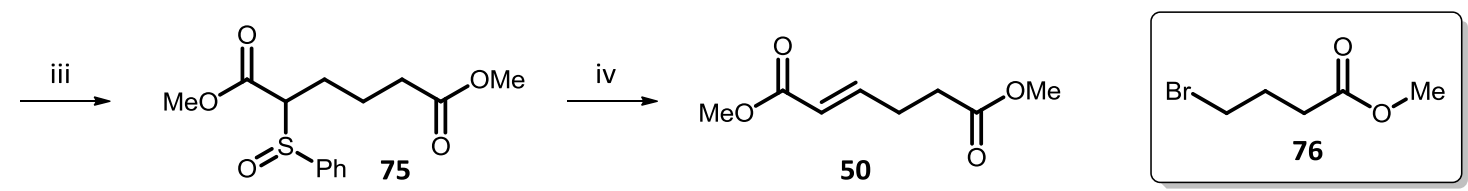

Reagents and conditions: (i) $\mathrm{Et}_{3} \mathrm{~N}$, toluene, r.t., 16 h (98\%); (ii) $\mathrm{NalO}_{4}, \mathrm{H}_{2} \mathrm{O}, \mathrm{MeOH}$, r.t., 16 h (93\%); (iii) NaH, HMPA, DME, r.t., 30 min; then, 76, 16 h; (iv) DME, relfux, 16 h (49\%, 2 steps).

Scheme 16. Synthesis of dimethyl hexenedioate 50, from thiophenol, 71, and methyl bromoacetate 72.

\subsubsection{1,3-Cycloaddition reaction of nitrone $\mathbf{4 9}$ to olefin $\mathbf{5 0}$}

In previous work of our group, the 1,3-cycloaddition reaction between nitrone $\mathbf{4 9}$ and diester $\mathbf{5 0}$ was performed in toluene at the reflux temperature for $10 \mathrm{~h}$ to obtain a mixture of the expected endo-anti isoxazolidine 51 (78\% yield), along with a minor quantity of its exo-anti diastereoisomer 65 (5\% yield) (Scheme 17). ${ }^{38}$

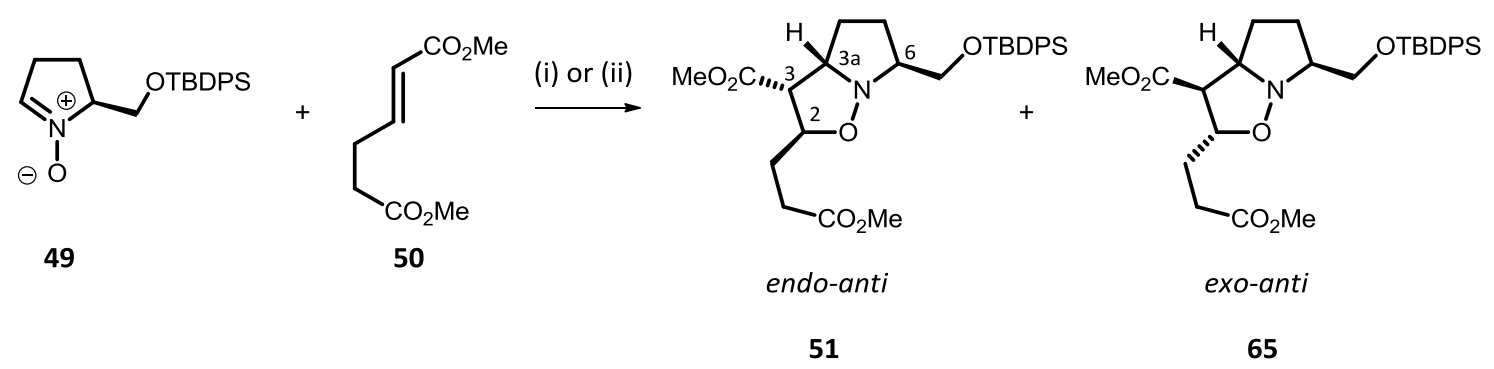

Reagents and conditions: (i) toluene, reflux, $10 \mathrm{~h}$ (78\%); 51:65 15:1; (ii) toluene, $90{ }^{\circ} \mathrm{C}, 1.5 \mathrm{~h}$ (79\%); only 51.

Scheme 17. 1,3-dipolar cycloaddition reaction of nitrone $\mathbf{4 9}$ to olefin $\mathbf{5 0 .}$

In this thesis, the cycloaddition reaction between $\mathbf{4 9}$ and $\mathbf{5 0}$ lacked reproducibility when performing it in toluene at the reflux temperature during $10 \mathrm{~h}$, rendering sometimes low yields of cycloadducts and/or decomposition products. However, we found out that, when the reaction was carried out in toluene at $90{ }^{\circ} \mathrm{C}$ during $1.5 \mathrm{~h}, \mathbf{5 1}$ was isolated as the only product in $79 \%$ yield. Running the reaction for this shorter period of time, equilibration between the kinetical endo cycloadduct and the starting material is avoided, preventing the formation of the most stable exo cycloadduct and other products resulting from the nitrone decomposition. 
The isoxazolidine $\mathbf{5 1}$ resulting of the cycloaddition contained four stereogenic centers, three of which $\left(C_{2}, C_{3}\right.$ and $\left.C_{3 a}\right)$ were generated in the reaction. The relative trans geometry between $\mathrm{H}_{2}$ and $\mathrm{H}_{3}$ is a consequence of the $E$ configuration of the starting olefin $\mathbf{5 0}$. The trans configuration between $\mathrm{H}_{3 a}$ and $\mathrm{H}_{6}$ is the result of the preferred antifacial approach between the reagents in the TS, which has been extensively demonstrated in precedent works. ${ }^{40,41,42}$

To determine the complete stereochemistry of the cycloaddition, the relative geometry between protons $\mathrm{H}_{3}$ and $\mathrm{H}_{3 a}$ should be also established. The relationship between $\mathrm{H}_{3}$ and $\mathrm{H}_{3 a}$ indicates if the cycloadduct comes from an exo (trans relationship) or endo TS (cis relationship). Previous studies performed in our group with similar cycloadducts indicated that values of $J_{3,3 a} \approx 8$ $\mathrm{Hz}$ were characteristic of the cis relative geometry of endo cycloadducts, while the corresponding exo showed a $\mathrm{J}_{3,3 \mathrm{a}} \approx 5-6 \mathrm{~Hz}$. The ${ }^{1} \mathrm{H}-\mathrm{NMR}$ spectrum of isoxazolidine 51 presents a $\mathrm{J}_{3,3 \mathrm{a}}=9.3 \mathrm{~Hz}$ and hence it was identified as an endo adduct.

In previous works, the enantiomeric purity of $\mathbf{5 1}$ was determined. ${ }^{38}$ It was considered important to determine it at this point, because any epimerization that may take place later on in the synthetic sequence would provide diastereoisomers and therefore it could be readily detected by NMR techniques.

To this end, the synthesis was repeated starting from D-prolinol until achieving the corresponding isoxazolidine ent-51. This compound and the cycloadduct obtained from Lprolinol, 51, were compared using a chiral HPLC analysis (Figure 9). It was found that the racemate could be separated by CHPLC using a Daicel Chiralpak AD-H $4.6 \times 250 \mathrm{~mm}$ column ('PrOH:hexanes, 1:99; $0.8 \mathrm{~mL} \cdot \mathrm{min}^{-1}$ ). Figure 9 displays three chromatograms. Chromatogram $\mathrm{A}$ resulted of an injection of an approximately 6:1 mixture of both enantiomers, $\mathbf{5 1}$ and ent-51, respectively. Once the best separation conditions were established, each isomer was injected separately. Chromatogram B was obtained from the injection of 51, which derives from Lprolinol, and chromatogram C from the injection of ent-51, that derives from D-prolinol. Thus, the enantiomeric purity was secured and it was proved that undoubtedly there was no racemization of the nitrone before the cycloaddition took place. 

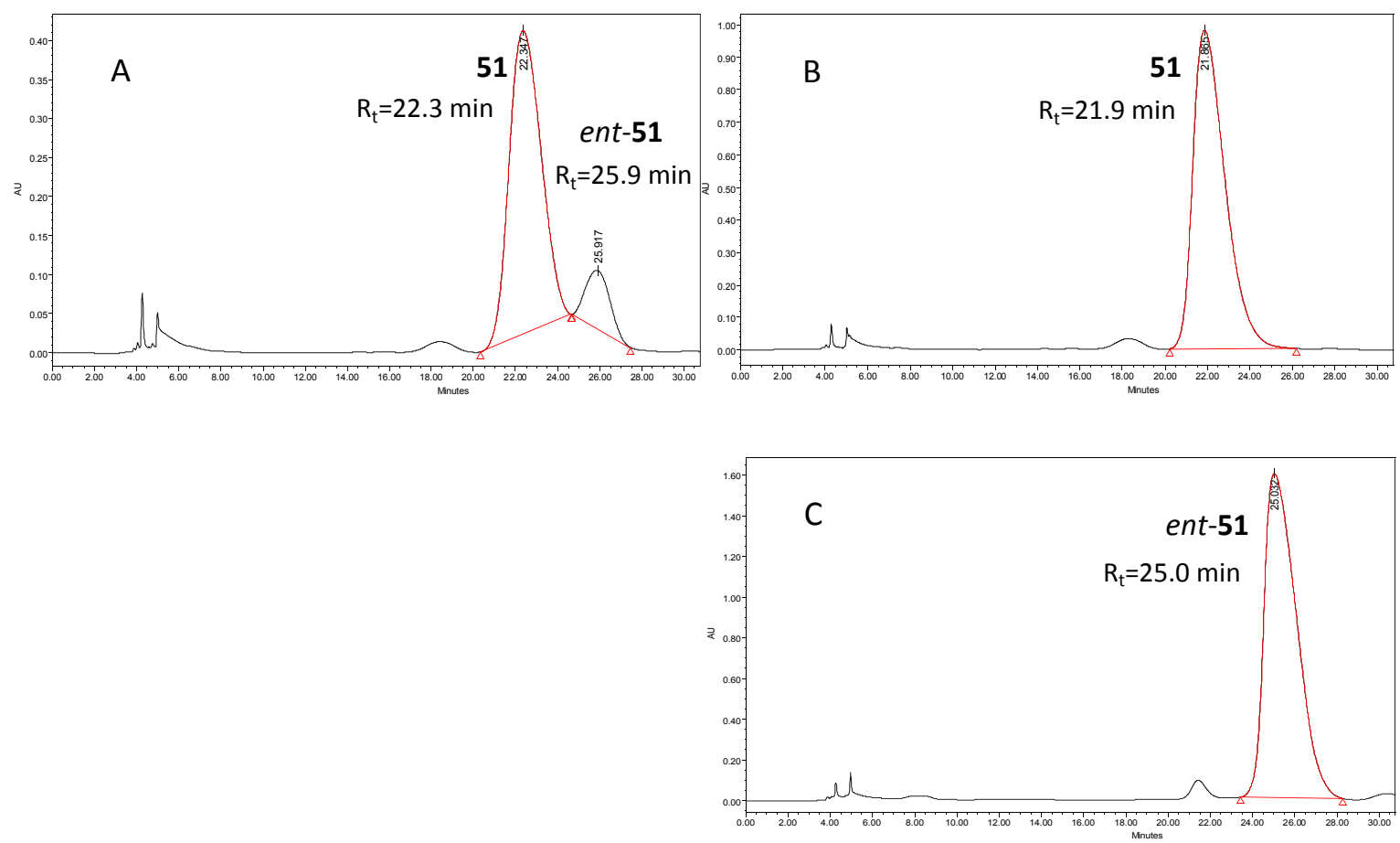

Figure 9. CHPLC chromatograms obtained from the injection of $( \pm)-51(A), 51(B)$ and ent-51 (C).

\subsection{Construction of the pyrrolo[1,2-a]azepinone core. Synthesis of intermediate 52}

Once the isoxazolidine $\mathbf{5 1}$ had been prepared, the next step was the formation of the characteristic azabicyclic nucleus. Reductive cleavage of the N-O bond of $\mathbf{5 1}$ was performed by treatment with activated $\mathrm{Zn}^{51}$ in glacial acetic acid. Basification of the quaternary ammonium salt with aqueous $\mathrm{NH}_{3}$ and subsequent heating furnished lactam $\mathbf{5 2}$ in 91\% yield (Scheme 18).

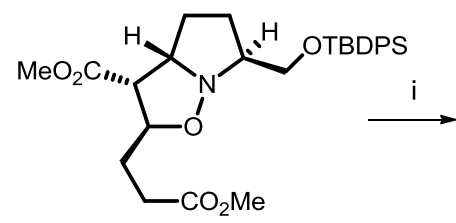

51

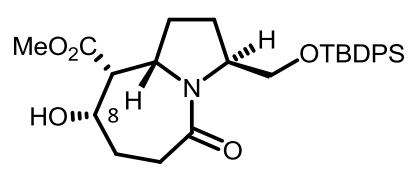

52

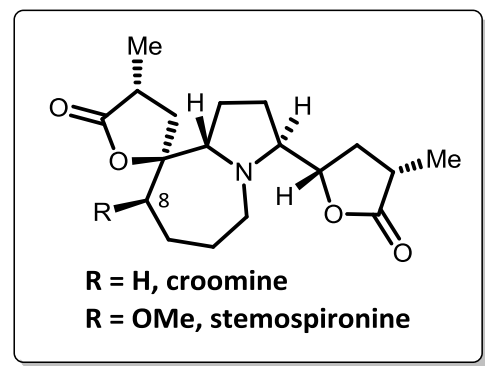

Reagents and conditions: (i) $\mathrm{Zn}, \mathrm{AcOH}$; then, aq. $\mathrm{NH}_{3}, \mathrm{CHCl}_{3}$; then, toluene, reflux, $16 \mathrm{~h}$ (91\%).

Scheme 18. Synthesis of lactam 52.

\footnotetext{
${ }^{51}$ Newman, M. S.; Evans, F. J. J. Am. Chem. Soc. 1955, 77, 946-497.
} 
In both the tuberostemospironine and stemoamide groups, all the alkaloids bearing an oxygen atom at $C_{8}$, such as stemospironine, present the same configuration at this center, which is the opposite to that in lactam 52. On the other hand, manipulation of the hydroxyl group at $\mathrm{C}_{8}$ for further synthetic elaboration usually led to elimination products. ${ }^{16 r, t}$

Moreover, a simple conformational analysis of the azabicyclic skeleton of these compounds showed that the concave face was more sterically hindered and, consequently, less accessible (Figure 10). Taking all this information into account, it seemed a good strategy dehydrating lactam $\mathbf{5 2}$ firstly and then performing a diastereoselective dihydroxylation of the $\alpha, \beta$-unsaturated ester (Scheme 19).

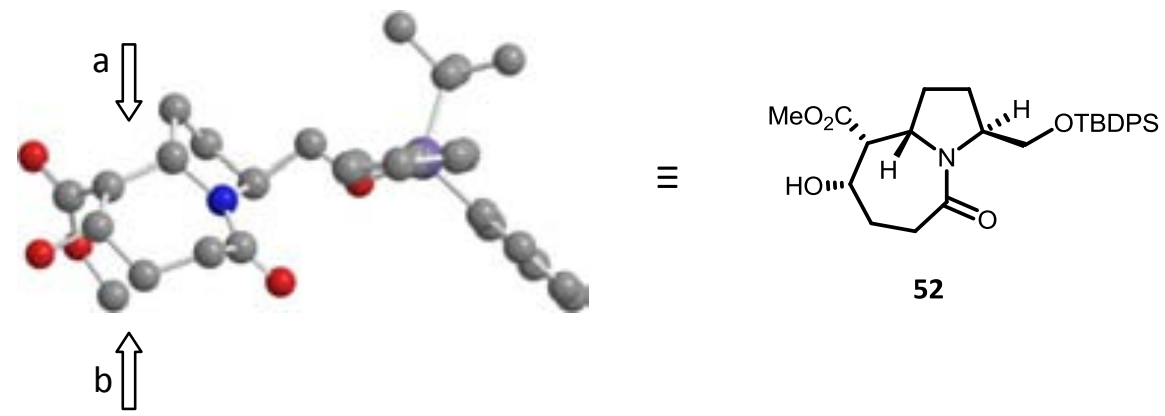

a) convex face, less steric hindrance; b) concave face, less accessible.

Figure 10. Molecular model of lactam 52 (ChemBio3D Ultra 12.0).

\subsection{Preparation of the key intermediate 53}

Accordingly, the next step in the sequence was the preparation of the olefin $\mathbf{7 7}$ and its subsequent dihydroxylation to yield diol 78 (Scheme 19). This diol 78 should be a suitable precursor of various alkaloids, such as stemospironine (tuberostemospironine group) and stemonine (stemoamide group), because it presents the correct configuration at $C_{8}$ and could undergo convenient transformations to form the spiro- or fused lactones with the appropriate configuration at $C_{9}$. 

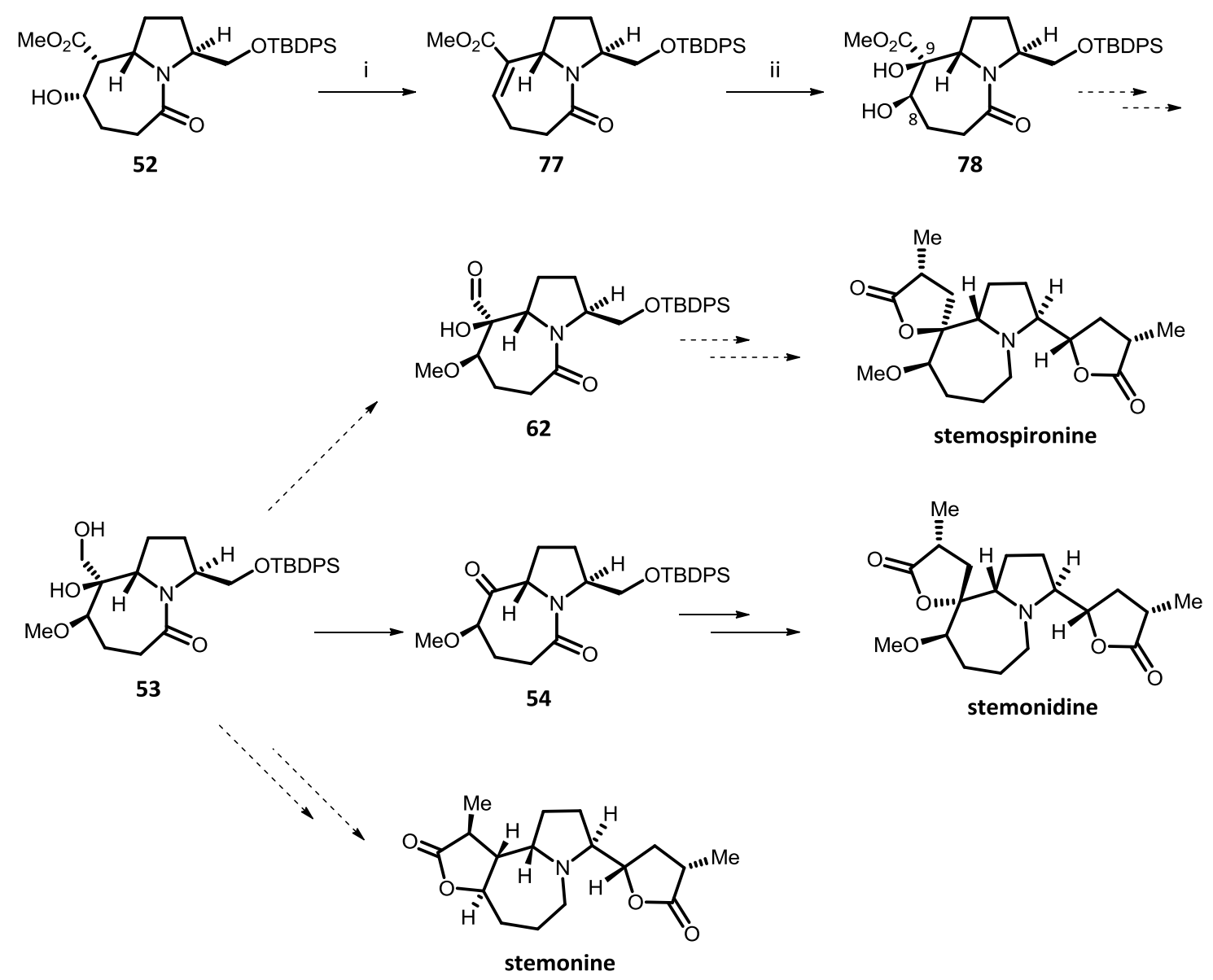

Reagents and conditions: (i) $\mathrm{PPh}_{3}, \mathrm{DIAD}, \mathrm{PhCO}_{2} \mathrm{H}$, THF, r.t., $1.5 \mathrm{~h}$ (85\%); (ii) OsO ${ }_{4}, \mathrm{NMO}$, acetone: $\mathrm{H}_{2} \mathrm{O}(9: 1), 60{ }^{\circ} \mathrm{C}, 1.5 \mathrm{~h}$ (96\%).

Scheme 19. Synthesis of diol 78 and synthetic plan for stemospironine, stemonidine and stemonine.

The dehydration of lactam $\mathbf{5 2}$ was accomplished under Mitsunobu's conditions ${ }^{52}$ in THF and in the presence of benzoic acid, furnishing olefin 77 in $85 \%$ yield.

In preceding investigations with the related compound $\mathbf{7 9}$ (Scheme 20), ${ }^{38}$ it was observed that the presence of benzoic acid avoids the formation of a byproduct (81) resulting of double bond isomerization. The lack of planarity in the preferential conformation of $\mathbf{8 0}$ did not allow conjugation, giving more stability to the migration product $\mathbf{8 1}$. The formation of $\mathbf{8 1}$ could be easily avoided controlling the $\mathrm{pH}$ of the media by adding benzoic acid.

\footnotetext{
${ }^{52}$ Mitsunobu, O. Synthesis, 1981, 1-28.
} 


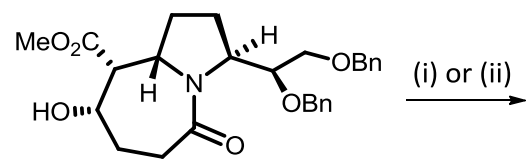

79

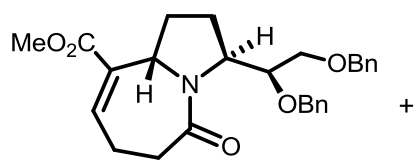

80

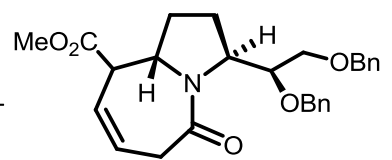

81

Reagents and conditions: (i) $\mathrm{PPh}_{3}$, DIAD, THF, r.t., 1 h (78\%); 80:81 1.9:1; (ii) $\mathrm{PPh}_{3}$, DIAD, $\mathrm{PhCO}_{2} \mathrm{H}$, THF, r.t., 1 h (84\%); only $\mathbf{8 0}$.

Scheme 20. Dehydration of compound 79.

The dihydroxylation of the $\alpha, \beta$-unsaturated ester $\mathbf{7 7}$ was performed by treatment with $\mathrm{OsO}_{4}$ and $\mathrm{NMO}$, furnishing diol 78 as the only product in $96 \%$ yield, with complete facial diastereoselectivity, as it was expected from previous results. We assumed that the reaction took place over the convex face of the molecule. This hypothesis was later corroborated by chemical correlation with the natural product stemospironine and by means of an X-ray diffraction analysis of an advanced intermediate.

The following step was the regioselective methylation of the secondary alcohol (Scheme 21). Initially, the alkylation was performed through a two-step protocol via the formation of a tin acetal intermediate, which is a common methodology for the selective protection of 1,2-diols. ${ }^{53}$ Thus, diol 78 was treated with dibutyltin oxide in $\mathrm{MeOH}$ at the reflux temperature and, when tin acetal formation was assumed, $\mathrm{TBABr}$ and $\mathrm{Me}_{2} \mathrm{SO}_{4}$ were added to the reaction mixture.

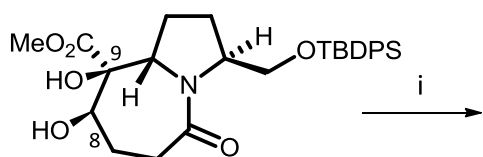

78

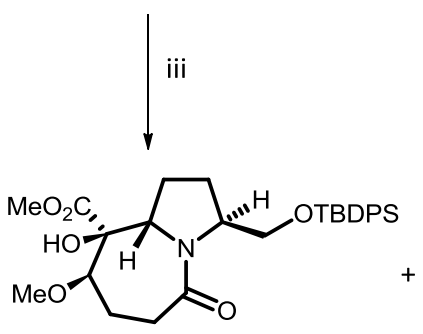

83

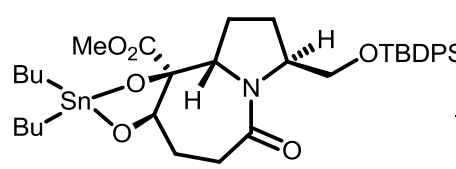

82

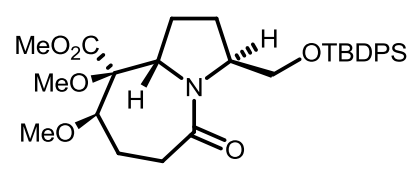

85

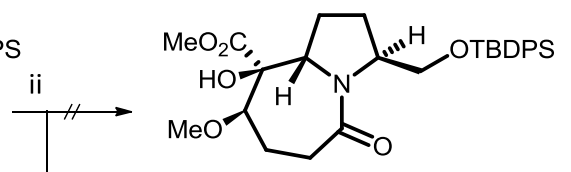

83

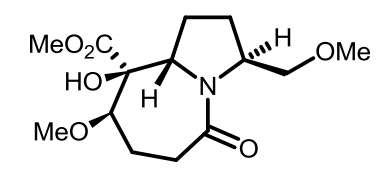

84

Reagents and conditions: (i) $\mathrm{Bu}_{2} \mathrm{SnO}, \mathrm{MeOH}$, reflux, $1.5 \mathrm{~h}$; (ii) $\mathrm{TBABr}, \mathrm{Me}_{2} \mathrm{SO}_{4}$, toluene, $80^{\circ} \mathrm{C}$; (iii) $\mathrm{NaH}, \mathrm{THF}, 0^{\circ} \mathrm{C}, 0.5 \mathrm{~h}$; then, $\mathrm{Me}_{2} \mathrm{SO}_{4}, 0^{\circ} \mathrm{C}$ to r.t., $16 \mathrm{~h}$ (84\% yield over unrecovered 78 ).

Scheme 21. Methylation of the secondary alcohol in 78.

\footnotetext{
53 (a) Wagner, D.; Verheyden, J. P. H.; Moffat, J. G. J. Org. Chem. 1974, 39, 24-29; (b) Busqué, F.; Hopkins, S. A.; Konopelski, J. P. J. Org. Chem. 2002, 67, 6097-6103.
} 
Unfortunately, the ${ }^{1} \mathrm{H}-\mathrm{NMR}$ analysis of the crude material allowed the identification of the dimethyl derivative $\mathbf{8 4}$ as the main product, instead of the desired monoether $\mathbf{8 3}$. Therefore, not only the expected alkylation of the secondary alcohol was taking place, but also the deprotection and subsequent methylation of the primary one.

A reference experiment carried out without the addition of the ammonium salt rendered a crude material consisting of starting diol $\mathbf{7 8}$ and the expected monomethylated product $\mathbf{8 3}$, but none of the dimethyl derivative. This fact proved that the ammonium salt was responsible for the deprotection of the primary alcohol in the reaction medium. Therefore, we moved to a different synthetic methodology. Thus, diol 78 was treated with an excess of $\mathrm{NaH}$ in THF at $0{ }^{\circ} \mathrm{C}$ and, when dianion formation was assumed, $\mathrm{Me}_{2} \mathrm{SO}_{4}$ was added. The reaction mixture was warmed up slowly to room temperature and stirred overnight to furnish the monomethyl derivative $\mathbf{8 3}$ in $84 \%$ yield considering unrecovered $\mathbf{7 8}$, together with a minor amount (2\%) of the dimethyl derivative 85 .

Subsequent reduction of the ester functionality with $\mathrm{LiBH}_{4}$ in $\mathrm{THF}$ provided diol $\mathbf{5 3}$ in $\mathbf{7 6 \%}$ yield (Scheme 22).

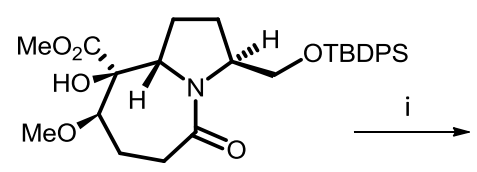

83

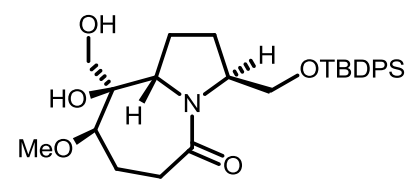

53

Reagents and conditions: (i) $\mathrm{LiBH}_{4}$, THF, r.t., $16 \mathrm{~h}$ (76\%).

Scheme 22. Preparation of diol 53.

\subsection{Construction of the spiranic lactone. Synthesis of compound 63}

Next, we turned our attention to the construction of the west-side lactone. Diol $\mathbf{5 3}$ was visualized as the key intermediate for the collective syntheses ${ }^{54}$ of several Stemona alkaloids. In particular, it should give access to a spiranic lactam with either $R$ or $S$ configuration of the spirocenter, depending on the subsequent transformations applied (Scheme 23). Thus, when the goal was the synthesis of stemonidine, ${ }^{38}$ diol $\mathbf{5 3}$ was transformed by oxidative cleavage to ketone 54 in order to construct the spirolactone with the required $R$ configuration through reaction with

\footnotetext{
54 Jones, S. B.; Simmons, B.; Mastracchio, A.; MacMillan, D. W. Nature 2011, 475, 183-188.
} 
ethyl bromomethylacrylate, $\mathbf{6 1}$, and $\mathrm{Zn},{ }^{55}$ that takes place on the most accessible convex face of ketone 54. However, for the synthesis of (-)-stemospironine, we planned oxidizing the primary alcohol to aldehyde $\mathbf{6 2}$ and then assaying a Wittig type cyclization that should deliver the lactone with the required $S$ configuration.

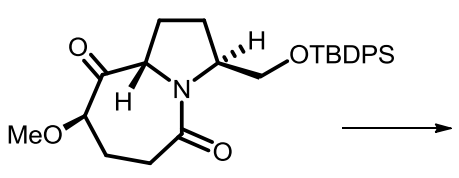

54

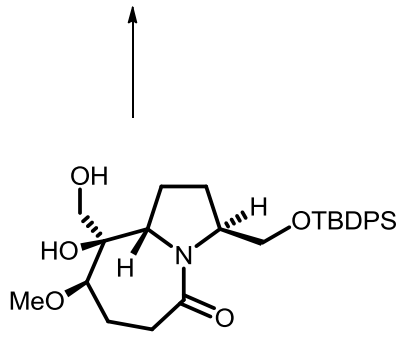

53

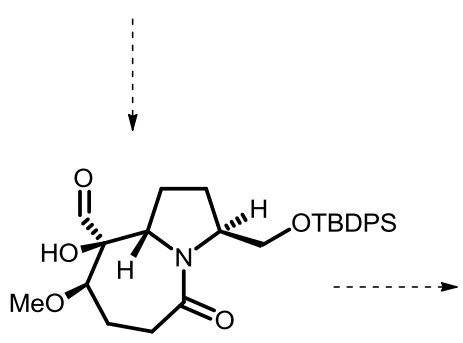

62

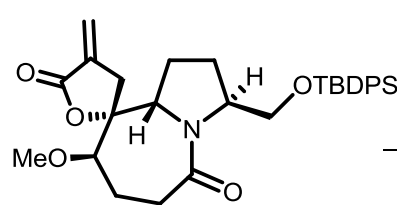

55

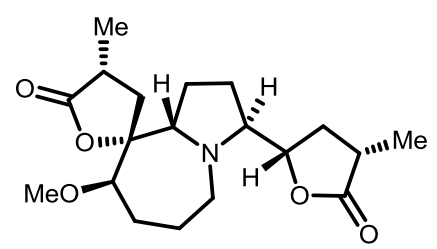

stemonidine

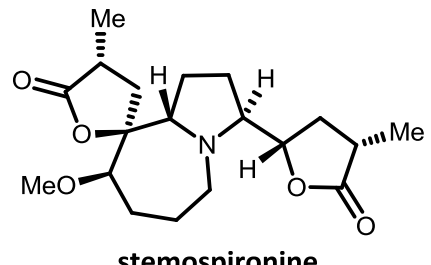

stemospironine

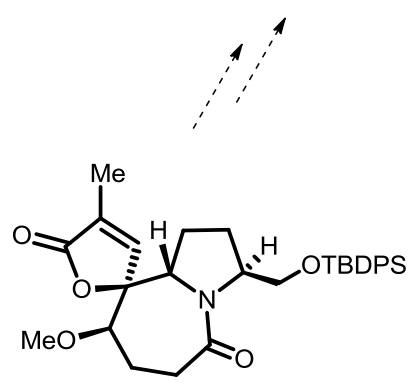

63

Scheme 23. Synthetic plan for stemonidine and stemospironine.

The oxidation of the primary alcohol in $\mathbf{5 3}$ was first attempted by treatment with DessMartin periodinane. In the event, the hydroxyaldehyde $\mathbf{6 2}$ was obtained in very low yields, along with some starting material and also ketone $\mathbf{5 4}$ (Scheme 24). Then, we explored the possibility of forming aldehyde 62 under Swern oxidation conditions, at both $-60{ }^{\circ} \mathrm{C}$ and $-78{ }^{\circ} \mathrm{C} ;{ }^{56}$ however, in both cases ketone 54 was the only identified product and ${ }^{1} \mathrm{H}-\mathrm{NMR}$ of the crude material showed no signals of the expected aldehyde. Parikh-Doering oxidation was also assayed, which consists on employing a sulfur-trioxide-pyridine complex instead of oxalyl chloride used in the standard

\footnotetext{
${ }^{55}$ Rauter, A. P.; Figueiredo, J.; Ismael, M.; Canda, T.; Font, J.; Figueredo, M. Tetrahedron: Asymmetry 2001, 12, 11311146.

${ }^{56}$ Corey, E. J.; Li, W.; Reichard, G. A. J. Am. Chem. Soc. 1998, 120, 2330-2336.
} 
Swern oxidation. We tried two different bases when performing this variation of the Swern oxidation, namely $\mathrm{Et}_{3} \mathrm{~N}^{57}$ and ${ }^{i} \mathrm{Pr}_{2} \mathrm{NEt}^{58}{ }^{58}$ but in both cases we only isolated ketone 54, along with decomposition products.

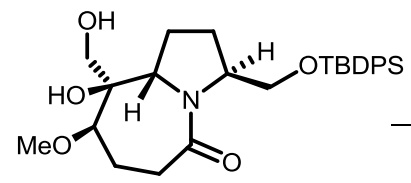

53
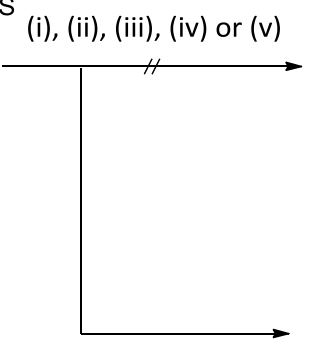

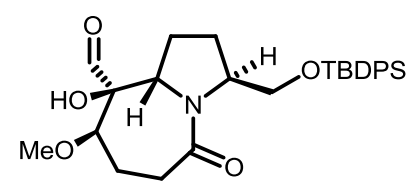

62

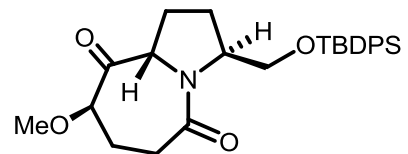

54

Reagents and conditions: (i) Dess-Martin periodinane, $\mathrm{CH}_{2} \mathrm{Cl}_{2}$, r.t., $1.5 \mathrm{~h}$; (ii) DMSO, $\mathrm{Et}_{3} \mathrm{~N},\left(\mathrm{COCl}_{2}, \mathrm{CH}_{2} \mathrm{Cl}_{2},-60{ }^{\circ} \mathrm{C}, 2\right.$ h; (iii) DMSO, $\mathrm{Et}_{3} \mathrm{~N},(\mathrm{COCl})_{2}, \mathrm{CH}_{2} \mathrm{Cl}_{2},-78{ }^{\circ} \mathrm{C}, 2 \mathrm{~h}$; (iv) DMSO, $\mathrm{Et}_{3} \mathrm{~N}, \mathrm{SO}_{3} \cdot$ pyridine, $\mathrm{CH}_{2} \mathrm{Cl}_{2}, 0{ }^{\circ} \mathrm{C}, 2 \mathrm{~h}$; (v) DMSO, ${ }^{i} \mathrm{Pr}_{2} \mathrm{NEt}$, $\mathrm{SO}_{3} \cdot$ pyridine, $\mathrm{CH}_{2} \mathrm{Cl}_{2}, 0^{\circ} \mathrm{C}, 2 \mathrm{~h}$.

Scheme 24. Attempted formation of hydroxyaldehyde 62.

We also explored the possibility of preparing aldehyde $\mathbf{6 2}$ directly from hydroxyester $\mathbf{7 8}$ by reduction with DIBAL-H at $-78^{\circ} \mathrm{C}$ in dichloromethane (Scheme 25$)$. Unfortunately, this reaction was not reproducible, affording most of the times the over-reduced diol $\mathbf{5 3}$ as the major product.

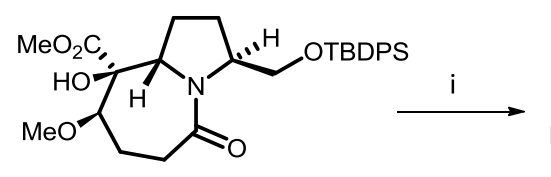

78

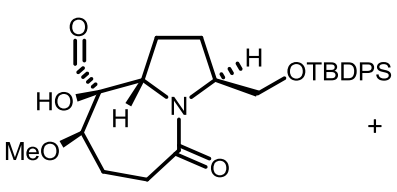

62

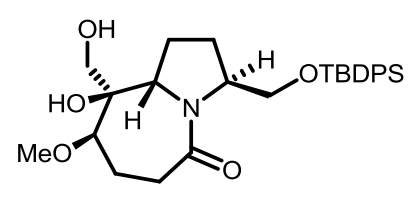

53

Reagents and conditions: (i) DIBAL- $\mathrm{H}, \mathrm{CH}_{2} \mathrm{Cl}_{2},-78^{\circ} \mathrm{C}$.

Scheme 25. Attempted reduction of ester $\mathbf{7 8}$ to hydroxyaldehyde $\mathbf{6 2 .}$

After these failed trials, we succeeded in preparing aldehyde 62 through a mild methodology of oxidation based on the use of TEMPO..$^{59}$ Thus, the oxidation of alcohol $\mathbf{5 3}$ was

\footnotetext{
${ }^{57}$ Patel, P.; Lee, G.-J.; Kim, S.; Grant, G. E.; Powell, W. S.; Rokach, J. J. Org. Chem. 2008, 73, 7213-7218.

${ }^{58}$ Veitch, G. E.; Beckmann, E.; Burke, B. J.; Boyer, A.; Maslen, S. L.; Ley, S. V. Angew. Chem. Int. Ed. 2007, 46, 7629-2632.

${ }^{59}$ Einhorn, J.; Einhorn, C.; Ratajczak, F.; Pierre, J.-L. J. Org. Chem. 1996, 61, 7452-7454.
} 
performed with $\mathrm{N}$-chlorosuccinimide (NCS) as stoichiometric oxidant, in the presence of TEMPO and tetrabutylammonium chloride in basic medium and a biphasic system $\left(\mathrm{CH}_{2} \mathrm{Cl}_{2}\right.$-water), yielding aldehyde 62 in $91 \%$ yield (Scheme 26). Under these conditions, primary alcohols are reported to be oxidized to aldehydes without any noticeable over-oxidation to carboxylic acids, even with an excess of NCS. Using this methodology, the formation of ketone $\mathbf{5 4}$ by oxidative cleavage was never observed.

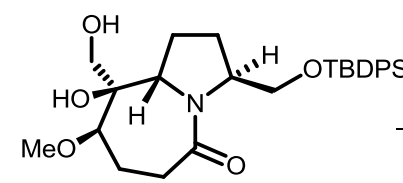

53

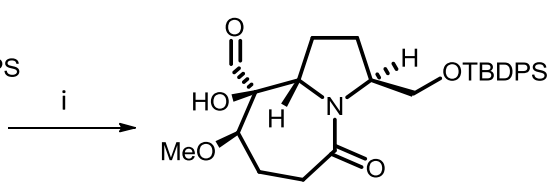

62

Reagents and conditions: (i) TEMPO, NCS, TBACl, $\mathrm{CH}_{2} \mathrm{Cl}_{2}: \mathrm{H}_{2} \mathrm{O}(1: 1), \mathrm{K}_{2} \mathrm{CO}_{3}, \mathrm{NaHCO}_{3}$, r.t., $2 \mathrm{~h}(91 \%)$.

Scheme 26. Synthesis of hydroxyaldehyde 62 .

The ${ }^{1} \mathrm{H}$-NMR spectrum of 62 shows a characteristic signal of aldehyde at $9.80 \mathrm{ppm}$. This signal is consistent with that observed in the ${ }^{13} \mathrm{C}-\mathrm{NMR}$ spectrum at $202.2 \mathrm{ppm}$.

The esterification reaction of $\mathbf{6 2}$ with 2-diethoxyphosphorylpropionic acid, 88, should afford aldehyde 86 presumably as a mixture of diastereoisomers, and basic treatment of the intermediate phosphonate should render lactone $\mathbf{6 3}$ (Scheme 23).

First of all, acid $\mathbf{8 8}$ was prepared by hydrolysis of the corresponding ethyl ester $\mathbf{8 7},{ }^{60}$ commercially available from Aldrich (Scheme 27). Thus, ester 87 was dissolved in $10 \mathrm{M}$ aqueous $\mathrm{NaOH}$ and it was stirred for one hour. Then, the corresponding carboxylate anion was protonated with concentrated $\mathrm{HCl}$, rendering acid $\mathbf{8 8}$ in quantitative yield.

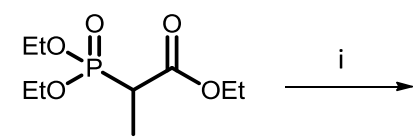

87

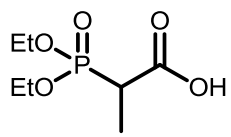

88

Reagents and conditions: (i) $\mathrm{NaOH} 10 \mathrm{M}, 0{ }^{\circ} \mathrm{C}, 1 \mathrm{~h}$; then, r.t., $2.5 \mathrm{~h}$; then, concd. $\mathrm{HCl}$ (until $\mathrm{pH}=1$ ), $0{ }^{\circ} \mathrm{C}$ (quant.).

Scheme 27. Hydrolysis of the ester $\mathbf{8 7} .^{60}$

\footnotetext{
${ }^{60}$ Luke, G. P.; Seekamp, C. K.; Wang, Z.-Q.; Chenard, B. L. J. Org. Chem. 2008, 73, 6397-6400.
} 
To carry out the esterification reaction of the tertiary alcohol (62 to 86), we decided to apply a methodology described by Melman and Nahmany for the acylation of sterically hindered alcohols (Scheme 28). ${ }^{61}$ According to the authors, this methodology, based on the use of DCC, is specific for carboxylic acids possessing strongly electron withdrawing groups such as $\mathrm{CN}, \mathrm{COOR}$ or $\mathrm{P}(\mathrm{O})(\mathrm{OEt})_{2}$ at the $\alpha$-position and occurs through the corresponding ketene intermediate 92 . Even highly hindered and chemically sensitive alcohols are acylated under these neutral conditions at room temperature.

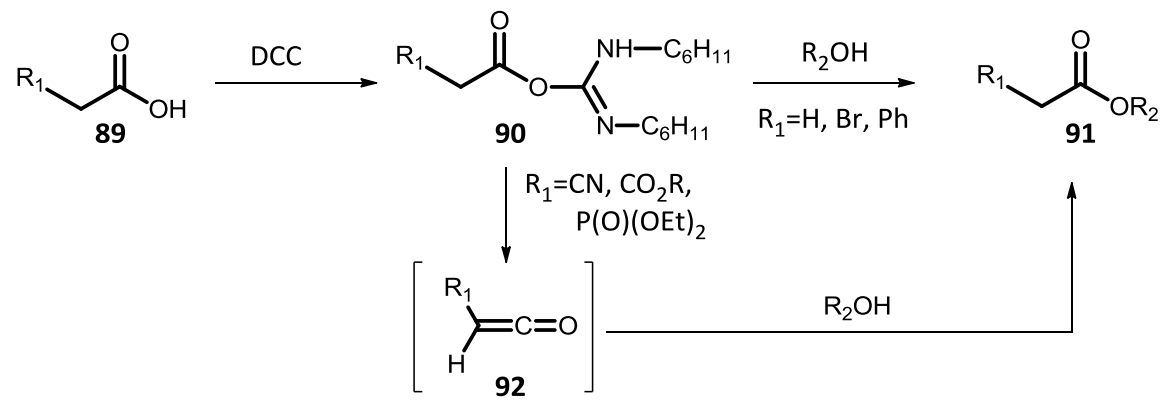

Scheme 28. Mechanistical proposal for the esterification of sterically hindered alcohols. ${ }^{61}$

Thus, freshly prepared acid $\mathbf{8 8}$ was added to a solution of aldehyde $\mathbf{6 2}$, and then DCC was slowly added (Scheme 29). After 4 hours, a mixture of diastereoisomeric aldehydes 86 was obtained. Although the presence of two diastereoisomers complicated the ${ }^{1} \mathrm{H}-\mathrm{NMR}$ spectrum of the crude reaction material, two aldehyde signals at $\delta 9.56$ and $9.54 \mathrm{ppm}$ could be clearly observed. This mixture was filtered through silica gel and then treated with ${ }^{t} \mathrm{BuOK}$ to promote the cyclization.

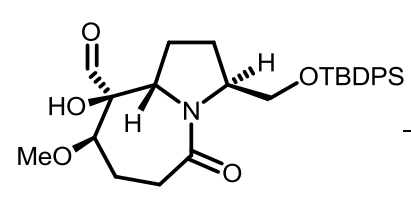

62

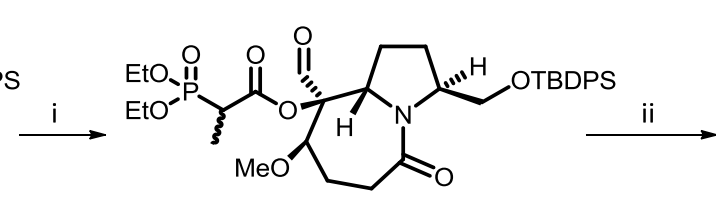

86

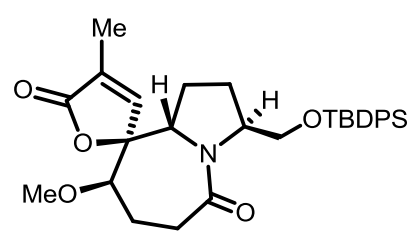

63

Reagents and conditions: (i) 88, $1 \mathrm{M}$ in $\mathrm{CH}_{2} \mathrm{Cl}_{2}, \mathrm{DCC} 1 \mathrm{M}, \mathrm{CH}_{2} \mathrm{Cl}_{2}, 4 \mathrm{~h}$; (ii) ${ }^{t} \mathrm{BuOK}, \mathrm{THF}$, reflux, $2.5 \mathrm{~h}$ (71\%, 2 steps).

Scheme 29. Construction of lactone 63.

\footnotetext{
${ }^{61}$ (a) Nahmany, M.; Melman, A. Org. Lett. 2001, 3, 3733-3735; (b) Shelkov, R.; Nahmany, M.; Melman, A. J. Org. Chem. 2002, 67, 8975-8982; (c) Shelkov, R.; Nahmany, M.; Melman, A. Org. Biomol. Chem. 2004, 2, 397-401.
} 
It was observed that when this Wittig-like reaction is performed at room temperature, after $2 \mathrm{~h}$, the aldehyde is totally consumed. However, the ${ }^{1} \mathrm{H}-\mathrm{NMR}$ spectrum of the crude material shows two compounds. The minor component is the expected lactone $\mathbf{6 3}$, identified by a characteristic signal of the conjugated double bond at $6.93 \mathrm{ppm}$, whereas the major component was identified as $\mathbf{9 3}$, an addition product of the ylide to the aldehyde that did not evolve to eliminate the phosphate (Scheme 30).

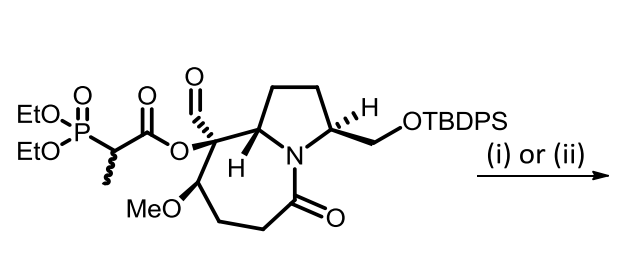

86

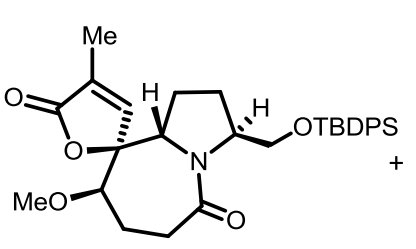

63

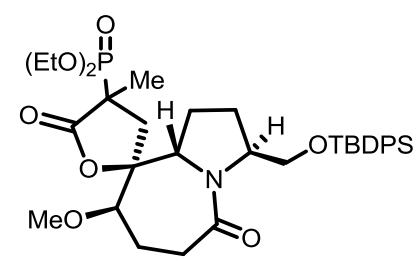

93

Reagents and conditions: (i) ${ }^{t} \mathrm{BuOK}, \mathrm{THF}$, r.t., 2 h; 63:93 1:6.4; (ii) ${ }^{t} \mathrm{BuOK}, \mathrm{THF}$, reflux, 16 h; only 63.

Scheme 30. Optimization of the preparation of olefin 63.

Fortunately, compound 93 could be transformed into lactone 63 by heating it in THF at the reflux temperature in the presence of ${ }^{t} \mathrm{BuOK}$. Thus, lactone 63 could be directly obtained from the mixture of aldehydes 86 by treatment with ${ }^{t} \mathrm{BuOK}$ in THF at the reflux temperature during $2.5 \mathrm{~h}$. This period of time was enough to render 63 as the sole product in $71 \%$ yield from aldehyde 62. In the ${ }^{1} \mathrm{H}-\mathrm{NMR}$ spectrum of $\mathbf{6 3}$, we could observe the characteristic signal of the olefinic proton at $6.93 \mathrm{ppm}$ as a quartet, and also the vinylic methyl group as a doublet at 1.97 ppm.

At this stage, we had already constructed three of the four rings present in the targeted alkaloid (-)-stemospironine. Now, our efforts were focused on the preparation of the east-side $\alpha$ methyl- - -butyrolactone.

\subsection{Construction of the "eastern" lactone. Synthesis of bislactone 106}

\subsubsection{Synthetic precedents}

In earlier investigations of our research group, ${ }^{62}$ the eastern lactone, which is a common structural feature of several Stemona alkaloids, was attempted to be installed through a

\footnotetext{
${ }^{62}$ Blanco Merinero, P. Ph.D. Thesis, Universitat Autònoma de Barcelona, 2004.
} 
methodology formerly developed in our laboratories and based on a condensation reaction between an epoxide and an $\alpha$-phenylselenoacetic acid (Scheme 31). ${ }^{63} \mathrm{~A}$ main advantage of this method is that the stereochemical information in the precursor epoxide is retained in the lactone product. For this reason our first generation approach to stemonidine started from nitrone 47, derived from D-glyceraldehyde, which contains an additional stereocenter in respect to nitrone 49. This additional stereocenter corresponds to $C_{14}$ in the targeted alkaloid.

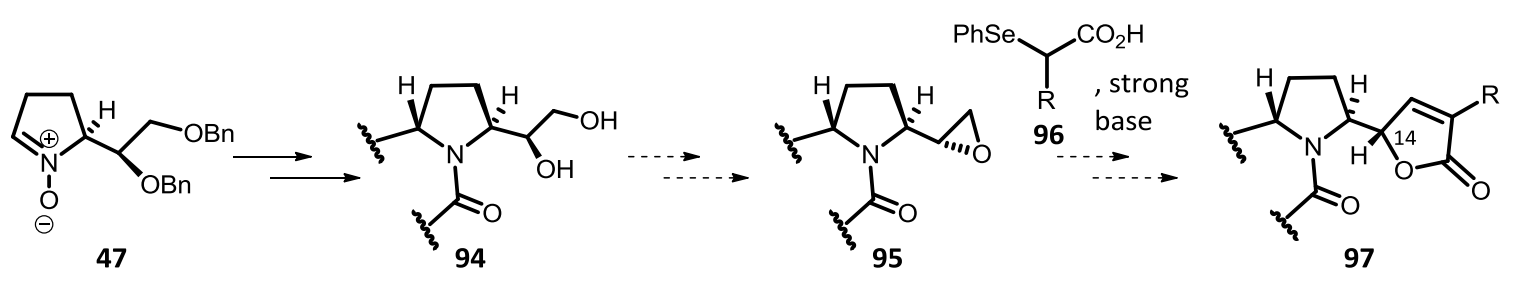

Scheme 31. Methodology assayed in a previous thesis to prepare $y$-lactones from epoxides. ${ }^{63}$

Hence, en route to stemonidine, the conversion of diol 98 into epoxide 103 was necessary (Scheme 32). A priori, the dehydration of similar glycols with inversion of configuration is an ordinary transformation requiring only the temporary protection of the primary alcohol before the activation of the secondary one. However, although many efforts were devoted to this endeavour, the transformation of diol $\mathbf{9 8}$ into the desired epoxide 103 proved fruitless. The attempted regioselective silylation of the primary alcohol was not achieved and the disilyl derivative 100 was obtained instead, along with unreacted starting material. This fact was attributed to the existence of an arrangement of intramolecular hydrogen bonding that made the secondary alcohol more reactive than the primary one. After extensive experimentation, the monoprotected alcohol $\mathbf{9 9}$ could finally be obtained through formation of an intermediate tin acetal, followed by regioselective opening and then silylation, although the overall yield was quite low (42\%). In any case, the mesylation of the secondary alcohol in $\mathbf{9 9}$, subsequent deprotection of the silyl protected hydroxyl group, and basic treatment, instead of the expected epoxide $\mathbf{1 0 3}$, furnished diol $\mathbf{1 0 2}$, epimer of $\mathbf{9 8}$, presumably formed by rapid hydrolysis of the epoxide.

\footnotetext{
63 (a) Figueredo, M.; Font, J.; Virgili, A. Tetrahedron 1987, 43, 1881-1886; (b) Busqué, F.; de March, P.; Figueredo, M.; Font, J.; Sanfeliu, E. Tetrahedron Lett. 2002, 43, 5583-5585; (c) Blanco, P.; Busqué, F.; de March, P.; Figueredo, M.; Font, L.; Sanfeliu, E. Eur. J. Org. Chem. 2004, 48-53.
} 
<smiles>COC1CCC(=O)N2C(C(O)CO)CCC12C=C(C)C(=O)O</smiles>

98
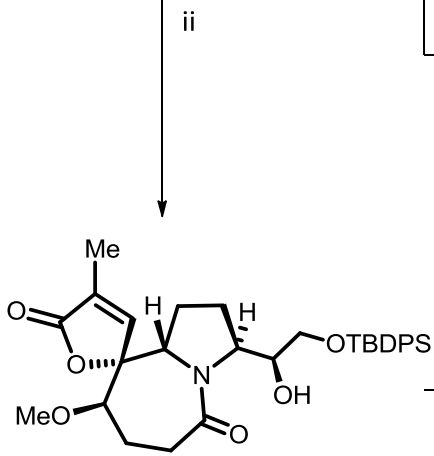

99

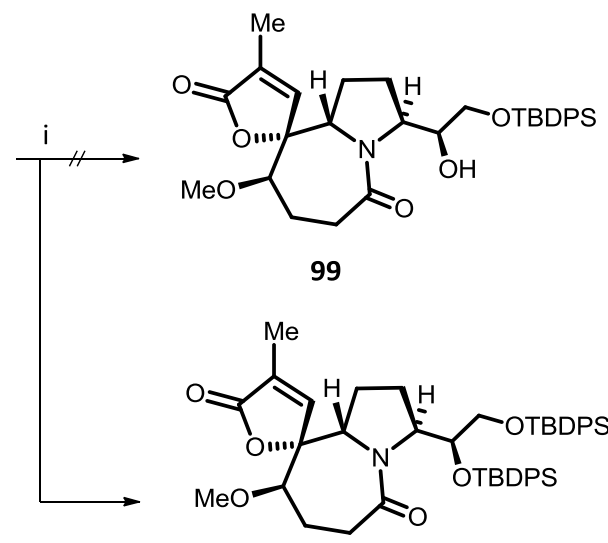

100

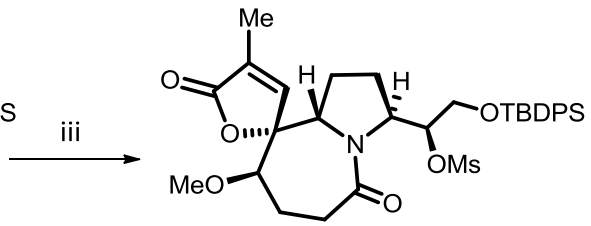

101

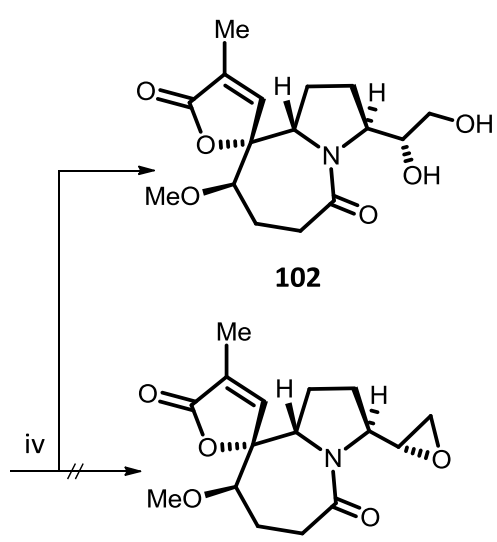

103

Reagents and conditions: (i) TBDPSOTf, $\mathrm{Et}_{3} \mathrm{~N}, \mathrm{CH}_{2} \mathrm{Cl}_{2}$, r.t.; (ii) $\mathrm{Bu}_{2} \mathrm{SnO}, \mathrm{MeOH}$, reflux, $2 \mathrm{~h}$; then, TBABr, TBDPSIm, toluene, reflux, 16 h (42\%); (iii) $\mathrm{MsCl}$, pyr, $\mathrm{CH}_{2} \mathrm{Cl}_{2}$, r.t. (71\%); (iv) TBAF, THF, r.t., 1 h; then, $\mathrm{NaOH}, \mathrm{MeOH} / \mathrm{THF}$ (88\%).

Scheme 32. Attempted formation of epoxide 103.

Other alternatives for the formation of the epoxide were also investigated, such as transforming the lactam to thiolactam, with the aim of affecting the hydrogen bonding array, and then applying the same previous set of reactions, or performing a Mitsunobu inversion of configuration of the secondary alcohol in 98, taking advantage of its higher reactivity. Unfortunately, none of these tactical modifications ended up with the expected epoxide 103.

Once all the possibilities related to the epoxide formation were excluded, the oxidative cleavage of the glycol in $\mathbf{9 8}$ and then a Reformatsky-type reaction over the corresponding aldehyde $\mathbf{5 6}$ was considered the best option to construct the eastern lactone (Scheme 33). Obviously, the stereochemical information provided by the starting nitrone $\mathbf{4 7}$ that was initially expected to be transferred into the east-side lactone through the corresponding epoxide is lost in that cleavage, but the preparation of diastereoisomers of the naturally occurring alkaloids is also interesting, both in terms of bioactivity tests and structural elucidation. Considering that the preparation of aldehyde 56, or an analog of it, could be achieved starting from the simpler nitrone 49, and that the preparation of this nitrone from L-proline is more straightforward than that of nitrone $\mathbf{4 7}$ from D-glyceraldehyde, it was decided to continue the synthetic studies towards stemonidine and stemospironine from the former. 


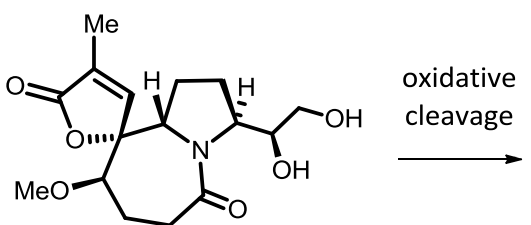

98

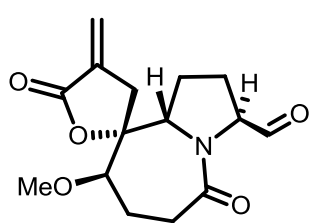

56<smiles>[Te][I+]I</smiles>

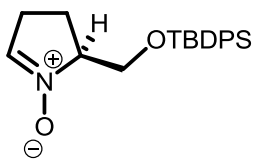

49

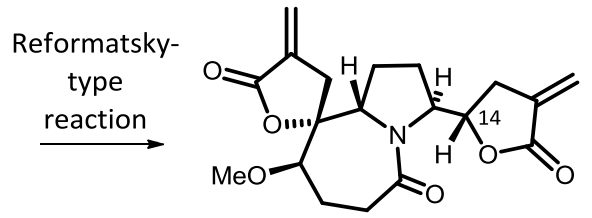

57

$+\mathrm{C}_{14}$ epimer

Scheme 33. Synthetic alternative for the construction of the east-side lactone $\mathbf{5 7}$ followed in the synthesis of the putative structure of stemonidine ${ }^{38}$ and in the present thesis.

\subsubsection{New strategy for the construction of the eastern lactone}

The remaining transformations to conclude the synthesis of (-)-stemospironine from lactone 63 are shown in Scheme 34. After removal of the silyl group, primary alcohol 104 would be oxidized to aldehyde 105. Further treatment of 105 with $\mathrm{Zn}$ and ethyl bromomethylacrylate, ${ }^{55}$ 61, should provide bislactone 106 which, theoretically, after double bond and lactam reduction would render the targeted alkaloid.

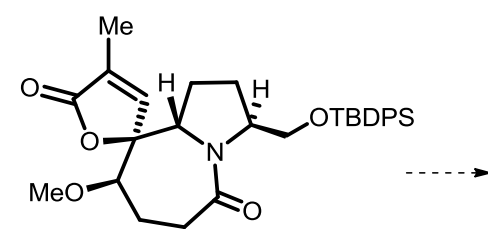

63<smiles>COC1CCC(=O)N2C(CO)CC[C@@]12C=C(C)C(=O)O</smiles>

104<smiles>COC1CCC(=O)N2C(C=O)CC[C@@]12C=C(C)C(=O)O</smiles>

105

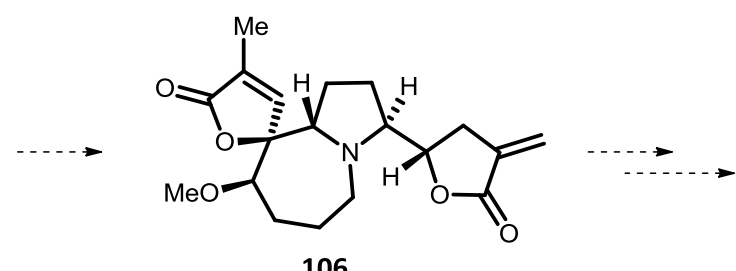

106

stemospironine

Scheme 34. Planned synthesis of (-)-stemospironine.

The removal of the silyl group was accomplished by treatment of the intermediate $\mathbf{6 3}$ with $\mathrm{Et}_{3} \mathrm{~N} \cdot 3 \mathrm{HF}$ in THF at the reflux temperature, affording alcohol 104 in 92\% yield (Scheme 35). 
The deprotection of the primary alcohol was clearly evidenced in the ${ }^{1} \mathrm{H}-\mathrm{NMR}$ spectrum of 104 by the absence of the TBDPS typical signals at the aromatic region and the singlet at around $1 \mathrm{ppm}$ of the tert-butil group.

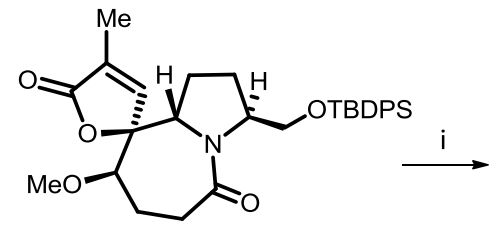

63

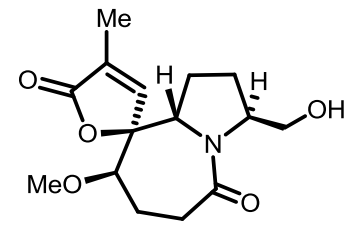

104

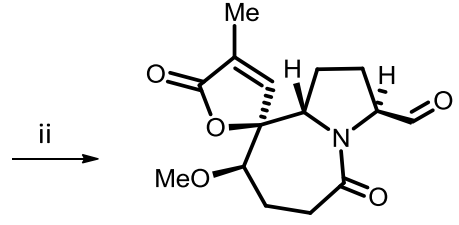

105

Reagents and conditions: (i) $\mathrm{Et}_{3} \mathrm{~N} \cdot 3 \mathrm{HF}$, THF, reflux, $4 \mathrm{~h}$ (92\%); (ii) Dess-Martin periodinane, $\mathrm{CH}_{2} \mathrm{Cl}_{2}$, r.t., $2.3 \mathrm{~h}$ (82\%).

Scheme 35. Syntheses of alcohol 104 and aldehyde 105.

Further oxidation of alcohol 104 with Dess-Martin periodinane in $\mathrm{CH}_{2} \mathrm{Cl}_{2}$ furnished aldehyde 105 as a white solid in $82 \%$ yield, which should be the precursor of bislactone 106 . Its ${ }^{1} \mathrm{H}-\mathrm{NMR}$ spectrum presented a doublet at $9.45 \mathrm{ppm}$, characteristic of the aldehyde functionality. This signal was consistent with that observed in the ${ }^{13} \mathrm{C}-\mathrm{NMR}$ spectrum, where a signal corresponding to the new carbonyl group could be observed at $197.3 \mathrm{ppm}$.

Next, the aldehyde 105 was treated with ethyl bromomethylacrylate, 61, and freshly activated $\mathrm{Zn}^{51}$ under Reformatsky conditions (Scheme 36$) .{ }^{55}$ After $1 \mathrm{~h}$ in THF at the reflux temperature, a roughly 1:1 mixture of bislactones 106 and 107 was obtained, which were separated by flash column chromatography.

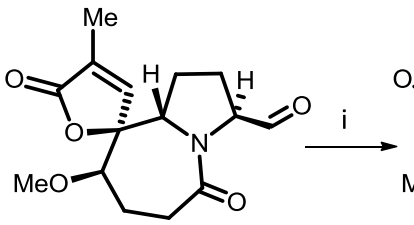

105

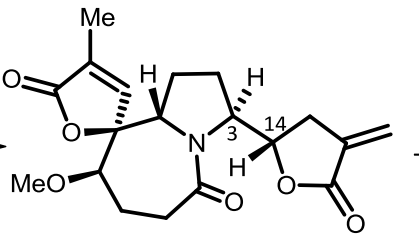

106

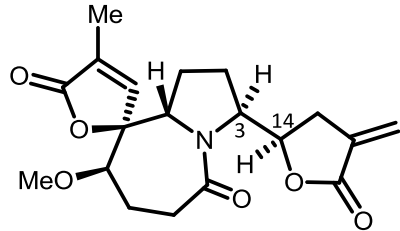

107

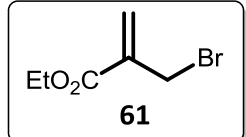

61

Reagents and conditions: (i) 61, Zn, THF, reflux, 1 h (74\%) 106:107 1:1.

Scheme 36. Reformatsky-type reaction for the preparation of bislactones 106 and 107.

The relative erythro/threo configuration of 106 and 107 was tentatively assigned by NMR in comparison with related compounds in the literature ${ }^{17 b, c, 38,63 b, c}$ and unambiguously established in a more advanced intermediate by means of an X-ray diffraction analysis and by chemical 
correlation with the natural product stemospironine, as will be explained later on. The most significant NMR data of the couple of epimers 106 and 107 are summarized in Table 1.

Table 1. Some significant NMR chemical shift of bislactones 106 and 107.

\begin{tabular}{ccccc} 
& $\delta \mathrm{H}_{\mathbf{3}}{ }^{\mathrm{a}}$ & $\boldsymbol{\delta} \mathrm{C}_{\mathbf{3}}{ }^{\mathrm{b}}$ & $\boldsymbol{\delta \mathrm { H } _ { \mathbf { 1 4 } } { } ^ { \mathrm { a } }}$ & $\delta \mathrm{C}_{\mathbf{1 4}}{ }^{\mathrm{b}}$ \\
\hline 106, threo & 4.37 & 60.3 & 5.06 & 77.2 \\
107, erythro & 4.16 & 62.2 & 5.21 & 75.7 \\
\hline
\end{tabular}

NMR experiments performed in $\mathrm{CDCl}_{3} . \delta$ values in ppm. a) $400 \mathrm{MHz}$. b) $100 \mathrm{MHz}$.

It can be observed that proton $\mathrm{H}_{3}$ in the erythro isomer $107(4.16 \mathrm{ppm})$ is upfield shifted in relation to the threo isomer $106(4.37 \mathrm{ppm})$ and the same trend is observed for carbon $\mathrm{C}_{14}$ (75.7 and 77.2 ppm, respectively), while the opposite occurs for $H_{14}$ (5.21 and 5.06 ppm, respectively) and $C_{3}$ (62.2 and $60.3 \mathrm{ppm}$, respectively). Moreover, two new olefinic signals appeared in the ${ }^{1} \mathrm{H}-\mathrm{NMR}$ spectrum of each compound between 5.4 and $6.5 \mathrm{ppm}$, characteristic of the exocyclic double bond.

\subsection{Syntheses of two new diastereoisomeric analogs of stemospironine}

To complete the synthesis of (-)-stemospironine from the threo bislactone 106, the reduction of the carbon-carbon double bond and lactam functionalities had to be accomplished.

In related compounds containing both a thiolactam and an $\alpha, \beta$-unsaturated lactone, it was observed that overexposure to Raney-Ni resulted in desulfuration of the thiolactam and concomitant olefin reduction in one single step. ${ }^{38,64}$ In previous studies of our group towards the synthesis of stemonidine, this methodology was tested starting from the analogous erythro isomer 108 (Scheme 37). Thus, treatment of 108 with Lawesson's reagent furnished the expected unsaturated thiolactam 109, which by reaction with Raney-Ni in EtOH delivered a mixture of amines 110 and 111. Conversely, when the same procedure was applied to the threo bislactone 57, the corresponding thiolactam underwent rapid decomposition. Accordingly, to complete the syntheses of stemonidine and its epimer at $C_{11}, 60$, it became necessary to firstly hydrogenate the carbon-carbon double bonds in $\mathbf{5 7}$, and then proceed to the formation of the derived thiolactams and their subsequent reduction by treatment with Raney-Ni.

\footnotetext{
${ }^{64}$ González, D. Ph.D. Thesis, Universitat Autònoma de Barcelona, 2009.
} 
<smiles>C=C1C[C@@]2(OC1=O)C(OC)CCC(=O)N1CCC[C@]13CC(=C)C2C(=O)O3</smiles>

108

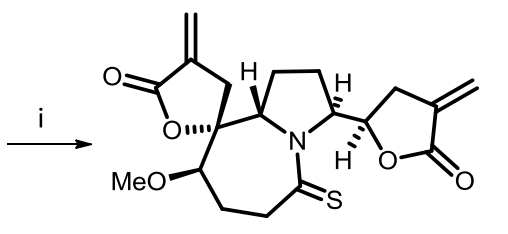

109

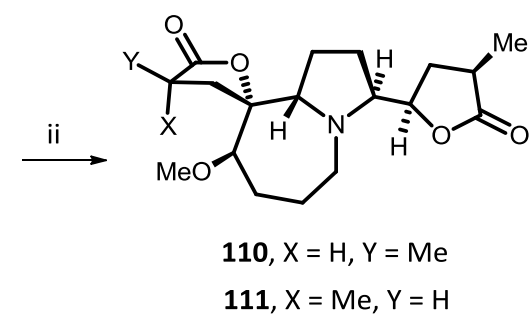

111, $X=M e, Y=H$<smiles>C=C1C[C@@]2(CCC3N(C[C@]34CC(=C)C(=O)O4)C(=O)CCC2OC)OC1=O</smiles>

57

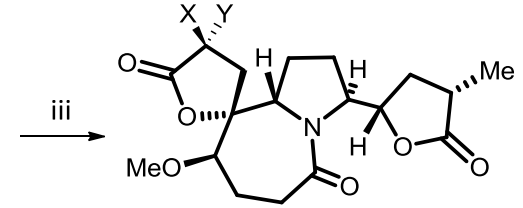

58, $X=M e, Y=H$

59, $X=H, Y=M e$

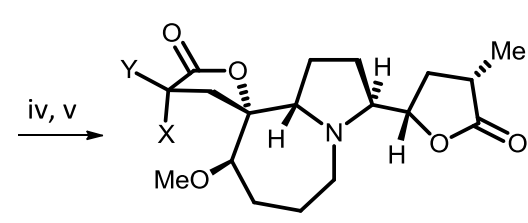

(-)-stemonidine, $X=H, Y=M e$

60, (-)-11-epistemonidine, $X=M e, Y=H$

Reagents and conditions: (i) Lawesson's reagent, THF, reflux, 4.5 h; (ii) Raney-Ni, EtOH, reflux, 2 h (54\%, 2 steps); (iii) $\mathrm{H}_{2}$ (6 bar), Pd/C, EtOH:HCl (9:1), 23 h (68\%); (iv) Lawesson's reagent, THF, reflux, 4h; (v) Raney-Ni, EtOH, reflux, 2 h (45\%, 2 steps).

Scheme 37. Last steps in the syntheses of stemonidine and its analogs. ${ }^{38}$

In the present work we decided also to explore the possibility of reducing the carboncarbon double bonds and the thiolactam functionality in one single step (Scheme 38). Hence, lactams 106 and 107 were treated, separately, with Lawesson's reagent. In this case, in contrast to the behaviour of 108 and $\mathbf{5 7}$, the threo thiolactam 112 was isolated, although in moderate yield (52\%), whereas its erythro isomer 113 could not be obtained, rendering only decomposition products.

On the ${ }^{1} \mathrm{H}-\mathrm{NMR}$ spectrum of $\mathbf{1 1 2}$, the most significant change with respect to that of its precursor lactam was the downfield shifting experienced by $H_{14}$ from 5.06 ppm in 106 to 5.46 ppm 112. The same happened with $\mathrm{H}_{9 a}$, that moved from 4.86 to $5.20 \mathrm{ppm}$, and with $\mathrm{H}_{3}$, which moved from 4.37 to $5.09 \mathrm{ppm}$.

The hydrogenation of thiolactam 112 was attempted by treatment with Raney-Ni, but unfortunately it ended up with decomposition products. 


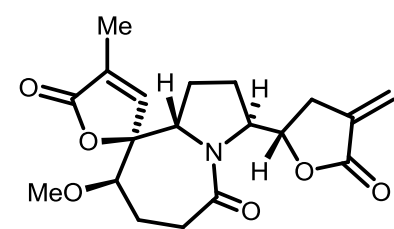

106

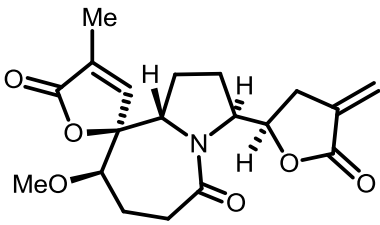

107

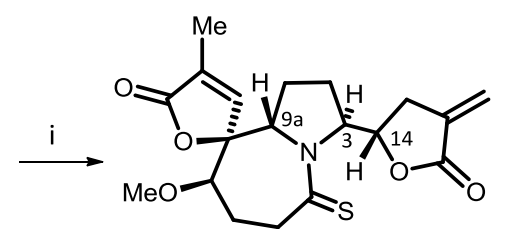

112

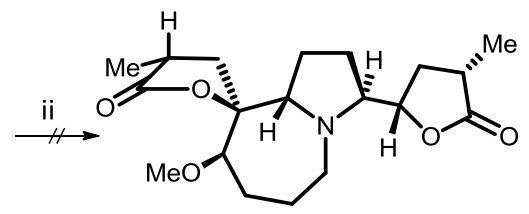

$(-)$-stemospironine

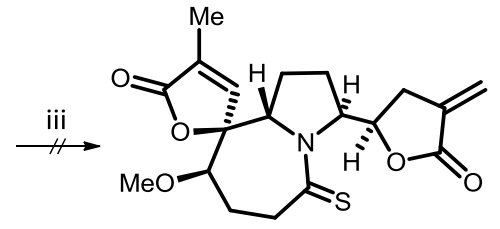

113

Reagents and conditions: (i) Lawesson's reagent, THF, reflux, 45 min (52\%); (ii) Raney-Ni, EtOH, reflux, (iii) Lawesson's reagent, THF, reflux.

Scheme 38. Attempts of reducing carbon-carbon double bonds and thiolactam functionality in one step.

Considering these results, we decided, for both isomers 106 and 107, to perform the hydrogenation of the endo- and exocyclic olefins in the first place and then carry out the deoxygenation of the lactam. The devised plan is shown in Scheme 39.

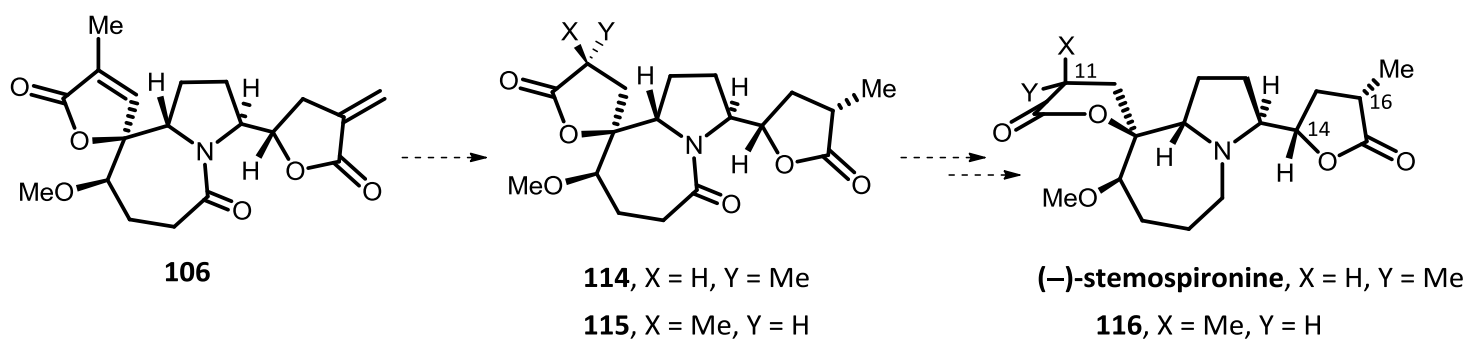<smiles>C=C1C[C@H](C2CC[C@@]3(C)C2C(=C)C(=O)O[C@@H]3C)OC1=O</smiles>

107

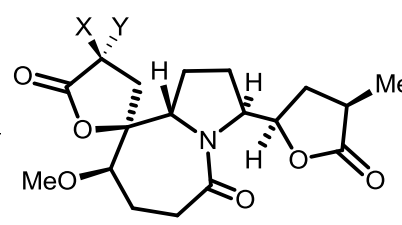

117, $X=H, Y=M e$

118, $X=M e, Y=H$

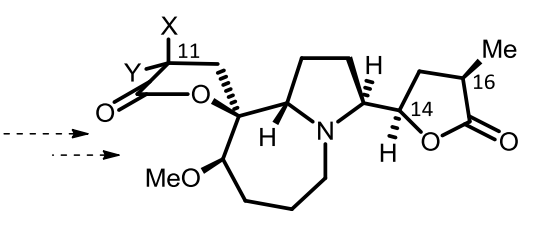

119, $X=H, Y=M e$

120, $X=M e, Y=H$

Scheme 39. Planned final steps for the syntheses of (-)-stemospironine and its analogs. 


\subsubsection{Hydrogenation of the carbon-carbon double bonds of bislactones 106 and 107}

Thus, we proceeded to assay the simultaneous hydrogenation of both the endo- and exocyclic olefins. In this reaction, two new stereogenic centers are created at the $\alpha$-carbonyl positions. The reduction was performed for both epimeric bislactones 106 and 107, separately. Hence, in each hydrogenation process up to four stereoisomers could be obtained.

However, on the basis of bibliographic precedents (Scheme 40), ${ }^{17 b, c, 38}$ we expected that the hydrogenation of the eastern lactone would occur in a stereoselective manner through the less hindered face, leading to a cis relationship of the substituents of the ring. This trend was observed in precedent examples, even for substrates where the conjugated double bond was exocyclic. We assumed that in the acidic media in which the hydrogenation was performed, the migration of the exocyclic double bond to the endocyclic position would be faster than the reduction. On the contrary, for the spiranic lactone we assumed that the reduction could be unselective, rendering both $\mathrm{C}_{11}$ epimers.

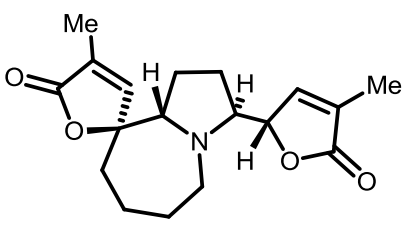

22

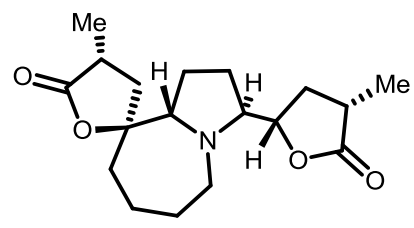

croomine

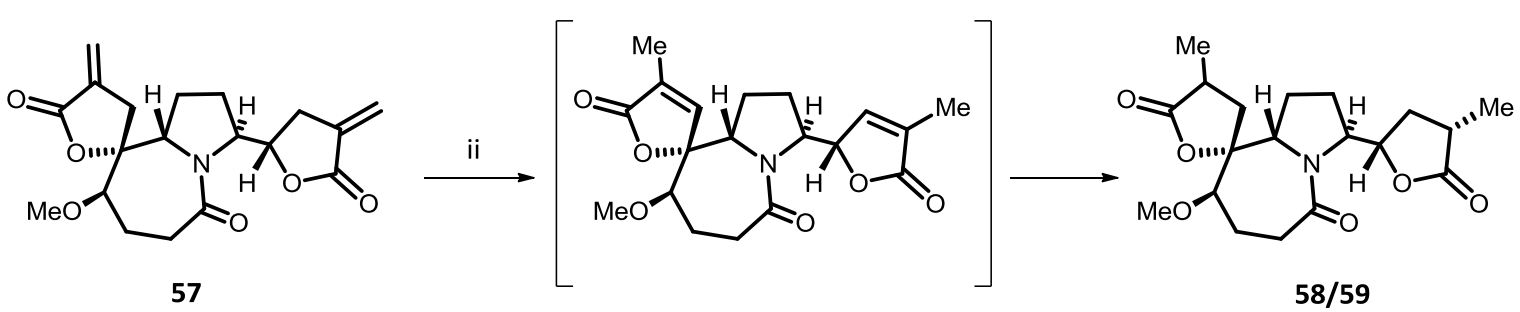

Reagents and conditions: (i) $\mathrm{H}_{2}, \mathrm{Pd} / \mathrm{C}, \mathrm{EtOH}, \mathrm{HCl}(81 \%)$; (ii) $\mathrm{H}_{2}, \mathrm{Pd} / \mathrm{C}, \mathrm{EtOH}, \mathrm{HCl}$ (68\%).

Scheme 40. Catalytic hydrogenation of $\alpha, \beta$-unsaturated furanones structurally related to our compounds. ${ }^{17 c, 38}$

With these predictions in mind, from the hydrogenation of each substrate 106 and 107, we were expecting the two isomers depicted on Scheme 39. Thus, 106 and 107 were submitted to hydrogenation at atmospheric pressure in the presence of $\mathrm{Pd} / \mathrm{C}$ under standard conditions 
(Scheme 41). ${ }^{17 b, c, 38}$ To our surprise, these reactions delivered only one product from each bislactone in good yields.<smiles>C=C1C[C@H](C2CC[C@@]3(C=C(C)C(=O)O3)[C@H]2C)OC(=O)CCC1=O</smiles>

106<smiles>C=C1C[C@]2(CCC[C@]23CCC(OC)[C@]2(C=C(C)C(=O)O2)OC3=O)OC1=O</smiles>

107

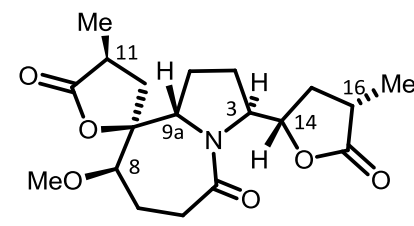

115

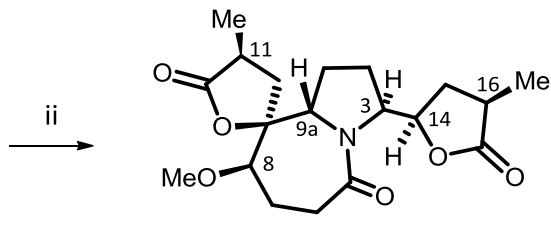

118

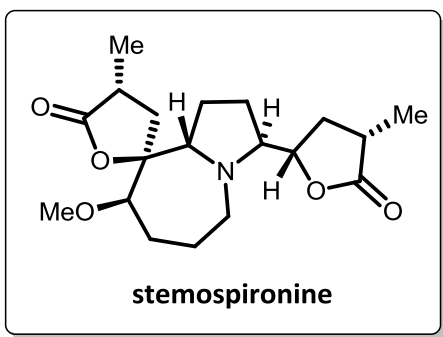

Reagents and conditions: (i) $\mathrm{H}_{2}(1 \mathrm{~atm}), \mathrm{Pd} / \mathrm{C}, \mathrm{EtOH}: \mathrm{HCl} 10 \%$ (1:1), $24 \mathrm{~h}$ (81\%); (ii) $\mathrm{H}_{2}(1 \mathrm{~atm}), \mathrm{Pd} / \mathrm{C}, \mathrm{EtOH}: \mathrm{HCl} 10 \%(1: 1)$, $24 \mathrm{~h}(84 \%)$.

Scheme 41. Catalytic hydrogenation of bislactones 106 and 107.

The hydrogenated threo derivative 115 presents on its ${ }^{1} \mathrm{H}-\mathrm{NMR}$ spectrum (Figure 11) a double triplet at $5.21 \mathrm{ppm}$, a doublet of doublets at $4.75 \mathrm{ppm}$ and a double triplet at 4.56 , corresponding to $\mathrm{H}_{14}, \mathrm{H}_{9 a}$ and $\mathrm{H}_{3}$, respectively. The most significant change with respect to the precursor 106 is the absence of the olefinic signals and the presence of two doublets at 1.29 and $1.25 \mathrm{ppm}$ of the methyl groups instead. The ${ }^{1} \mathrm{H}-\mathrm{NMR}$ spectrum of bislactone 118 (Figure 13) displays a doublet of doublets at $5.07 \mathrm{ppm}$, a doublet at $4.80 \mathrm{ppm}$ and a doublet at 4.29 , corresponding to $\mathrm{H}_{14}, \mathrm{H}_{9 a}$ and $\mathrm{H}_{3}$, respectively, and the characteristic doublets of the methyl groups at 1.29 and $1.25 \mathrm{ppm}$.

The cis relationship between proton $\mathrm{H}_{14}$ and $\mathrm{H}_{16}$ in $\mathbf{1 1 5}$ and $\mathbf{1 1 8}$ was determined by n.O.e. experiments. Figure 11 shows the n.O.e. experiment for $\mathbf{1 1 5}$ when proton $\mathrm{H}_{14}$ was irradiated, where we can see a remarkable effect at $\mathrm{H}_{16}$, proving that $\mathrm{H}_{14}$ and $\mathrm{H}_{16}$ are cis to each other. Moreover, Figure 12 shows that the irradiation of $\mathrm{H}_{8}$ in $\mathbf{1 1 5}$ resulted in a considerable n.O.e. on proton $H_{11}$. Hence, this experiment allowed to establish the proximity between $H_{8}$ and $H_{11}$, demonstrating that the configuration of the stereocenter at $C_{11}$ is the opposite for stemospironine, as depicted in Scheme 41 for 115. 

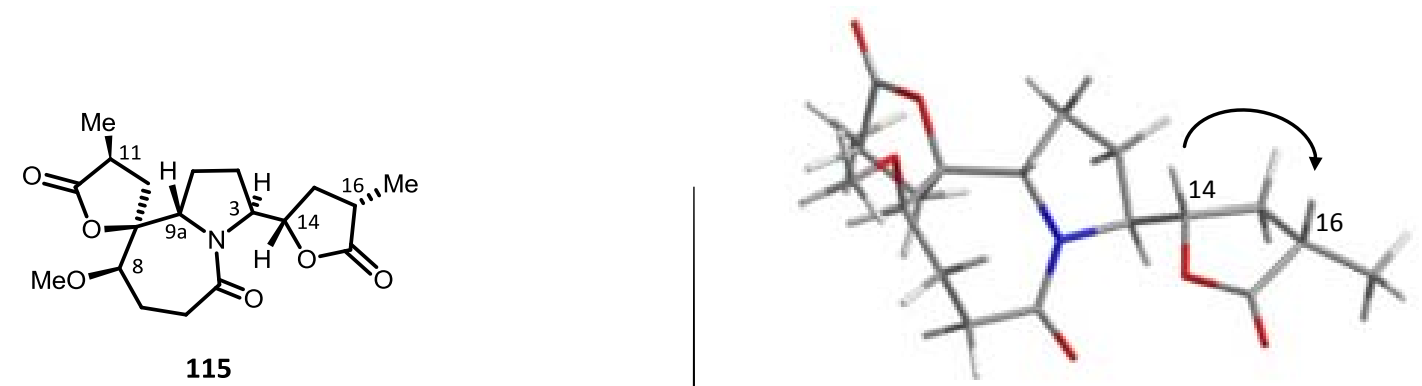

115

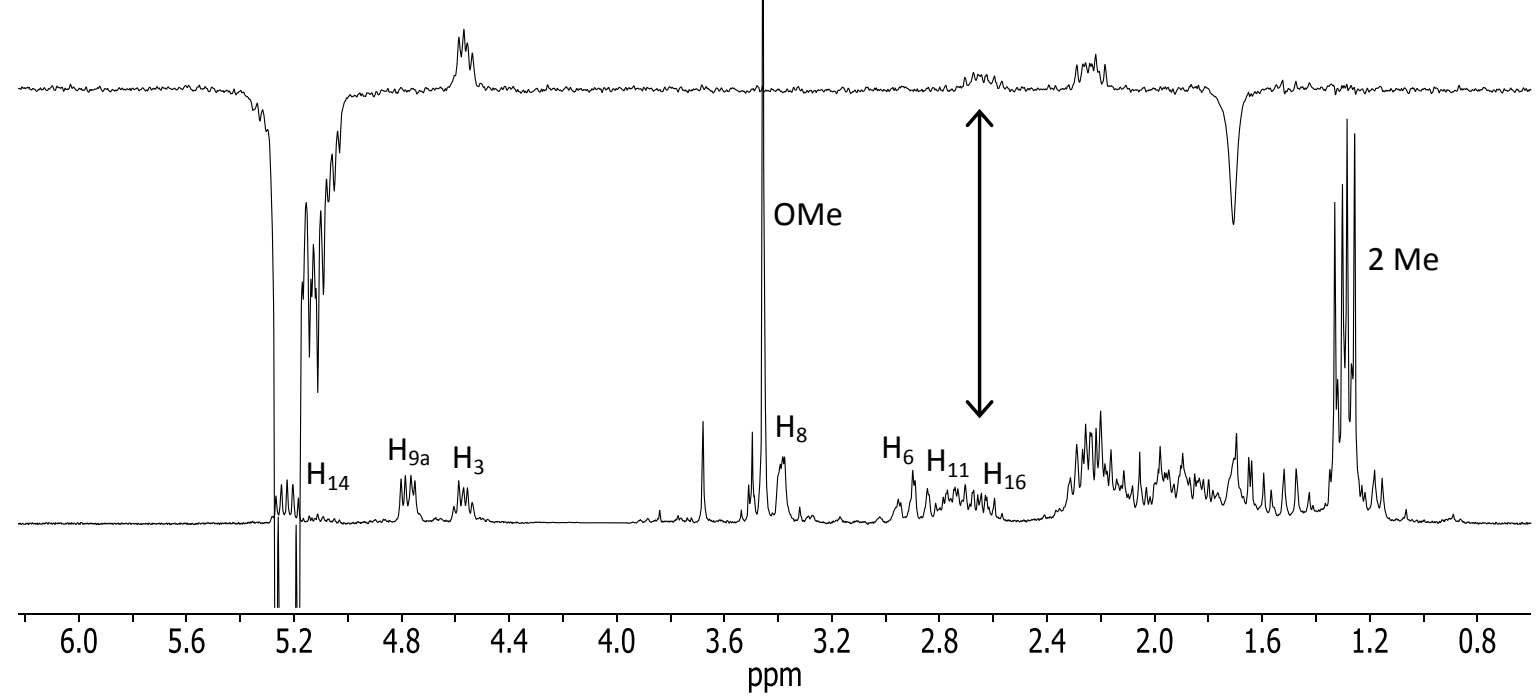

Figure 11. n.O.e. experiment ( $250 \mathrm{MHz}, \mathrm{CDCl}_{3}$ ) on irradiating $\mathrm{H}_{14}$ in 115.

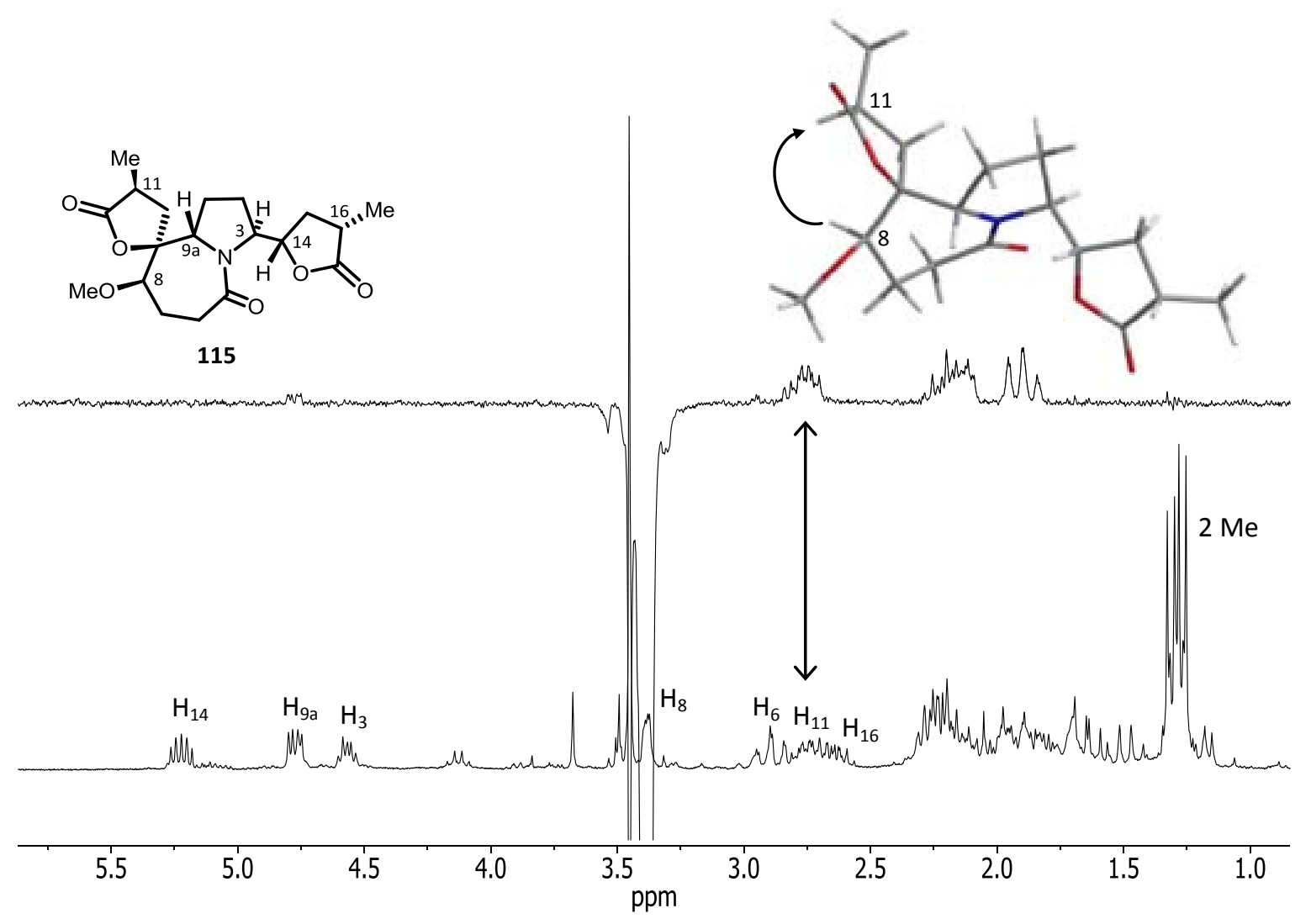

Figure 12. n.O.e. experiment ( $250 \mathrm{MHz}, \mathrm{CDCl}_{3}$ ) on irradiating $\mathrm{H}_{8}$ in 115. 


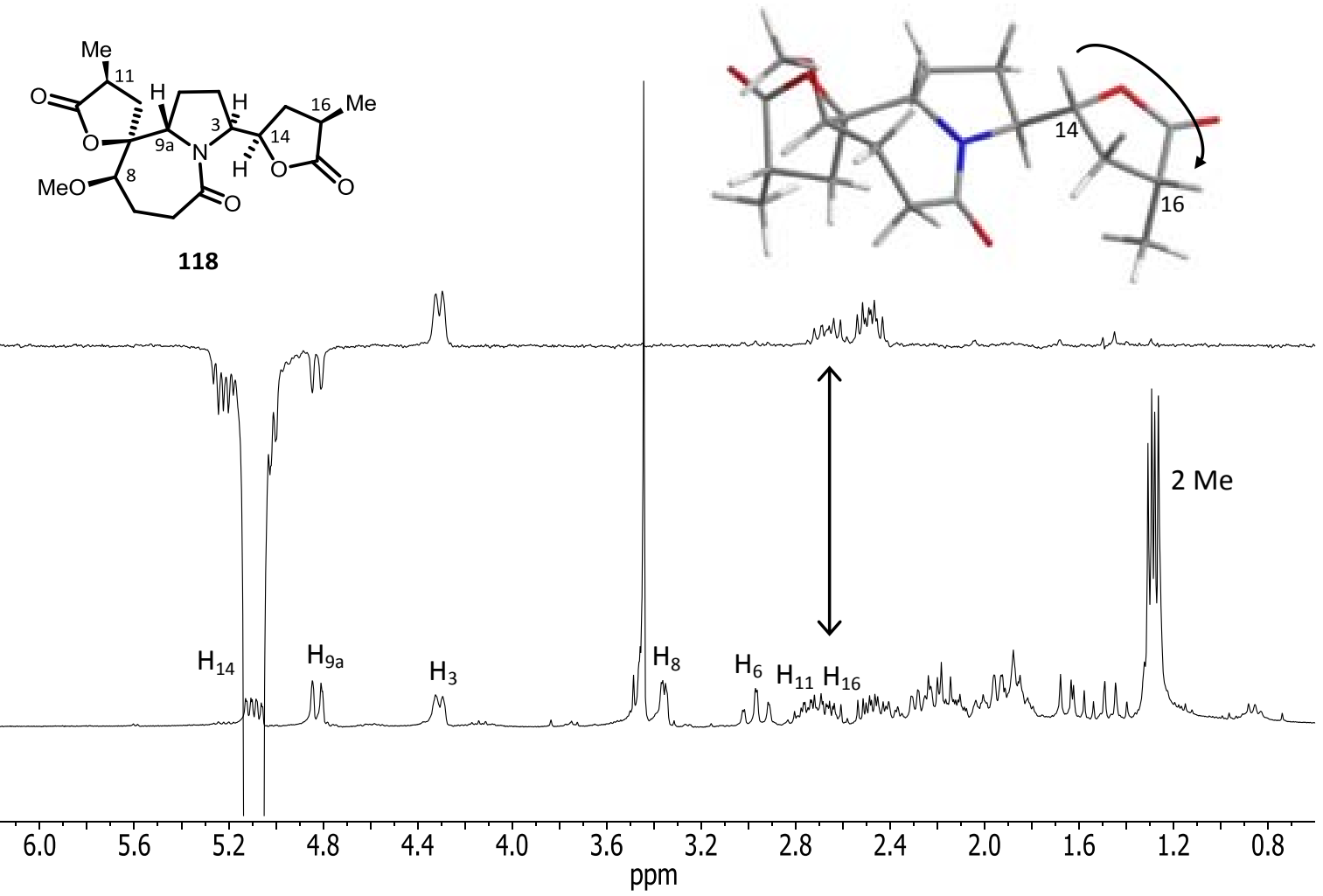

Figure 13. n.O.e. experiment $\left(250 \mathrm{MHz}, \mathrm{CDCl}_{3}\right)$ on irradiating $\mathrm{H}_{14}$ in 118 .
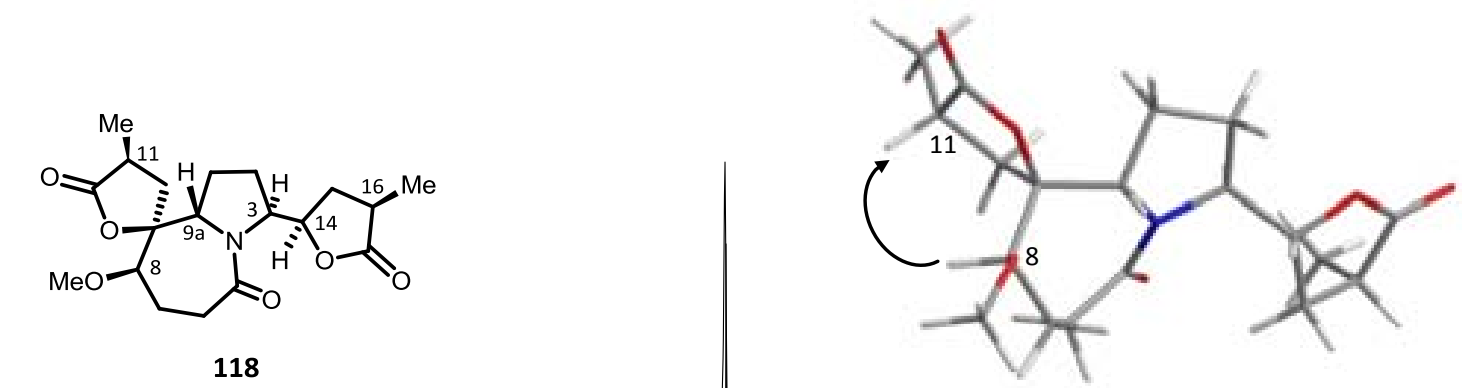

118

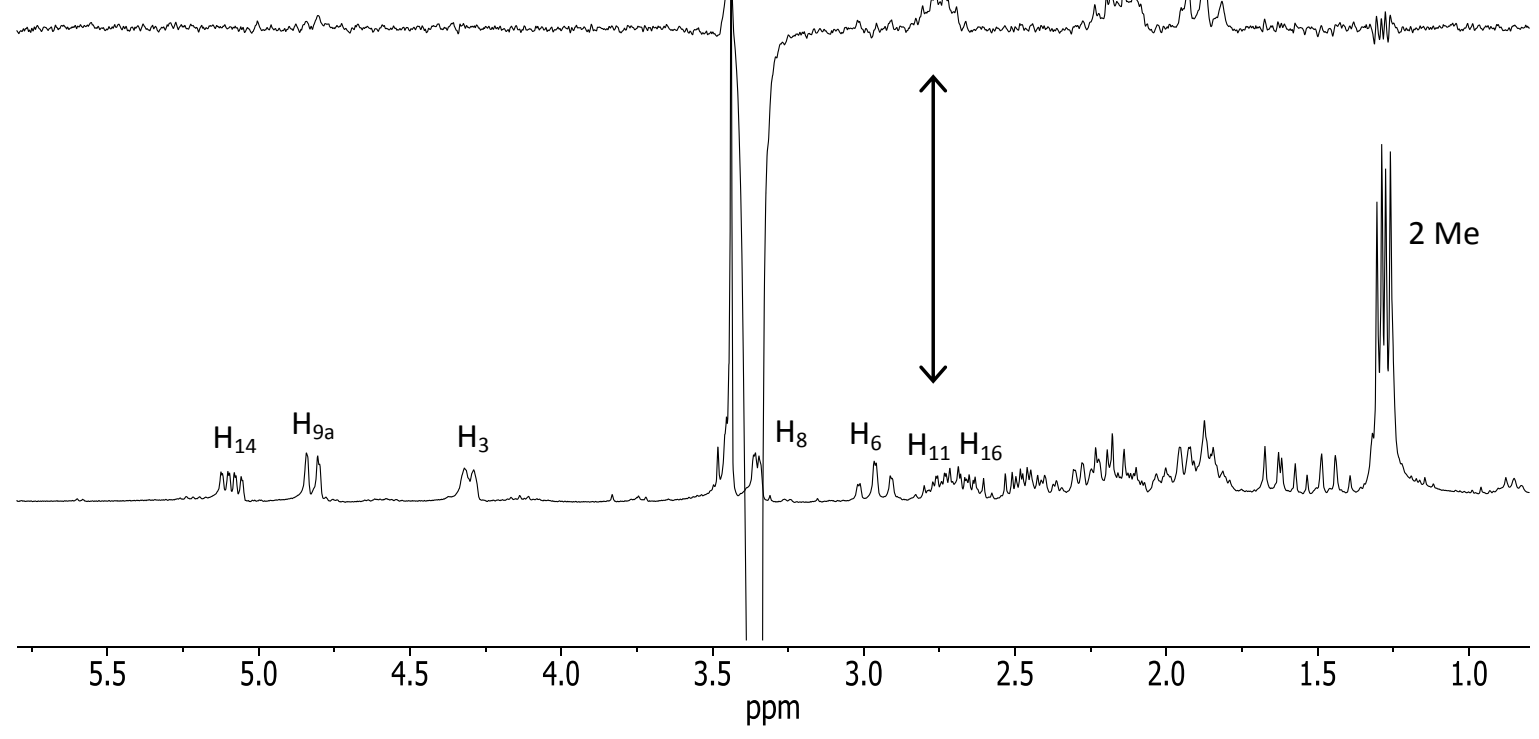

Figure 14. n.O.e. experiment ( $\left.250 \mathrm{MHz}, \mathrm{CDCl}_{3}\right)$ on irradiating $\mathrm{H}_{8}$ in 118. 
Parallel n.O.e. experiments were carried out for compound $\mathbf{1 1 8}$ too. When proton $\mathrm{H}_{14}$ was irradiated, a n.O.e. could be observed on proton $\mathrm{H}_{16}$ (Figure 13), proving again that $\mathrm{H}_{14}$ and the methyl group at $\mathrm{C}_{16}$ are trans to each other. Furthermore, irradiation of proton $\mathrm{H}_{8}$ showed a n.O.e. on $\mathrm{H}_{11}$, as we can observe in Figure 14, indicating that the configuration at $\mathrm{C}_{11}$ in $\mathbf{1 1 8}$ is also contrary to that of the natural alkaloid.

For both bislactones 115 and 118, the configuration at $C_{16}$ was consistent with the expected approach of the hydrogen by the less hindered face of the east-side lactone. On the other hand, a rational explanation of the configuration at $C_{11}$ may be found by observation of simple tridimensional molecular models of bislactone 106 (Figure 15) or 107. It can be observed that the pyrrolidine ring obstructs one of the faces of the spiranic lactone forcing the hydrogen attack by the other side.

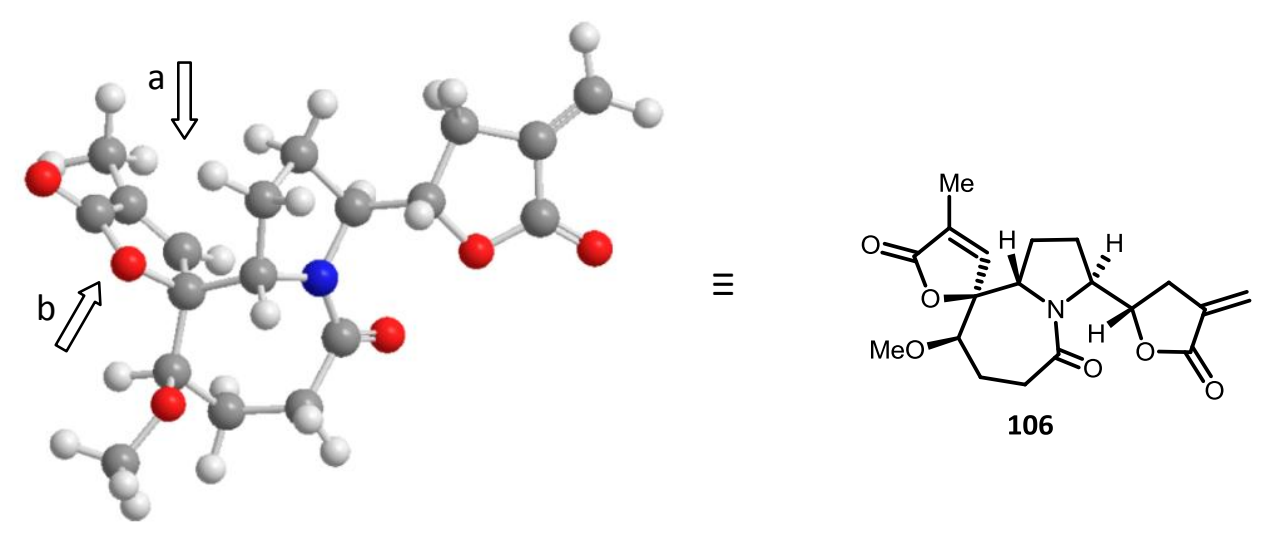

a) more hindered face; b) more accessible face.

Figure 15. Molecular model of bislactone 106 (ChemBio3D Ultra 12.0).

In view of these results, we decided to assay alternative methodologies to reduce the C-C double bonds in 106 and 107 in order to get the opposite $R$ configuration at $C_{11}$. The new protocols were tested with the erythro isomer 107, which cannot generate the natural stemospironine. The reduction through hydride conjugate addition to the $\alpha, \beta$-unsaturated lactones was explored with two different sets of reagents and conditions (Scheme 42). 


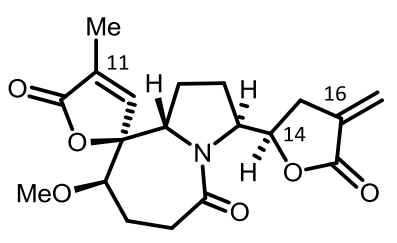

107

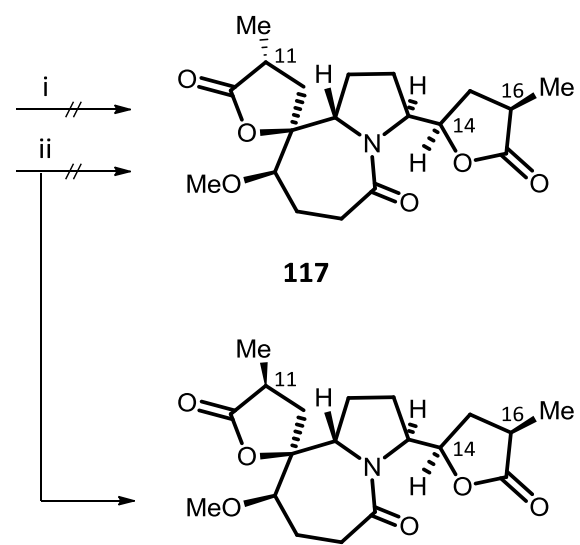

118

Reagents and conditions: (i) $\mathrm{Ph}_{2} \mathrm{SiH}_{2}, \mathrm{Pd}\left(\mathrm{PPh}_{3}\right)_{4}, \mathrm{ZnCl}_{2}, \mathrm{CHCl}_{3}$, r.t.; (ii) $\mathrm{NiCl}_{2}, \mathrm{NaBH}_{4}, \mathrm{MeOH}, \mathrm{H}_{2} \mathrm{O}$, r.t.

Scheme 42. Attempts of preparing lactam 117 from 107.

Firstly, bislactone 107 was treated with a three-component reducing mixture, which comprised $\mathrm{Pd}\left(\mathrm{PPh}_{3}\right)_{4}$ as catalyst, diphenylsilane as hydride donor and zinc chloride. ${ }^{65}$ From this experiment, we were not able to isolate or identify any reaction products. Then, we decided to test the methodology described by Khurana and Sharma. ${ }^{66}$ Thus, compound 107 was treated with $\mathrm{NaBH}_{4}$ and $\mathrm{NiCl}_{2}$, to generate nickel boride in situ as the reducing species. In this trial, the reaction rendered again $\mathbf{1 1 8}$ as the only product and the $C_{11}$ epimer of $\mathbf{1 1 8}$ was not detected.

\subsubsection{Reduction of the lactam functionality in 115 and $\mathbf{1 1 8}$}

In view of the previous results, we decided to continue with the deoxygenation of the lactam present in bislactones $\mathbf{1 1 5}$ and 118, as depicted in Scheme 43. These reactions would provide two new diastereoisomeric analogs of the natural alkaloid stemospironine and, besides, experience in this last reductive transformation would be acquired. On the other hand, considering the high and continuously increasing number of Stemona alkaloids isolated from natural sources and the subtle structural differences between some of them, we considered of special interest to achieve the corresponding amines 116 and 120, although up to the moment none of them have been isolated as natural alkaloids.

\footnotetext{
${ }^{65}$ Keinan, E.; Greenspoon, N. J. Am. Chem. Soc. 1986, 108, 7314-7325.

${ }^{66}$ Khurana, J.M.; Sharma, P. Bull. Chem. Soc. Jpn. 2004, 77, 549-552.
} 


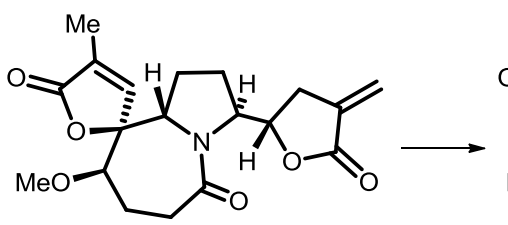

106

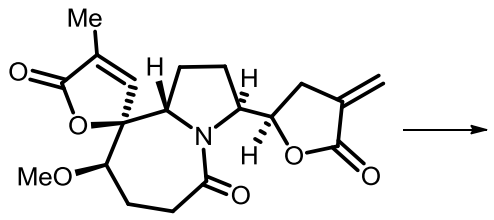

107<smiles>COC1CCC(=O)N2C([C@H]3C[C@H](C)C(=O)O3)CC[C@@]2(C)[C@]12CC(=O)C(=O)O2</smiles>

115

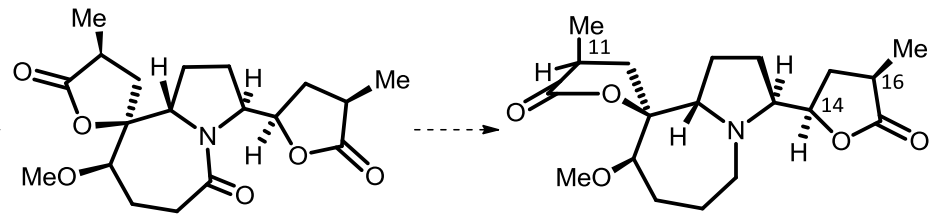

118

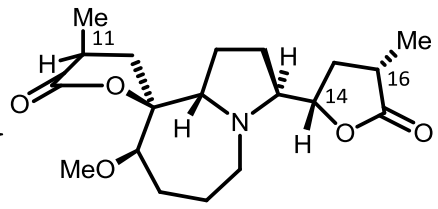

116

120

Scheme 43. Synthetic plan for the construction of amines $\mathbf{1 1 6}$ and $\mathbf{1 2 0 .}$

We first studied the direct reduction of the lactam functionality to amine for both compounds $\mathbf{1 1 5}$ and $\mathbf{1 1 8}$. The use of borane to selectively reduce a lactam without affecting the ester moiety has been documented in the literature, ${ }^{67,68}$ and it is also known that $\mathrm{AlH}_{3}$ is able to reduce lactams much faster than esters. ${ }^{68,69}$ Hence, we submitted bislactones $\mathbf{1 1 5}$ and $\mathbf{1 1 8}$ to treatment with these reagents under different conditions, as it is shown in Table 2.

Table 2. Attempted direct reduction of lactam 115 to amine 116.

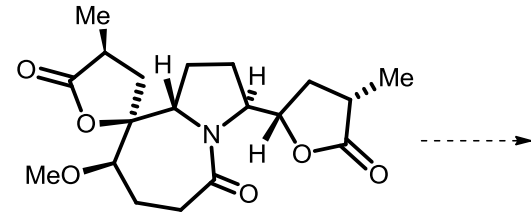

115

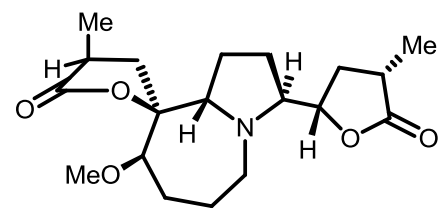

116

\begin{tabular}{ccccc}
\hline Entry $^{\mathrm{a}}$ & Reductive agent & Temp. & time & $\mathbf{1 1 5 : 1 1 6}^{\mathrm{c}}$ \\
\hline $\mathbf{1}$ & $\mathrm{BH}_{3} \cdot \mathrm{THF}$ & $0{ }^{\circ} \mathrm{C}$ & $3.5 \mathrm{~h}$ & $1:-$ \\
$\mathbf{2}$ & $\mathrm{BH}_{3} \cdot \mathrm{THF}$ & r.t. & $48 \mathrm{~h}$ & $2.6: 1$ \\
$\mathbf{3}$ & $\mathrm{BH}_{3} \cdot \mathrm{THF}$ & reflux & $0.8 \mathrm{~h}$ & - \\
$\mathbf{4}$ & $\mathrm{AlH}_{3}{ }^{\mathrm{b}}$ & $0{ }^{\circ} \mathrm{C}$ & $10 \mathrm{~min}$ & $1:-$ \\
\hline
\end{tabular}

a) All reactions were performed in dry THF. b) $\mathrm{AlH}_{3}$ was freshly prepared from $\mathrm{LiAlH}_{4}$ and $\mathrm{AlCl}_{3}{ }^{70} \mathrm{c}$ ) The crude reaction material was not purified. The ratio was determined by ${ }^{1} \mathrm{H}-\mathrm{NMR}$.

${ }^{67}$ (a) Kling, A.; Backfish, G.; Delzer, J.; Geneste, H.; Graef, C. Hornberger, W.; Lange, U. E. W.; Lauterbach, A.; Seitz, W.; Subkowski, T. Bioorg. Med. Chem. 2003, 11, 1319-1341; ; (b) Garrido, N. M.; Sánchez, M. R.; Díez, D.; Sanz, F.; Urones, J. G. Tetrahedron: Assymetry 2011, 872-880; (c) Dupont, C.; Guénard, D.; Tchertanov, L.; Thoret, S.; Guéritte, F. Bioorg. Med. Chem. 1999, 7, 2961-2969.

${ }^{68}$ González-Gálvez, D.; García-García, E.; Alibés, R.; Bayón, P.; de March, P.; Figueredo, M.; Font, J. J. Org. Chem. 2009, 74, 6199-6211.

${ }^{69}$ Brown, H. C.; Yoon, N. M. J. Am. Soc. Chem. 1966, 88, 1464-1472.

${ }^{70}$ Giraud, L.; Huber, V.; Jenny, T. Tetrahedron 1998, 54, 11899-11906. 
When the threo isomer 115 was treated with the complex $\mathrm{BH}_{3} \cdot \mathrm{THF}$ at $0{ }^{\circ} \mathrm{C}$ (entry 1 ), there was no reaction, but we could observe the signals of the amine 116 in the ${ }^{1} \mathrm{H}-\mathrm{NMR}$ spectrum of the crude material when the reduction was performed at room temperature (entry 2). Nevertheless, after $48 \mathrm{~h}$ most of the starting material remained unchanged. Unfortunately, when the reaction was run in THF at the reflux temperature (entry 3) we ended up with decomposition products. When $\mathrm{AlH}_{3}$ was used as reducing agent at $0{ }^{\circ} \mathrm{C}$ for 10 min (entry 4), we could only observe the presence of the starting lactam 115.

For the erythro isomer 118, we were not able to identify the expected amine 120 in any of the reactions assayed in the conditions that were used for the attempted reduction of 115.

After these failed tests, we decided to reduce the lactam functionality in two steps, through the intermediate thiolactam, as shown in Scheme 44.

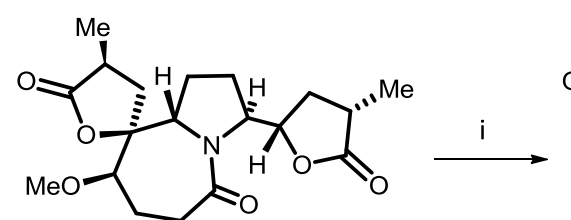

115

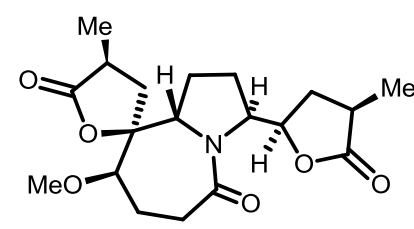

118

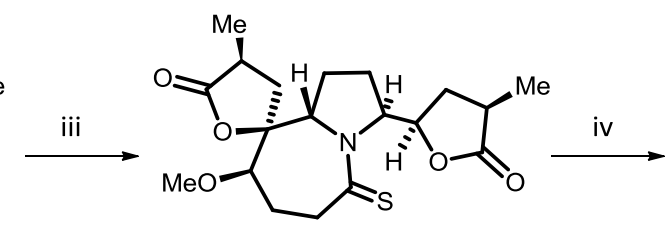

122

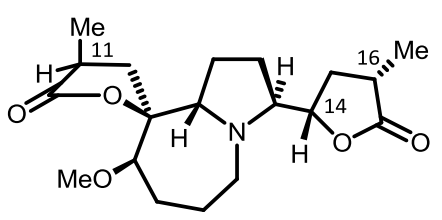

116, 11-epi-stemospironine

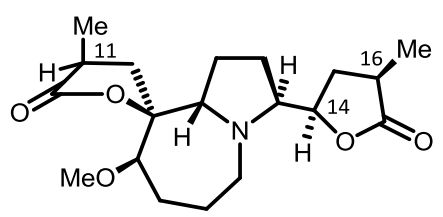

120, 11-epi-14-epi-16-epi-stemospironine

Reagents and conditions: (i) Lawesson's reagent, THF, reflux, 45 min; (ii) Raney-Ni, EtOH, reflux, $1 \mathrm{~h}$ (51\% yield, 2 steps); (iii) Lawesson's reagent, THF, reflux, 45 min (72\% yield); (iv) Raney-Ni, EtOH, reflux, 1 h (71\% yield).

Scheme 44. Syntheses of amines 116 and 120.

This protocol was first tested starting from the erythro isomer 118. Accordingly, bislactone 118 was treated with Lawesson's reagent in THF at the reflux temperature to afford the corresponding thiolactam 122 in $72 \%$ yield. It is important to mention that the use of neutral $\mathrm{Al}_{2} \mathrm{O}_{3}$ for the flash chromatographic purification substantially reduced the impurities associated to the use of the Lawesson's reagent. On the ${ }^{1} \mathrm{H}-\mathrm{NMR}$ spectrum of 122 (Figure 16), the most significant change with respect to that of the precursor was the downfield shifting experienced by $\mathrm{H}_{14}$ from $5.07 \mathrm{ppm}$ in $\mathbf{1 1 8}$ to $5.52 \mathrm{ppm}$ in $\mathbf{1 2 2}$. $\mathrm{H}_{9 \mathrm{a}}$ was also shifted from $4.80 \mathrm{ppm}$ to $5.11 \mathrm{ppm}$, and $\mathrm{H}_{3}$ from $4.29 \mathrm{ppm}$ to $4.96 \mathrm{ppm}$. 


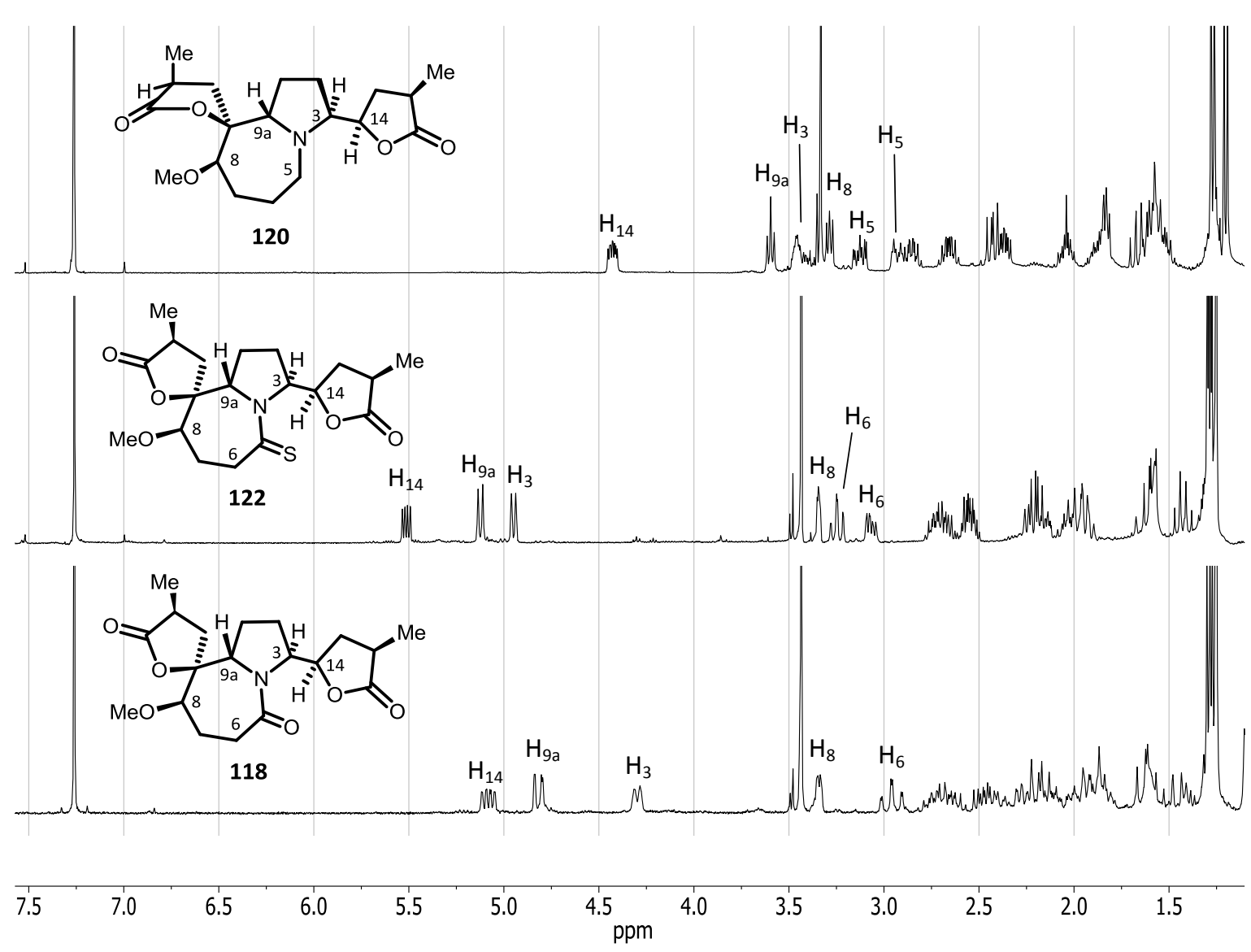

Figure 16. Comparison of the ${ }^{1} \mathrm{H}-\mathrm{NMR}$ spectra $\left(400 \mathrm{MHz}, \mathrm{CDCl}_{3}\right)$ of lactam 118, thiolactam 122 and 11-epi14-epi-16-epi-stemospironine, 120.

Fortunately, we could analyse the structure of this thiolactam by X-ray crystallography, which confirmed the structural assignment of this compound and, consequently, of all the other intermediates involved in the synthesis (Figure 17).

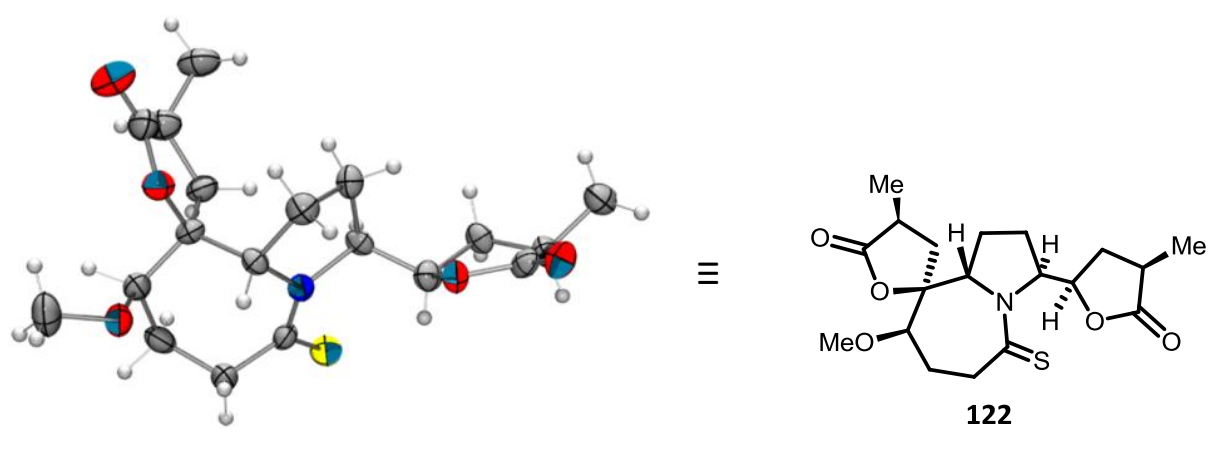

Figure 17. Crystal structure of thiolactam 122. 
Further treatment of $\mathbf{1 2 2}$ with Raney-Ni in $\mathrm{EtOH}$ at the reflux temperature afforded exclusively amine 120, namely 11-epi-14-epi-16-epi-stemospironine, in 71\% yield, with an optical rotation $[\alpha]_{D}^{20}=-30.3\left(c 0.45, \mathrm{CHCl}_{3}\right)$. Thus, we achieved this analog in 15 steps starting from nitrone $\mathbf{4 9}$ and $3.3 \%$ overall yield.

We can clearly see on its ${ }^{1} \mathrm{H}$-NMR spectrum (Figure 16) that the chemical shift of protons $\mathrm{H}_{14}, \mathrm{H}_{9 \mathrm{a}}$ and $\mathrm{H}_{3}$ experienced a considerable shielding due to the reduction of the thiolactam functionality.

On the other hand, bislactone $\mathbf{1 1 5}$ was also treated with Lawesson's reagent in THF at the reflux temperature to yield the thiolactam 121 (Scheme 44). In this case, the intermediate thiolactam was not purified, the crude material was simply filtered through $\mathrm{Al}_{2} \mathrm{O}_{3}$ and directly submitted to reduction with Raney-Ni. Thus, we obtained 11-epi-stemospironine, 116, in 51\% yield for the two steps, with an optical rotation $[\alpha]_{D}^{20}=-20.3\left(c 0.41, \mathrm{CHCl}_{3}\right)$. Hence, this analog was prepared in 15 steps starting from nitrone $\mathbf{4 9}$ and $3.0 \%$ overall yield.

The most significant difference between the ${ }^{1} \mathrm{H}-\mathrm{NMR}$ spectra of $\mathbf{1 1 6}$ (Figure 18) and $\mathbf{1 2 0}$ is the chemical shift of proton $\mathrm{H}_{14}$ (4.24 ppm and $4.42 \mathrm{ppm}$ for 116 and 120, respectively). Hence, with this synthetic route we achieved two new diastereoisomeric analogs of the natural alkaloid (-)-stemospironine.

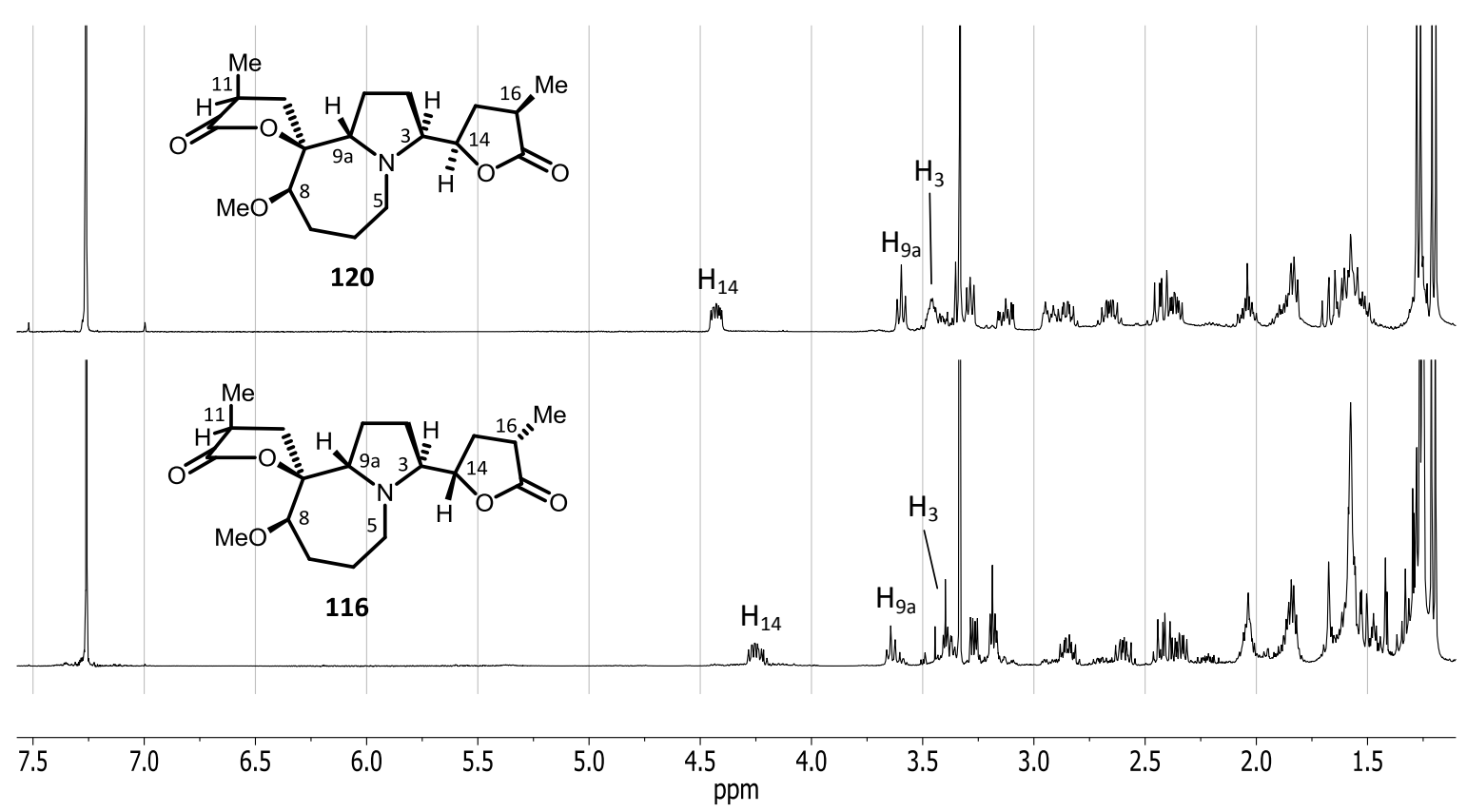

Figure 18. Comparison of the ${ }^{1} \mathrm{H}-\mathrm{NMR}$ spectra $\left(400 \mathrm{MHz}, \mathrm{CDCl}_{3}\right.$ ) of 11-epi-stemospironine, 116 and 11-epi14-epi-16-epi-stemospironine, 120. 


\subsubsection{Attempt to epimerize 11-epi-stemospironine, 120}

Considering that $\mathbf{1 2 0}$ is an epimer of $(-)$-stemospironine at an $\alpha$-carbonyl position $\left(C_{11}\right)$, we thought it could be worthy to try if base-promoted epimerization of $\mathbf{1 2 0}$ furnished the natural product (Scheme 45).

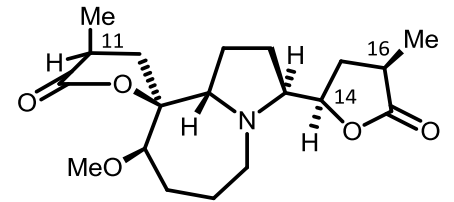

120

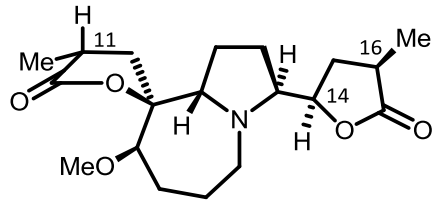

(-)-stemospironine

Reagents and conditions: (i) MeONa, $\mathrm{MeOH}$, r.t.

Scheme 45. Attempted epimerization of $\mathbf{1 2 0 .}$

Epimerization of $\mathrm{C}_{11}$ was attempted by using $\mathrm{MeONa}$ in $\mathrm{MeOH}$, but the starting material was recovered as a sole product. This fact was consistent with the results obtained by Martin and co-workers with a structurally related compound, which was an intermediate in their synthesis of (+)-croomine. ${ }^{17 c}$ In their work, they made a separate study to epimerize 124 to 123 (Scheme 46). In this study, a (2:1) mixture of $\mathbf{1 2 3}$ and $\mathbf{1 2 4}$ was treated with methanolic MeONa and they obtained a (1:2) mixture of diastereoisomers in which 124 was the major product. No epimerization of $C_{3}$ was observed and, hence, they concluded that the unnatural configuration at $\mathrm{C}_{11}$ in these tricyclic compounds was the thermodynamically preferred.

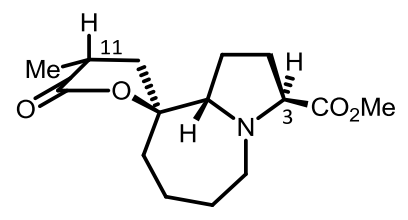

123
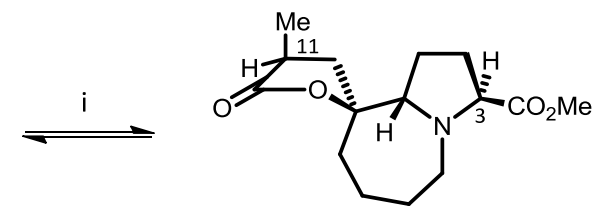

124

Reagents and conditions: (i) $\mathrm{MeONa}, \mathrm{MeOH}$, r.t.

Scheme 46. Epimerization study carried out by Martin and co-workers. ${ }^{17 c}$ 


\subsection{New approach to the synthesis of (-)-stemospironine}

In view of the high diastereoselectivity accomplished in the reduction of the $C_{10}-C_{11}$ double bond in intermediates 106 and 107 by the less hindered face, we reasoned that the methylation of an enolate formed by deprotonation of $C_{11}$ of an intermediate lacking the methyl group should occur with the same facial selectivity, leading to the correct stemospironine-like configuration.

To test this hypothesis, we decided to undertake the sequence depicted in Scheme 47. The spirolactonization of hydroxyaldehyde $\mathbf{6 2}$ by treatment with diethoxyphosphorylacetic acid should render 126. After hydrogenation of the double bond and then methylation we should presumably obtain the west-side lactone with the correct configuration at $\mathrm{C}_{11}$. The following transformations to achieve the alkaloid would be the same as in the previous syntheses of the two diastereoisomeric analogs $\mathbf{1 1 6}$ and $\mathbf{1 2 0 .}$

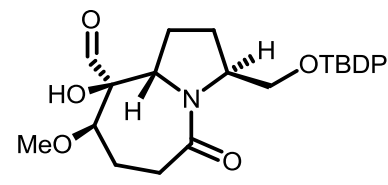

62

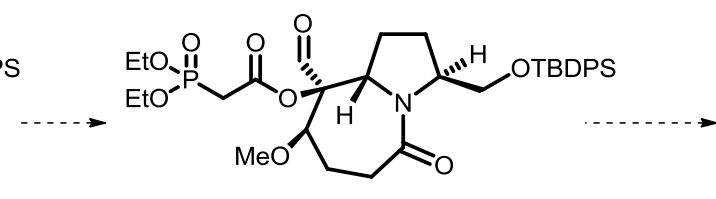

125

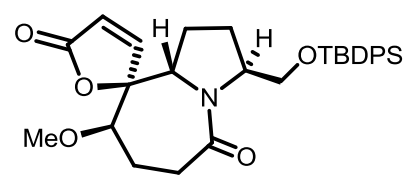

126

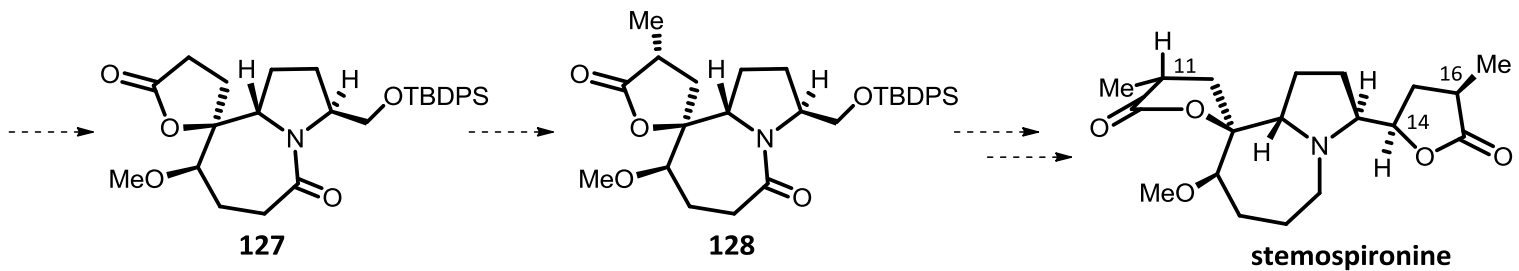

Scheme 47. Proposed new route for the synthesis of (-)-stemospironine.

\subsubsection{Construction of the spiranic lactone. Synthesis of $\mathbf{1 2 6}$}

The synthesis of the ester $\mathbf{1 2 5}$ was performed in the same way as that of ester $\mathbf{8 6} .{ }^{61}$ Thus, a solution of the commercially available acid $\mathbf{1 2 9}$ was added to a solution of aldehyde $\mathbf{6 2}$, and then DCC was slowly added (Scheme 48). After $1.5 \mathrm{~h}$, ester 125 was obtained in 79\% yield. On its ${ }^{1} \mathrm{H}-\mathrm{NMR}$ spectrum one can clearly see the characteristic aldehyde signal at $9.56 \mathrm{ppm}$ and the $\alpha$ phosphoryl protons at $3.10 \mathrm{ppm}$, which appear as a doublet of doublets with a coupling constant of $22 \mathrm{~Hz}$ with the phosphorus atom and a geminal coupling of $14 \mathrm{~Hz}$ (Figure 19). 


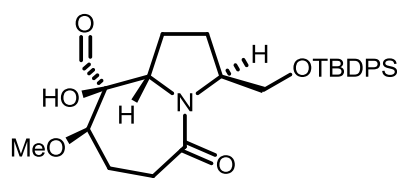

62

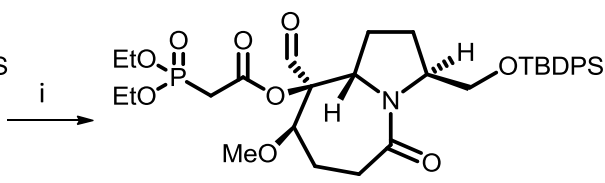

125

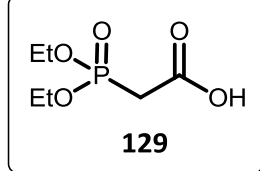

Reagents and conditions: (i) 129, $1 \mathrm{M}$ in $\mathrm{CH}_{2} \mathrm{Cl}_{2}$, DCC $1 \mathrm{M}, \mathrm{CH}_{2} \mathrm{Cl}_{2}$, r.t., $1.5 \mathrm{~h}$ (79\%).

Scheme 48. Construction of phosphoryl acetate 125.
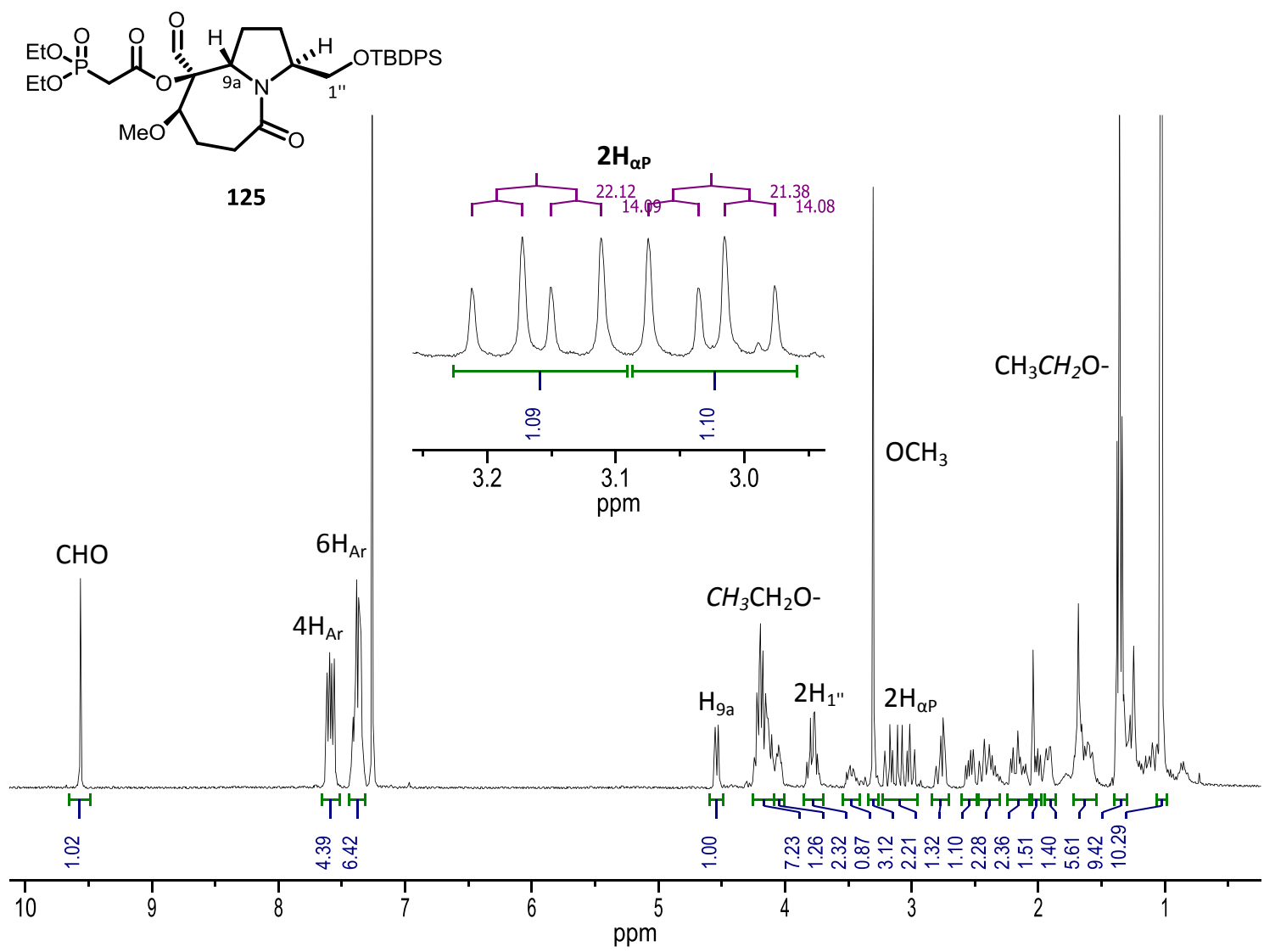

$\mathrm{OCH}_{3}$

Figure 19. ${ }^{1} \mathrm{H}-\mathrm{NMR}$ spectrum $\left(250 \mathrm{MHz}, \mathrm{CDCl}_{3}\right)$ of compound 125.

Then, compound 125 was treated with ${ }^{t} \mathrm{BuOK}$ (Scheme 49). This reaction delivered the expected lactone 126, along with another product that, after a thorough analysis of its spectroscopic data, was identified as the phosphonate 130 , which was obtained via a competitive Knoevenagel reaction. 


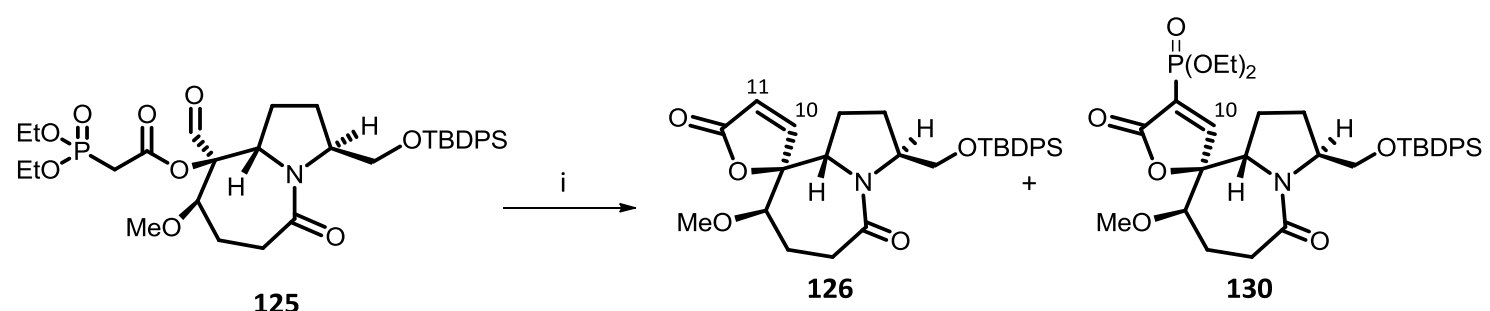

Reagents and conditions: (i) ${ }^{t} \mathrm{BuOK}, \mathrm{THF}$, r.t., $15 \mathrm{~min}$ (29\% for $126,41 \%$ for 130$)$.

Scheme 49. Construction of the west-side lactone.

The ${ }^{1} \mathrm{H}-\mathrm{NMR}$ spectrum of $\mathbf{1 2 6}$ shows a doublet at 6.27 ppm corresponding to proton $\mathrm{H}_{11}$, while the other olefinic proton $\mathrm{H}_{10}$ is hidden under the aromatic signals of the TBDPS group, at $7.38 \mathrm{ppm}$. For compound 130, the most characteristic signal is the doublet at $7.92 \mathrm{ppm}$ for proton $\mathrm{H}_{10}$, which has a coupling constant of $9.8 \mathrm{~Hz}$ with the phosphorus atom.

This competitive Knoevenagel reaction has been described in the literature in a similar process and the authors affirm that the choice of the base for the intramolecular HornerWadsworth-Emmons (HWE) reaction proved to be critical. ${ }^{71}$ Thus, we decided to test different reaction conditions in order to avoid this competitive pattern (Table 3).

Table 3. Base-promoted cyclization of 125.

\begin{tabular}{|c|c|c|c|c|c|}
\hline Entry & Base & Solvent & Temp. & time & $126: 130^{\mathrm{a}}$ \\
\hline 1 & ${ }^{t} \mathrm{BuOK}$ & THF & $-20^{\circ} \mathrm{C}$ & $30 \mathrm{~min}$ & 1:1 \\
\hline 2 & ${ }^{t} \mathrm{BuOK}$ & THF & r.t. & $15 \mathrm{~min}$ & 1:1.4 \\
\hline 3 & ${ }^{t} \mathrm{BuOK}$ & THF & reflux & $15 \mathrm{~min}$ & - \\
\hline 4 & ${ }^{t} \mathrm{BuOK}$ & toluene & reflux & $15 \mathrm{~min}$ & - \\
\hline $5^{71,72}$ & $\begin{array}{c}\mathrm{K}_{2} \mathrm{CO}_{3} \\
\text { 18-crown-6 }\end{array}$ & THF & r.t. & $30 \mathrm{~min}$ & $1: 23$ \\
\hline $6^{73}$ & $\mathrm{NaH}$ & THF & r.t. & $15 \mathrm{~min}$ & 1:5 \\
\hline $7^{71}$ & $\mathrm{LiOH}$ & THF & $-20^{\circ} \mathrm{C}$ & $15 \mathrm{~min}$ & $1: 2$ \\
\hline $8^{72 b, 74}$ & $\mathrm{NEt}_{3}, \mathrm{LiBr}$ & THF & r.t. & $1 \mathrm{~h}$ & $1: 2.5$ \\
\hline
\end{tabular}

a) The crude reaction material was not purified. The conversion is, in all cases, $100 \%$. The ratio and conversion were determined by ${ }^{1} \mathrm{H}-\mathrm{NMR}$.

\footnotetext{
${ }^{71}$ Yan, B.; Spilling, C. D. J. Org. Chem. 2008, 73, 5385-5396.

${ }^{72}$ (a) Carson, C. A.; Kerr, M. A. Angew. Chem. Int. Ed. 2006, 45, 6560-6563; (b) Krawczyk, E.; Koprowski, M.; Luczak, J. Tetrahedron: Assymetry 2007, 18, 1780-1787.

${ }^{73}$ Medeiros, M. R.; Wood, J. L. Tetrahedron 2010, 66, 4701-4709.

${ }^{74}$ Leduc, A. B.; Kerr, M.A. Angew. Chem. Int. Ed. 2008, 47, 7945-7948.
} 
It is noteworthy that we performed preliminary qualitative experiments and after we found the best conditions, the reaction products were isolated and the respective yields determined.

The initial experiments (entries 1-4) were performed with ${ }^{\mathrm{t}} \mathrm{BuOK}$, according to the conditions previously and successfully applied to the HWE cyclization of the methyl analog 86 . Although the conditions of entry 1 afforded a more favourable 1:1 mixture of $\mathbf{1 2 6}$ and $\mathbf{1 3 0}$, those of entry 2 rendered more reproducible results and were considered the best conditions within this series of trials with ${ }^{\mathrm{t}} \mathrm{BuOK}$. According to the literature, ${ }^{71}$ the desired HWE reaction appeared to be favoured by the use of $\mathrm{K}_{2} \mathrm{CO}_{3}$ in the presence of 18-crown-6. However, in our case the opposite trend was observed (entry 5). This combination of reagents furnished a 23:1 mixture, where $\mathbf{1 3 0}$ was the major component. Other bases such as $\mathrm{NaH}$ (entry 6), LiOH (entry 7) and $\mathrm{NEt}_{3}$ (entry 8) were also tested, but in all cases the competitive Knoevenagel reaction was the preferred pathway. It is noteworthy that the ratio 126:130 was determined by the relative area of the signal corresponding to proton $\mathrm{H}_{11}$ for lactone $\mathbf{1 2 6}$ and proton $\mathrm{H}_{10}$ for phosphonate $\mathbf{1 3 0}$ in the ${ }^{1} \mathrm{H}-\mathrm{NMR}$ spectrum of the crude reaction material. Considering all the tested reactions, entry 2 was the most reproducible and cleaner, and hence these conditions were considered those of choice (Scheme 49), affording 126 and 130 in 29\% and 41\% yield, respectively.

The mechanism of the two competitive reactions is shown in Scheme 50.

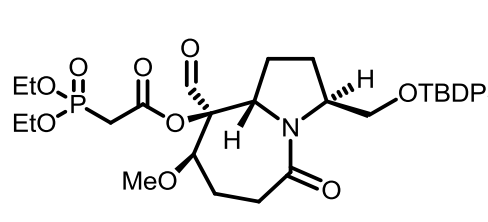

125

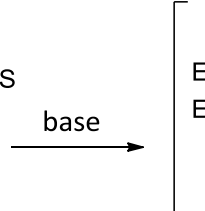

EtO

$\mathrm{EtO}^{-} \mathrm{P}-\mathrm{OH}$

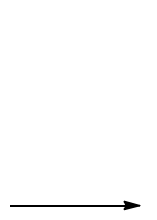

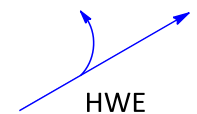

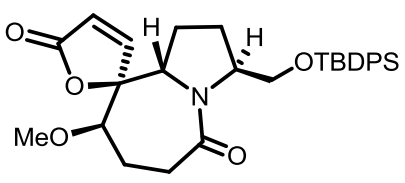

126

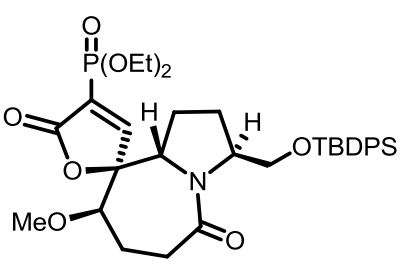

130

Scheme 50. Mechanism of the HWE and the competitive Knoevenagel reaction. ${ }^{71}$ 
Since this side reaction could not be inhibited, we tried to develop other synthetic transformations in order to obtain lactone $\mathbf{1 2 6}$ as the major product. Two alternative methodologies were considered. The first one was based on an intermolecular HWE reaction, and the second in an intramolecular ring closing metathesis as the key steps.

The plan for preparing the spiranic lactone through an intermolecular HWE reaction is shown in Scheme 51. After the HWE, the subsequent hydrogenation may generate two epimeric esters which, upon acyl transfer would render the corresponding epimeric lactones $\mathbf{1 2 8}$ and/or 135, with 128 having the appropriate configuration at $C_{11}$ for stemospironine.

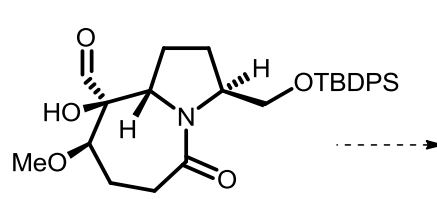

62

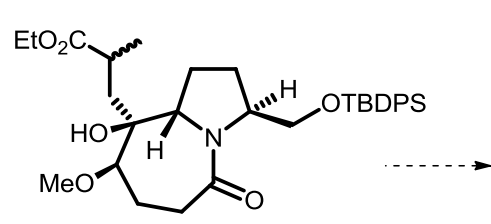

134

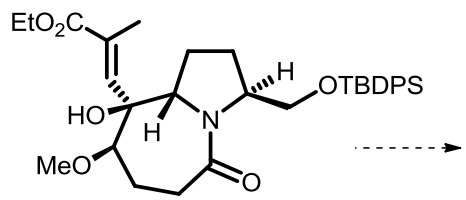

133

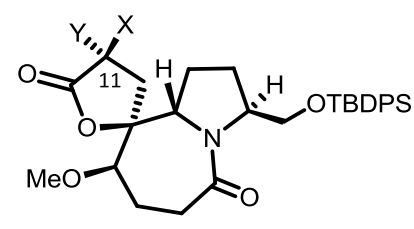

128, $\mathrm{X}=\mathrm{H}, \mathrm{Y}=\mathrm{Me}$

135, $\mathrm{X}=\mathrm{Me}, \mathrm{Y}=\mathrm{H}$

Scheme 51. Proposed transformations for the construction of the spiranic lactone.

According to the plan, aldehyde $\mathbf{6 2}$ was submitted to the intermolecular HWE olefination by reaction with ethyl 2-(diethoxyphosphoryl)propanoate, 87, using ${ }^{t} \mathrm{BuOK}$ as base (Scheme 52 ). In some reported examples, a similar intermolecular reaction was performed over substrates containing a free hydroxyl group, ${ }^{75}$ that is why the reaction was attempted directly on the hydroxyaldehyde 62 without any protection of the alcohol.

\footnotetext{
75 (a) Meyers, Spohn, R. F.; Linderman, R. J. J. Org. Chem. 1985, 50, 3633-3635, (b) Hicks, D. R.; Fraser-Reid, B. Chem. Comm. 1976, 869-870; (c) Olejniczak, K.; Frank, R. W. J. Org. Chem. 1982, 47, 380-381; (d) Bonadies, F.; Cardilli, A.; Lattanzi, A.; Pesci, S.; Scettri, A. Tetrahedron Lett. 1995, 36, 2839-2840.
} 

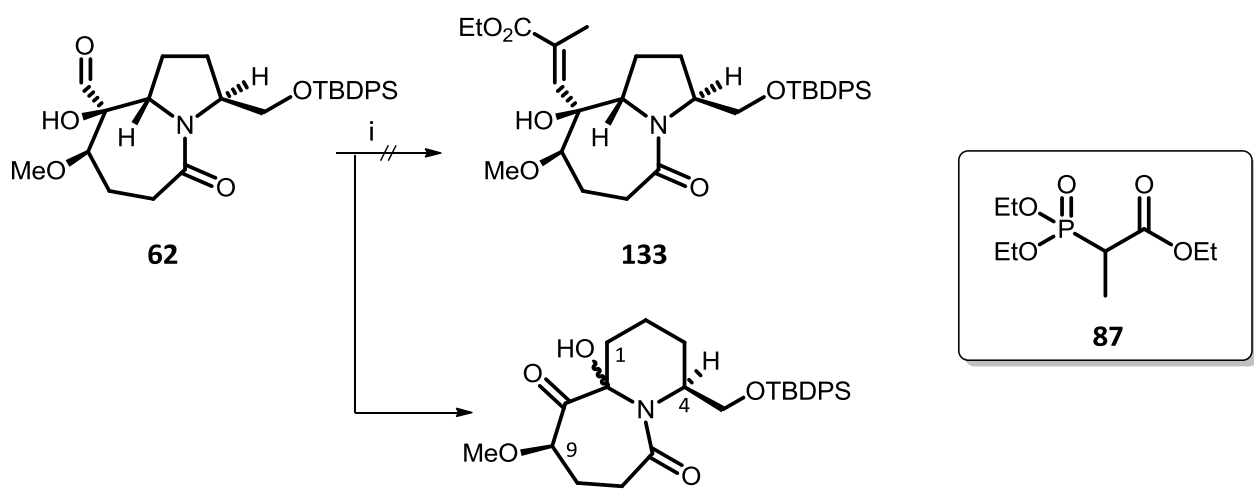

136

Reagents and conditions: (i) ${ }^{t} \mathrm{BuOK}, 87$, r.t., 5 min; then, $62, \mathrm{THF},-78{ }^{\circ} \mathrm{C}$ to r.t. (30\%).

Scheme 52. Attempted preparation of 133.

In the event, a mixture of phosphonate 87 and ${ }^{t} \mathrm{BuOK}$ was stirred at room temperature for $5 \mathrm{~min}$, and then hydroxyaldehyde 62 was added. Under these conditions, instead of the expected olefin 133, we isolated 136 as the only product in $30 \%$ yield. On its ${ }^{1} \mathrm{H}$-NMR spectrum it could be observed that the signal corresponding to proton $\mathrm{H}_{4}$ is upfield shifted due to the change of the ring size, and the ${ }^{13} \mathrm{C}-\mathrm{NMR}$ displays a signal at $214.2 \mathrm{ppm}$ corresponding to a new carbonyl group. This reaction had been already observed in our research group for a similar compound under basic treatment. ${ }^{62}$ According to our mechanistic proposal (Scheme 53), the phosphonate does not play any role in the formation of $\mathbf{1 3 6}$, the reaction takes place due to the presence of the base and hence the formation of an $\alpha$-oxoalkoxide initiates the process.

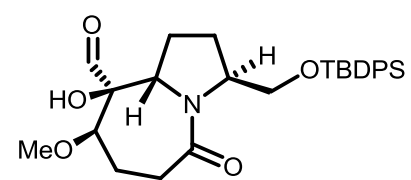

62

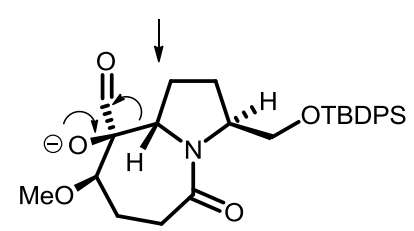

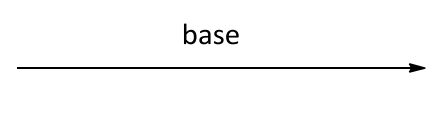

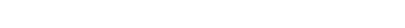

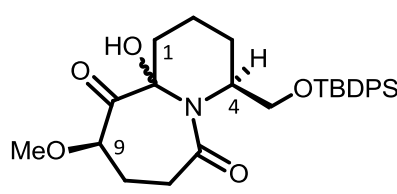

136
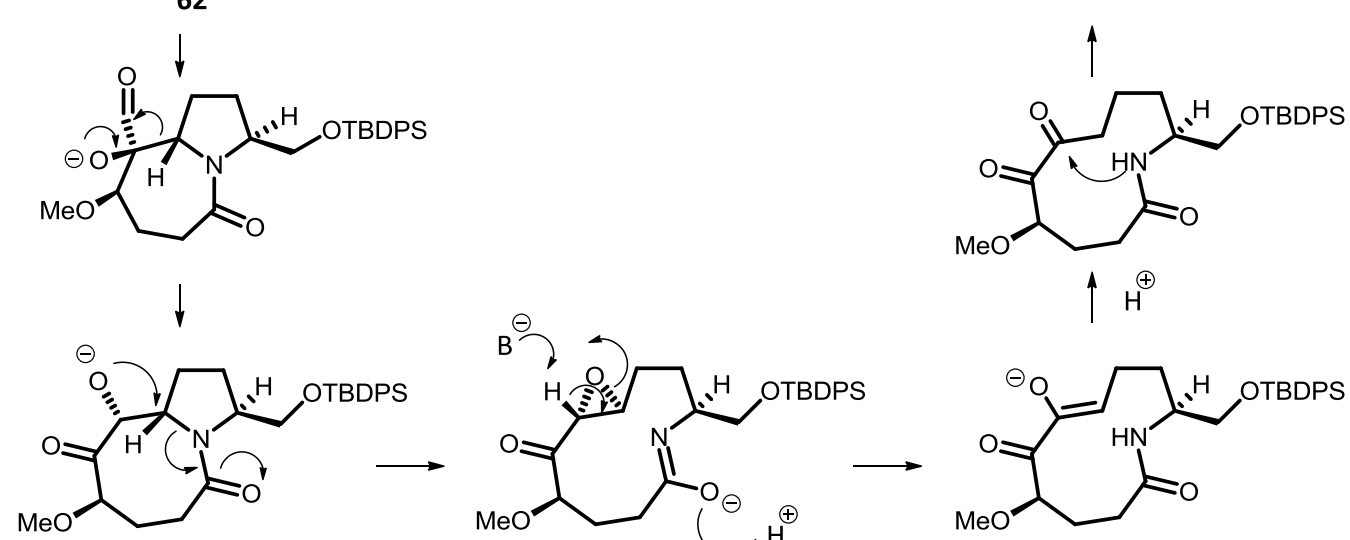

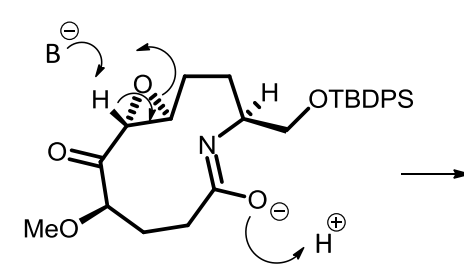

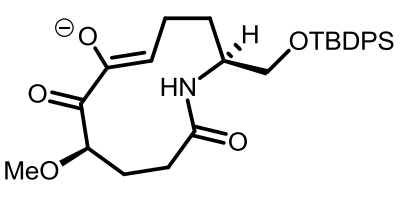

Scheme 53. Proposed mechanism for the formation of 136. 
Accordingly, we decided to protect the tertiary alcohol before performing the HWE reaction, as in other intermolecular HWE olefinations described in the literature. ${ }^{76}$ Although some other more robust protecting groups were attempted, due to the steric hindrance, we were only successful in making the TMS ether. ${ }^{77}$ Unfortunately, this silyl ether was too labile to withstand the subsequent HWE reaction with ${ }^{\mathrm{t}} \mathrm{BuOK}$ in the media.

After these frustrated trials, we decided to assay the pathway based on intramolecular metathesis and depicted on Scheme 54. The devised plan starts with the formation of acrylate 137, followed by a Wittig olefination to diene 138, which should render spirolactone 126 after the ring closing metathesis.

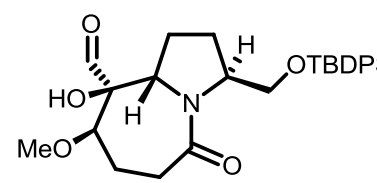

62

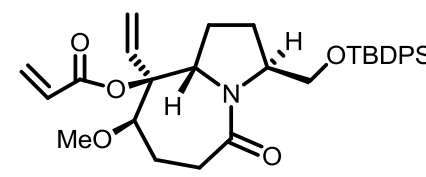

138

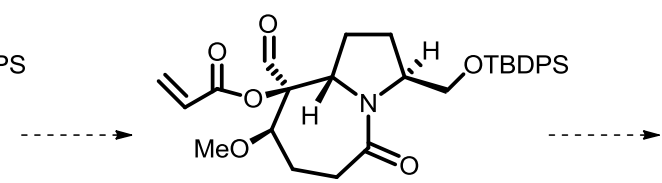

137

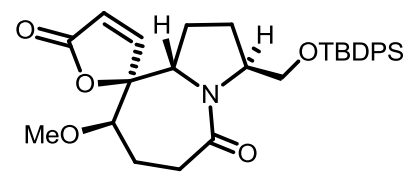

126

Scheme 54. Synthetic plan for the construction of lactone 126.

Since the use of a strong base was precluded to avoid the formation of the pyridoazepinone 136, we used $\mathrm{Et}_{3} \mathrm{~N}$ (Scheme 55 ), ${ }^{78}$ but, unfortunately, the reaction did not take place, rendering decomposition products.

\footnotetext{
${ }^{76}$ (a) Kitazume, T.; Kobayashi, T.; Yamamoto, T.; Yamazaki, T. J. Org. Chem. 1987, 52, 3218-3223; (b) Ishihara, K.; Kawaguchi, T.; Matsuya, Y.; Sakurai, H.; Saiki, I.; Nemoto, H. Eur. J. Org. Chem. 2004, 3973-3978; (c) Ensch, C.; Hesse, M. Helv. Chim. Acta 2003, 86, 233-246; (d) Suenaga, K.; Mutou, T.; Shibata, T.; Itoh, T.; Fujita, T.; Takada, N.; Hayamizu, K.; Takagi, M.; Irifune, T.; Kigoshi, H.; Yamada, K. Tetrahedron 2004, 60, 8509-8527.

${ }^{77}$ Crisóstomo, F. R.; Lledó, A.; Shenoy, S. R.; Iwasawa, T.; Rebek, J. J. Am. Chem. Soc. 2009, 131, 7402-7410.

${ }^{78}$ D'Annibale, A.; Ciaralli, L. J. Org. Chem. 2007, 72, 6067-6074.
} 


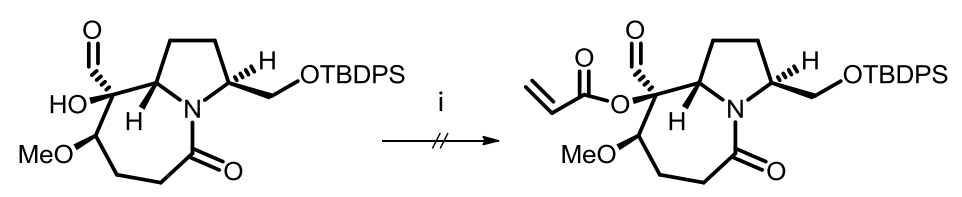

62

137

Reagents and conditions: (i) acryloyl chloride, $\mathrm{Et}_{3} \mathrm{~N}, \mathrm{CH}_{2} \mathrm{Cl}_{2}, 0^{\circ} \mathrm{C}$.

Scheme 55. Attempt of preparation of 137.

In parallel studies, we investigated the transformation of the Knoevenagel product $\mathbf{1 3 0}$ to the required lactone 126, and we found that, fortunately, compound $\mathbf{1 3 0}$ could be converted to 126 by treatment of the former with $\mathrm{MeONa}$ in $\mathrm{MeOH}$ to afford the latter in 93\% yield (Scheme 56). ${ }^{79}$

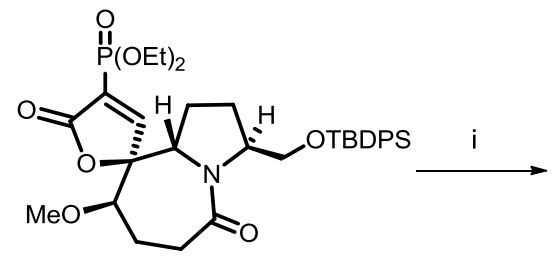

130

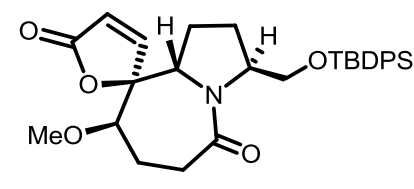

126

Reagents and conditions: (i) $\mathrm{MeONa}, \mathrm{MeOH}$, r.t., 16 h (93\%).

Scheme 56. Transformation of 130 to 126.

The formation of $\mathbf{1 2 6}$ can be rationalised by the mechanism shown in Scheme 57 for the simplified compound 139, described by Janecki and Blaszczyk. ${ }^{79}$ Firstly, a base-promoted conjugate addition of the ethanol to butenolide 139 furnishes compound 140, which suffers nucleophilic attack of the ethoxide ion on the phosphorous atom to produce the anion 141. Subsequent elimination of triethylphosphate and ethoxide ion from $\mathbf{1 4 1}$ renders butenolide 142.

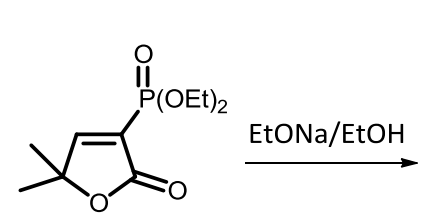

139

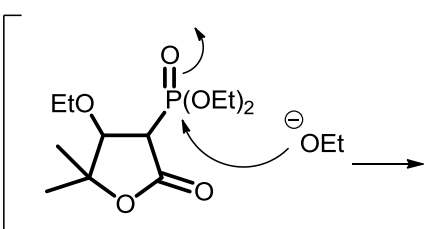

140

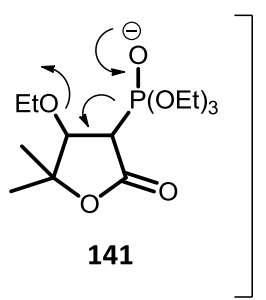

$-\mathrm{PO}(\mathrm{OEt})_{3}$

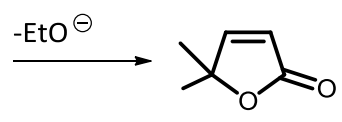

142

Scheme 57. Mechanism for the transformation of 139 to butenolide $142 .^{79}$

\footnotetext{
${ }^{79}$ Janecki, T.; Blaszczyk, E. Synthesis 2001, 3, 403-408.
} 
In view that compound $\mathbf{1 3 0}$ could be reprocessed to $\mathbf{1 2 6}$ by treatment with MeONa in $\mathrm{MeOH}$, we attempted the formation of lactone 126 from ester 125 using two equivalents of $\mathrm{MeONa}$, one for the HWE reaction and one for the conversion of 130 to 126 (Scheme 58). However, we were not able to identify or isolate any product from this reaction.

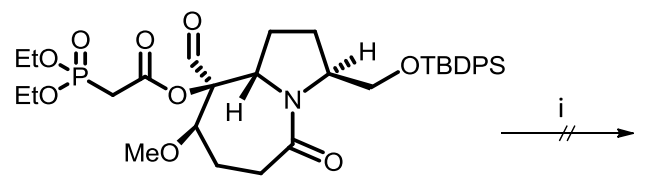

125

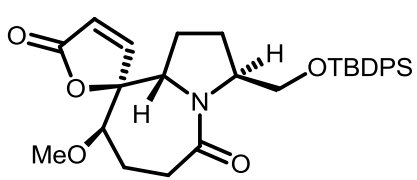

126

Reagents and conditions: (i) $\mathrm{MeONa}, \mathrm{MeOH}$, r.t.

Scheme 58. Attempted HWE reaction with MeONa.

Considering these results, we decided to prepare the west-side lactone $\mathbf{1 2 6}$ through the esterification reaction of aldehyde 62 (Scheme 48), subsequent HWE reaction rendering both lactone 126 and phosphonate 130 (Scheme 49), and then reprocessing of the latter under methanolysis conditions (Scheme 56). In this way, the unsaturated lactone 126 could be obtained in a reasonable 53\% yield from hydroxyaldehyde $6 \mathbf{2}$.

\subsubsection{Hydrogenation of the double bond and methylation. Synthesis of $\mathbf{1 2 8}$}

Following our synthetic plan (Scheme 47), the next transformation was the reduction of the carbon-carbon double bond of the spiranic lactone. For this purpose, compound $\mathbf{1 2 6}$ was submitted to hydrogenation at atmospheric pressure in the presence of $\mathrm{Pd} / \mathrm{C}$ in ethanolic media (Scheme 59). After $4 \mathrm{~h}$, the saturated lactone 127 was obtained in $93 \%$ yield. On its ${ }^{1} \mathrm{H}-\mathrm{NMR}$ spectrum we could clearly observe the disappearance of the olefinic proton and the new signal at $2.60 \mathrm{ppm}$ for the $\alpha$-carbonyl protons $\mathrm{H}_{11}$.

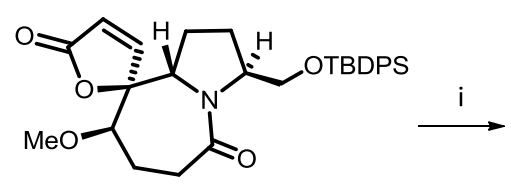

126

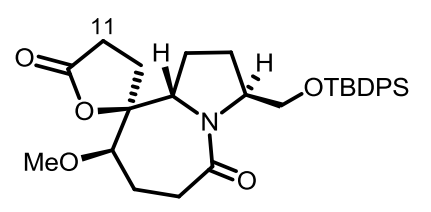

127

Reagents and conditions: (i) $\mathrm{H}_{2}$ (1 atm), Pd/C, EtOH, 4 h (93\%).

Scheme 59. Hydrogenation of compound $\mathbf{1 2 6 .}$ 
The following step was the methylation of the $\alpha$-carbonyl position. If we were right with our previous predictions, the reaction would occur stereoselectively to afford exclusively the methylated lactone with the same configuration at $\mathrm{C}_{11}$ as in stemospironine.

The $\alpha$-methylation of similar lactones has been widely reported in literature in relation with the synthesis of Stemona alkaloids. ${ }^{16 n, 18 d, e, f, 21 f, g, h, i, 32 a, 36}$ In most examples of these works, LiHMDS is used as the base and Mel as the alkylating agent. Accordingly, we assayed the same combination of reagents for the methylation of lactone $\mathbf{1 2 7}$ under various reaction conditions (Table 4).

Table 4. Methylation of 127.

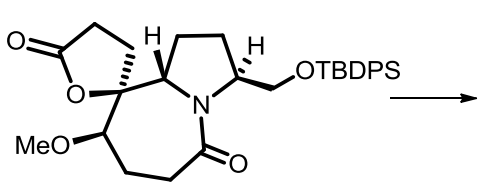

127

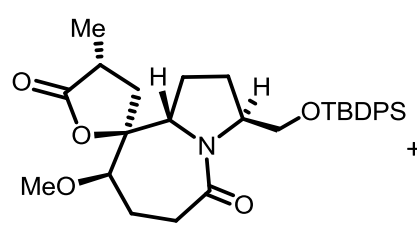

128

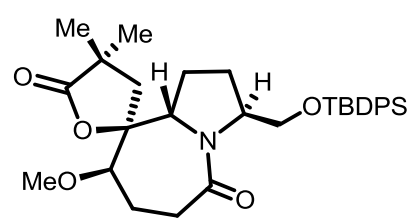

143

\begin{tabular}{|c|c|c|c|c|c|}
\hline \multirow[t]{2}{*}{ Entry $^{a}$} & \multicolumn{2}{|c|}{ LiHMDS } & \multicolumn{2}{|c|}{ Mel } & \multirow[t]{2}{*}{$127: 128: 143$} \\
\hline & Equiv. & time & Equiv. & time & \\
\hline 1 & 2 & $45 \mathrm{~min}$ & 10 & $45 \mathrm{~min}$ & - : :1:1.9 \\
\hline 2 & 1.4 & $45 \mathrm{~min}$ & 4 & $2 \mathrm{~h}$ & $1: 2.1: 1.25$ \\
\hline 3 & 1.1 & $45 \mathrm{~min}$ & 5 & $1 \mathrm{~h}$ & 1:1.6: - \\
\hline 4 & 1.1 & $45 \mathrm{~min}$ & 15 & $45 \mathrm{~min}$ & 1:5:- \\
\hline
\end{tabular}

a) All reactions were performed in dry THF at $-78{ }^{\circ} \mathrm{C}$. b) The crude reaction material was not purified. The ratio was determined by ${ }^{1} \mathrm{H}-\mathrm{NMR}$.

As it can be observed in Table 4, when a large excess of base and Mel were used (entry 1), all the starting material was consumed, but the dimethylated lactone $\mathbf{1 4 3}$ was mainly obtained, along with a minor quantity of the monomethylated one 128. Unfortunately, these two compounds could not be separated even after repetitive flash column chromatography. Decreasing the excess of base and Mel (entry 2 ) led to recovering of some starting material but the dimethylation was not inhibited. Thus, in the next experiments we used only 1.1 equivalents of LiHMDS and, once the formation of the enolate was assumed, it was trapped with a fast addition of a large excess of Mel, in order to avoid the equilibrium between the enolates of compounds 127 and 128 (entries 3 and 4). The best results were obtained when 15 equivalents of alkylating agent were used, affording a 5:1 mixture of the desired methylated compound $\mathbf{1 2 8}$ 
and unreacted starting material $\mathbf{1 2 7}$, which could be easily separated by flash column chromatography. The overall yield was 83\% over unrecovered 127.

The ${ }^{1} \mathrm{H}-\mathrm{NMR}$ spectra of compounds 127,128 and 143 were performed in deuterated benzene because it was easier to identify each product, since in $\mathrm{CDCl}_{3}$ some signals were overlapped preventing the determination of the product ratio.

The most significant difference on their ${ }^{1} \mathrm{H}-\mathrm{NMR}$ spectra (Figure 20) is the chemical shift of proton $\mathrm{H}_{8}$, whose signal is downfield shifted on going from 127 (2.71 ppm) to 128 (2.75 ppm) to 143 (3.03 ppm).

To confirm that compound $\mathbf{1 2 8}$ had the same configuration at $C_{11}$ as in stemospironine, we decided to perform the hydrogenation of the TBDPS derivative 63 (Scheme 60), intermediate in the syntheses of the diastereoisomeric analogs 11-epi-stemospironine, 116, and 11-epi-14-epi16-epi-stemospironine, $\mathbf{1 2 0}$, and then compare their ${ }^{1} \mathrm{H}-\mathrm{NMR}$ spectra.

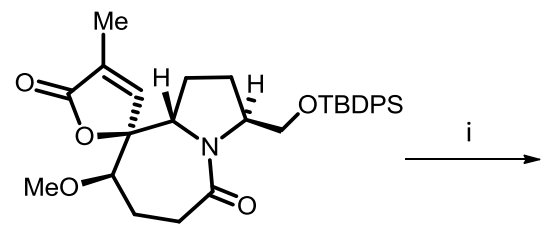

63

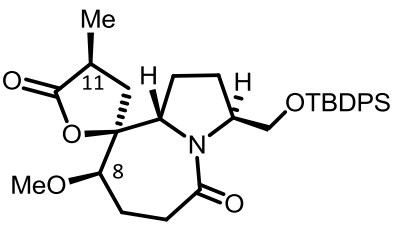

135

Reagents and conditions: (i) $\mathrm{H}_{2}$ (1 atm), Pd/C, EtOH: $\mathrm{HCl}(1: 1), 24 \mathrm{~h}(90 \%)$.

Scheme 60. Hydrogenation of compound 63.

According to our predictions, hydrogenation of $\mathbf{6 3}$ should also be stereoselective, as hydrogen would approach by the less hindered face of the spiranic lactone and should furnish, therefore, the $\mathrm{C}_{11}$ epimer of 128. Hence, the hydrogenation was carried out in acidic ethanol and $\mathrm{Pd} / \mathrm{C}$ as catalyst and delivered $\mathbf{1 3 5}$ as a sole product in $90 \%$ yield. A remarkable n.O.e. between $\mathrm{H}_{8}$ and $\mathrm{H}_{11}$ evidenced the $S$ configuration of the $\alpha$-carbonyl stereocenter at $\mathrm{C}_{11}$. A comparison of the ${ }^{1} \mathrm{H}-\mathrm{NMR}$ spectra of $\mathbf{1 3 5}$ and $\mathbf{1 2 8}$ confirmed that the later presents $R$ configuration at $\mathrm{C}_{11}$ and hence the methylation of $\mathbf{1 2 7}$ takes place with the predicted stereoselectivity. 


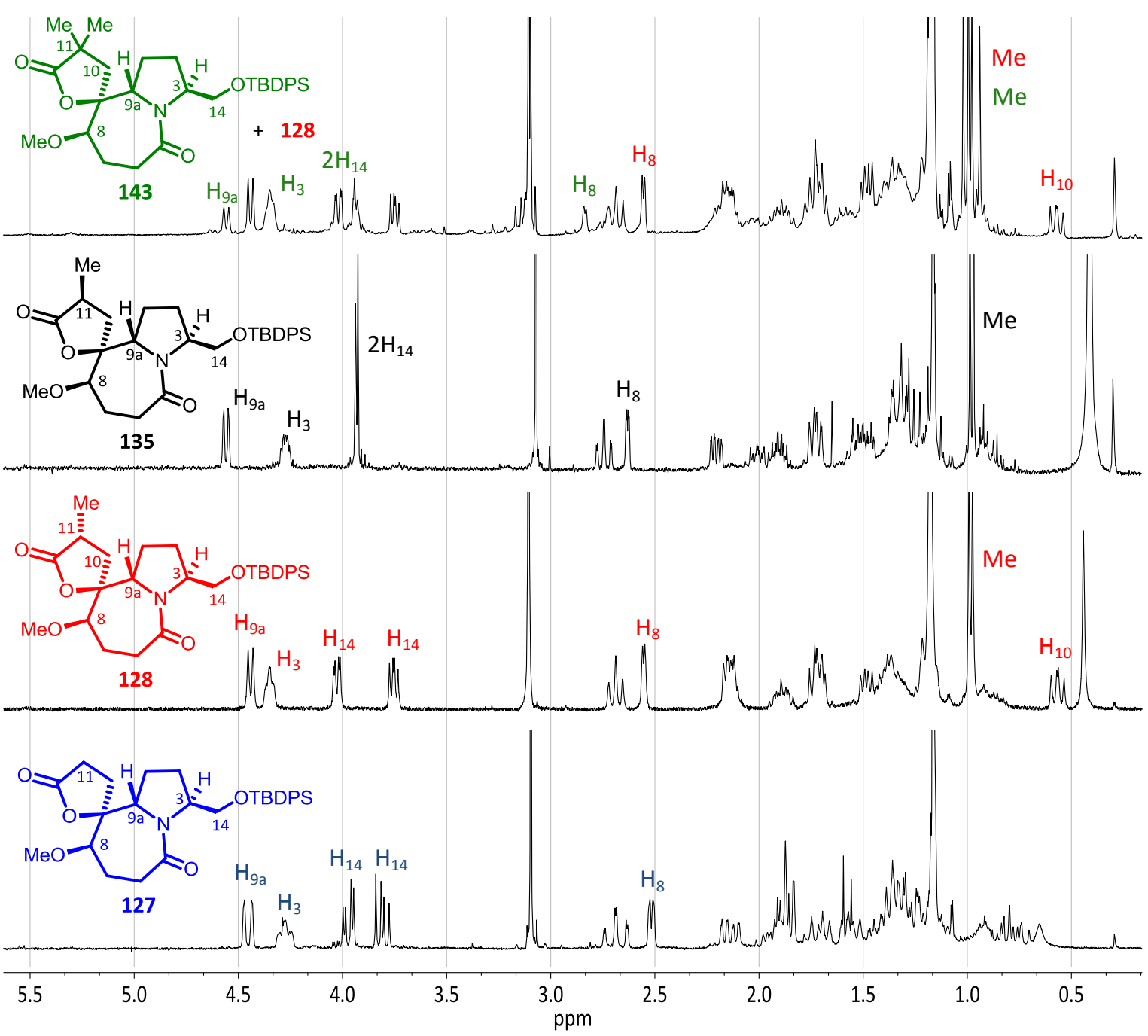

Figure 20. Comparison of the ${ }^{1} \mathrm{H}-\mathrm{NMR}$ spectra $\left(250 \mathrm{MHz}, \mathrm{C}_{6} \mathrm{D}_{6}\right)$ of lactones $127,128,143$ and an unseparable mixture of $\mathbf{1 2 8}$ and 143.

\subsubsection{Construction of the east-side lactone. Syntheses of 146 and $\mathbf{1 4 7}$}

Once the key methylation step was successfully solved, the eastern lactone should be constructed. The planed transformations are depicted in Scheme 61. 


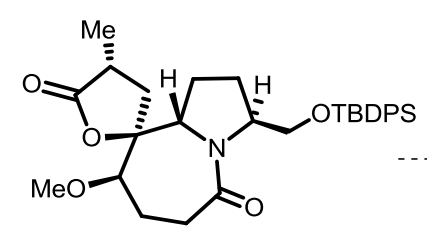

128<smiles>COC1CCC(=O)N2C(CO)CCC23C[C@H](O)C(=O)O[C@]13C</smiles>

144

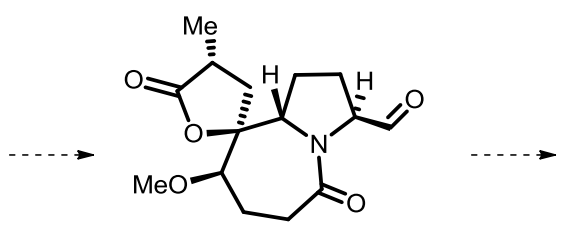

145

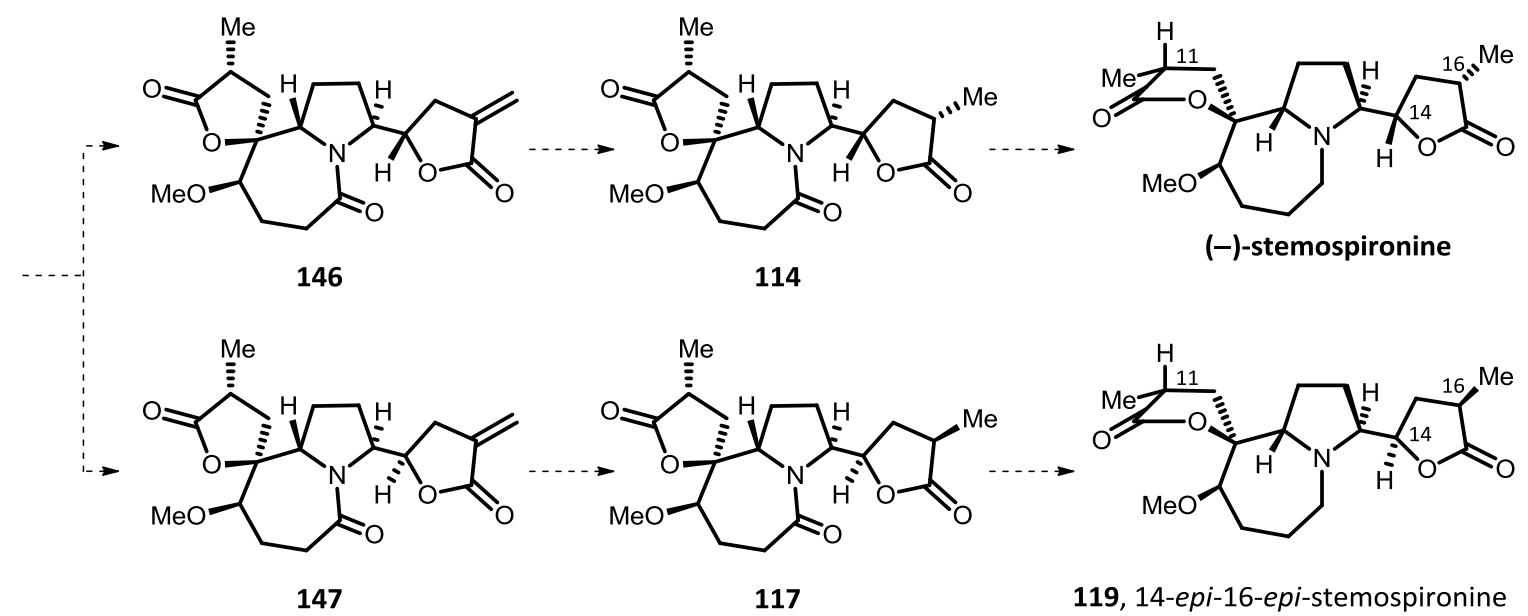

Scheme 61. Devised plan for the syntheses of stemospironine and 14-epi-16-epi-stemospironine, 119.

The syntheses of (-)-stemospironine and 14-epi-16-epi-stemospironine, 119, were completed using the previously established protocols during the syntheses of the other analogs of the natural alkaloid, 116 and $\mathbf{1 2 0}$.

Thus, silyl group removal in lactone $\mathbf{1 2 8}$ was accomplished by treatment with $\mathrm{Et}_{3} \mathrm{~N} \cdot 3 \mathrm{HF}$ in THF in $85 \%$ yield, and subsequent oxidation with Dess-Martin periodinane delivered aldehyde 145 in 83\% yield (Scheme 62). The formation of 145 was evidenced by the appearance of the characteristic doublet at $9.45 \mathrm{ppm}$ in its ${ }^{1} \mathrm{H}-\mathrm{NMR}$ spectrum and a signal at $197.2 \mathrm{ppm}$ in its ${ }^{13} \mathrm{C}$ NMR spectrum, both corresponding to the new aldehyde moiety.

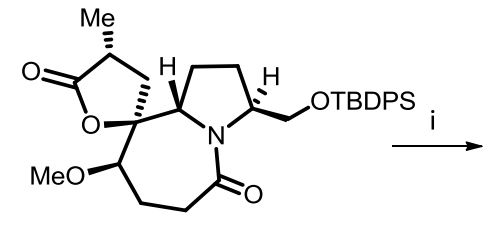

128

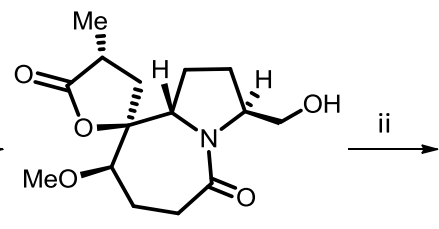

144

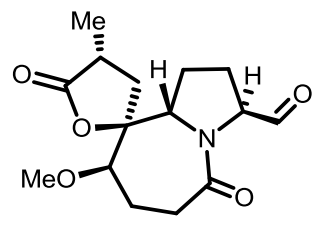

145

Reagents and conditions: (i) $\mathrm{Et}_{3} \mathrm{~N} \cdot 3 \mathrm{HF}$, THF, reflux, $4 \mathrm{~h}$ (85\%); (ii) Dess-Martin periodinane, $\mathrm{CH}_{2} \mathrm{Cl}_{2}, 2 \mathrm{~h}(83 \%$ ).

Scheme 62. Preparation of alcohol 144 and further oxidation to aldehyde 145. 
As expected, the reaction of aldehyde 145 with ethyl bromomethylacrylate, 61, and activated zinc ${ }^{51,55}$ furnished a mixture of the threo, 146, and erythro, 147, epimers in a roughly 1:1 ratio and excellent overall yield of $91 \%$ (Scheme 63). The two isomers were separable by flash column chromatography, and their stereochemical assignment was confirmed by their further conversion to the targeted alkaloids.

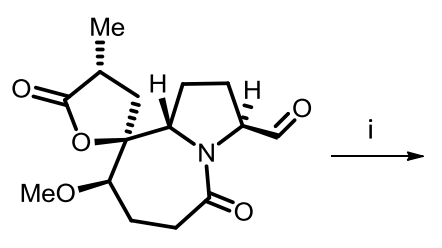

145

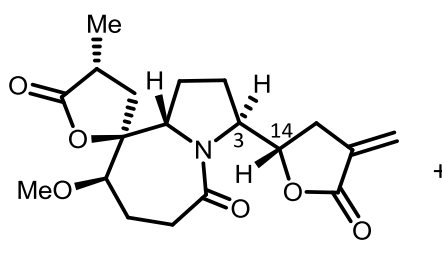

146

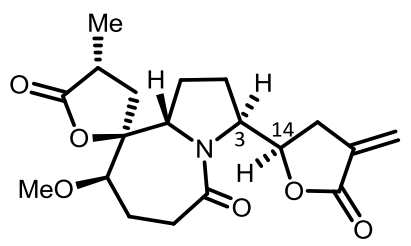

147

Reagents and conditions: (i) 61, Zn, THF, reflux, 1 h (91\%) 146:147 1:1.

Scheme 63. Reformatsky-type reaction performed for the preparation of bislactones 146 and 147.

The formation of $\mathbf{1 4 6}$ and $\mathbf{1 4 7}$ was clearly evidenced by the appearance of the two olefinic signals on their ${ }^{1} \mathrm{H}-\mathrm{NMR}$ spectra around $6.2 \mathrm{ppm}$ and $5.6 \mathrm{ppm}$. Proton $\mathrm{H}_{3}$ in bislactone 146 experienced a deshielding compared to that of the erythro isomer, while the opposite occurred with proton $\mathrm{H}_{14}$.

\subsubsection{Hydrogenation of the eastern lactone. Syntheses of 114 and 117}

Next, the bislactones 146 and 147 were separately submitted to hydrogenation, at atmospheric pressure in the presence of $\mathrm{Pd} / \mathrm{C}$ in ethanol (Scheme 64). Again, hydrogenation of the eastern lactone occurred in a stereoselective manner through the less hindered face, leading to a cis relationship of the substituents of the ring. Thus, a single saturated isomer was obtained from each bislactone in very good yields. 


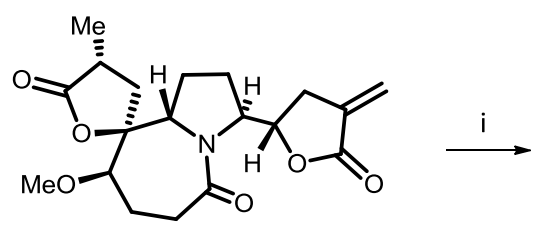

146

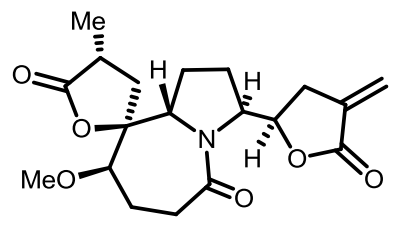

147<smiles>COC1CCC(=O)N2C(C3C[C@H](C)C(=O)O3)CC[C@@]23C[C@H](C)C(=O)O[C@]13C</smiles>

114

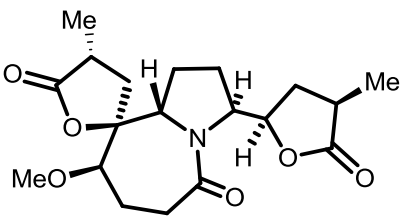

117

Reagents and conditions: (i) $\mathrm{H}_{2}$ (1 atm), $\mathrm{Pd} / \mathrm{C}, \mathrm{EtOH}, 4 \mathrm{~h}$ (quant.); (ii) $\mathrm{H}_{2}(1 \mathrm{~atm}), \mathrm{Pd} / \mathrm{C}, \mathrm{EtOH}, 4 \mathrm{~h}(94 \%)$.

Scheme 64. Catalytic hydrogenation of bislactones 146 and 147.

The ${ }^{1} \mathrm{H}-\mathrm{NMR}$ spectra of both compounds $\mathbf{1 1 4}$ and $\mathbf{1 1 7}$ do not present any olefinic signals and, compared to their precursors, one can observe the appearance of a new doublet around 1.2 ppm corresponding to the new methyl group.

\subsubsection{Reduction of the lactam functionality. Syntheses of (-)-stemospironine and 14-epi-16-} epi-stemospironine, 119

To complete the synthesis, lactams $\mathbf{1 1 4}$ and $\mathbf{1 1 7}$ were deoxygenated via the corresponding thiolactams 148 and $\mathbf{1 4 9}$, respectively (Scheme 65).

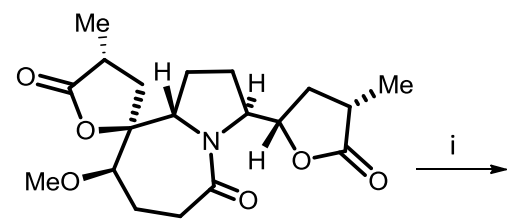

114

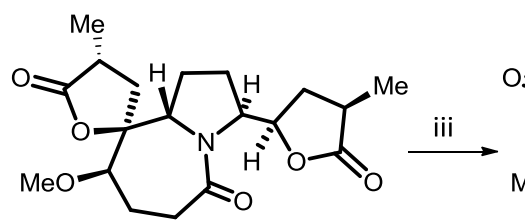

117

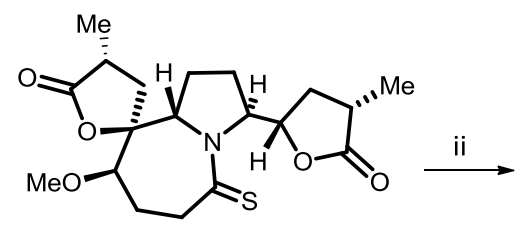

148<smiles>COC1CCC(=S)N2C([C@H]3CC(C)C(=O)O3)CCC23C[C@@H](C)C(=O)O[C@]13C</smiles>

149

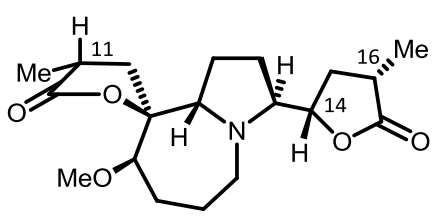

(-)-stemospironine

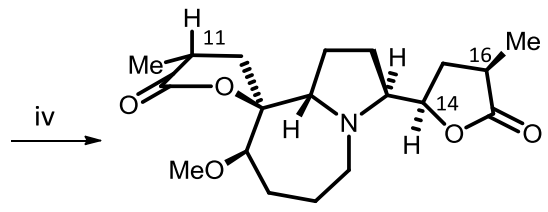

119, 14-epi-16-epi-stemospironine

Reagents and conditions: (i) Lawesson's reagent, THF, reflux, 45 min; (ii) Raney-Ni, EtOH, reflux, $1 \mathrm{~h}$ (54\% yield, 2 steps); (iii) Lawesson's reagent, THF, reflux, 45 min; (iv) Raney-Ni, EtOH, reflux, 1 h (52\% yield, 2 steps).

Scheme 65. Syntheses of stemospironine and 14-epi-16-epi-stemopsironine, 119. 
Hence, bislactone $\mathbf{1 1 4}$ was treated with Lawesson's reagent in refluxing THF to render thiolactam 148. As previously observed for thiolactam 122, protons $\mathrm{H}_{14}, \mathrm{H}_{9 a}$ and $\mathrm{H}_{3}$ experienced a considerable deshielding of approximately 0.5 ppm compared to those of $\mathbf{1 1 4}$ (Figure 21). Further treatment with Raney- $\mathrm{Ni}$ in ethanol at the reflux temperature afforded stemospironine in $54 \%$ yield for the two steps. Therefore, we synthesized the alkaloid in 17 steps, starting from nitrone 49, in $2.1 \%$ overall yield. The analytical data of our synthetic stemospironine including optical rotation, $[\alpha]_{D}^{20}=-8.6\left(c 0.23, \mathrm{CHCl}_{3}\right)$, are in total agreement with those described for the natural alkaloid, $[\alpha]_{D}{ }^{27}=-8.2\left(c 0.92, \mathrm{CHCl}_{3}\right) .{ }^{11}$

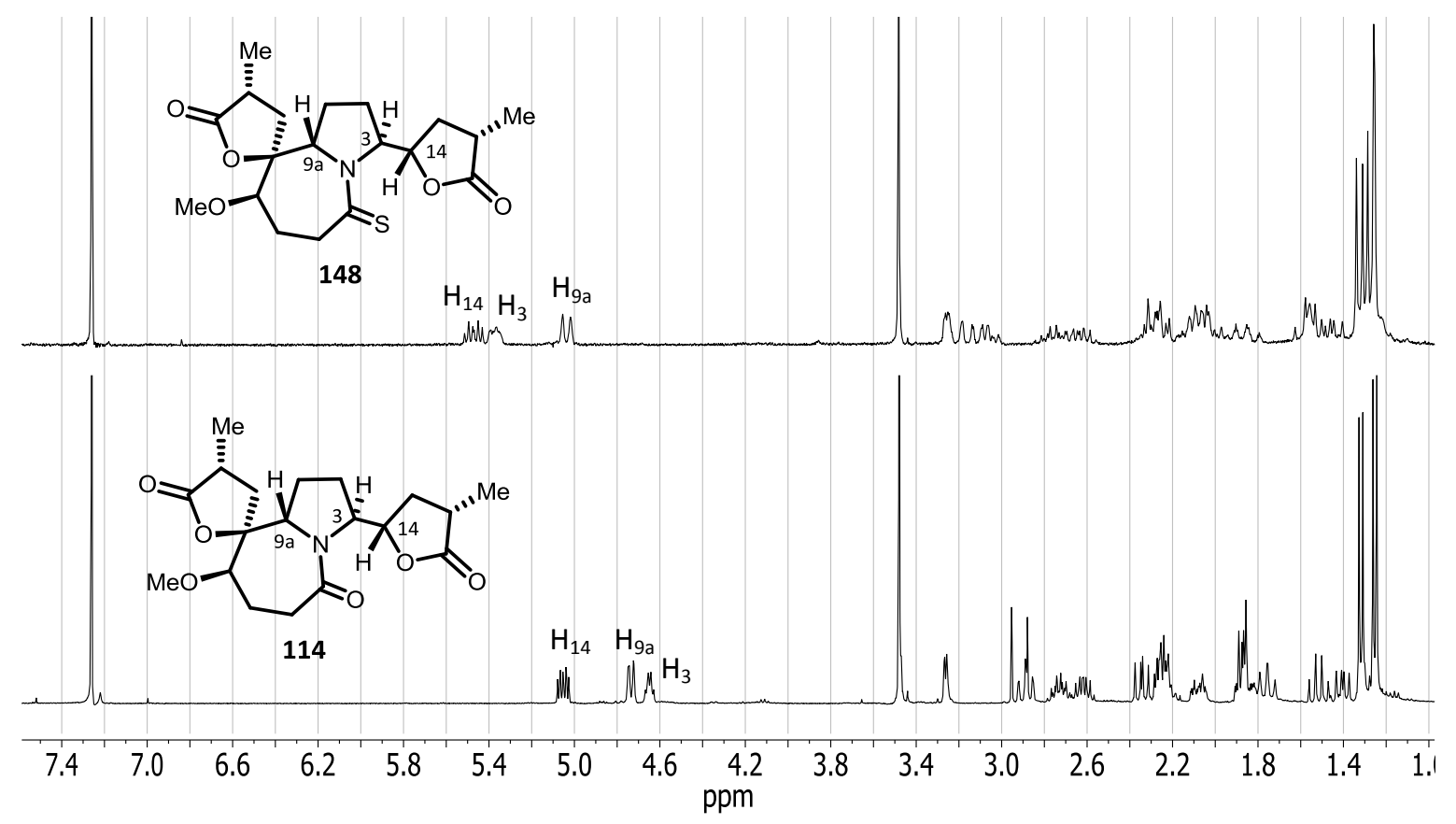

Figure 21. Comparison of the ${ }^{1} \mathrm{H}-\mathrm{NMR}$ spectra $\left(400 \mathrm{MHz}, \mathrm{CDCl}_{3}\right.$ ) of bislactone 114 and thiolactam 148.

We wanted to compare the ${ }^{1} \mathrm{H}-\mathrm{NMR}$ data of stemospironine with that of the isolated natural alkaloid. However, in the literature ${ }^{11}$ only a few characteristic signals were described. Accordingly, this comparison was made with the ${ }^{1} \mathrm{H}-\mathrm{NMR}$ data provided by Williams and coworkers. ${ }^{27 a}$ Figure 22 shows the perfect matching between the ${ }^{1} \mathrm{H}$-NMR spectrum of the stemospironine synthesized by Williams (a), and the one synthesized in this thesis (b). ${ }^{27 b}$ Likewise, the comparison in Table 5 for the ${ }^{13} \mathrm{C}$-NMR data published for the natural alkaloid ${ }^{11}$ and the corresponding ${ }^{13} \mathrm{C}-\mathrm{NMR}$ data that we have obtained for the synthetic stemospironine exhibits a perfect correlation. 

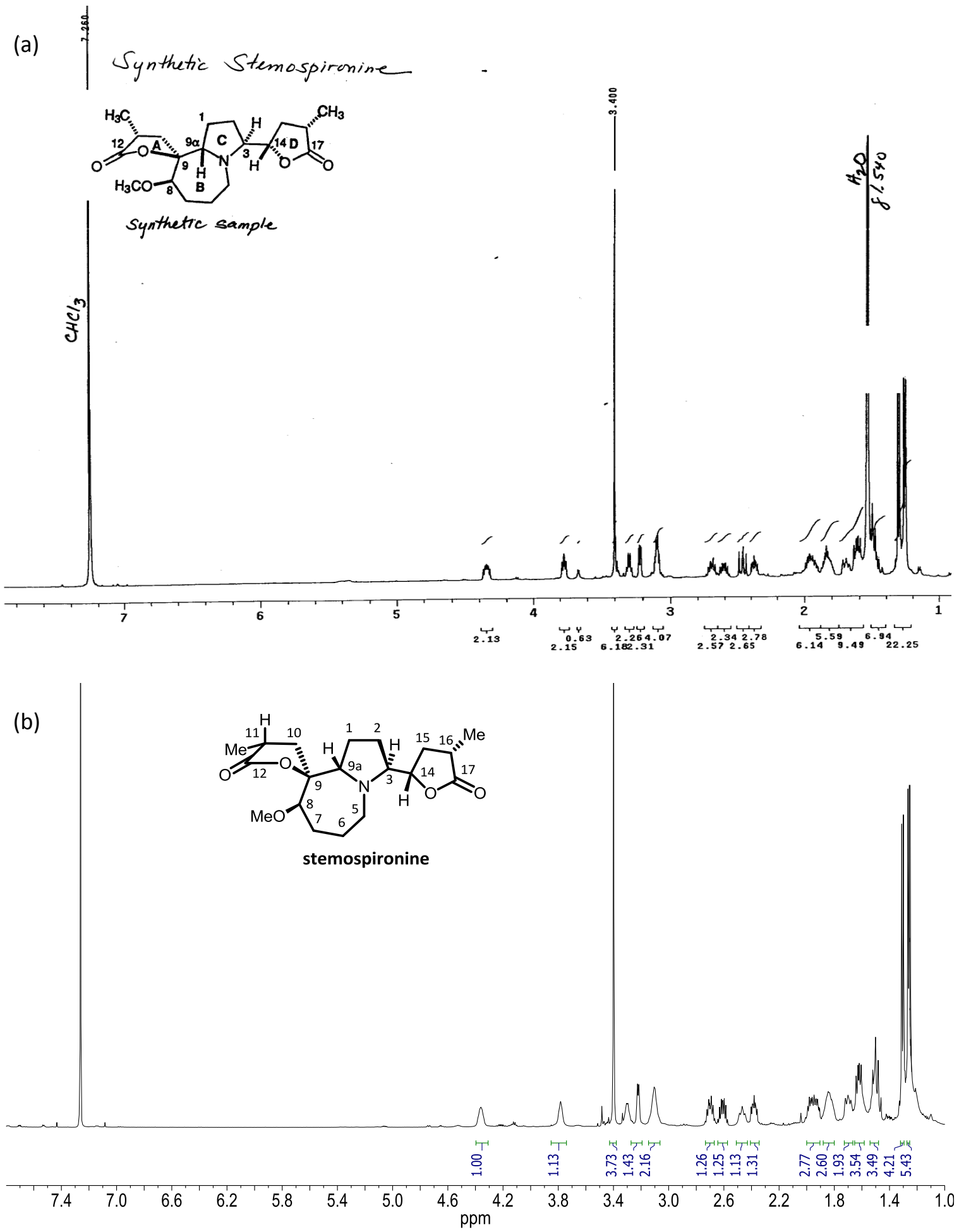

Figure 22. ${ }^{1} \mathrm{H}-\mathrm{NMR}$ spectrum of synthetic stemospironine: (a) prepared by Williams and co-workers (500 $\left.\mathrm{MHz}, \mathrm{CDCl}_{3}\right){ }^{27 \mathrm{a}}$ (b) prepared in this thesis $\left(600 \mathrm{MHz}, \mathrm{CDCl}_{3}\right) .{ }^{27 \mathrm{~b}}$ 
Table 5. Comparison of ${ }^{13} \mathrm{C}-\mathrm{NMR}$ data of isolated stemospironine ${ }^{11}$ and the one prepared in this thesis. ${ }^{27 \mathrm{~b}}$

\begin{tabular}{|c|c|c|}
\hline$C_{n}$ & stemospironine $^{11}$ & synthetic stemospironine ${ }^{27 b}$ \\
\hline $\mathrm{C}_{12}+\mathrm{C}_{17}$ & $179.5(2)$ & $179.5(2)$ \\
\hline $\mathrm{C}_{9}$ & 90.5 & 90.6 \\
\hline $\mathrm{C}_{8}$ & 85.2 & 85.4 \\
\hline $\mathrm{C}_{14}$ & 80.0 & 80.1 \\
\hline $\mathrm{C}_{9 \mathrm{a}}$ & 67.7 & 67.9 \\
\hline $\mathrm{C}_{3}$ & 63.1 & 63.2 \\
\hline $\mathrm{OCH}_{3}$ & 58.0 & 58.2 \\
\hline \multirow[t]{2}{*}{$\mathrm{C}_{5}$} & 48.9 & 49.0 \\
\hline & 35.7 & 35.8 \\
\hline \multirow[t]{4}{*}{$\mathrm{C}_{11} / \mathrm{C}_{16} / \mathrm{C}_{10} / \mathrm{C}_{15}$} & 35.0 & 35.3 \\
\hline & 35.0 & 35.1 \\
\hline & 34.6 & 34.7 \\
\hline & 27.0 & 27.2 \\
\hline \multirow[t]{3}{*}{$\mathrm{C}_{1} / \mathrm{C}_{2} / \mathrm{C}_{6} / \mathrm{C}_{7}$} & 26.5 & 26.7 \\
\hline & 25.7 & 25.8 \\
\hline & 22.4 & 22.4 \\
\hline $\mathrm{CH}_{3}$ & 17.5 & 17.7 \\
\hline $\mathrm{CH}_{3}$ & 14.8 & 15.0 \\
\hline
\end{tabular}

${ }^{13} \mathrm{C}-\mathrm{NMR}$ experiments performed in $\mathrm{CDCl}_{3}$, a) $100 \mathrm{MHz}$, b) $150 \mathrm{MHz}$. $\delta$ values in ppm.

On the other hand, bislactone $\mathbf{1 1 7}$ was also treated with Lawesson's reagent in THF at the reflux temperature to yield thiolactam 149 , which was subsequently submitted to reduction with Raney-Ni (Scheme 68). Thus, we obtained 14-epi-16-epi-stemospironine, 119, in 52\% yield for the two steps. Hence, $\mathbf{1 1 9}$ was prepared in 17 steps starting from nitrone $\mathbf{4 9}$ in a $2.0 \%$ overall yield. On its ${ }^{1} \mathrm{H}-\mathrm{NMR}$ (Figure 23) we can observe that protons $\mathrm{H}_{14}, \mathrm{H}_{9 a}$ and $\mathrm{H}_{3}$ suffered a significant shielding compared to the precursor lactam. Proton $\mathrm{H}_{14}$ moved from 5.02 in $\mathbf{1 1 7}$ to $4.52 \mathrm{ppm}$ in 119, proton $\mathrm{H}_{9 a}$ from 4.80 to $3.77 \mathrm{ppm}$, and proton $\mathrm{H}_{3}$ from 4.35 to $3.38 \mathrm{ppm}$. This is in agreement with the conversion of the lactam to amine. 


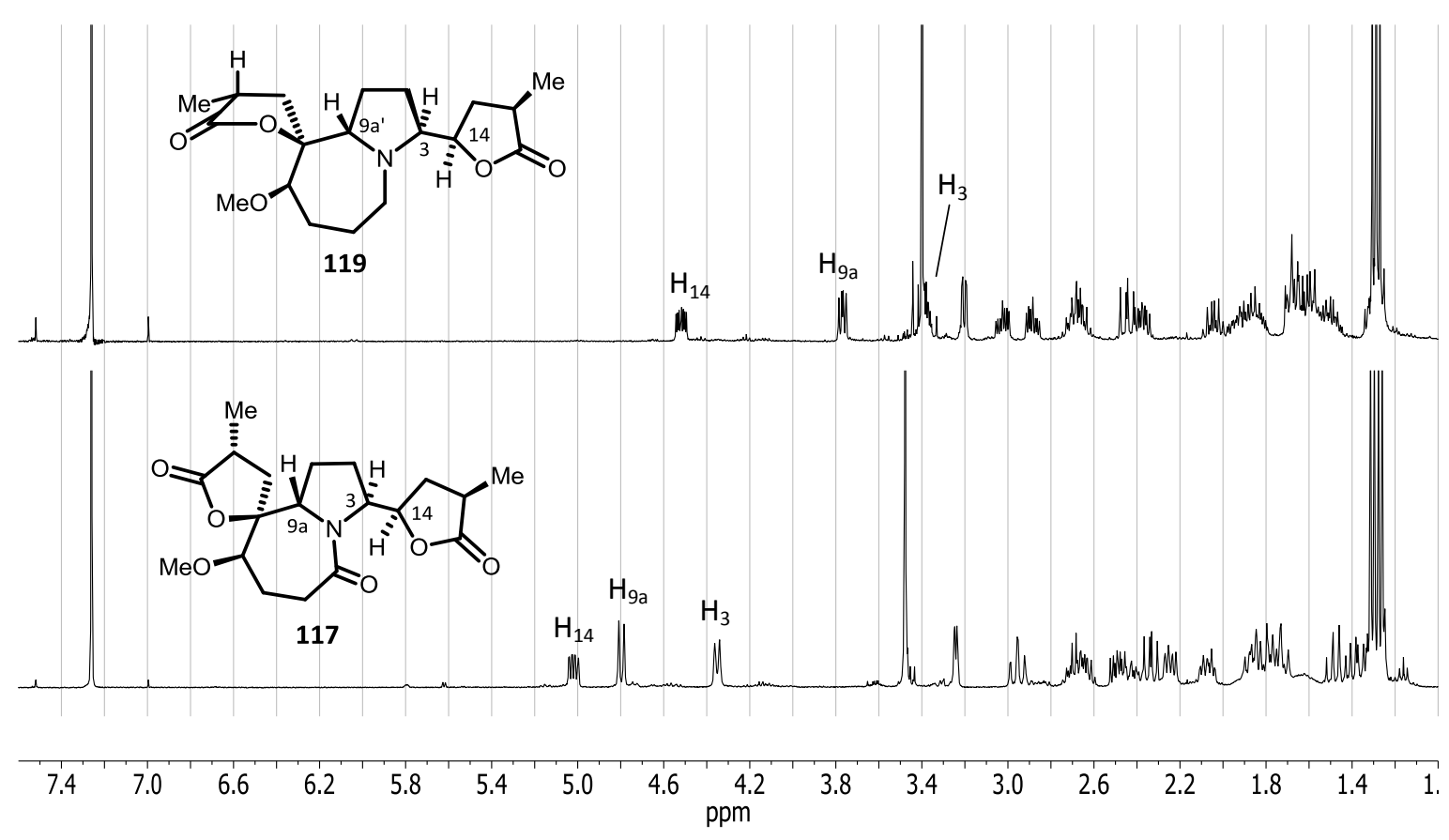

Figure 23. Comparison of the ${ }^{1} \mathrm{H}-\mathrm{NMR}$ spectra (400 MHz, $\mathrm{CDCl}_{3}$ ) of lactam 117 and 14-epi-16-epistemospironine, 119.

Thus, by means of this tactical modification consisting on introducing the methyl group of the west-side lactone in a later step of the sequence, we were able to synthesize stemospironine and its analog 14-epi-16-epi-stemospironine, 119, completing a series of four different stereoisomers. Stemospironine was synthesized in 17 steps starting from nitrone $\mathbf{4 9}$ and $2.1 \%$ overall yield, which is a considerable improvement if we compare it with the previous synthesis performed by Williams and co-workers in 2001, ${ }^{27 a}$ that featured 27 steps starting from ketone 23 and $0.3 \%$ overall yield (Scheme 66 ).

If we make a more detailed analysis of William's synthesis of stemospironine, we can observe that they used four chiral pool materials to induce the stereochemistry. Chirality at $\mathrm{C}_{8}$ was introduced via Midland reduction of the conjugated ynone $\mathbf{2 3}$ with $(R)$-alpine borane, leading to 24 in $88 \%$ ee. The configurations of the stereogenic centers at $C_{11}$ and $C_{16}$ were controlled by the use of $\mathbf{3 5}$ and $\mathbf{3 4}$, whose syntheses from commercial materials required several steps, to elaborate the corresponding fragments of the "west"- and "east"-side lactones, respectively. The relative configurations at $C_{9}$ and $C_{9 a}$ were established by means of a highly diastereoselective Sharpless epoxidation ( $80 \%$ de) of the allylic alcohol 26. Configuration at $C_{3}$ and $C_{14}$ was induced through an impressive iodine-induced double cyclization reaction, but even though it was 
reproducible, it had low yield (30\%). As it was commented in the Introduction section, in this synthesis the azabicyclic core was prepared from an advanced intermediate (in fact, in the last step) containing all the stereocenters and specifically assembled for the target alkaloid stemospironine.
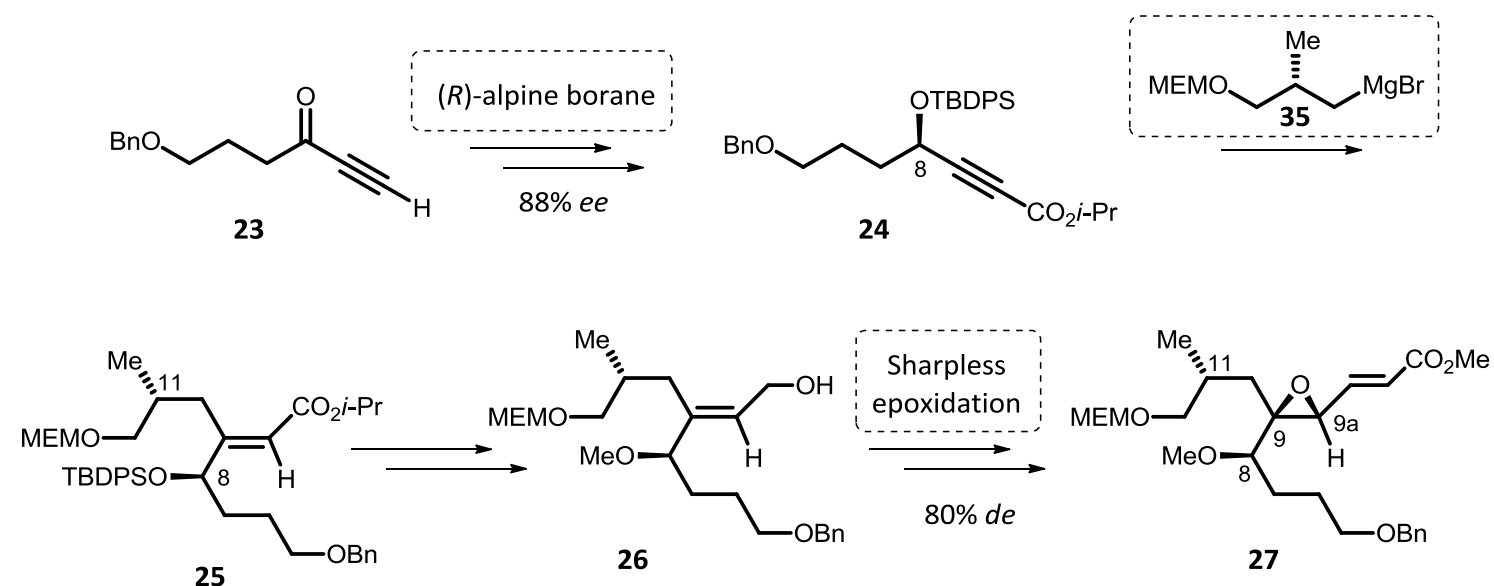

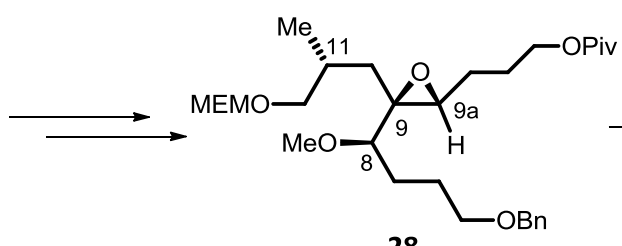

28
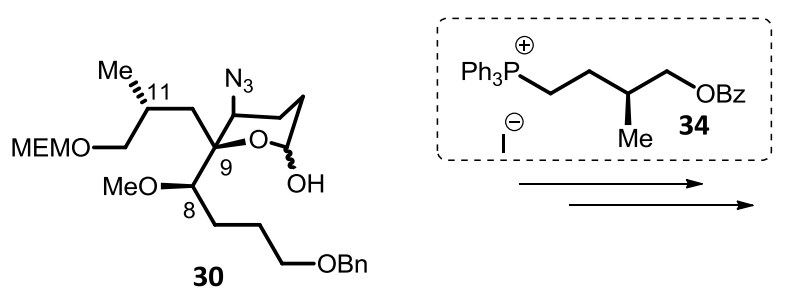
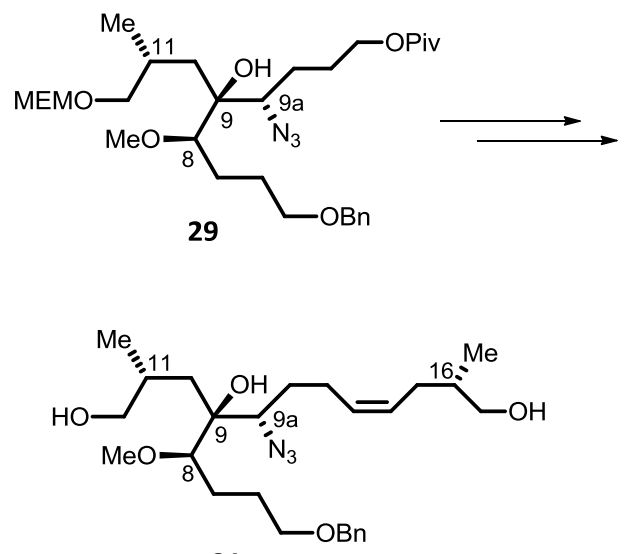

31
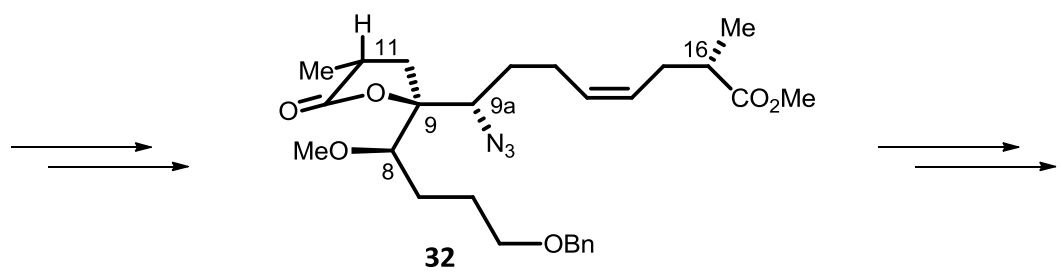

32

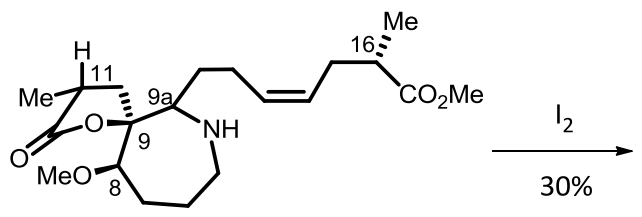

33

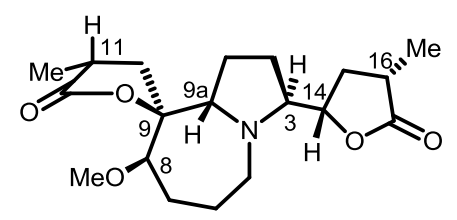

(-)-stemospironine

Scheme 66. Williams' strategy for the synthesis of (-)-stemospironine. ${ }^{27 a}$ 
Conversely, in our syntheses of stemospironine and analogs (Scheme 67), ${ }^{27 b}$ the azabicyclic core was generated at an early stage of the sequence, and the butyrolactone motifs and other specific fragments were incorporated later. In this way, we developed a very flexible approach, with some intermediates being common precursors for various alkaloids of the family. The starting material was a chiral pool compound derived from L-proline, establishing the configuration at $C_{3}$ that remained unchanged throughout the entire synthetic route. The stereochemistry in the other centers was induced by the substrate involved in each individual step. Thus, the configuration of the stereocenter at $C_{9 a}$ was mainly secured via a highly regio- and stereoselective 1,3-dipolar cycloaddition between nitrone $\mathbf{4 9}$ and alkene $\mathbf{5 0}$ to afford $\mathbf{5 1}$ as a sole product; and the sense of chirality in $C_{8}$ and $C_{9}$ was induced via a totally diastereoselective dihydroxylation of olefin $\mathbf{7 7}$. On the other hand, the relative configuration at $C_{11}$ was introduced via a diastereoselective methylation of lactone 127 , and the chirality in $C_{16}$ was induced via a selective hydrogenation of the advanced intermediate 146 . However, the configuration of $\mathrm{C}_{14}$ could not be selectively generated because the Reformatsky-type reaction of aldehyde $\mathbf{1 4 5}$ with bromoacrylate $\mathbf{6 1}$ is not stereoselective. 

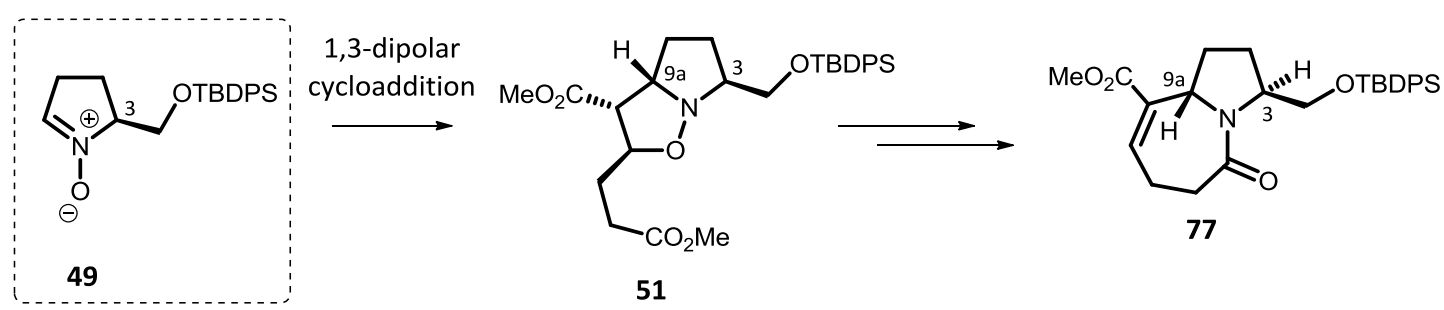

51

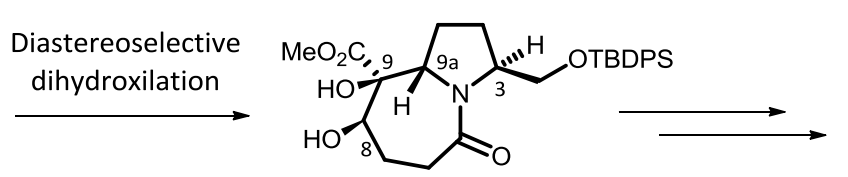

78

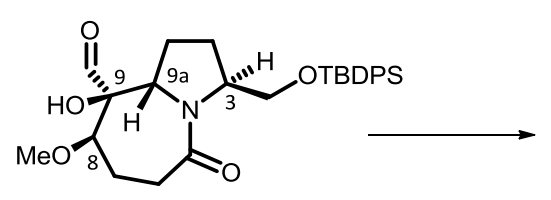

62

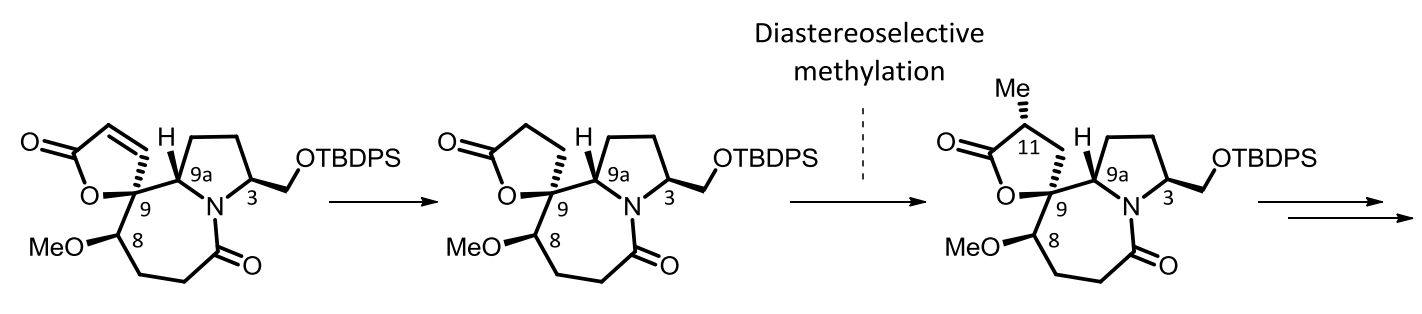

126

127

128

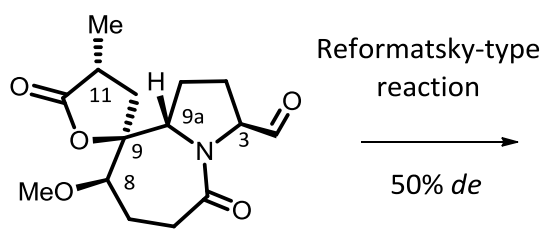

145

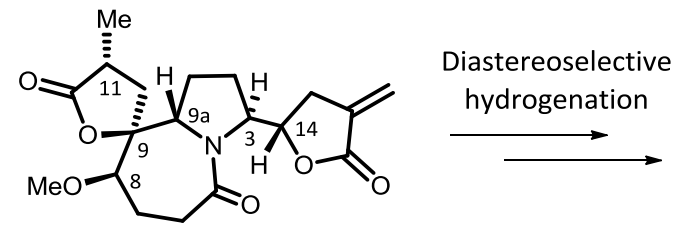

146

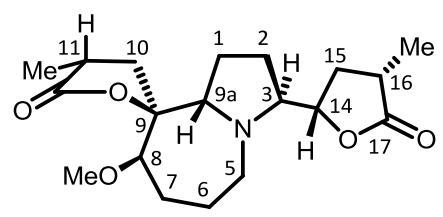

(-)-stemospironine

Scheme 67. Our strategy for the synthesis of (-)-stemospironine. ${ }^{27 b}$

Taking everything into account, we have accomplished the syntheses of stemospironine and three additional diastereoisomers 11-epi-stemospironine, 116, 11-epi-14-epi-16-epistemospironine, 120, and 14-epi-16-epi-stemospironine, 119, through a flexible strategy that allows the preparation of different Stemona alkaloids. The configuration of the stereogenic center at $\mathrm{C}_{11}$ has been totally controlled by a fine-tunning of the synthetic pathway.

Table 6 shows the ${ }^{13} \mathrm{C}-\mathrm{NMR}$ data of stemospironine and its three analogs 116, 119, and 120. The most significant differences between them are that the carbon atoms $C_{8}$ and $C_{5}$ are downfield shifted in stemospironine and $\mathbf{1 1 9}$ compared to $\mathbf{1 2 0}$ and $\mathbf{1 1 6 .}$ 
Table 6. Comparison of the ${ }^{13} \mathrm{C}-\mathrm{NMR}$ data of stemospironine, 11-epi-stemospironine, 116, 11-epi-14-epi-16epi-stemospironine, 120 , and 14-epi-16-epi-stemospironine, $119 .^{27 \mathrm{~b}}$

\begin{tabular}{|c|c|c|c|c|}
\hline$C_{n}$ & Stemospironine ${ }^{a}$ & $\begin{array}{c}\text { 14-epi-16-epi- } \\
\text { stemospironine, } \\
120^{b}\end{array}$ & $\begin{array}{c}\text { 11-epi-14-epi-16- } \\
\text { epi-stemospironine, } \\
121^{\mathrm{b}}\end{array}$ & $\begin{array}{c}\text { 11-epi- } \\
\text { stemospironine, } \\
117^{b}\end{array}$ \\
\hline $\mathrm{C}_{12} / \mathrm{C}_{17}$ & $179.5(2)$ & 179.5 & 180.2 & 180.2 \\
\hline $\mathrm{C}_{12} / \mathrm{C}_{17}$ & & 179.3 & 179.3 & 179.6 \\
\hline$C_{9}$ & 90.6 & 90.4 & 91.3 & 91.6 \\
\hline $\mathrm{C}_{8}$ & 85.4 & 85.5 & 82.9 & 82.8 \\
\hline $\mathrm{C}_{14}$ & 80.1 & 78.6 & 79.2 & 81.4 \\
\hline $\mathrm{C}_{9 \mathrm{a}}$ & 67.9 & 66.1 & 67.4 & 66.7 \\
\hline $\mathrm{C}_{3}$ & 63.2 & 63.6 & 63.5 & 64.8 \\
\hline $\mathrm{OCH}_{3}$ & 58.2 & 58.2 & 57.9 & 57.9 \\
\hline \multirow[t]{2}{*}{$C_{5}$} & 49.0 & 49.1 & 45.9 & 45.9 \\
\hline & 35.8 & 35.8 & 38.0 & 37.5 \\
\hline \multirow[t]{4}{*}{$\mathrm{C}_{11} / \mathrm{C}_{16} / \mathrm{C}_{10} / \mathrm{C}_{15}$} & 35.3 & 35.7 & 35.7 & 35.1 \\
\hline & 35.1 & 35.1 & 35.0 & 35.0 \\
\hline & 34.7 & 33.9 & 33.5 & 34.6 \\
\hline & 27.2 & 27.1 & 27.4 & 27.5 \\
\hline \multirow[t]{3}{*}{$\mathrm{C}_{1} / \mathrm{C}_{2} / \mathrm{C}_{6} / \mathrm{C}_{7}$} & 26.7 & 26.2 & 26.4 & 26.4 \\
\hline & 25.8 & 25.9 & 25.6 & 26.3 \\
\hline & 22.4 & 22.9 & 22.4 & 21.2 \\
\hline $\mathrm{CH}_{3}$ & 17.7 & 17.5 & 16.0 & 16.0 \\
\hline $\mathrm{CH}_{3}$ & 15.0 & 15.3 & 15.3 & 15.0 \\
\hline
\end{tabular}

${ }^{13} \mathrm{C}$-NMR experiments performed in $\mathrm{CDCl}_{3}$, a) $150 \mathrm{MHz}$, b) $100 \mathrm{MHz}$. $\delta$ values in ppm.

This NMR data collection can provide some useful information for further structural elucidations and studies for possible biological activities. 
3. Summary and Conclusions 



\section{Summary and Conclusions}

The work developed in the present thesis is part of a research project that pursues the preparation of a group of compounds known as Stemona alkaloids. In the strategy designed, the azabicyclic core is generated at an early stage of the sequence, with the aim of developing a flexible approach, where some intermediates could be common precursors to various alkaloids.

This approach previously succeeded in culminating the synthesis of stemonidine, ${ }^{38}$ and has now been applied to the preparation of stemospironine and three new analogs 11-epistemospironine, 116, 14-epi-16-epi-stemospironine, 119, and 11-epi-14-epi-16-epistemospironine, 120. Such achievements evidence that our synthetic design is a reliable methodology for the syntheses of these alkaloids.

The first step in the syntheses of stemospironine and its analogs was the 1,3-dipolar cycloaddition between nitrone $\mathbf{4 9}$ and diester $\mathbf{5 0}$ (Scheme 68), followed by reductive cleavage of the $\mathrm{N}-\mathrm{O}$ bond in $\mathbf{5 1}$ and then 7-exo-trig cyclization, furnishing azepinone $\mathbf{5 2}$. Then, dehydration and subsequent diastereoselective dihydroxylation rendered diol $\mathbf{7 8}$, which was regioselectively methylated delivering methyl ether 83. Reduction of $\mathbf{8 3}$ with $\mathrm{LiBH}_{4}$ furnished diol 53, the branching point where the synthetic pathways to stemonidine and stemospironine diverge, depending on the further transformations. Next, alcohol $\mathbf{5 3}$ was oxidized with $\mathrm{N}$ chlorosuccinimide in the presence of TEMPO, providing aldehyde 62 in $91 \%$ yield. Spirolactonization was accomplished by esterification of the tertiary alcohol by reaction with 2(diethoxyphosphoryl)propanoic acid, 88, and dicyclohexylcarbodiimide, followed by basic treatment of the intermediate phosphonate, in $71 \%$ yield. Then, the silyl protection was removed and the primary alcohol was oxidized to the corresponding aldehyde 105, which treated with ethyl bromomethylacrylate, 61, and zinc furnished a 1:1 mixture of bislactones 106 and 107. Hydrogenation of the $\mathrm{C}-\mathrm{C}$ double bonds in 106 and 107, and subsequent deoxygenation of the lactam functionality in each saturated bislactone by treatment with Lawesson's reagent and then Raney-Ni, provided 11-epi-stemospironine, 116, and 11-epi-14-epi-16-epi-stemospironine, 120, respectively. Hence, we obtained the stemospironine analogs $\mathbf{1 1 6}$ and $\mathbf{1 2 0}$ in 15 steps starting from nitrone 49 , and $3.0 \%$ and $3.3 \%$ overall yield, respectively. 


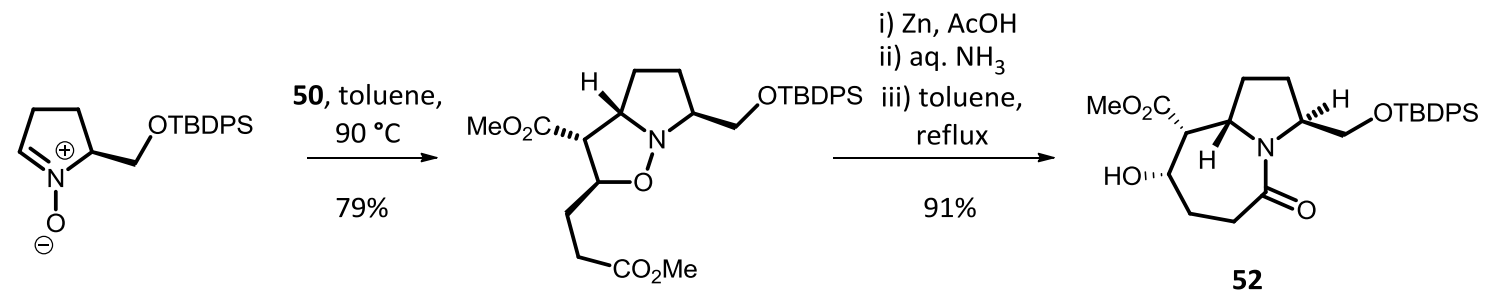

49

51
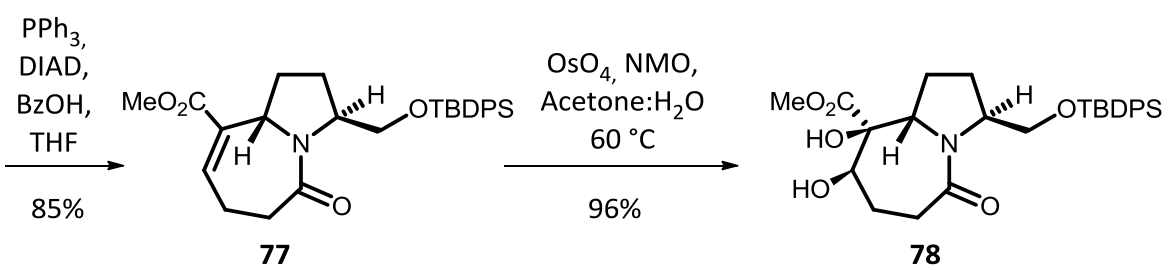

i) $\mathrm{NaH}, \mathrm{THF}, 0^{\circ} \mathrm{C}$

ii) $\mathrm{Me}_{2} \mathrm{SO}_{4}$ $0{ }^{\circ} \mathrm{C}$ to r.t.

$84 \%$

TEMPO, NCS

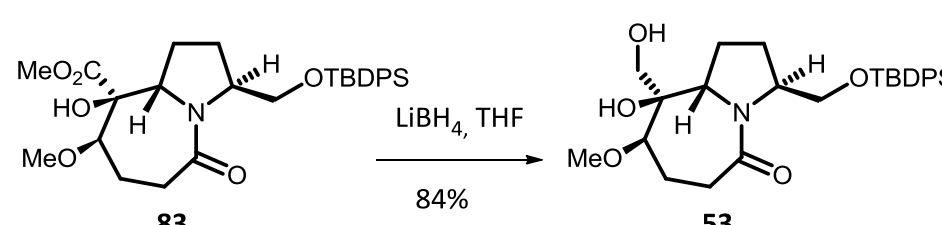

83

53

$\mathrm{TBACl}, \mathrm{K}_{2} \mathrm{CO}_{3}$,

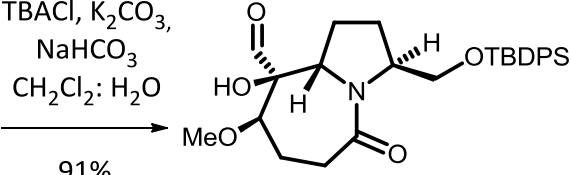

62

i) $88, \mathrm{DCC}, \mathrm{CH}_{2} \mathrm{Cl}_{2}$

ii) ${ }^{\mathrm{t}} \mathrm{BuOK}, \mathrm{THF}$, reflux

$71 \%$ (2 steps)

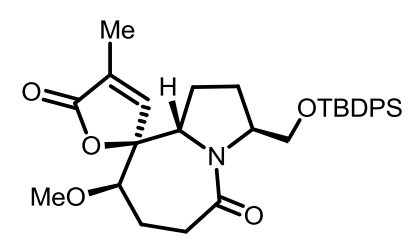

63

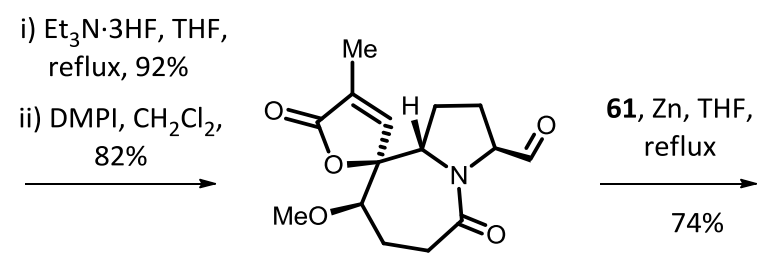

105

i) $\mathrm{H}_{2}$ (1 atm), Pd/C, EtOH: $\mathrm{HCl}$, $81 \%$

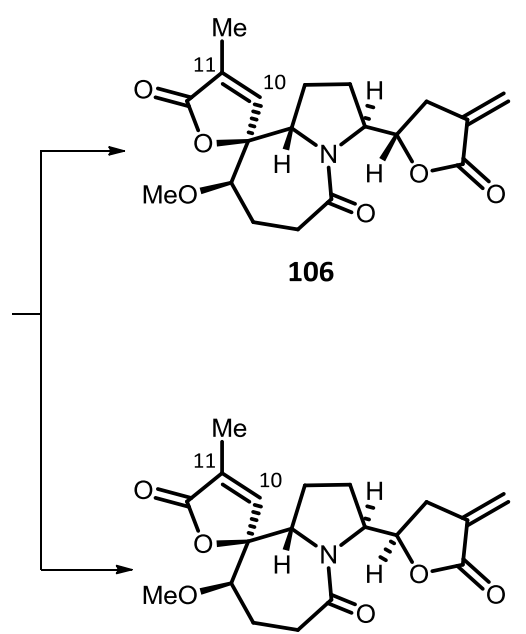

107

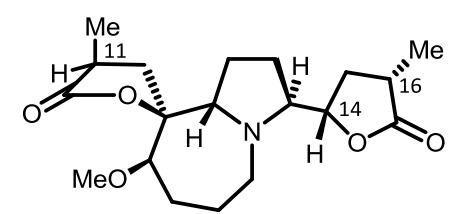

116, 11-epi-stemospironine

i) $\mathrm{H}_{2}(1 \mathrm{~atm}), \mathrm{Pd} / \mathrm{C}, \mathrm{EtOH}: \mathrm{HCl}$,

$84 \%$

ii) Lawesson's r., THF, reflux, $72 \%$

iii) Raney-Ni, EtOH, reflux, $71 \%$

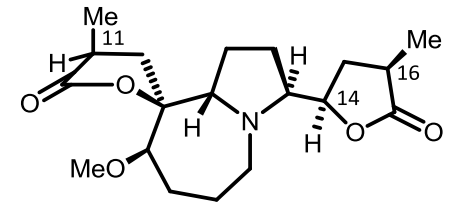

120, 11-epi-14-epi-16-epi-stemospironine

Scheme 68. Synthesis of 11-epi-stemospironine, 116, and 11-epi-14-epi-16-epi-stemospironine, 120. 
In view of the high diastereoselectivity accomplished in the reduction of the $C_{10}-C_{11}$ double bond in intermediates 106 and 107 by the less hindered face, we reasoned that the methylation of an enolate formed by deprotonation of $C_{11}$ should occur with the same facial selectivity, leading to the correct stemospironine-like configuration.

Thus, spirolactonization of aldehyde 62 with diethoxyphosphorylacetic acid, 129, and subsequent basic treatment was studied (Scheme 69). This reaction furnished a mixture of the expected lactone 126 and the undesired Knoevenagel product 130. Although many conditions such as changing the base, temperature and solvent were attempted, this competitive pattern could not be completely inhibited. Fortunately, compound $\mathbf{1 3 0}$ could be reprocessed to $\mathbf{1 2 6}$ by treatment with $\mathrm{MeONa}$ in $\mathrm{MeOH}$, rendering 126 in 53\% overall yield from aldehyde 62. Catalytic hydrogenation furnished lactone 127, which was $\alpha$-methylated with the predicted stereochemistry delivering 128 in 83\% yield (over unrecovered 127). Installation of the east-side lactone was made as before. Hence, the silyl protection was removed to give alcohol 144, which was oxidized with Dess-Martin periodinane to furnish aldehyde 145 in 83\% yield. As expected, reaction of 145 with ethyl bromomethylacrylate, $\mathbf{6 1}$, and zinc yielded a 1:1 mixture of bislactones threo, 146, and erythro, 147 in $91 \%$ combined yield. These bislactones were separately submitted to catalytic hydrogenation and deoxygenation of the lactam functionality via the corresponding thiolactams, rendering stemospironine and 14-epi-16-epi-stemospironine, 119, respectively. Hence, stemospironine and its diastereomeric analog 119 were obtained in 17 steps, starting from nitrone 49 , in $2.1 \%$ overall yield for each one. The analytical data of our synthetic stemospironine including optical rotation, $[\alpha]_{D}{ }^{20}=-8.6\left(c 0.23, \mathrm{CHCl}_{3}\right)$, are in total agreement with those described for the natural alkaloid, $[\alpha]_{D}{ }^{27}=-8.2\left(c 0.92, \mathrm{CHCl}_{3}\right),{ }^{11}$ and a comparison of the ${ }^{1} \mathrm{H}-$ and ${ }^{13} \mathrm{C}-\mathrm{NMR}$ data published in literature with the one we have obtained exhibits also a perfect correlation.

Most of this work has been published in Organic Letters. The corresponding paper ${ }^{27 b}$ is enclosed below. 


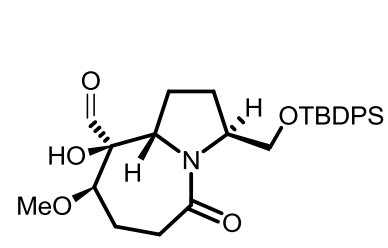

62 i) $129, \mathrm{DCC}, \mathrm{CH}_{2} \mathrm{Cl}_{2}$

ii) ${ }^{\mathrm{B}} \mathrm{BOK}, \mathrm{THF}$, r.t.

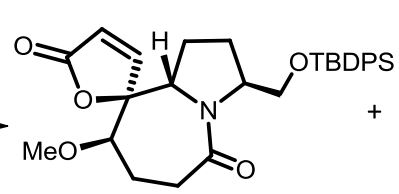

126

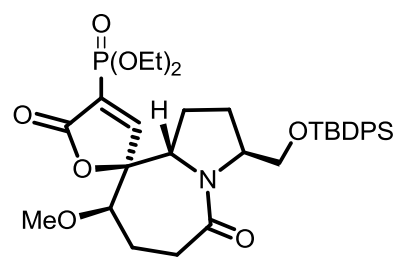

130

$\uparrow \mathrm{MeONa}, \mathrm{MeOH}$

$53 \%$ (overall)

126

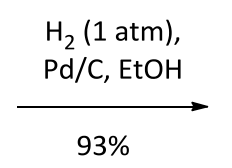

i) LiHMDS, $-78^{\circ} \mathrm{C}$ ii) $\mathrm{Mel}-78^{\circ} \mathrm{C}$

$83 \%$

127

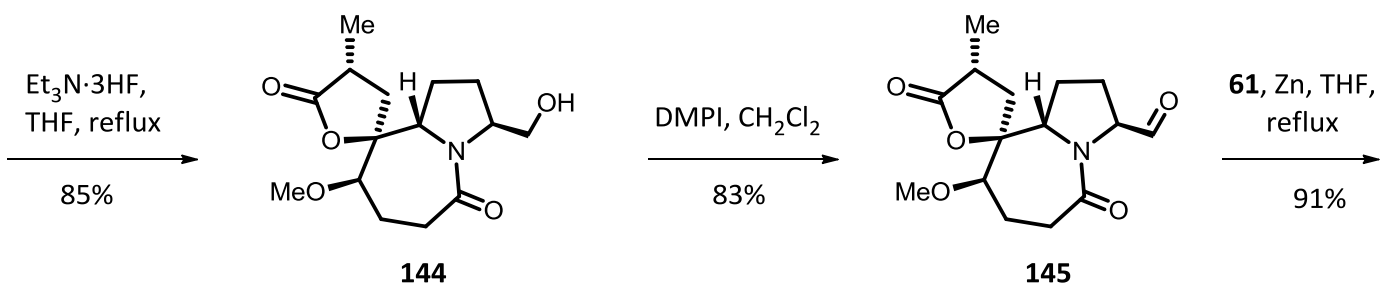

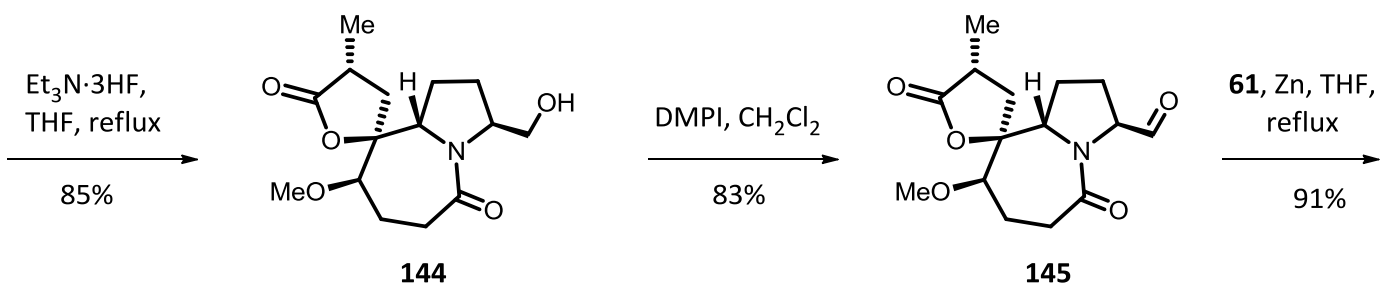

144<smiles>COC1CCC(=O)N2C(CO[Pb])CCC23CC(C)C(=O)O[C@@]13C</smiles>

128

i) $\mathrm{H}_{2}(1 \mathrm{~atm}), \mathrm{Pd} / \mathrm{C}, \mathrm{EtOH}: \mathrm{HCl}$, quant.

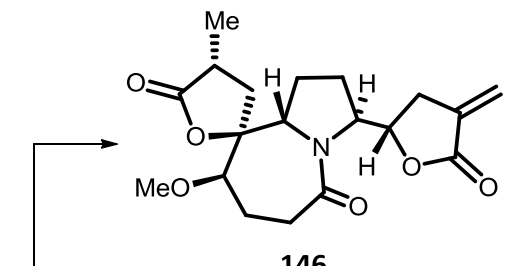

146

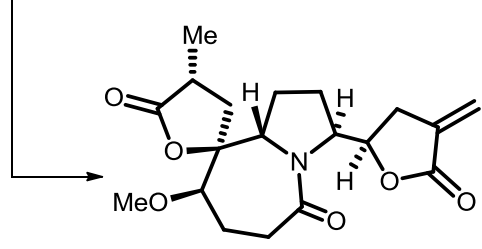

147 ii) Lawesson's r., THF, reflux

iii) Raney-Ni, EtOH, reflux, 54\% (2 steps)

i) $\mathrm{H}_{2}(1 \mathrm{~atm}), \mathrm{Pd} / \mathrm{C}, \mathrm{EtOH}: \mathrm{HCl}$, $94 \%$

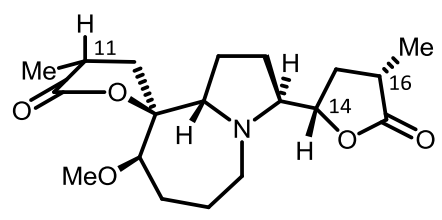

stemospironine

ii) Lawesson's r., THF, reflux

iii) Raney-Ni, EtOH, reflux, $52 \%$ ( 2 steps)

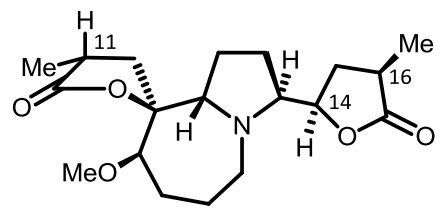

119, 14-epi-16-epi-stemospironine

Scheme 69. Synthesis of stemospironine and 14-epi-16-epi-stemospironine, 119. 


\title{
Flexible Approach to Stemona Alkaloids: Total Syntheses of $(-)$-Stemospironine and Three New Diastereoisomeric Analogs
}

2012

Vol. 14, No. 18

4854-4857

\author{
Nuria Bardají, Francisco Sánchez-lzquierdo, Ramón Alibés, Josep Font, \\ Félix Busqué,* and Marta Figueredo*
}

Universitat Autònoma de Barcelona, Departament de Química, 08193 Bellaterra, Spain

marta.figueredo@uab.es;felix.busque@uab.es

Received August 6, 2012

ABSTRACT
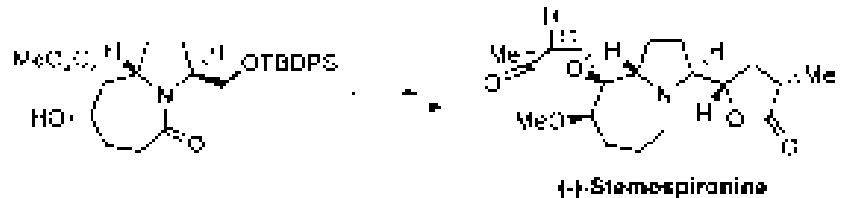

Total syntheses of (-)-stemospironine and three new diastereoisomeric analogs have been completed through a flexible strategy devised for Stemona alkaloids. The azabicycle 7 is the pivotal intermediate, from which the sequence splits according to each particular target. The most remarkable differential feature for stemospironine is the installation of the spiranic $\gamma$-lactone through an intramolecular Horner-WadsworthEmmons olefination. The configuration of the stereogenic center at $\mathrm{C}-11$ was controlled by fine-tuning of the synthetic sequence.

The extracts of several plants of the Stemonaceae family have long been used in East Asian countries for the treatment of respiratory disorders, as antihelmintics, and also as domestic insecticides. Significant constituents of these extracts are a series of structurally related alkaloids that may be responsible for their medicinal and antiparasitic properties, although studies on the specific activity of individual members of this alkaloid family are scarce. ${ }^{1}$

All the Stemona alkaloids are polycyclic and most of them enclose a pyrrolo[1,2- $a$ ]azepine core and one or more $\alpha$-methyl- $\gamma$-butyrolactone units as the most characteristic structural features (Figure 1). Their intricate architectures have motivated the development of imaginative strategies for the construction of their skeletons. ${ }^{2}$ Nevertheless, among the roughly 140 natural Stemona alkaloids currently known, ${ }^{1 \mathrm{a}}$ the reported total syntheses target fewer than 20 members of the family, and in most of them, the azabicyclic skeleton is generated from a quite advanced intermediate, usually with several stereogenic centers, and, therefore, specifically assembled for one particular target.

(1) For comprehensive reviews, see: (a) Pilli, R. A.; Rosso, G. B.; de Oliveira, M. C. F. Nat. Prod. Rep. 2010, 27, 1908. (b) Pilli, R. A.; Rosso, G. B.; de Oliveira, M. C. F. In The Alkaloids; Cordell, G. A., Ed.; Elsevier: New York, 2005; Vol. 62, p 77. (c) Greger, H. Planta Med. 2006, 72, 99.

(2) For a recent review on synthetic strategies to Stemona alkaloids, see: Alibés, R.; Figueredo, M. Eur. J. Org. Chem. 2009, 2421.
Considering the high and continuously increasing number of Stemona alkaloids isolated from natural sources, and the subtle structural differences between some of them, we thought that a flexible synthetic design with some common intermediates was very desirable. Therefore, we devised a strategy in which the azabicyclic core was generated at an early stage of the sequence and the $\gamma$-butyrolactone moieties and other specific fragments were incorporated later (Scheme 1). ${ }^{3}$ We planned the formation of the azabicycle via 1,3-dipolar cycloaddition of a pyrroline $N$-oxide to a suitable olefin, followed by reductive cleavage of the $\mathrm{N}-\mathrm{O}$ bond and then 7-exo-trig cyclization. Previous studies regarding the cycloadditions of nitrones such as $\mathbf{4}$, to electrondeficient olefins of type $\mathbf{3}$, had indicated the relative trans configuration of the stereogenic centers at C-3 and C-9a would be attained as required for the target alkaloids. ${ }^{3 b, 4}$

With respect to their connectivity pattern ${ }^{1 \mathrm{~b}}$ and biogenetic relations, ${ }^{1 \mathrm{c}}$ the Stemona alkaloids have been classified into several groups. The tuberostemospironine group is characterized by the presence of a spiro- $\gamma$-butyrolactone

(3) (a) Cid, P.; Closa, M.; de March, P.; Figueredo, M.; Font, J.; Sanfeliu, E.; Soria, A. Eur. J. Org. Chem. 2004, 4215. (b) Alibés, R.; Blanco, P.; Casas, E.; Closa, M.; de March, P.; Figueredo, M.; Font, J.; Sanfeliu, E.; Álvarez-Larena, A. J. Org. Chem. 2005, 70, 3157.

(4) (a) Closa, M.; de March, P.; Figueredo, M.; Font, J. Tetrahedron: Asymmetry 1997, 8, 1031. (b) Busqué, F.; de March, P.; Figueredo, M.; Font, J.; Gallagher, T.; Milán, S. Tetrahedron: Asymmetry 2002, 13, 437. 

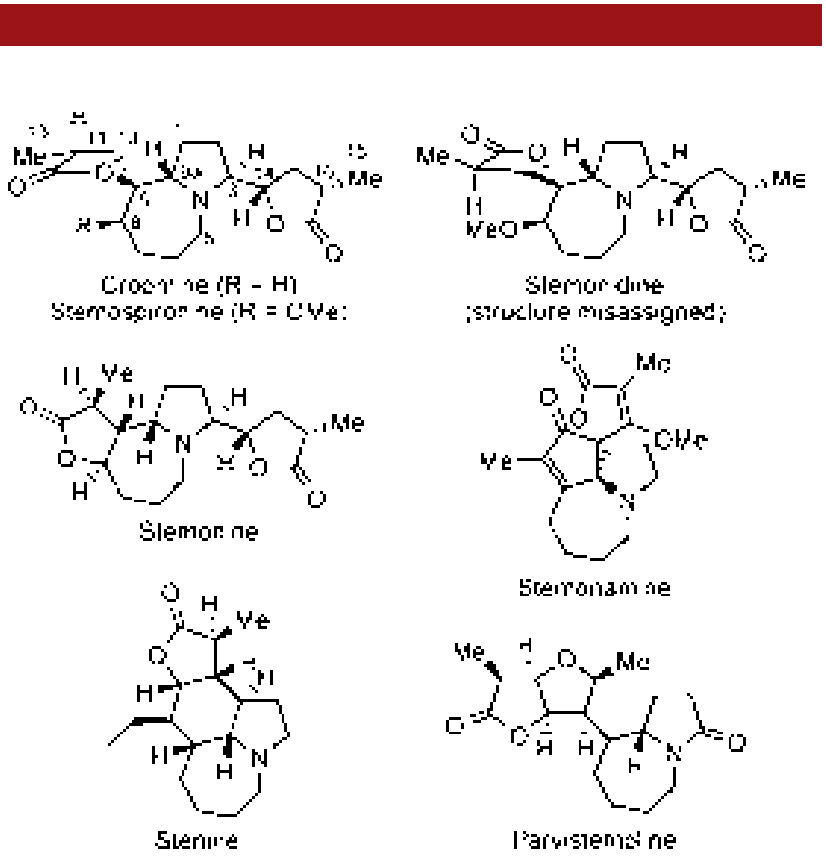

Figure 1. Some representative examples of Stemona alkaloids.

Scheme 1. Retrosynthetic analysis for some Stemona alkaloids

Croorine. Sterrostumine.

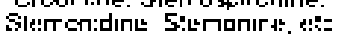

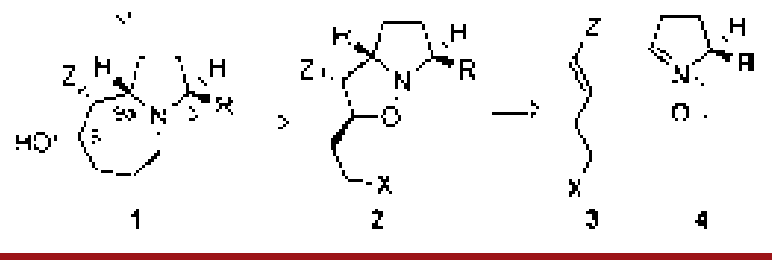

attached to C-9 and includes 12 members. Within this group, only four successful total syntheses have been described to date. The first one (which was also the first described synthesis of any Stemona alkaloid) was that of $(+)$-croomine reported by Williams and co-workers in $1989,{ }^{5}$ through an impressive 24 -step linear sequence, involving the preliminary construction of a branched carbon chain, followed by consecutive ring closures to generate each heterocycle. Some years later, the same group completed, by an analogous pathway, the synthesis of (-)-stemospironine. ${ }^{6}$ A second synthesis of (+)-croomine, starting from L-pyroglutamic acid, was described by Martin and Barr. ${ }^{7}$ We recently described the synthesis of the proposed stemonidine ${ }^{8}$ and, in so-doing, demonstrated that the hypothetical stemonidine was in fact stemospironine, as had been previously suggested. ${ }^{6}$ Starting from

(5) Williams, D. R.; Brown, D. L.; Benbow, J. W. J. Am. Chem. Soc. 1989, 111, 1923.

(6) Williams, D. R.; Fromhold, M. G.; Early, J. D. Org. Lett. 2001, 3, 2721.

(7) Martin, S. F.; Barr, K. J. J. Am. Chem. Soc. 1996, 118, 3299.

(8) Sánchez-Izquierdo, F.; Blanco, P.; Busqué, F.; Alibés, R.; de March, P.; Figueredo, M.; Font, J.; Parella, T. Org. Lett. 2007, 9, 1769. diol 8, an intermediate en route to stemonidine, we have now completed the synthesis of stemospironine and three additional analogs, thus demonstrating the flexibility of our synthetic design.

Scheme 2. Preparation of Diol 8

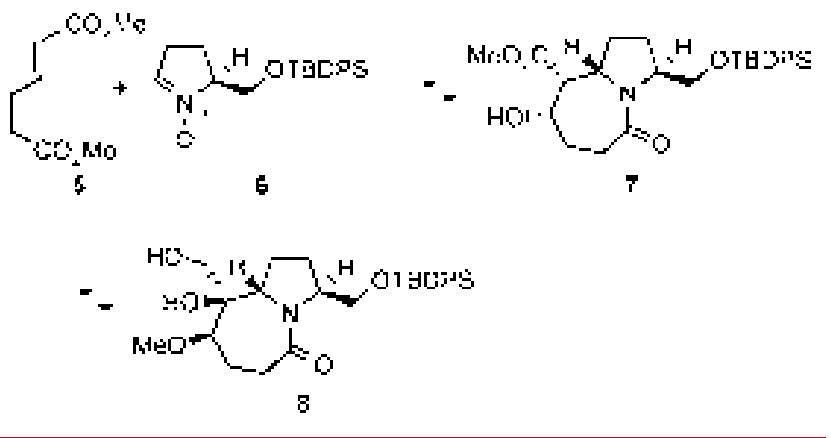

Stemospironine possesses a methoxy group at C-8 with the same stereochemical orientation as that of the putative stemonidine, but requires the formation of the spiranic lactone with the opposite configuration. We envisaged the installation of this lactone through an intramolecular HornerWadsworth-Emmons olefination of a derivative of the common intermediate 8, which was prepared from the $\alpha, \beta$-unsaturated diester $\mathbf{5}$ and the enantiomerically pure nitrone $6,{ }^{9}$ derived from L-(+)-prolinol, as previously reported (Scheme 2) ${ }^{8}$ It is remarkable that, after the initial formation of the azabicycle 7 , the inversion of configuration at $\mathrm{C}_{8}$ and the diastereofacial oxidation at $\mathrm{C}_{9}$ was efficiently accomplished in a cooperative manner through dehydration and subsequent dihydroxylation. The "eastern" lactone, appended to the pyrrolidine ring, features identically in both alkaloids.

Progression of our synthesis of stemospironine was attempted as shown in Scheme 3. The oxidation of alcohol 8 with $N$-chlorosuccinimide in the presence of TEMPO and tetrabutylammonium chloride in basic medium and a biphasic system ${ }^{10}$ provided aldehyde 9 in $91 \%$ yield. Spirolactonization was accomplished by esterification of the tertiary alcohol by reaction with 2-(diethoxyphosphoryl)propanoic acid and cyclohexylcarbodiimide, ${ }^{11}$ followed by a basic treatment of the intermediate phosphonate, in $71 \%$ yield. Next, the silyl protection was removed and the primary alcohol was oxidized to the corresponding aldehyde 12, which treated with ethyl bromomethylacrylate and zinc ${ }^{12}$ furnished a roughly 1:1 mixture of bislactones $\mathbf{1 3}$ and 14 in $74 \%$ overall yield. The relative erythro/threo configuration of 13 and 14 was tentatively assigned by NMR in comparison with literature data ${ }^{7,13}$ and unambigously established in a more advanced intermediate (vide infra).

(9) Gella, C.; Ferrer, E.; Alibés, R.; Busqué, F.; de March, P.; Figueredo, M.; Font, J. J. Org. Chem. 2009, 74, 6365.

(10) Einhorn, J.; Einhorn, C.; Ratajczak, F.; Pierre, J.-L. J. Org. Chem. 1996, 61, 7452.

(11) Nahmany, M.; Melman, A. Org. Lett. 2001, 3, 3733.

(12) Rauter, A. P.; Figueiredo, J.; Ismael, M.; Canda, T.; Font, J.; Figueredo, M. Tetrahedron: Asymmetry 2001, 12, 1131. 
Scheme 3. Preparation of Bislactones 13 and 14
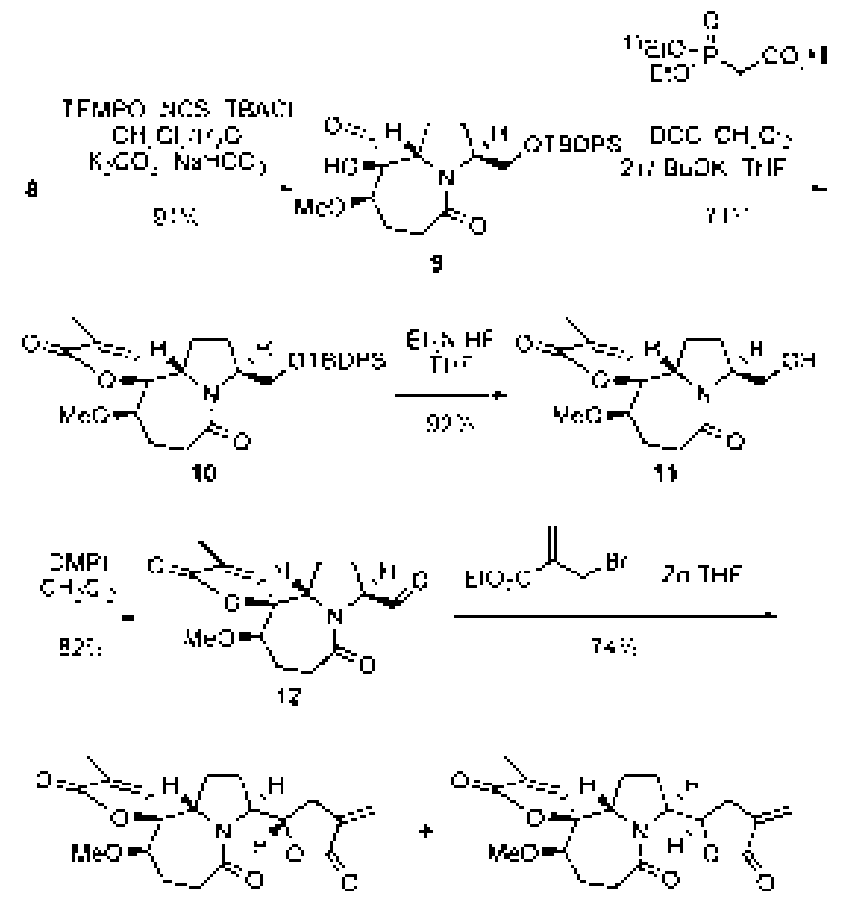

15

14

From the threo isomer 13, the remaining transformations to conclude the synthesis of stemospironine were, theoretically, the hydrogenation of the endo- and exocyclic $\mathrm{C}-\mathrm{C}$ double bonds and the deoxygenation of the lactam. These transformations were undertaken from both epimeric bislactones, 13 and 14, separately (Scheme 4).

Despite the fact that the hydrogenation reaction generates two new stereogenic centers at $C_{11}$ and $C_{16}$, lactams 15 and 18 were exclusively isolated from 13 and 14, respectively, in good yields. The configuration at $\mathrm{C}_{16}$ was consistent with the approach of the hydrogen by the less hindered face of the "eastern" lactone, as expected, ${ }^{8}$ while a rational explanation of the configuration at $\mathrm{C}_{11}$, which is the opposite in stemospironine, may be found by observation of a simple tridimensional molecular model of compound 13 (Figure 2) that shows how the pyrrolidine ring obstructs one of the faces of the "western" lactone. Although other reduction protocols were tried, the $C_{11}$ epimers of 15 or $\mathbf{1 8}$ were never detected. The deoxygenation of lactams $\mathbf{1 5}$ and 18, accomplished by treatment with Lawesson's reagent and then $\mathrm{Ra}-\mathrm{Ni}$, gave 11-epi-stemospironine, 17, and 11-epi-14-epi-16-epi-stemospironine, 20, respectively. The structural assignment of all the intermediates was confirmed by X-ray analysis of thiolactam 19 (Figure 3).

In view of the high diastereoselectivity accomplished in the reduction of the $\mathrm{C}_{10}-\mathrm{C}_{11}$ double bond, we reasoned that the methylation of an enolate formed by deprotonation of $\mathrm{C}_{11}$ should occur with the same facial selectivity, leading to the correct stemospironine-like configuration.

(13) Blanco, P.; Busqué, F.; de March, P.; Figueredo, M.; Font, J.; Sanfeliu, E. Eur. J. Org. Chem. 2004, 48.
Scheme 4. Synthesis of 11-epi-Stemospironine, 17, and 11-epi14-epi-16-epi-Stemospironine, 20
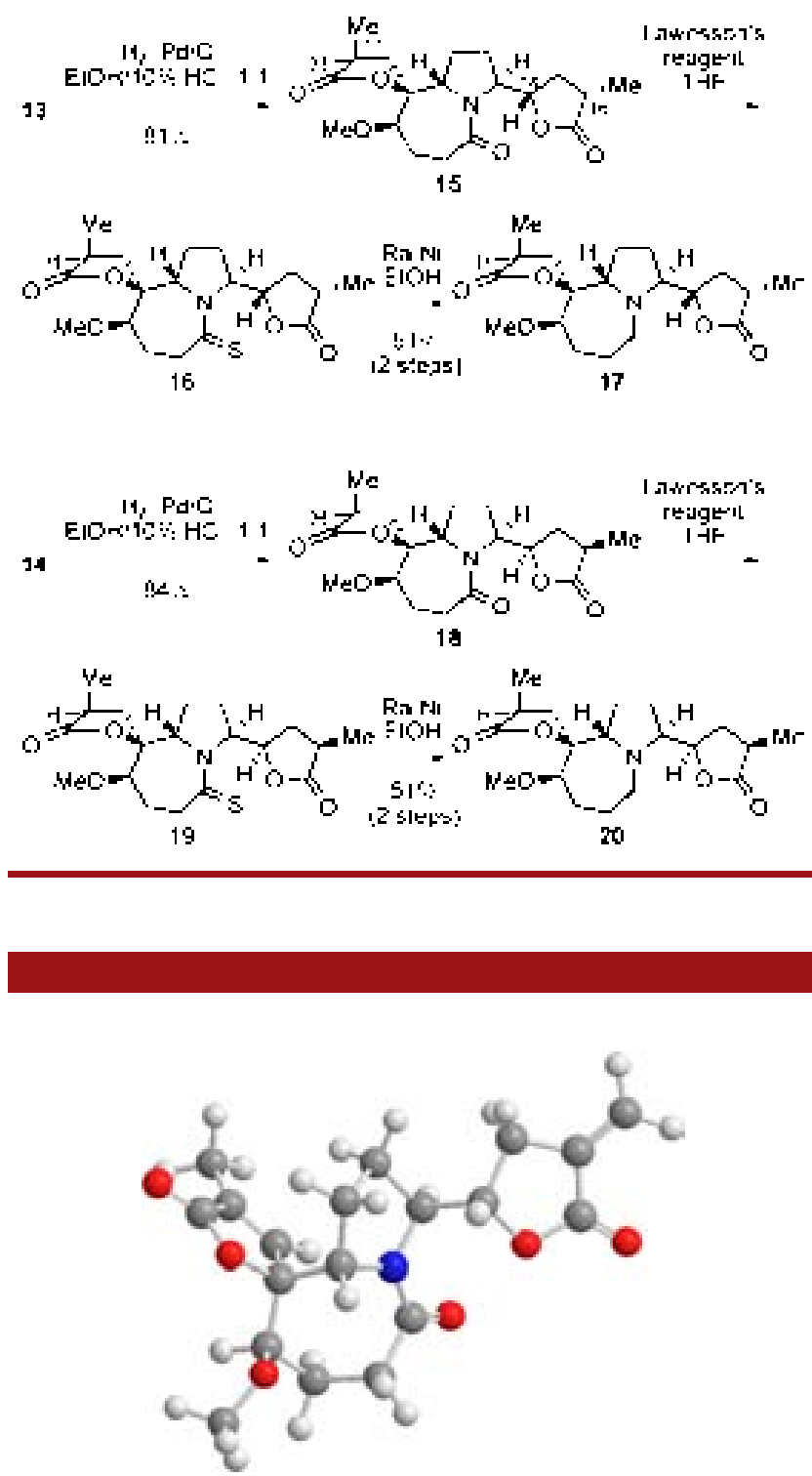

Figure 2. Molecular model of bislactone 13 (ChemBio3D Ultra 12.0).

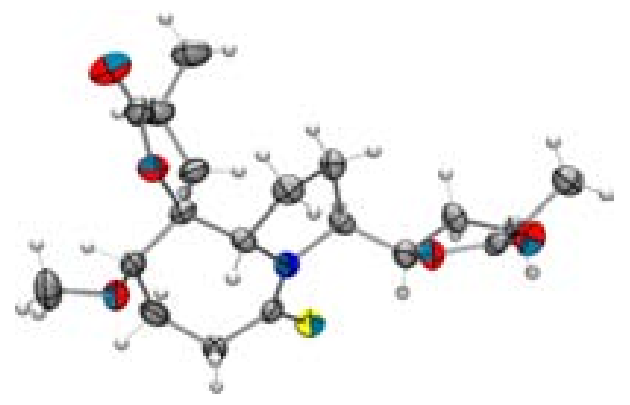

Figure 3. Crystal structure of thiolactam 19. 
Scheme 5. Preparation of Bislactones 27 and 28
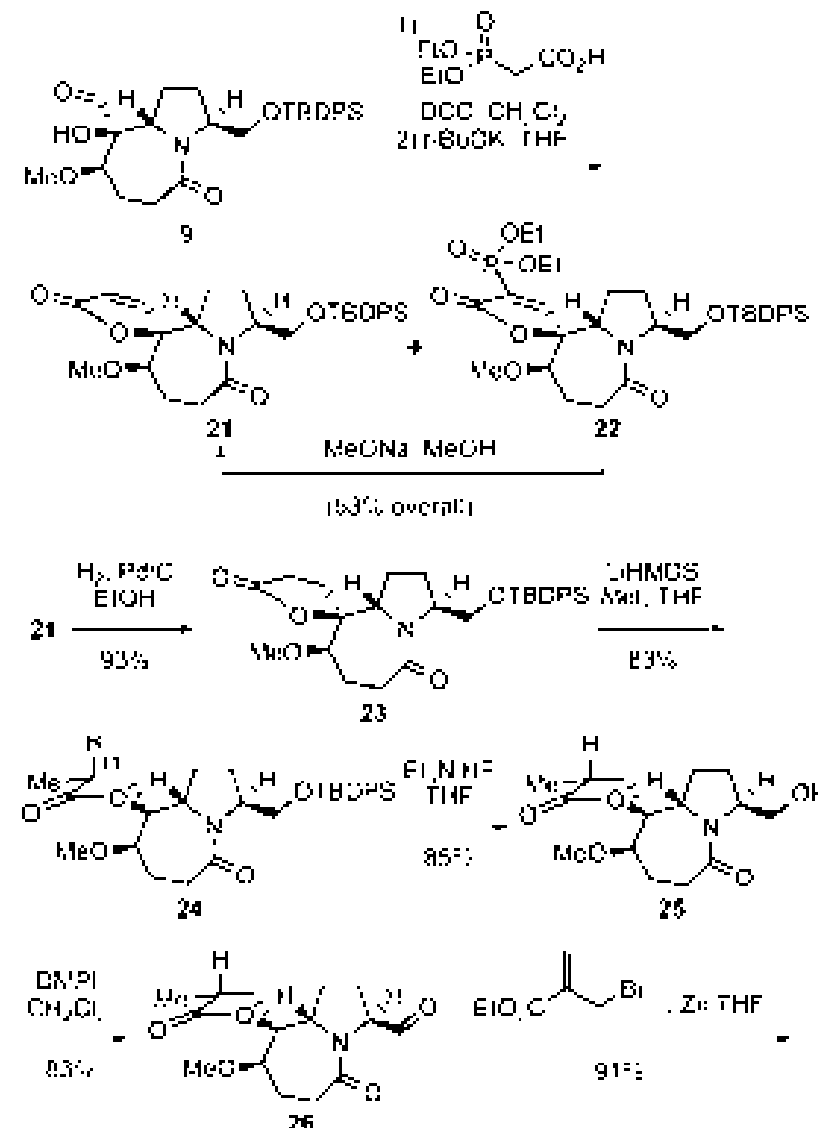

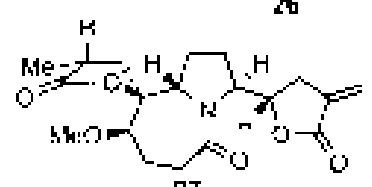

ZT

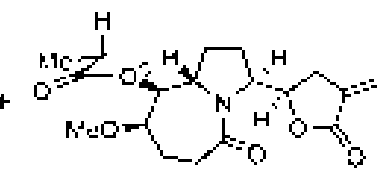

20
To test this hypothesis, we decided to investigate the spirolactonization of aldehyde 9 with diethoxyphosphorylacetic acid (Scheme 5). This reaction delivered the expected lactone 21, along with the undesired Knoevenagel product 22, and despite many attempts including changing the base, solvent, and other experimental conditions, this competitive pattern could not be completely inhibited. Fortunately, compound $\mathbf{2 2}$ could be recycled to $\mathbf{2 1}$ by treatment of the former with $\mathrm{MeONa}$ in $\mathrm{MeOH}$ to afford the latter in a reasonable $53 \%$ yield. Catalytic hydrogenation furnished the saturated lactone 23, which was $\alpha$-methylated without problems and with the previously predicted stereoselectivity to furnish $\mathbf{2 4}$ in good yield. Installation of the second lactone was made, as before, by desilylation of $\mathbf{2 4}$, followed by oxidation to the aldehyde $\mathbf{2 5}$ and then reaction with ethyl bromomethylacrylate and zinc. As expected, this last reaction furnished a mixture of the threo, 27, and erythro, 28, epimers in a roughly 1:1 ratio and excellent overall yield. The stereochemical assignment of these bislactones was confirmed by their conversion to the target alkaloids (Scheme 6).

The syntheses of stemospironine and 14-epi-16-epi-stemospironine, 33, were completed using the previously
Scheme 6. Synthesis of Stemospironine and 14-epi-16-epi-Stemospironine, $\mathbf{3 3}$

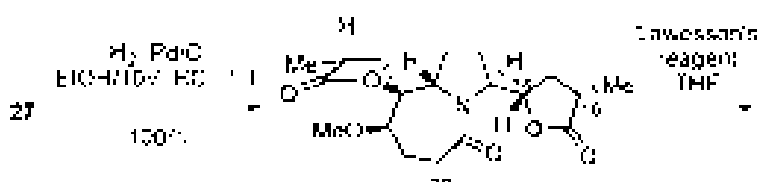

29
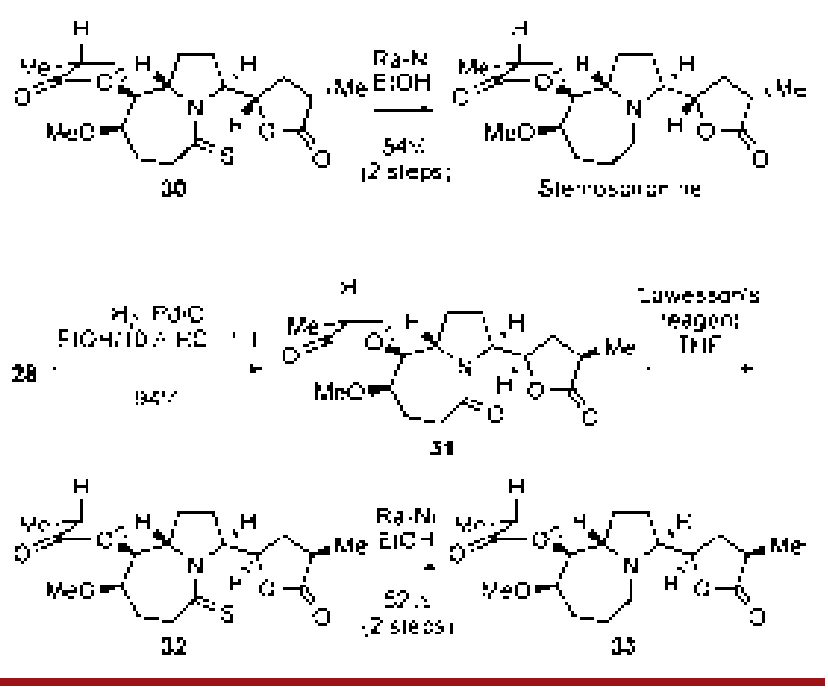

established protocols, namely, catalytic hydrogenation of the precursor bislactones $\mathbf{2 7}$ and $\mathbf{2 8}$, followed by deoxygenation via the corresponding thiolactams $\mathbf{3 0}$ and $\mathbf{3 2}$, respectively. The analytical data of our synthetic stemospironine including optical rotation, $[\alpha]_{\mathrm{D}}{ }^{20}-8.6(c 0.23$, $\mathrm{CHCl}_{3}$ ), are in total agreement with those described for the natural alkaloid, $[\alpha]_{\mathrm{D}}{ }^{27}-8.2\left(c 0.92, \mathrm{CHCl}_{3}\right) .{ }^{14}$

In summary, we have accomplished the syntheses of stemospironine and the three additional diastereoisomers 11-epi-stemospironine, 17, 11-epi-14-epi-16-epi-stemospironine, 20, and 14-epi-16-epi-stemospironine, 33, through a flexible strategy, which allows the preparation of different Stemona alkaloids by splitting the sequence in the appropriate late-stage step. The configuration of the stereogenic center at $\mathrm{C}_{11}$ has been totally controlled by a fine-tunning of the synthetic pathway.

Acknowledgment. We acknowledge financial support from DGI (Project CTQ2010-15380) and grants from MECD (F.S.) and MCI (N.B.). We are grateful to Dr. Inhar Imaz, Catalan Institute of Nanotechnology, for performing the X-ray analysis of $\mathbf{1 9}$ and to Dr. Tamsyn Montagnon, University of Crete, for her critical reading of the manuscript.

Supporting Information Available. Experimental details, spectral data and copies of NMR spectra for all new compounds. This material is available free of charge via the Internet at http://pubs.acs.org.

(14) Sakata, K.; Aoki, K.; Chang, C.-F.; Sakurai, A.; Tamura, S.; Murakoshi, S. Agric. Biol. Chem. 1978, 42, 457.

The authors declare no competing financial interest. 
4. Experimental Part 



\subsection{GENERAL PROCEDURES}

All commercially available reagents were used as received. The solvents were dried by distillation over the appropriate drying agents: $\mathrm{CH}_{2} \mathrm{Cl}_{2}\left(\mathrm{CaH}_{2}\right)$, $\operatorname{THF}\left(\mathrm{Na}^{0}\right)$, toluene $\left(\mathrm{Na}^{0}\right.$, without benzophenone). When needed, reactions were performed avoiding moisture by standard procedures and under nitrogen atmosphere.

\subsubsection{Spectroscopy}

Nuclear magnetic resonance spectra (NMR) have been registered at the Servei de Ressonància Magnètica Nuclear in the Universitat Autònoma de Barcelona. ${ }^{1} \mathrm{H}-\mathrm{NMR}$ spectra were recorded on Bruker DPX250 (250 MHz), Bruker DPX360 (360 MHz) and Bruker ARX400 (400 MHz) spectrometers. Proton chemical shifts are reported in ppm $(\delta)\left(C^{2} C_{3}, \delta 7.26 \mathrm{ppm}\right.$ and $\mathrm{C}_{6} \mathrm{D}_{6}, 7.16$ ppm). ${ }^{13}$ C-NMR spectra were recorded with complete proton decoupling on Bruker DPX250 (63 MHz), Bruker DPX360 (90 MHz) and Bruker ARX400 (100 MHz) spectrometers. Carbon chemical shifts are reported in ppm $\left(\mathrm{CDCl}_{3}, \delta 77.16 \mathrm{ppm}\right.$ and $\left.\mathrm{C}_{6} \mathrm{D}_{6}, 128.06 \mathrm{ppm}\right)$. NMR signals were assigned with the help of COSY, selective NOE, NOESY, HSQC and HMBC experiments. All spectra have been registered at $298 \mathrm{~K}$.

The abbreviation used to describe signal multiplicities are: $s$ (singlet), $d$ (doublet), brd (broad doublet), t (triplet), q (quadruplet), dd (double doublet), ddd (double double doublet), dt (double triplet), ddt (double double triplet), td (triple doublet), tt (triple triplet), m (multiplet) and $J$ to indicate the coupling constants.

Infrared spectra were recorded on a Sapphire-ATR Spectrophotometer. Peaks are reported in $\mathrm{cm}^{-1}$.

\subsubsection{Mass spectrometry}

High resolution mass spectra (HRMS) were recorded at the Servei d'Anàlisi Química in the Universitat Autònoma de Barcelona in a Bruker micrOTOFQ spectrometer using ESIMS (QTOF).

\subsubsection{Chromatography}

All reactions were monitored by analytical thin-layer chromatography (TLC) using silica gel 60 F254 pre-coated aluminum plates ( $0.25 \mathrm{~mm}$ thickness). Developing has been made using an UV lamp at $254 \mathrm{~nm}$ and/or using a $\mathrm{KMnO}_{4} / \mathrm{KOH}$ aqueous solution. 
Flash column chromatography was performed using silica gel (230-400 mesh), Florisil ${ }^{\circledR}$ (100-200 mesh) or alumina Brockman I (when so indicated).

\subsubsection{Optical rotatory power}

Specific optical rotations were measured on Propol Automatisches Dr. Kermchen polarimeter at $20 \pm 2{ }^{\circ} \mathrm{C}$ and through a $0.05 \mathrm{dm}$ optical path length or by a J-715 (Jasco) polarimeter with temperature regulator, using a $0.1 \mathrm{dm}$ long tray.

\subsubsection{Melting point}

Melting points were determined on a REICHERT Koffler hot stage melting point apparatus, and are uncorrected.

\subsection{EXPERIMENTAL DESCRIPTION}

(3S,8R,9S,9aS)-3-tert-Butyldiphenylsilyloxymethyl-9-hydroxy-8-methoxy-5-oxooctahydro-1Hpyrrolo[1,2-a]azepine-9-carbaldehyde, 62

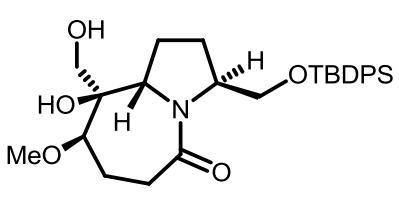

53

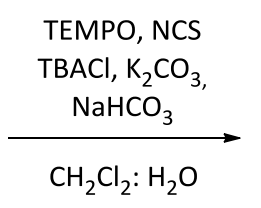

$\mathrm{CH}_{2} \mathrm{Cl}_{2}: \mathrm{H}_{2} \mathrm{O}$

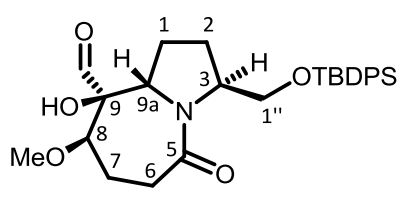

62

To a stirred solution of alcohol $\mathbf{5 3}^{38}$ (450 $\left.\mathrm{mg}, 0.90 \mathrm{mmol}\right)$ in $\mathrm{CH}_{2} \mathrm{Cl}_{2}(9.4 \mathrm{~mL})$, water $(9.4$ $\mathrm{mL}$ ), $\mathrm{NaHCO}_{3}(454 \mathrm{mg}, 5.40 \mathrm{mmol}), \mathrm{K}_{2} \mathrm{CO}_{3}(99 \mathrm{mg}, 0.71 \mathrm{mmol}), \mathrm{TBACl}(46 \mathrm{mg}, 0.17 \mathrm{mmol})$ and NCS (233 $\mathrm{mg}, 1.74 \mathrm{mmol}$ ) were added at room temperature. Then, TEMPO (36 mg, $0.23 \mathrm{mmol}$ ) was added portion-wise over $15 \mathrm{~min}$. After $2 \mathrm{~h}$, TLC analysis (EtOAc) of the reaction mixture revealed the absence of starting alcohol. The two phases were separated and the aqueous one was extracted with $\mathrm{CH}_{2} \mathrm{Cl}_{2}$ (3x8 $\mathrm{mL}$ ). The combined organic extracts were dried over anhydrous $\mathrm{MgSO}_{4}$ and concentrated under reduced pressure. The resulting oil was purified by flash column chromatography on silica gel (EtOAc:hexanes 9:1) to afford aldehyde 62 (408 mg, $0.82 \mathrm{mmol}$, $91 \%$ yield). 


\section{Physical and spectroscopic data of $\mathbf{6 2}:$}

$[\alpha]_{D}^{20}=-80.0\left(c 0.90, \mathrm{CH}_{2} \mathrm{Cl}_{2}\right)$.

IR (ATR): 3338, 3070, 2954, 2929, 2856, 1731, 1626, 1447, 1426, 1391, 1376, 1360, 1190, 1174, $1094,1044,1012 \mathrm{~cm}^{-1}$.

${ }^{1} \mathrm{H}-\mathrm{NMR}\left(360 \mathrm{MHz}, \mathrm{CDCl}_{3}\right): \delta 9.80(\mathrm{~s}, 1 \mathrm{H}: \mathrm{CHO}), 7.61\left(\mathrm{~m}, 4 \mathrm{H}_{\mathrm{Ar}}\right), 7.38\left(\mathrm{~m}, 6 \mathrm{H}_{\mathrm{Ar}}\right), 4.27\left(\mathrm{~m}, 1 \mathrm{H}: \mathrm{H}_{9 \mathrm{a}}\right)$, $4.12\left(\mathrm{~m}, 1 \mathrm{H}: \mathrm{H}_{3}\right), 3.79\left(\mathrm{~m}, 2 \mathrm{H}: 2 \mathrm{H}_{1^{\prime \prime}}\right), 3.57(\mathrm{~s}, 1 \mathrm{H}: \mathrm{OH}), 3.41\left(\mathrm{~s}, 3 \mathrm{H}: \mathrm{OCH}_{3}\right), 3.38(\mathrm{dd}, J=1.5,2.4 \mathrm{~Hz}$, $\left.1 \mathrm{H}: \mathrm{H}_{8}\right), 2.79$ (ddd, J = 14.6, $\left.11.04 .1 \mathrm{~Hz}, 1 \mathrm{H}: \mathrm{H}_{6}\right), 2.27\left(\mathrm{~m}, 3 \mathrm{H}: \mathrm{H}_{1}, \mathrm{H}_{2}, \mathrm{H}_{6}\right), 2.08\left(\mathrm{~m}, 2 \mathrm{H}: 2 \mathrm{H}_{7}\right), 1.98(\mathrm{~m}$, $\left.1 \mathrm{H}: \mathrm{H}_{1}\right), 1.56\left(\mathrm{~m}, 1 \mathrm{H}: \mathrm{H}_{2}\right), 1.04\left(\mathrm{~s}, 9 \mathrm{H}: \mathrm{C}\left(\mathrm{CH}_{3}\right)_{3}\right)$.

${ }^{13} \mathrm{C}-\mathrm{NMR}\left(90 \mathrm{MHz}, \mathrm{CDCl}_{3}\right): \delta 202.2(\mathrm{CHO}), 172.4\left(\mathrm{C}_{5}\right), 135.6\left(\mathrm{C}_{\mathrm{Ph}}\right), 135.5\left(\mathrm{C}_{\mathrm{Ph}}\right), 133.5\left(\mathrm{C}_{\mathrm{Ph}}\right), 133.4$ $\left(C_{\mathrm{Ph}}\right), 129.7\left(C_{\mathrm{Ph}}\right), 129.6\left(C_{\mathrm{Ph}}\right), 127.7\left(\mathrm{C}_{\mathrm{Ph}}\right), 127.6\left(\mathrm{C}_{\mathrm{Ph}}\right), 79.6\left(\mathrm{C}_{8}\right), 79.5\left(\mathrm{C}_{9}\right), 63.1\left(\mathrm{C}_{1^{\prime \prime}}\right), 60.3\left(\mathrm{C}_{9 \mathrm{a}}\right), 59.9$

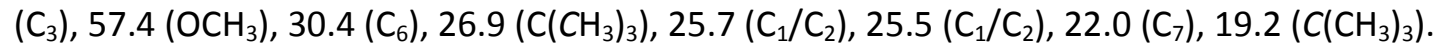

HRMS (ESI+): calcd for $\mathrm{C}_{28} \mathrm{H}_{38} \mathrm{NO}_{5} \mathrm{Si}: 496.2514\left[\mathrm{M}+\mathrm{H}^{+}\right]$; found 496.2510.

(2S,3'S,8'R,9a'S)-3'-tert-butyldiphenylsilyloxymethyl-8'-methoxy-4-methyl-1',2', 3',7', 8', 9a'hexahydro-5H-spiro\{furan-2,9'-pyrrolo[1,2-a]azepine\}-5,5'(6'H)-dione, 63

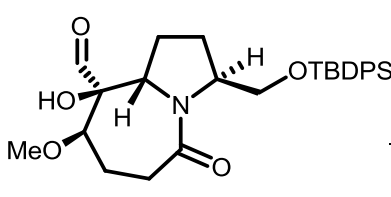

62

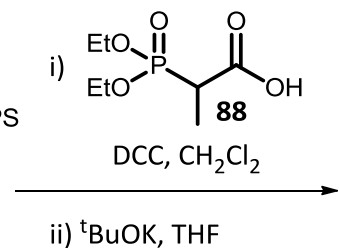

ii) ${ }^{\mathrm{B}} \mathrm{BuOK}, \mathrm{THF}$

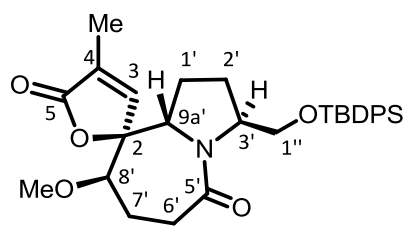

63

A recently prepared solution of 2-diethoxyphosphorylpropionic acid, $88,{ }^{60}$ in $\operatorname{dry~} \mathrm{CH}_{2} \mathrm{Cl}_{2}$ $(1 \mathrm{M}, 0.92 \mathrm{~mL}, 0.92 \mathrm{mmol}$ ) was added to a stirred solution of aldehyde $62(378 \mathrm{mg}, 0.76 \mathrm{mmol})$ in dry $\mathrm{CH}_{2} \mathrm{Cl}_{2}(2.8 \mathrm{~mL})$ under $\mathrm{N}_{2}$ atmosphere at room temperature. Then, a solution of DCC (1M in $\mathrm{CH}_{2} \mathrm{Cl}_{2}, 1.3 \mathrm{~mL}, 1.3 \mathrm{mmol}$ ) was slowly added. After $4 \mathrm{~h}$, TLC analysis (EtOAc) showed no starting material. The mixture was filtered through a sintered glass and the organic solvent was evaporated under vacuum. The remaining residue was filtered through silica gel (EtOAc) and the solvent was evaporated in vacuo to afford a colorless oil, which was dissolved in THF (5 ml). Then, ${ }^{\mathrm{t}} \mathrm{BuOK}(173 \mathrm{mg}, 1.54 \mathrm{mmol}$ ) was added and the reaction mixture was heated at the reflux temperature for $2.5 \mathrm{~h}$. The organic solvent was evaporated under reduced pressure and the 
resulting oil was purified on silica gel (EtOAc:hexanes 1:1) to furnish 63 ( $288 \mathrm{mg}, 0.54 \mathrm{mmol}, 71 \%$ yield for the two steps) as a yellowish oil.

Physical and spectroscopic data of 63 :

$[\alpha]_{D}^{20}=-114.9\left(c 1.01, \mathrm{CHCl}_{3}\right)$.

IR (ATR): 3070, 2929, 2855, 1760, 1640, 1447, 1444, 1411, 1376, 1360, 1194, 1163, 1105, 1042 $\mathrm{cm}^{-1}$.

${ }^{1} \mathrm{H}-\mathrm{NMR}\left(400 \mathrm{MHz}, \mathrm{CDCl}_{3}\right): \delta 7.62\left(\mathrm{~m}, 4 \mathrm{H}_{\mathrm{Ar}}\right), 7.40\left(\mathrm{~m}, 6 \mathrm{H}_{\mathrm{Ar}}\right), 6.93\left(\mathrm{q}, J=1.5 \mathrm{~Hz}, 1 \mathrm{H}: \mathrm{H}_{3}\right), 4.74(\mathrm{~d}, J=$ $\left.8.7 \mathrm{~Hz}, 1 \mathrm{H}: \mathrm{H}_{9 \mathrm{a}^{\prime}}\right), 4.19\left(\mathrm{~m}, 1 \mathrm{H}: \mathrm{H}_{3^{\prime}}\right), 3.83\left(\mathrm{dd}, J=9.9,3.1 \mathrm{~Hz}, 1 \mathrm{H}: \mathrm{H}_{1^{\prime \prime}}\right), 3.71(\mathrm{dd}, J=9.9 \mathrm{~Hz}, 6.1 \mathrm{~Hz}$, $\left.1 \mathrm{H}: \mathrm{H}_{1^{\prime \prime}}\right), 3.50\left(\mathrm{~s}, 3 \mathrm{H}: \mathrm{OCH}_{3}\right), 3.15\left(\mathrm{dd}, J=4.7,1.5 \mathrm{~Hz}, 1 \mathrm{H}: \mathrm{H}_{8^{\prime}}\right), 2.79\left(\mathrm{t}, J=13.5 \mathrm{~Hz}, 1 \mathrm{H}: \mathrm{H}_{6^{\prime}}\right), 2.26(\mathrm{~m}$, $\left.1 \mathrm{H}: \mathrm{H}_{6^{\prime}}\right), 2.15\left(\mathrm{~m}, 2 \mathrm{H}: \mathrm{H}_{1^{\prime}}, \mathrm{H}_{7^{\prime}}\right), 1.97\left(\mathrm{~d}, J=1.5 \mathrm{~Hz}, 3 \mathrm{H}: \mathrm{CH}_{3}\right), 1.93\left(\mathrm{~m}, 1 \mathrm{H}: \mathrm{H}_{2^{\prime}}\right), 1.81(\mathrm{t}, J=13.5 \mathrm{~Hz}$, $\left.1 \mathrm{H}: \mathrm{H}_{7^{\prime}}\right), 1.67\left(\mathrm{~m}, 1 \mathrm{H}: \mathrm{H}_{1^{\prime}}\right), 1.50\left(\mathrm{~m}, 1 \mathrm{H}: \mathrm{H}_{2^{\prime}}\right), 1.06\left(\mathrm{~s}, 9 \mathrm{H}: \mathrm{C}\left(\mathrm{CH}_{3}\right)_{3}\right)$.

${ }^{13} \mathrm{C}-\mathrm{NMR}\left(100 \mathrm{MHz}, \mathrm{CDCl}_{3}\right): \delta 173.4\left(\mathrm{C}_{5^{\prime}}\right), 172.7\left(\mathrm{C}_{5}\right), 146.9\left(\mathrm{C}_{3}\right), 135.7\left(\mathrm{C}_{\mathrm{ph}}\right), 135.6\left(\mathrm{C}_{\mathrm{ph}}\right), 133.6\left(\mathrm{C}_{\mathrm{ph}}\right)$, $133.5\left(C_{4}\right), 133.4\left(C_{P h}\right), 129.9\left(C_{P h}\right), 127.84\left(C_{P h}\right), 127.83\left(C_{P h}\right), 89.2\left(C_{2}\right), 83.1\left(C_{8^{\prime}}\right), 63.1\left(C_{1^{\prime \prime}}\right), 60.1$ $\left(\mathrm{C}_{3^{\prime}}\right), 59.2\left(\mathrm{OCH}_{3}\right), 57.2\left(\mathrm{C}_{9 \mathrm{a}^{\prime}}\right), 30.5\left(\mathrm{C}_{6^{\prime}}\right), 27.1\left(\mathrm{C}^{\prime}\left(\mathrm{CH}_{3}\right)_{3}\right), 26.8\left(\mathrm{C}_{2^{\prime}}\right), 26.4\left(\mathrm{C}_{1^{\prime}}\right), 25.1\left(\mathrm{C}_{7^{\prime}}\right), 19.4$ $\left(\mathrm{C}\left(\mathrm{CH}_{3}\right)_{3}\right), 11.2\left(\mathrm{CH}_{3}\right)$.

HRMS (ESI+): calcd for $\mathrm{C}_{31} \mathrm{H}_{39} \mathrm{NO}_{5} \mathrm{Si}: 556.2490\left[\mathrm{M}+\mathrm{Na}^{+}\right]$; found 556.2480 .

(2S,3'S,8'R,9a'S)-3'-Hydroxymethyl-8'-methoxy-4-methyl-1',2',3',7',8',9a'-hexahydro-5Hspiro\{furan-2,9'-pyrrolo[1,2-a]azepine\}-5,5'(6'H)-dione, 104

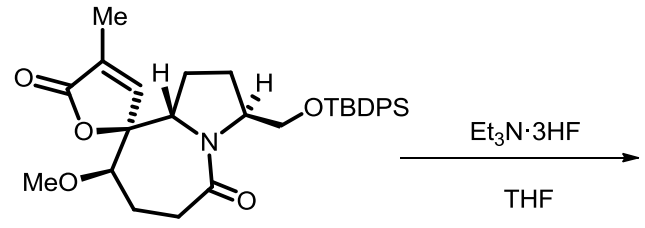

63

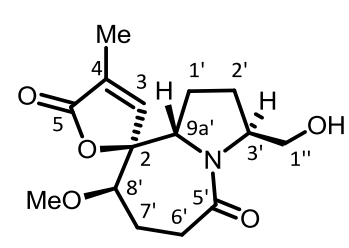

104

To a stirred solution of 63 (581 mg, $1.09 \mathrm{mmol})$ in dry THF $(19 \mathrm{~mL}), \mathrm{Et}_{3} \mathrm{~N} \cdot 3 \mathrm{HF}(3.5 \mathrm{~mL}$, $21.47 \mathrm{mmol}$ ) was added. The reaction mixture was heated at the reflux temperature for $4 \mathrm{~h}$, when TLC analysis showed no starting material. The excess of $\mathrm{Et}_{3} \mathrm{~N} \cdot 3 \mathrm{HF}$ was quenched with $\mathrm{NaHCO}_{3}$ saturated solution. Then, EtOAc was added and the aqueous phase was extracted with 
$\mathrm{CH}_{2} \mathrm{Cl}_{2}(2 \times 18 \mathrm{~mL})$. The combined organic extracts were dried over anhydrous $\mathrm{MgSO}_{4}$ and concentrated in vacuo. The resulting oil was filtered through silica gel (EtOAc) to furnish alcohol 104 (296 mg, $1.00 \mathrm{mmol}, 92 \%$ yield) as a white solid.

Physical and spectroscopic data of 104:

$[\alpha]_{D}^{20}=-70.6\left(c 0.96, \mathrm{CHCl}_{3}\right)$.

m.p. $=178-181^{\circ} \mathrm{C}$.

IR (ATR): 3302, 2953, 2835, 1754, 1613, 1439, 1370, 1351, 1198, 1184, 1160, 1095, $1059 \mathrm{~cm}^{-1}$.

${ }^{1} \mathrm{H}-\mathrm{NMR}\left(400 \mathrm{MHz}, \mathrm{CDCl}_{3}\right.$ ): $\delta 6.90$ (q, J = $1.5 \mathrm{~Hz}, 1 \mathrm{H}: \mathrm{H}_{3}$ ), 4.85 (dd, J = 8.5, $3.1 \mathrm{~Hz}, 1 \mathrm{H}: \mathrm{H}_{9 \mathrm{a}^{\prime}}$ ), 4.40 (dd, $J=8.0,3.5 \mathrm{~Hz}, 1 \mathrm{H}: \mathrm{OH}), 4.00\left(\mathrm{~m}, 1 \mathrm{H}: \mathrm{H}_{3^{\prime}}\right), 3.64\left(\mathrm{~m}, 2 \mathrm{H}: 2 \mathrm{H}_{1^{\prime \prime}}\right), 3.49\left(\mathrm{~s}, 3 \mathrm{H}: \mathrm{OCH}_{3}\right), 3.16(\mathrm{dd}, J=1.7,4.7$ $\left.\mathrm{Hz}, 1 \mathrm{H}: \mathrm{H}_{8^{\prime}}\right), 3.01\left(\mathrm{td}, J=13.7,1.7 \mathrm{~Hz}, 1 \mathrm{H}: \mathrm{H}_{6^{\prime}}\right), 2.36\left(\mathrm{dd}, J=13.9,1.3 \mathrm{~Hz}, 1 \mathrm{H}: \mathrm{H}_{6^{\prime}}\right), 2.15\left(\mathrm{~m}, 1 \mathrm{H}: \mathrm{H}_{7^{\prime}}\right)$, $2.05\left(\mathrm{~m}, 1 \mathrm{H}: \mathrm{H}_{1^{\prime}}\right), 1.97\left(\mathrm{~d}, J=1.6 \mathrm{~Hz}, 3 \mathrm{H}: \mathrm{CH}_{3}\right), 1.81\left(\mathrm{tt}, J=15.9,1.6 \mathrm{~Hz}, 1 \mathrm{H}: \mathrm{H}_{7^{\prime}}\right), 1.62(\mathrm{~m}$, $\left.3 \mathrm{H}: \mathrm{H}_{1^{\prime}}, 2 \mathrm{H}_{2^{\prime}}\right)$.

${ }^{13} \mathrm{C}-\mathrm{NMR}\left(100 \mathrm{MHz}, \mathrm{CDCl}_{3}\right): \delta 175.4\left(\mathrm{C}_{5^{\prime}}\right), 172.4\left(\mathrm{C}_{5}\right), 146.1\left(\mathrm{C}_{3}\right), 134.2\left(\mathrm{C}_{4}\right), 89.1\left(\mathrm{C}_{2}\right), 82.7\left(\mathrm{C}_{8^{\prime}}\right)$, $65.8\left(C_{1^{\prime \prime}}\right), 63.0\left(C_{3^{\prime}}\right), 59.2\left(\mathrm{OCH}_{3}\right), 57.6\left(C_{9 a^{\prime}}\right), 30.5\left(C_{6^{\prime}}\right), 27.8\left(C_{2^{\prime}} / C_{7^{\prime}}\right), 26.3\left(C_{1^{\prime}}\right), 24.9\left(C_{2^{\prime}} / C_{7^{\prime}}\right), 11.2$ $\left(\mathrm{CH}_{3}\right)$.

HRMS (ESI+): calcd for $\mathrm{C}_{15} \mathrm{H}_{21} \mathrm{NO}_{5}: 318.1312\left[\mathrm{M}+\mathrm{Na}^{+}\right]$; found 318.1313.

(2S,3'S,8'R,9a'S)-8'-Methoxy-4-methyl-5,5'-dioxo-1',2',3',5',6',7',8', 9a'-octahydro-5Hspiro\{furan-2,9'-pyrrolo[1,2-a]azepine\}-3'-carbaldehyde, 105

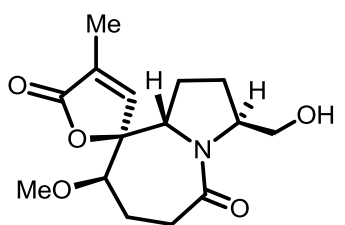

104

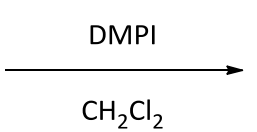

$\mathrm{CH}_{2}$

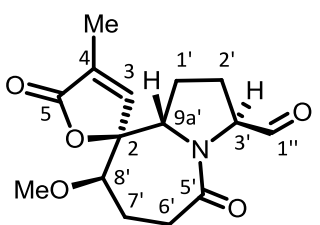

105

A commercially available solution of Dess-Martin periodinane in $\mathrm{CH}_{2} \mathrm{Cl}_{2}(15 \% \mathrm{wt}, 2.4 \mathrm{~mL}$, $1.16 \mathrm{mmol}$ ) was added via syringe to a solution of alcohol 104 (290 mg, $0.99 \mathrm{mmol})$ in dry $\mathrm{CH}_{2} \mathrm{Cl}_{2}$ $(8.3 \mathrm{~mL})$. After $2.3 \mathrm{~h}$ of stirring at room temperature, TLC analysis indicated the complete consumption of the starting material. The solution was washed with $\mathrm{NaHCO}_{3}$ saturated solution 
containing a sevenfold excess of $\mathrm{Na}_{2} \mathrm{~S}_{2} \mathrm{O}_{3}$, the aqueous phase was extracted with $\mathrm{CH}_{2} \mathrm{Cl}_{2}(2 \times 7 \mathrm{~mL})$, and the combined organic extracts were dried over anhydrous $\mathrm{MgSO}_{4}$ and concentrated in vacuo. Flash column chromatography on silica gel (EtOAc) provided aldehyde 105 (238 mg, $0.81 \mathrm{mmol}$, $82 \%$ yield) as a white solid.

Physical and spectroscopic data of 105:

$[\alpha]_{D}^{20}=-101.7\left(c\right.$ 08, $\left.\mathrm{CHCl}_{3}\right)$.

m.p. $=182-184^{\circ} \mathrm{C}$.

IR (ATR): 2982, 2944, 2856, 1743, 1720, 1633, 1416, 1372, 1353, 1195, 1163, 1096, 1064, 1023, $1000 \mathrm{~cm}^{-1}$.

${ }^{1} \mathrm{H}-\mathrm{NMR}\left(400 \mathrm{MHz}, \mathrm{CDCl}_{3}\right): \delta 9.45(\mathrm{~d}, J=2.1 \mathrm{~Hz}, 1 \mathrm{H}: \mathrm{CHO}), 6.93\left(\mathrm{~m}, 1 \mathrm{H}: \mathrm{H}_{3}\right), 4.92(\mathrm{dd}, J=8.6,3.3 \mathrm{~Hz}$, $\left.1 \mathrm{H}: \mathrm{H}_{9 \mathrm{a}^{\prime}}\right), 4.34\left(\mathrm{~m}, 1 \mathrm{H}: \mathrm{H}_{3^{\prime}}\right), 3.50\left(\mathrm{~s}, 3 \mathrm{H}: \mathrm{OCH}_{3}\right), 3.20\left(\mathrm{dd}, J=5.0,1.5 \mathrm{~Hz}, 1 \mathrm{H}: \mathrm{H}_{8^{\prime}}\right), 3.11(\mathrm{td}, J=13.4,1.7$ $\left.\mathrm{Hz}, 1 \mathrm{H}: \mathrm{H}_{6^{\prime}}\right), 2.37\left(\mathrm{dd}, J=6.7,14.2 \mathrm{~Hz}, 1 \mathrm{H}: \mathrm{H}_{6^{\prime}}\right), 2.17\left(\mathrm{~m}, 1 \mathrm{H}: \mathrm{H}_{7^{\prime}}\right), 2.03\left(\mathrm{~m}, 1 \mathrm{H}: \mathrm{H}_{1^{\prime}}\right), 1.98(\mathrm{~d}, J=1.6 \mathrm{~Hz}$, $\left.3 \mathrm{H}: \mathrm{CH}_{3}\right), 1.85\left(\mathrm{~m}, 2 \mathrm{H}: \mathrm{H}_{2^{\prime}}, \mathrm{H}_{7^{\prime}}\right), 1.67\left(\mathrm{~m}, 2 \mathrm{H}: \mathrm{H}_{2^{\prime}}, \mathrm{H}_{1^{\prime}}\right)$.

${ }^{13}$ C-NMR $\left(100 \mathrm{MHz}, \mathrm{CDCl}_{3}\right): \delta 197.3\left(\mathrm{C}_{1^{\prime \prime}}\right), 173.7\left(\mathrm{C}_{5^{\prime}}\right), 172.2\left(\mathrm{C}_{5}\right), 145.6\left(\mathrm{C}_{3}\right), 134.6\left(\mathrm{C}_{4}\right), 89.0\left(\mathrm{C}_{2}\right)$, $82.4\left(C_{8^{\prime}}\right), 66.2\left(C_{3^{\prime}}\right), 59.2\left(\mathrm{OCH}_{3}\right), 56.6\left(C_{9 a^{\prime}}\right), 29.4\left(C_{6^{\prime}}\right), 26.1\left(C_{2^{\prime}} / C_{7^{\prime}}\right), 25.4\left(C_{2^{\prime}} / C_{7^{\prime}}\right), 24.9\left(C_{1^{\prime}}\right), 11.2$ $\left(\mathrm{CH}_{3}\right)$.

HRMS (ESI+): calcd for $\mathrm{C}_{15} \mathrm{H}_{19} \mathrm{NO}_{5}: 316.1155\left[\mathrm{M}+\mathrm{Na}^{+}\right]$; found 316.1161 .

(2S,3'S,8'R,9a'S,2'S)-, 106, and (2S,3'S,8'R,9a'S,2'R)-8'-Methoxy-4-methyl-3'-(4-methylene-5oxotetrahydrofuran-2-yl)-1',2',3',7',8',9a'-hexahydro-5H-spiro\{furan-2,9'-pyrrolo[1,2-a] azepine\}-5,5'(6'H)-dione, 107

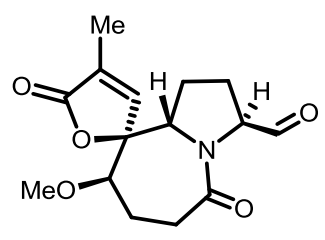

105

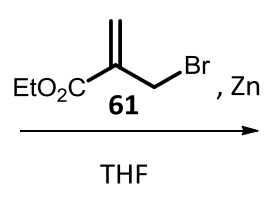

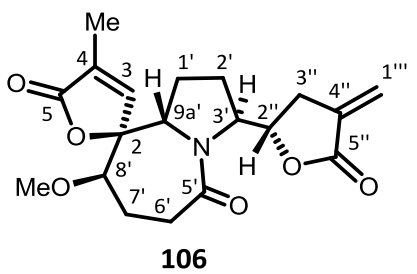

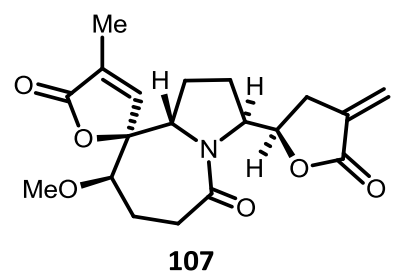

To a stirred solution of aldehyde $105(220 \mathrm{mg}, 0.75 \mathrm{mmol})$ in dry THF (3.8 mL) under $\mathrm{N}_{2}$ atmosphere, activated $\mathrm{Zn}^{51}$ (152 mg, $2.34 \mathrm{mmol}$ ) was added. The solution was heated up and, 
when reflux started, a solution of ethyl 2-(bromomethyl)acrylate, $61(153 \mu \mathrm{L}, 1.1 \mathrm{mmol})$, in dry THF (3.5 mL) was added. After $1 \mathrm{~h}$, TLC analysis of the reaction mixture (EtOAc:MeOH 9:1) revealed the absence of the starting aldehyde. The reaction mixture was filtered through Celite ${ }^{\circledR}$ and the organic solvent was evaporated under vacuum to afford a mixture of diastereoisomers (201 mg, $0.55 \mathrm{mmol}, 74 \%$ yield). The remaining colorless oil was purified by flash column chromatography on Florisil ${ }^{\circledR}$ (EtOAc) to provide the following fractions: i) threo-bislactone 106 (97.6 mg, $0.27 \mathrm{mmol}$, 36\% yield); ii) erythro-bislactone 107 (103 mg, $0.28 \mathrm{mmol}, 38 \%$ yield).

Physical and spectroscopic data of 106 (threo):

$[\alpha]_{D}^{20}=-85.4\left(c 0.10, \mathrm{CHCl}_{3}\right)$.

m.p. $=70-72^{\circ} \mathrm{C}$.

IR (ATR): 2929, 1753, 1643, 1443, 1403, 1274, 1252, 1143, 1097, 1055, 1031, $1000 \mathrm{~cm}^{-1}$.

${ }^{1} \mathrm{H}-\mathrm{NMR}\left(400 \mathrm{MHz}, \mathrm{CDCl}_{3}\right): \delta 6.85\left(\mathrm{q}, J=1.5 \mathrm{~Hz}, 1 \mathrm{H}: \mathrm{H}_{3}\right), 6.18\left(\mathrm{t}, J=2.6 \mathrm{~Hz}, 1 \mathrm{H}: \mathrm{H}_{1^{\prime \prime \prime}}\right), 5.59(\mathrm{t}, J=2.6$ $\left.\mathrm{Hz}, 1 \mathrm{H}: \mathrm{H}_{1^{\prime \prime \prime}}\right), 5.06\left(\mathrm{td}, J=6.7,3.9 \mathrm{~Hz}, 1 \mathrm{H}: \mathrm{H}_{2^{\prime \prime}}\right), 4.86\left(\mathrm{dd}, J=8.5,3.0 \mathrm{~Hz}, 1 \mathrm{H}: \mathrm{H}_{9 \mathrm{a}^{\prime}}\right), 4.37$ (dt, $J=7.6,3.8$ $\left.\mathrm{Hz}, 1 \mathrm{H}: \mathrm{H}_{3^{\prime}}\right), 3.48\left(\mathrm{~s}, 3 \mathrm{H}: \mathrm{OCH}_{3}\right), 3.15\left(\mathrm{dd}, J=4,3,1.7 \mathrm{~Hz}, 1 \mathrm{H}: \mathrm{H}_{8^{\prime}}\right), 2.95\left(\mathrm{td}, J=13.5,1.9 \mathrm{~Hz}, 1 \mathrm{H}: \mathrm{H}_{6^{\prime}}\right)$, $2.85\left(\mathrm{dt}, J=6.8,2.7 \mathrm{~Hz}, 2 \mathrm{H}: 2 \mathrm{H}_{3^{\prime \prime}}\right), 2.30\left(\mathrm{~m}, 1 \mathrm{H}: \mathrm{H}_{6^{\prime}}\right), 2.15\left(\mathrm{~m}, 2 \mathrm{H}: \mathrm{H}_{7^{\prime}}, \mathrm{H}_{1^{\prime}}\right), 1,94\left(\mathrm{~d}, J=1.5 \mathrm{~Hz}, 3 \mathrm{H}: \mathrm{CH}_{3}\right)$, $1.78\left(\mathrm{tt}, J=14.4,1.7 \mathrm{~Hz}, 1 \mathrm{H}: \mathrm{H}_{7^{\prime}}\right), 1.64\left(\mathrm{~m}, 3 \mathrm{H}: 2 \mathrm{H}_{2^{\prime}}, \mathrm{H}_{1^{\prime}}\right)$.

${ }^{13} \mathrm{C}-\mathrm{NMR}\left(100 \mathrm{MHz}, \mathrm{CDCl}_{3}\right): \delta 174.5\left(\mathrm{C}_{5^{\prime}}\right), 172.3\left(\mathrm{C}_{5}\right), 170.0\left(\mathrm{C}_{5^{\prime \prime}}\right), 145.8\left(\mathrm{C}_{3}\right), 134.4\left(\mathrm{C}_{4}\right), 134.2\left(\mathrm{C}_{4^{\prime \prime}}\right)$, $122.0\left(C_{1^{\prime \prime \prime}}\right), 89.4\left(C_{2}\right), 83.0\left(C_{8^{\prime}}\right), 77.2\left(C_{2^{\prime \prime}}\right), 60.3\left(C_{3^{\prime}}\right), 59.2\left(\mathrm{OCH}_{3}\right), 57.7\left(C_{9 a^{\prime}}\right), 30.5\left(C_{3^{\prime \prime}}\right), 29.9\left(C_{6^{\prime}}\right)$, $26.5\left(C_{7^{\prime}}\right), 26.1\left(C_{1^{\prime}}\right), 25.4\left(C_{2^{\prime}}\right), 11.2\left(\mathrm{CH}_{3}\right)$.

HRMS (ESI+): calcd for $\mathrm{C}_{19} \mathrm{H}_{23} \mathrm{NO}_{6}: 384.1418\left[\mathrm{M}+\mathrm{Na}^{+}\right]$; found 384.1414 .

Physical and spectroscopic data of 107 (erythro):

$[\alpha]_{D}^{20}=-105.2\left(c 0.17, \mathrm{CHCl}_{3}\right)$.

m.p. $=72-75^{\circ} \mathrm{C}$.

IR (ATR): 2928, 1755, 1638, 1444, 1409, 1278, 1254, 1166, 1097, 1057, $1024 \mathrm{~cm}^{-1}$.

${ }^{1} \mathrm{H}-\mathrm{NMR}\left(400 \mathrm{MHz}, \mathrm{CDCl}_{3}\right): \delta 6.90\left(\mathrm{q}, J=1.5 \mathrm{~Hz}, 1 \mathrm{H}: \mathrm{H}_{3}\right), 6.26\left(\mathrm{t}, J=2.9 \mathrm{~Hz}, 1 \mathrm{H}: \mathrm{H}_{1^{\prime \prime \prime}}\right), 5.66(\mathrm{t}, J=2.6$ $\left.\mathrm{Hz}, 1 \mathrm{H}: \mathrm{H}_{1^{\prime \prime \prime}}\right), 5.21$ (ddd, $\left.J=8.2,6.3,1.7 \mathrm{~Hz}, 1 \mathrm{H}: \mathrm{H}_{2^{\prime \prime}}\right), 4.96$ (d, $\left.J=8.8 \mathrm{~Hz}, 1 \mathrm{H}: \mathrm{H}_{9 \mathrm{a}^{\prime}}\right), 4.16(\mathrm{~d}, J=8.5 \mathrm{~Hz}$, $\left.1 \mathrm{H}: \mathrm{H}_{3^{\prime}}\right), 3.50\left(\mathrm{~s}, 3 \mathrm{H}: \mathrm{OCH}_{3}\right), 3.15\left(\mathrm{~d}, J=4.8 \mathrm{~Hz}, 1 \mathrm{H}: \mathrm{H}_{8^{\prime}}\right), 3.08\left(\mathrm{~m}, 2 \mathrm{H}: \mathrm{H}_{6^{\prime}}, \mathrm{H}_{3^{\prime \prime}}\right), 2.51$ (ddt, J = 17.8, 6.1, 
$\left.2.9 \mathrm{~Hz}, 1 \mathrm{H}: \mathrm{H}_{3^{\prime \prime}}\right), 2.35\left(\mathrm{~m}, 1 \mathrm{H}: \mathrm{H}_{6^{\prime}}\right), 2.19\left(\mathrm{~m}, 2 \mathrm{H}: \mathrm{H}_{1^{\prime}}, \mathrm{H}_{7^{\prime}}\right), 1.95\left(\mathrm{~d}, J=1.5 \mathrm{~Hz}, 3 \mathrm{H}: \mathrm{CH}_{3}\right), 1.83(\mathrm{t}, J=15.2$ $\left.\mathrm{Hz}, 1 \mathrm{H}: \mathrm{H}_{7^{\prime}}\right), 1.65\left(\mathrm{~m}, 2 \mathrm{H}: \mathrm{H}_{1^{\prime}}, \mathrm{H}_{2^{\prime}}\right), 1.48\left(\mathrm{~m}, 1 \mathrm{H}: \mathrm{H}_{2^{\prime}}\right)$.

${ }^{13}$ C-NMR (100 MHz, $\left.\mathrm{CDCl}_{3}\right): \delta 174.4\left(\mathrm{C}_{5^{\prime}}\right), 172.4\left(\mathrm{C}_{5}\right), 170.0\left(\mathrm{C}_{5^{\prime \prime}}\right), 146.2\left(\mathrm{C}_{3}\right), 134.0\left(\mathrm{C}_{4}\right), 133.6\left(\mathrm{C}_{4^{\prime \prime}}\right)$, $123.2\left(\mathrm{C}_{1^{\prime \prime \prime}}\right), 89.0\left(\mathrm{C}_{2}\right), 82.9\left(\mathrm{C}_{8^{\prime}}\right), 75.7\left(\mathrm{C}_{2^{\prime \prime}}\right), 62.2\left(\mathrm{C}_{3^{\prime}}\right), 59.3\left(\mathrm{OCH}_{3}\right), 57.4\left(\mathrm{C}_{9 \mathrm{a}^{\prime}}\right), 30.5\left(\mathrm{C}_{3^{\prime \prime}}\right), 30.46\left(\mathrm{C}_{6^{\prime}}\right)$, $26.5\left(\mathrm{C}_{7^{\prime}}\right), 25.6\left(\mathrm{C}_{1^{\prime}}\right), 23.5\left(\mathrm{C}_{2^{\prime}}\right), 11.2\left(\mathrm{CH}_{3}\right)$.

HRMS (ESI+): calcd for $\mathrm{C}_{19} \mathrm{H}_{23} \mathrm{NO}_{6}: 384.1418\left[\mathrm{M}+\mathrm{Na}^{+}\right]$; found 384.1427 .

(2S,3'S,8'R,9a'S,2'S)-8'-Methoxy-4-methyl-3'-(4-methylene-5-oxotetrahydrofuran-2-yl)-5'thioxo-1',2',3',5',6',7',8',9a'-octahydro-5H-spiro\{furan-2,9'-pyrrolo[1,2-a] azepine\}-5-one, 112

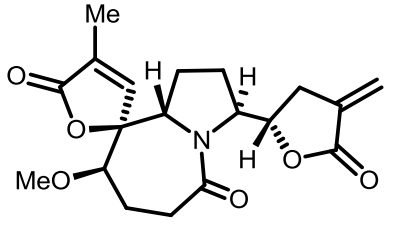

106
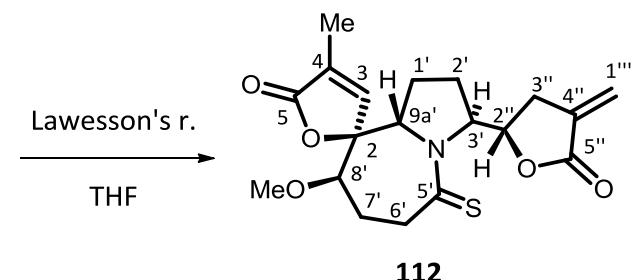

112

Lawesson's reagent $(10.1 \mathrm{mg}, 25 \mu \mathrm{mol})$ was added to a solution of 106 (16 mg, $44 \mu \mathrm{mol})$ in dry THF $(2 \mathrm{~mL})$ and the mixture was heated at the reflux temperature for $45 \mathrm{~min}$. The solvent was removed under vacuum and the residue was filtered through $\mathrm{Al}_{2} \mathrm{O}_{3}$ Brockman I using EtOAc as eluent. Evaporation of the solvent under reduced pressure afforded 112 as a white solid (8.6 mg, $22.8 \mu \mathrm{mol}, 52 \%$ yield).

Spectroscopic data of 112:

${ }^{1} \mathrm{H}-N M R\left(400 \mathrm{MHz}, \mathrm{CDCl}_{3}\right): \delta 6.83\left(\mathrm{~m}, 1 \mathrm{H}: \mathrm{H}_{3}\right), 6.23\left(\mathrm{t}, J=2.9 \mathrm{~Hz}, 1 \mathrm{H}: \mathrm{H}_{1^{\prime \prime \prime}}\right), 5.64(\mathrm{t}, J=2.5 \mathrm{~Hz}$, $\left.1 \mathrm{H}: \mathrm{H}_{1^{\prime \prime \prime}}\right), 5.47\left(\mathrm{~m}, 1 \mathrm{H}: \mathrm{H}_{2^{\prime \prime}}\right), 5.21\left(\mathrm{~d}, J=8.9 \mathrm{~Hz}, 1 \mathrm{H}: \mathrm{H}_{9 \mathrm{a}^{\prime}}\right), 5.09\left(\mathrm{~m}, 1 \mathrm{H}: \mathrm{H}_{3^{\prime}}\right), 3.50\left(\mathrm{~s}, 3 \mathrm{H}: \mathrm{OCH}_{3}\right), 3.31(\mathrm{t}, J$ $\left.=12.9 \mathrm{~Hz}, 1 \mathrm{H}: \mathrm{H}_{6^{\prime}}\right), 3.13\left(\mathrm{~m}, 2 \mathrm{H}: \mathrm{H}_{6^{\prime}}, \mathrm{H}_{8^{\prime}}\right), 2.91\left(\mathrm{ddt}, J=17.4,8.2,2.5 \mathrm{~Hz}, 1 \mathrm{H}: \mathrm{H}_{3^{\prime \prime}}\right), 2.76(\mathrm{ddt}, J=17.4$, 5.9, $\left.2.7 \mathrm{~Hz}, 1 \mathrm{H}: \mathrm{H}_{3^{\prime \prime}}\right), 2.20\left(\mathrm{~m}, 2 \mathrm{H}: \mathrm{H}_{1^{\prime}}, \mathrm{H}_{7^{\prime}}\right), 1.99\left(\mathrm{~m}, 1 \mathrm{H}: \mathrm{H}_{1^{\prime}}\right), 1.97\left(\mathrm{~s}, 3 \mathrm{H}: \mathrm{CH}_{3}\right), 1.89\left(\mathrm{~m}, 1 \mathrm{H}: \mathrm{H}_{7^{\prime}}\right), 1.79$ $\left(\mathrm{m}, 1 \mathrm{H}: \mathrm{H}_{2^{\prime}}\right), 1.71\left(\mathrm{~m}, 1 \mathrm{H}: \mathrm{H}_{2^{\prime}}\right)$.

${ }^{13}$ C-NMR (100 MHz, $\left.\mathrm{CDCl}_{3}\right): \delta 207.8\left(\mathrm{C}_{5^{\prime}}\right), 172.2 / 169.6\left(\mathrm{C}_{5^{\prime \prime}} / \mathrm{C}_{5}\right), 146.1\left(\mathrm{C}_{3}\right), 134.3 / 133.9\left(\mathrm{C}_{4} / \mathrm{C}_{4^{\prime \prime}}\right)$, $122.6\left(\mathrm{C}_{1^{\prime \prime \prime}}\right), 88.4\left(\mathrm{C}_{2}\right), 83.3\left(\mathrm{C}_{8^{\prime}}\right), 74.4\left(\mathrm{C}_{2^{\prime \prime}}\right), 65.2\left(\mathrm{C}_{3^{\prime}}\right), 62.3\left(\mathrm{C}_{9 \mathrm{a}^{\prime}}\right), 59.3\left(\mathrm{OCH}_{3}\right), 41.0\left(\mathrm{C}_{6^{\prime}}\right), 30.1$ $\left(\mathrm{C}_{1^{\prime}} / \mathrm{C}_{2^{\prime}} / \mathrm{C}_{7^{\prime}}\right), 28.6\left(\mathrm{C}_{3^{\prime \prime}}\right), 26.3 / 25.9\left(\mathrm{C}_{1^{\prime}} / \mathrm{C}_{2^{\prime}} / \mathrm{C}_{7^{\prime}}\right), 11.2\left(\mathrm{CH}_{3}\right)$. 
HRMS (ESI+): calcd for $\mathrm{C}_{19} \mathrm{H}_{23} \mathrm{NO}_{5} \mathrm{~S}: 400.1189\left[\mathrm{M}+\mathrm{Na}^{+}\right]$; found 400.1195 .

(2S,3'S,4S,8'R,9a'S,2"S,4"S)-8'-Methoxy-4-methyl-3'-(4-methyl-5-oxotetrahydrofuran-2yl)hexahydro-3H-spiro[furan-2,9'-pyrrolo[1,2-a]azepine]-5,5'(4H,6'H)-dione, 115
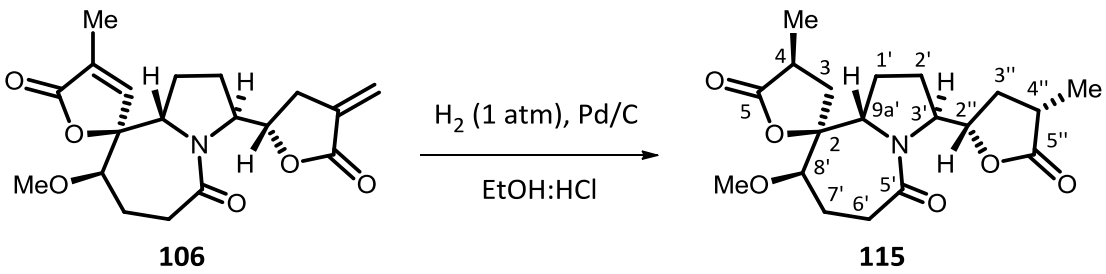

To a solution of bislactone $106(29.1 \mathrm{mg}, 80 \mu \mathrm{mol})$ in a 1:1 mixture of EtOH and $10 \% \mathrm{HCl}$ $(3.2 \mathrm{ml}), 10 \% \mathrm{Pd} / \mathrm{C}(54 \mathrm{mg}, 50.8 \mu \mathrm{mol})$ was added. The reaction mixture was stirred at atmospheric pressure of $\mathrm{H}_{2}$ for 24 h. Then, it was filtered through Celite ${ }^{\circledR}$ and the filtrate was washed with saturated solution of $\mathrm{NaHCO}_{3}$. The aqueous layer was extracted with $\mathrm{CH}_{2} \mathrm{Cl}_{2}(3 \times 2$ $\mathrm{mL}$ ). The combined organic extracts were dried over anhydrous $\mathrm{MgSO}_{4}$ and concentrated under reduced pressure. Purification of the residue by flash column chromatography on silica gel (EtOAc) furnished bislactone 115 (23.8 mg, $40 \mu \mathrm{mol}, 81 \%$ yield) as a white solid.

\section{Physical and spectroscopic data of 115:}

$[\alpha]_{\mathrm{D}}^{20}=-100.4\left(c 0.68, \mathrm{CHCl}_{3}\right)$.

m.p. $=155-157^{\circ} \mathrm{C}$.

IR (ATR): 3513, 2954, 2935, 1766, 1641, 1447, 1411, 1378, 1296, 1191, 1169, 1101, $1013 \mathrm{~cm}^{-1}$.

${ }^{1} \mathrm{H}-\mathrm{NMR}\left(400 \mathrm{MHz}, \mathrm{CDCl}_{3}\right): \delta 5.21\left(\mathrm{dt}, J=8.2,6.3 \mathrm{~Hz}, 1 \mathrm{H}: \mathrm{H}_{2^{\prime \prime}}\right), 4.75\left(\mathrm{dd}, J=8.8,3.2 \mathrm{~Hz}, 1 \mathrm{H}: \mathrm{H}_{9 \mathrm{a}^{\prime}}\right)$, $4.56\left(\mathrm{dt}, J=7.4,3.6 \mathrm{~Hz}, 1 \mathrm{H}: \mathrm{H}_{3^{\prime}}\right), 3.43\left(\mathrm{~s}, 3 \mathrm{H}: \mathrm{OCH}_{3}\right), 3.38\left(\mathrm{~m}, 1 \mathrm{H}: \mathrm{H}_{8^{\prime}}\right), 2.88\left(\mathrm{t}, J=13.2,1 \mathrm{H}: \mathrm{H}_{6^{\prime}}\right), 2.72$ $\left(m, 1 \mathrm{H}: \mathrm{H}_{4}\right), 2.63\left(\mathrm{~m}, 1 \mathrm{H}: \mathrm{H}_{4^{\prime \prime}}\right), 2.20\left(\mathrm{~m}, 5 \mathrm{H}: \mathrm{H}_{6^{\prime}}, \mathrm{H}_{3}, \mathrm{H}_{3^{\prime}}, \mathrm{H}_{1^{\prime}}, \mathrm{H}_{7^{\prime}}\right), 1.95\left(\mathrm{~m}, 3 \mathrm{H}: \mathrm{H}_{2^{\prime}}, \mathrm{H}_{1^{\prime}}, \mathrm{H}_{7^{\prime}}\right), 1.80(\mathrm{~m}$, $\left.1 \mathrm{H}: \mathrm{H}_{2^{\prime}}\right), 1.62\left(\mathrm{dd}, J=8.7,7.1 \mathrm{~Hz}, 1 \mathrm{H}: \mathrm{H}_{3}\right), 1.48\left(\mathrm{dd}, J=12.1,7.6 \mathrm{~Hz}, 1 \mathrm{H}: \mathrm{H}_{3^{\prime \prime}}\right), 1.29(\mathrm{~d}, J=7 \mathrm{~Hz}$, $\left.3 \mathrm{H}: \mathrm{CH}_{3}\right), 1.25\left(\mathrm{~d}, J=7.4 \mathrm{~Hz}, 3 \mathrm{H}: \mathrm{CH}_{3}\right)$.

${ }^{13} \mathrm{C}-\mathrm{NMR}\left(100 \mathrm{MHz}, \mathrm{CDCl}_{3}\right): \delta 178.8\left(\mathrm{C}_{5^{\prime \prime}}\right), 177.8\left(\mathrm{C}_{5}\right), 173.7\left(\mathrm{C}_{5^{\prime}}\right), 86.4\left(\mathrm{C}_{2}\right), 80.9\left(\mathrm{C}_{8^{\prime}}\right), 76.1\left(\mathrm{C}_{2^{\prime \prime}}\right)$, $60.2\left(\mathrm{C}_{3^{\prime}}\right), 59.0\left(\mathrm{OCH}_{3}\right), 57.8\left(\mathrm{C}_{9^{\prime}}\right), 35.7\left(\mathrm{C}_{4^{\prime \prime}}\right), 34.5\left(\mathrm{C}_{4}\right), 33.3\left(\mathrm{C}_{3}\right), 31.8\left(\mathrm{C}_{3^{\prime \prime}}\right), 30.8\left(\mathrm{C}_{6^{\prime}}\right), 26.2\left(\mathrm{C}_{7^{\prime}}\right)$, $24.5\left(\mathrm{C}_{1^{\prime}} / \mathrm{C}_{2^{\prime}}\right), 24.4\left(\mathrm{C}_{1^{\prime}} / \mathrm{C}_{2^{\prime}}\right), 15.8\left(\mathrm{CH}_{3}\right), 15.0\left(\mathrm{CH}_{3}\right)$. 
HRMS (ESI+): calcd for $\mathrm{C}_{19} \mathrm{H}_{27} \mathrm{NO}_{6}: 388.1731\left[\mathrm{M}+\mathrm{Na}^{+}\right]$; found 388.1736 .

(2S,3'S,4S,8'R,9a'S,2"S,4"S)-8'-Methoxy-4-methyl-3'-(4-methyl-5-oxotetrahydrofuran-2yl)octahydro-3H-spiro\{furan-2,9'-pyrrolo[1,2-a]azepin\}-5(4H)-one, 116

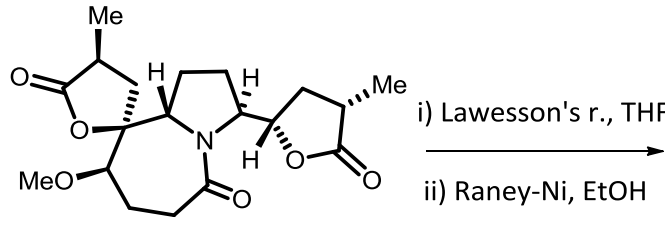

115

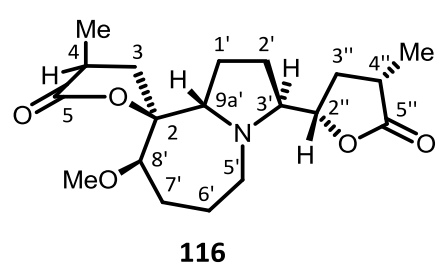

116

Lawesson's reagent $(9.4 \mathrm{mg}, 23 \mu \mathrm{mol})$ was added to a solution of $115(18 \mathrm{mg}, 44 \mu \mathrm{mol})$ in dry THF ( $2 \mathrm{~mL}$ ) and the mixture was heated at the reflux temperature for $45 \mathrm{~min}$. The solvent was removed under vacuum and the residue was filtered through $\mathrm{Al}_{2} \mathrm{O}_{3}$ Brockman I using EtOAc as eluent. Evaporation of the solvent under reduced pressure afforded a colorless oil, which was dissolved in EtOH $(1 \mathrm{~mL})$. Next, Raney-Ni $(170 \mathrm{mg}$ ) was added to the solution and the reaction mixture was heated at the reflux temperature for $1 \mathrm{~h}$. Then, it was filtered through Celite ${ }^{\circledR}$ and the solvent was evaporated in vacuo. Purification of the residue by flash chromatography on silica gel (EtOAc) furnished the amine $\mathbf{1 1 6}$ (9.3 mg, $26.4 \mu \mathrm{mol}, 51 \%$ yield) as an oil.

Physical and spectroscopic data of 116:

$[\alpha]_{\mathrm{D}}^{20}=-20.3\left(c 0.41, \mathrm{CHCl}_{3}\right)$.

IR (ATR): 3510, 2934, 2876, 2360, 1761, 1455, 1376, 1295, 1195, 1168, 1099, $1017 \mathrm{~cm}^{-1}$.

${ }^{1} \mathrm{H}-\mathrm{NMR}\left(400 \mathrm{MHz}, \mathrm{CDCl}_{3}\right): \delta 4.24\left(\mathrm{~m}, 1 \mathrm{H}: \mathrm{H}_{2^{\prime \prime}}\right), 3.63\left(\mathrm{t}, J=8.0 \mathrm{~Hz}, 1 \mathrm{H}: \mathrm{H}_{9 \mathrm{a}^{\prime}}\right), 3.41\left(\mathrm{~m}, 1 \mathrm{H}: \mathrm{H}_{3^{\prime}}\right), 3.35(\mathrm{~s}$, $\left.3 \mathrm{H}: \mathrm{OCH}_{3}\right), 3.26\left(\mathrm{dd}, J=8.1,4.2 \mathrm{~Hz}, 1 \mathrm{H}: \mathrm{H}_{8^{\prime}}\right), 3.18\left(\mathrm{~m}, 2 \mathrm{H}: \mathrm{H}_{5^{\prime}}\right), 2.85\left(\mathrm{~m}, 1 \mathrm{H}: \mathrm{H}_{4}\right), 2.59\left(\mathrm{~m}, 1 \mathrm{H}: \mathrm{H}_{4^{\prime \prime}}\right)$, $2.37\left(\mathrm{~m}, 2 \mathrm{H}: \mathrm{H}_{3}, \mathrm{H}_{3^{\prime \prime}}\right), 2.03\left(\mathrm{~m}, 1 \mathrm{H}: \mathrm{H}_{1^{\prime}}\right), 1.84\left(\mathrm{~m}, 3 \mathrm{H}: \mathrm{H}_{2^{\prime}}, 2 \mathrm{H}_{7^{\prime}}\right), 1.55\left(\mathrm{~m}, 6 \mathrm{H}: \mathrm{H}_{1^{\prime}}, \mathrm{H}_{2^{\prime}}, \mathrm{H}_{3^{\prime \prime}}, \mathrm{H}_{3}, 2 \mathrm{H}_{6^{\prime}}\right), 1.26$ (d, $\left.J=4.2 \mathrm{~Hz}, 3 \mathrm{H}: \mathrm{CH}_{3}\right), 1.20\left(\mathrm{~d}, J=4.0 \mathrm{~Hz}, 3 \mathrm{H}: \mathrm{CH}_{3}\right)$.

${ }^{13} \mathrm{C}-\mathrm{NMR}\left(100 \mathrm{MHz}, \mathrm{CDCl}_{3}\right)$ : $\delta 180.2\left(\mathrm{C}_{5^{\prime \prime}} / \mathrm{C}_{5}\right), 179.6\left(\mathrm{C}_{5^{\prime \prime}} / \mathrm{C}_{5}\right), 91.6\left(\mathrm{C}_{2}\right), 82.8\left(\mathrm{C}_{8^{\prime}}\right), 81.4\left(\mathrm{C}_{2^{\prime \prime}}\right), 66.7$ $\left(C_{9 a^{\prime}}\right), 64.8\left(C_{3^{\prime}}\right), 57.9\left(\mathrm{OCH}_{3}\right), 45.9\left(C_{5^{\prime}}\right), 37.5\left(C_{3}\right), 35.1 / 35.0 / 34.6\left(C_{4^{\prime \prime}} / C_{4} / C_{3^{\prime \prime}}\right), 27.5\left(C_{2^{\prime}}\right), 26.4$ $\left(\mathrm{C}_{1^{\prime}} / \mathrm{C}_{7^{\prime}}\right), 26.3\left(\mathrm{C}_{1^{\prime}} / \mathrm{C}_{7^{\prime}}\right), 21.2\left(\mathrm{C}_{6^{\prime}}\right), 16.0\left(\mathrm{CH}_{3}\right), 15.0\left(\mathrm{CH}_{3}\right)$.

HRMS (ESI+): calcd for $\mathrm{C}_{19} \mathrm{H}_{29} \mathrm{NO}_{5}$ : $352.2118\left[\mathrm{M}+\mathrm{H}^{+}\right]$; found 352.2119. 
(2S,3'S, 4S,8'R,9a'S,2"R,4"R)-8'-Methoxy-4-methyl-3'-(4-methyl-5-oxotetrahydrofuran-2-

yl)hexahydro-3H-spiro\{furan-2,9'-pyrrolo[1,2-a]azepine\}-5,5'(4H,6'H)-dione, 118

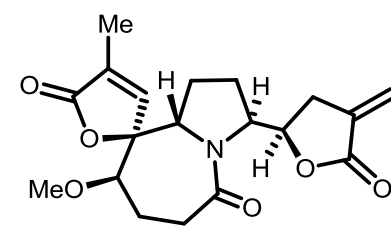

107
(2)
EtOH:HC

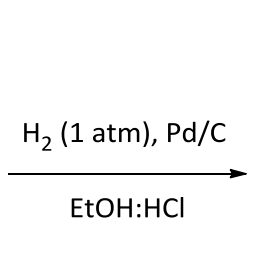

\footnotetext{
.
}

To a solution of bislactone $107(45.9 \mathrm{mg}, 127 \mu \mathrm{mol})$ in a $1: 1$ mixture of EtOH and $10 \% \mathrm{HCl}$ $(3.2 \mathrm{ml}), 10 \% \mathrm{Pd} / \mathrm{C}(72 \mathrm{mg}, 67.7 \mathrm{\mu mol})$ was added. The reaction mixture was stirred at atmospheric pressure of $\mathrm{H}_{2}$ for $24 \mathrm{~h}$. Then, it was filtered through Celite ${ }^{\circledR}$ and the filtrate was washed with saturated solution of $\mathrm{NaHCO}_{3}$. The aqueous layer was extracted with $\mathrm{CH}_{2} \mathrm{Cl}_{2}(3 \times 2$ $\mathrm{mL}$ ). The combined organic extracts were dried over anhydrous $\mathrm{MgSO}_{4}$ and concentrated under reduced pressure. Purification of the residue by flash column chromatography on silica gel (EtOAc) furnished bislactone 118 (39.0 mg, 94 umol, 84\% yield).

Physical and spectroscopic data of 118:

$[\alpha]_{\mathrm{D}}^{20}=-122.1\left(c 0.34, \mathrm{CHCl}_{3}\right)$

IR (ATR): 2930, 2360, 1764, 1637, 1444, 1411, 1294, 1169, 1097, $1012 \mathrm{~cm}^{-1}$.

${ }^{1} \mathrm{H}-\mathrm{NMR}\left(400 \mathrm{MHz}, \mathrm{CDCl}_{3}\right.$ ): $\delta 5.07$ (dd, $\left.J=11.1,5.7 \mathrm{~Hz}, 1 \mathrm{H}: \mathrm{H}_{2^{\prime \prime}}\right), 4.80\left(\mathrm{~d}, J=9.5 \mathrm{~Hz}, 1 \mathrm{H}^{\prime} \mathrm{H}_{9 \mathrm{a}^{\prime}}\right), 4.29$ $\left(\mathrm{d}, J=8.2 \mathrm{~Hz}, 1 \mathrm{H}: \mathrm{H}_{3^{\prime}}\right), 3.42\left(\mathrm{~s}, 3 \mathrm{H}: \mathrm{OCH}_{3}\right), 3.33\left(\mathrm{~d}, J=2.6 \mathrm{~Hz}, 1 \mathrm{H}: \mathrm{H}_{8^{\prime}}\right), 2.94\left(\mathrm{t}, J=13.3,1 \mathrm{H}: \mathrm{H}_{6^{\prime}}\right), 2.72$ $\left(\mathrm{m}, 1 \mathrm{H}: \mathrm{H}_{4}\right), 2.63\left(\mathrm{~m}, 1 \mathrm{H}: \mathrm{H}_{4^{\prime \prime}}\right), 2.46\left(\mathrm{~m}, 1 \mathrm{H}: \mathrm{H}_{3^{\prime \prime}}\right), 2.39\left(\mathrm{~m}, 1 \mathrm{H}: \mathrm{H}_{1^{\prime}}\right), 2.25\left(\mathrm{~m}, 1 \mathrm{H}: \mathrm{H}_{6^{\prime}}\right), 2.15(\mathrm{~m}$, $\left.2 \mathrm{H}: \mathrm{H}_{3}, \mathrm{H}_{7^{\prime}}\right), 1.90\left(\mathrm{~m}, 4 \mathrm{H}: 2 \mathrm{H}_{2^{\prime}}, \mathrm{H}_{1^{\prime}}, \mathrm{H}_{7^{\prime}}\right), 1.61\left(\mathrm{dd}, J=13.9,11.2 \mathrm{~Hz}, 1 \mathrm{H}: \mathrm{H}_{3}\right), 1.45\left(\mathrm{q}, J=12.1 \mathrm{~Hz}, 1 \mathrm{H}: \mathrm{H}_{3^{\prime \prime}}\right)$, $1.29\left(\mathrm{~d}, J=4.5 \mathrm{~Hz}, 3 \mathrm{H}: \mathrm{CH}_{3}\right), 1.25\left(\mathrm{~d}, J=4.4 \mathrm{~Hz}, 3 \mathrm{H}: \mathrm{CH}_{3}\right)$.

${ }^{13} \mathrm{C}-\mathrm{NMR}\left(100 \mathrm{MHz}, \mathrm{CDCl}_{3}\right): \delta 179.0\left(\mathrm{C}_{5^{\prime \prime}}\right), 177.9\left(\mathrm{C}_{5}\right), 173.8\left(\mathrm{C}_{5^{\prime}}\right), 86.1\left(\mathrm{C}_{2}\right), 81.0\left(\mathrm{C}_{8^{\prime}}\right), 76.7\left(\mathrm{C}_{2^{\prime \prime}}\right)$, $61.7\left(\mathrm{C}_{3^{\prime}}\right), 59.0\left(\mathrm{OCH}_{3}\right), 57.1\left(\mathrm{C}_{9 \mathrm{a}^{\prime}}\right), 35.6 / 34.6 / 33.3 / 31.8\left(\mathrm{C}_{4^{\prime \prime}} / \mathrm{C}_{4} / \mathrm{C}_{3} / \mathrm{C}_{3^{\prime \prime}}\right), 30.9\left(\mathrm{C}_{6^{\prime}}\right), 26.1 / 24.5 / 23.4$ $\left(\mathrm{C}_{1^{\prime}} / \mathrm{C}_{2^{\prime}} / \mathrm{C}_{7^{\prime}}\right), 15.9\left(\mathrm{CH}_{3}\right), 15.1\left(\mathrm{CH}_{3}\right)$.

HRMS (ESI+): calcd for $\mathrm{C}_{19} \mathrm{H}_{27} \mathrm{NO}_{6}$ : $388.1731\left[\mathrm{M}+\mathrm{Na}^{+}\right]$; found 388.1724. 
(2S,3'S,4S,8'R,9a'S,2"R,4"R)-8'-Methoxy-4-methyl-3'-(4-methyl-5-oxotetrahydrofuran-2-

yl)-5'-thioxooctahydro-3H-spiro[furan-2,9'-pyrrolo[1,2-a]azepin]-5(4H)-one, 122

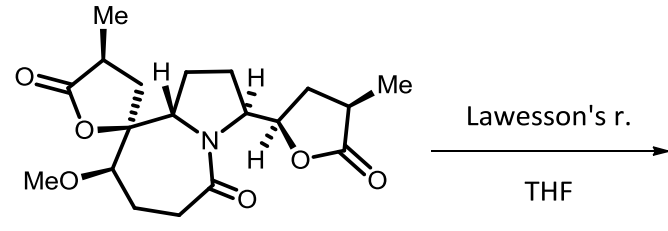

118

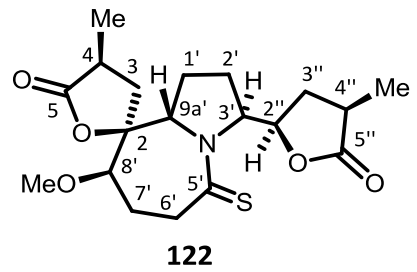

122

Lawesson's reagent $(9.2 \mathrm{mg}, 23 \mu \mathrm{mol})$ was added to a solution of $118(16 \mathrm{mg}, 44 \mu \mathrm{mol})$ in dry THF $(2 \mathrm{~mL}$ ) and the mixture was heated at the reflux temperature for $45 \mathrm{~min}$. The solvent was removed under vacuum and the residue was filtered through $\mathrm{Al}_{2} \mathrm{O}_{3}$ Brockman I using EtOAc as eluent. Evaporation of the solvent under reduced pressure afforded $\mathbf{1 2 2}$ as a white solid (12.0 $\mathrm{mg}, 31.5 \mu \mathrm{mol}, 72 \%$ yield).

Physical and spectroscopic data of 122:

$[\alpha]_{\mathrm{D}}^{20}=-38.3\left(\mathrm{c} 0.65, \mathrm{CHCl}_{3}\right)$.

m.p. $=180-182^{\circ} \mathrm{C}$ (hexane).

IR (ATR): 2929, 2362, 1770, 1440, 1377, 1294, 1171, $1090 \mathrm{~cm}^{-1}$.

${ }^{1} \mathrm{H}-\mathrm{NMR}\left(400 \mathrm{MHz}, \mathrm{CDCl}_{3}\right): \delta 5.52\left(\mathrm{dd}, J=11.1,5.7 \mathrm{~Hz}, 1 \mathrm{H}: \mathrm{H}_{2^{\prime \prime}}\right), 5.11\left(\mathrm{~d}, J=9.5 \mathrm{~Hz}, 1 \mathrm{H}: \mathrm{H}_{9 \mathrm{a}^{\prime}}\right), 4.96$ $\left(\mathrm{d}, J=8.2 \mathrm{~Hz}, 1 \mathrm{H}: \mathrm{H}_{3^{\prime}}\right), 3.42\left(\mathrm{~s}, 3 \mathrm{H}: \mathrm{OCH}_{3}\right), 3.34\left(\mathrm{~m}, 1 \mathrm{H}: \mathrm{H}_{8^{\prime}}\right), 3.25\left(\mathrm{td}, J=13.3,1.8 \mathrm{~Hz}, 1 \mathrm{H}: \mathrm{H}_{6^{\prime}}\right), 3.07$ $\left(\mathrm{dd}, J=13.3,6.8 \mathrm{~Hz}, 1 \mathrm{H}: \mathrm{H}_{6^{\prime}}\right), 2.72\left(\mathrm{~m}, 2 \mathrm{H}: \mathrm{H}_{4^{\prime \prime}}, \mathrm{H}_{4}\right), 2.55\left(\mathrm{~m}, 2 \mathrm{H}: \mathrm{H}_{3^{\prime \prime}}, \mathrm{H}_{1^{\prime}}\right), 2.29\left(\mathrm{~m}, 3 \mathrm{H}: \mathrm{H}_{3}, \mathrm{H}_{7^{\prime}}, \mathrm{H}_{1^{\prime}}\right), 1.95$ $\left(\mathrm{m}, 3 \mathrm{H}: 2 \mathrm{H}_{2^{\prime}}, \mathrm{H}_{7^{\prime}}\right), 1.61\left(\mathrm{~m}, 1 \mathrm{H}: \mathrm{H}_{3}\right), 1.42\left(\mathrm{q}, J=12.1 \mathrm{~Hz}, 1 \mathrm{H}: \mathrm{H}_{3^{\prime \prime}}\right), 1.29\left(\mathrm{~d}, J=3.1 \mathrm{~Hz}, 3 \mathrm{H}: \mathrm{CH}_{3}\right), 1.25(\mathrm{~d}$, $\left.J=3.0 \mathrm{~Hz}, 3 \mathrm{H}: \mathrm{CH}_{3}\right)$.

${ }^{13} \mathrm{C}-\mathrm{NMR}\left(100 \mathrm{MHz}, \mathrm{CDCl}_{3}\right)$ : $\delta 204.8\left(\mathrm{C}_{5^{\prime}}\right), 178.9\left(\mathrm{C}_{5^{\prime \prime}}\right), 177.7\left(\mathrm{C}_{5}\right), 85.1\left(\mathrm{C}_{2}\right), 80.9\left(\mathrm{C}_{8^{\prime}}\right), 76.0\left(\mathrm{C}_{2^{\prime \prime}}\right)$, $67.0\left(C_{3^{\prime}}\right), 61.6\left(C_{9 a^{\prime}}\right), 59.0\left(\mathrm{OCH}_{3}\right), 41.1\left(C_{6^{\prime}}\right), 35.5 / 34.6 / 34.5 / 34.2\left(C_{4^{\prime \prime}} / C_{4} / C_{3} / C_{3^{\prime \prime}}\right), 26.5 / 26.4$ $\left(\mathrm{C}_{1^{\prime}} / \mathrm{C}_{2^{\prime}}\right), 23.8\left(\mathrm{C}_{7^{\prime}}\right), 15.9\left(\mathrm{CH}_{3}\right), 15.2\left(\mathrm{CH}_{3}\right)$.

HRMS (ESI+): calcd for $\mathrm{C}_{19} \mathrm{H}_{27} \mathrm{NO}_{5} \mathrm{~S}: 404.1502\left[\mathrm{M}+\mathrm{Na}^{+}\right]$; found 404.1497. 
(2S,3'S, 4S, 8'R,9a'S, 2" R,4"R)-8'-Methoxy-4-methyl-3'-(4-methyl-5-oxotetrahydrofuran-2-

yl)octahydro-3H-spiro\{furan-2,9'-pyrrolo[1,2-a]azepin\}-5(4H)-one, 120

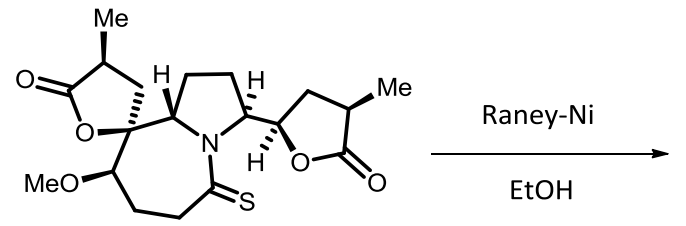

122

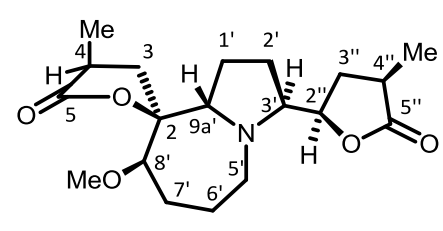

120

To a solution of $122(8 \mathrm{mg}, 21 \mu \mathrm{mol})$ in EtOH $(1 \mathrm{~mL})$, Raney-Ni $(170 \mathrm{mg})$ was added and the reaction mixture was heated at the reflux temperature for $1.3 \mathrm{~h}$. Then, it was filtered through Celite ${ }^{\circledast}$ and the solvent was evaporated in vacuo. Purification of the residue by flash chromatography on silica gel furnished amine 120 (5.2 mg, $14.8 \mu \mathrm{mol}, 71 \%$ yield) as an oil.

Physical and spectroscopic data of 120:

$[\alpha]_{D}^{20}=-30.3\left(c 0.45, \mathrm{CHCl}_{3}\right)$.

IR (ATR): 2935, 2360, 2341, 1764, 1456, 1376, 1196, 1169, 1100, $1018 \mathrm{~cm}^{-1}$.

${ }^{1} \mathrm{H}-\mathrm{NMR}\left(400 \mathrm{MHz}, \mathrm{CDCl}_{3}\right): \delta 4.42\left(\mathrm{ddd}, J=10.6,5.7,3.2 \mathrm{~Hz}, 1 \mathrm{H}: \mathrm{H}_{2^{\prime \prime}}\right), 3.60\left(\mathrm{t}, J=8.0 \mathrm{~Hz}, 1 \mathrm{H}: \mathrm{H}_{9 \mathrm{a}^{\prime}}\right.$ ), $3.46\left(\mathrm{~m}, 1 \mathrm{H}: \mathrm{H}_{3^{\prime}}\right), 3.35\left(\mathrm{~s}, 3 \mathrm{H}: \mathrm{OCH}_{3}\right), 3.28\left(\mathrm{dd}, J=8.1,4.2 \mathrm{~Hz}, 1 \mathrm{H}: \mathrm{H}_{8^{\prime}}\right), 3.12$ (ddd, $J=10.6,5.7,3.2$ $\left.\mathrm{Hz}, 1 \mathrm{H}: \mathrm{H}_{5^{\prime}}\right), 2.95\left(\mathrm{~m}, 1 \mathrm{H}: \mathrm{H}_{5^{\prime}}\right), 2.85\left(\mathrm{~m}, 1 \mathrm{H}: \mathrm{H}_{4}\right), 2.66\left(\mathrm{~m}, 1 \mathrm{H}: \mathrm{H}_{4^{\prime \prime}}\right), 2.43\left(\mathrm{dd}, J=12.79 .3 \mathrm{~Hz}, 1 \mathrm{H}: \mathrm{H}_{3}\right)$, $2.36\left(m, 1 \mathrm{H}: \mathrm{H}_{3^{\prime \prime}}\right), 2.03\left(\mathrm{~m}, 1 \mathrm{H}: \mathrm{H}_{1^{\prime}}\right), 1.84\left(\mathrm{~m}, 3 \mathrm{H}: \mathrm{H}_{2^{\prime}}, 2 \mathrm{H}_{7^{\prime}}\right), 1.60\left(\mathrm{~m}, 6 \mathrm{H}: \mathrm{H}_{1^{\prime}}, \mathrm{H}_{2^{\prime}}, \mathrm{H}_{3^{\prime \prime}}, \mathrm{H}_{3}, 2 \mathrm{H}_{6^{\prime}}\right), 1.26(\mathrm{~d}, J$ $\left.=4.2 \mathrm{~Hz}, 3 \mathrm{H}: \mathrm{CH}_{3}\right), 1.20\left(\mathrm{~d}, J=4.0 \mathrm{~Hz}, 3 \mathrm{H}: \mathrm{CH}_{3}\right.$ ).

${ }^{13} \mathrm{C}-\mathrm{NMR}\left(100 \mathrm{MHz}, \mathrm{CDCl}_{3}\right): \delta$ 180.2/179.3 $\left(\mathrm{C}_{5^{\prime \prime}} / \mathrm{C}_{5}\right), 91.3\left(\mathrm{C}_{2}\right), 82.9\left(\mathrm{C}_{8^{\prime}}\right), 79.2\left(\mathrm{C}_{2^{\prime \prime}}\right), 67.4\left(\mathrm{C}_{9^{\prime}}\right), 63.5$ $\left(C_{3^{\prime}}\right), 57.9\left(\mathrm{OCH}_{3}\right), 45.9\left(\mathrm{C}_{5^{\prime}}\right), 38.0\left(\mathrm{C}_{3}\right), 35.7 / 35.0 / 33.5\left(\mathrm{C}_{4^{\prime \prime}} / \mathrm{C}_{4} / \mathrm{C}_{3^{\prime \prime}}\right), 27.4 / 26.4 / 25.6\left(\mathrm{C}_{2^{\prime}} / \mathrm{C}_{1^{\prime}} / \mathrm{C}_{7^{\prime}}\right)$, $22.4\left(\mathrm{C}_{6}\right), 16.0\left(\mathrm{CH}_{3}\right), 15.3\left(\mathrm{CH}_{3}\right)$.

HRMS (ESI+): calcd for $\mathrm{C}_{19} \mathrm{H}_{29} \mathrm{NO}_{5}: 352.2118\left[\mathrm{M}+\mathrm{H}^{+}\right]$; found 352.2119 . 
(2S,3'S, 8'R,9a'S)-3'-tert-Butyldiphenylsilyloxymethyl-8'-methoxy-1',2',3',7',8',9a'-hexa-hydro$5 H$-spiro\{furan-2,9'-pyrrolo[1,2-a]azepine\}-5,5'(6'H)-dione, 126, and Diethyl (2S,3'S, 8'R,9a'S)-

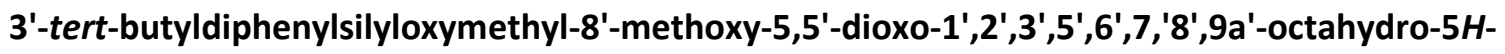
spiro\{furan-2,9'-pyrrolo[1,2-a]azepin\}-4-yl\}phosphonate, 130

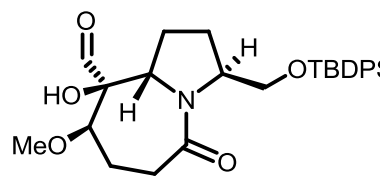

62

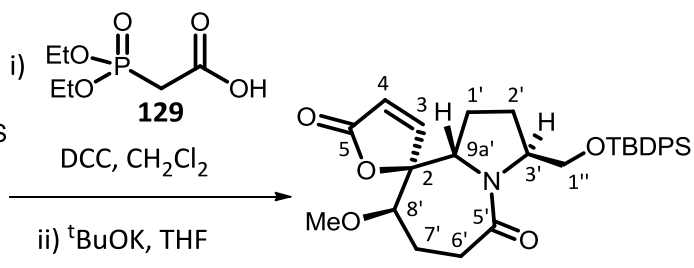

126

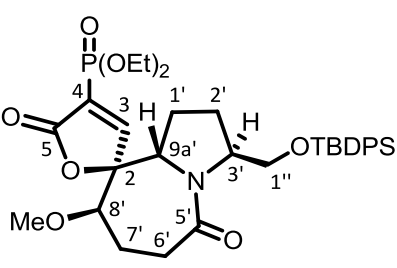

130

A solution of diethylphosphonoacetic acid, 129 , in dry $\mathrm{CH}_{2} \mathrm{Cl}_{2}(1 \mathrm{M}, 1.20 \mathrm{~mL}, 1.20 \mathrm{mmol})$ was added to a stirred solution of lactam $62(507.4 \mathrm{mg}, 1.02 \mathrm{mmol})$ in dry $\mathrm{CH}_{2} \mathrm{Cl}_{2}(3.8 \mathrm{~mL})$ under $\mathrm{N}_{2}$ atmosphere at room temperature. Then, a solution of $\mathrm{DCC}(1 \mathrm{M}, 1.2 \mathrm{~mL}, 1.2 \mathrm{mmol})$ was slowly added. After $1.5 \mathrm{~h}$, TLC analysis (EtOAc) showed no starting material. The mixture was filtered through a sintered glass and the organic solvent was evaporated under vacuum. The remaining residue was filtered through silica gel (EtOAc) and the solvent was evaporated in vacuo to afford a colorless oil, which was dissolved in THF (14 ml). Then, ${ }^{\mathrm{t}} \mathrm{BuOK}(90 \mathrm{mg}, 0.80 \mathrm{mmol}$ ) was added and the reaction mixture was stirred at room temperature for $20 \mathrm{~min}$. The organic solvent was evaporated under reduced pressure and the resulting oil was purified on silica gel (EtOAc:hexanes 1:1) to furnish 126 (154.8 mg, $0.24 \mathrm{mmol}, 23 \%$ yield) and 130 (168.7 mg, 0.33 mmol, 32\% yield) as yellowish oils.

\section{Physical and spectroscopic data of 126:}

$[\alpha]_{D}^{20}=-71.0\left(c 0.99, \mathrm{CHCl}_{3}\right)$.

IR (ATR): 2928, 2854, 1756, 1643, 1444, 1415, 1178, $1080 \mathrm{~cm}^{-1}$.

${ }^{1} \mathrm{H}-\mathrm{NMR}\left(400 \mathrm{MHz}, \mathrm{CDCl}_{3}\right): \delta 7.60\left(\mathrm{~m}, 4 \mathrm{H}_{\mathrm{Ar}}\right), 7.38\left(\mathrm{~m}, 7 \mathrm{H}: 6 \mathrm{H}_{\mathrm{Ar}}, \mathrm{H}_{3}\right), 6.27\left(\mathrm{~d}, J=5.8 \mathrm{~Hz}, 1 \mathrm{H}: \mathrm{H}_{4}\right), 4.77$ $\left(\mathrm{d}, J=8.9 \mathrm{~Hz}, 1 \mathrm{H}: \mathrm{H}_{9 \mathrm{a}^{\prime}}\right), 4.18\left(\mathrm{~m}, 1 \mathrm{H}: \mathrm{H}_{3^{\prime}}\right), 3.82\left(\mathrm{dd}, J=10.0,3.1 \mathrm{~Hz}, 1 \mathrm{H}: \mathrm{H}_{1^{\prime \prime}}\right), 3.75(\mathrm{dd}, J=10.0,5.9$ $\left.\mathrm{Hz}, 1 \mathrm{H}: \mathrm{H}_{1^{\prime \prime}}\right), 3.51\left(\mathrm{~s}, 3 \mathrm{H}: \mathrm{OCH}_{3}\right), 3.19\left(\mathrm{~d}, J=3.7 \mathrm{~Hz}, 1 \mathrm{H}: \mathrm{H}_{8^{\prime}}\right), 2.96\left(\mathrm{t}, J=13.1 \mathrm{~Hz}, 1 \mathrm{H}: \mathrm{H}_{6^{\prime}}\right), 2.20(\mathrm{~m}$, $\left.3 \mathrm{H}: \mathrm{H}_{1^{\prime}}, \mathrm{H}_{6^{\prime}}, \mathrm{H}_{7^{\prime}}\right), 1.94\left(\mathrm{dd}, J=13.0,7.9 \mathrm{~Hz}, 1 \mathrm{H}: \mathrm{H}_{2^{\prime}}\right), 1.81\left(\mathrm{t}, J=14.3 \mathrm{~Hz}, 1 \mathrm{H}: \mathrm{H}_{7^{\prime}}\right), 1.72(\mathrm{dd}, J=14.0,7.5$ $\left.\mathrm{Hz}, 1 \mathrm{H}: \mathrm{H}_{1^{\prime}}\right), 1.53\left(\mathrm{~m}, 1 \mathrm{H}: \mathrm{H}_{2^{\prime}}\right), 1.04\left(\mathrm{~s}, 9 \mathrm{H}: \mathrm{C}\left(\mathrm{CH}_{3}\right)_{3}\right)$. 
${ }^{13}$ C-NMR $\left(100 \mathrm{MHz}, \mathrm{CDCl}_{3}\right): \delta 173.3\left(\mathrm{C}_{5}\right), 171.4\left(\mathrm{C}_{5^{\prime}}\right), 154.7\left(\mathrm{C}_{3}\right), 135.72\left(\mathrm{C}_{\mathrm{Ph}}\right), 135.69\left(\mathrm{C}_{\mathrm{Ph}}\right), 133.6$ $\left(C_{\text {ph }}\right), 133.5\left(C_{\text {ph }}\right), 129.9\left(C_{\text {ph }}\right), 127.9\left(C_{\text {ph }}\right), 124.7\left(C_{4}\right), 91.8\left(C_{2}\right), 83.0\left(C_{8^{\prime}}\right), 63.1\left(C_{1^{\prime \prime}}\right), 60.1\left(C_{3^{\prime}}\right), 59.3$ $\left.\left(\mathrm{OCH}_{3}\right), 57.2\left(\mathrm{C}_{9 \mathrm{a}^{\prime}}\right), 30.4\left(\mathrm{C}_{6^{\prime}}\right), 27.1\left(\mathrm{C}\left(\mathrm{CH}_{3}\right)_{3}\right), 26.8 / 26.5 / 25.2\left(\mathrm{C}_{1^{\prime}} / \mathrm{C}_{2^{\prime}} / \mathrm{C}_{7^{\prime}}\right), 19.4\left(\mathrm{C}^{\prime} \mathrm{CH}_{3}\right)_{3}\right)$.

HRMS (ESI+): calcd for $\mathrm{C}_{30} \mathrm{H}_{37} \mathrm{NO}_{5} \mathrm{Si}: 542.2323\left[\mathrm{M}+\mathrm{Na}^{+}\right]$; found 542.2329 .

Physical and spectroscopic data of 130:

$[\alpha]_{D}^{20}=-59.6\left(c 0.90, \mathrm{CHCl}_{3}\right)$.

IR (ATR): 2929, 2850, 1767, 1646, 1444, 1408, 1256, 1163, 1104, $1019 \mathrm{~cm}^{-1}$.

${ }^{1} \mathrm{H}-\mathrm{NMR}\left(400 \mathrm{MHz}, \mathrm{CDCl}_{3}\right): \delta 7.92\left(\mathrm{~d}, J=9.8 \mathrm{~Hz}, 1 \mathrm{H}: \mathrm{H}_{3}\right), 7.62\left(\mathrm{~m}, 4 \mathrm{H}_{\mathrm{Ar}}\right), 7.40\left(\mathrm{~m}, 6 \mathrm{H}_{\mathrm{Ar}}\right), 4.78(\mathrm{~d}, J=$ $\left.9.0 \mathrm{~Hz}, 1 \mathrm{H}: \mathrm{H}_{9^{\prime}}\right), 4.28\left(\mathrm{~m}, 4 \mathrm{H}: 2 \mathrm{OCH}_{2} \mathrm{CH}_{3}\right), 4.21\left(\mathrm{~m}, 1 \mathrm{H}: \mathrm{H}_{3^{\prime}}\right), 3.79\left(\mathrm{~m}, 2 \mathrm{H}: 2 \mathrm{H}_{1^{\prime \prime}}\right), 3.51\left(\mathrm{~s}, 3 \mathrm{H}: \mathrm{OCH}_{3}\right)$, $3.25\left(\mathrm{~m}, 1 \mathrm{H}: \mathrm{H}_{8^{\prime}}\right), 2.94\left(\mathrm{td}, J=13.7,1.5 \mathrm{~Hz}, 1 \mathrm{H}: \mathrm{H}_{6^{\prime}}\right), 2.28\left(\mathrm{~m}, 2 \mathrm{H}: \mathrm{H}_{1^{\prime}}, \mathrm{H}_{6^{\prime}}\right), 2.17\left(\mathrm{~m}, 1 \mathrm{H}: \mathrm{H}_{7^{\prime}}\right), 1.97(\mathrm{dd}, J$ $\left.=13.2,7.6 \mathrm{~Hz}, 1 \mathrm{H}: \mathrm{H}_{2^{\prime}}\right), 1.84\left(\mathrm{~m}, 1 \mathrm{H}: \mathrm{H}_{7^{\prime}}\right), 1.70\left(\mathrm{~m}, 1 \mathrm{H}: \mathrm{H}_{1^{\prime}}\right), 1.50\left(\mathrm{~m}, 1 \mathrm{H}: \mathrm{H}_{2^{\prime}}\right), 1.40(\mathrm{t}, J=7.1 \mathrm{~Hz}, 6 \mathrm{H}$ : $\left.2 \mathrm{OCH}_{2} \mathrm{CH}_{3}\right), 1.06\left(\mathrm{~s}, 9 \mathrm{H}: \mathrm{C}\left(\mathrm{CH}_{3}\right)_{3}\right)$.

${ }^{13}$ C-NMR $\left(100 \mathrm{MHz}, \mathrm{CDCl}_{3}\right): \delta 173.1\left(\mathrm{C}_{5^{\prime}}\right), 168.1+167.9\left(\mathrm{C}_{5}\right), 164.6+164.5\left(\mathrm{C}_{3}\right), 135.7\left(\mathrm{C}_{\mathrm{Ph}}\right), 135.6$ $\left(\mathrm{C}_{\mathrm{Ph}}\right), 133.4\left(\mathrm{C}_{\mathrm{Ph}}\right), 129.90\left(\mathrm{C}_{\mathrm{Ph}} / \mathrm{C}_{4}\right), 127.8\left(\mathrm{C}_{\mathrm{Ph}} / \mathrm{C}_{4}\right), 91.4\left(\mathrm{C}_{2}\right), 82.3\left(\mathrm{C}_{8^{\prime}}\right), 63.8\left(\mathrm{OCH}_{2} \mathrm{CH}_{3}\right), 63.1\left(\mathrm{C}_{1^{\prime \prime}}\right)$, $60.1\left(\mathrm{C}_{3^{\prime}}\right), 59.3\left(\mathrm{OCH}_{3}\right), 57.5\left(\mathrm{C}_{9 a^{\prime}}\right), 30.2\left(\mathrm{C}_{6^{\prime}}\right), 27.0\left(\mathrm{C}\left(\mathrm{CH}_{3}\right)_{3}\right), 26.8 / 26.4 / 25.3\left(\mathrm{C}_{1^{\prime}} / \mathrm{C}_{2^{\prime}} / \mathrm{C}_{7^{\prime}}\right), 19.3$ $\left(\mathrm{C}\left(\mathrm{CH}_{3}\right)_{3}\right), 16.5\left(\mathrm{OCH}_{2} \mathrm{CH}_{3}\right)$.

HRMS (ESI+): calcd for $\mathrm{C}_{34} \mathrm{H}_{46} \mathrm{NO}_{8} \mathrm{PSi}: 678.2623\left[\mathrm{M}+\mathrm{Na}^{+}\right]$; found 678.2612.

Conversion of phosphonate 130 into 126

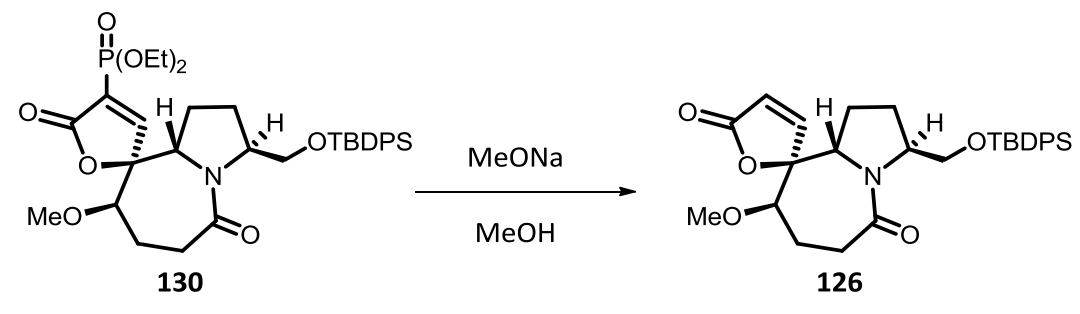

To a stirred solution of 130 (134.4 mg, $205 \mu \mathrm{mol})$ in $\mathrm{MeOH}(4 \mathrm{~mL})$, NaOMe (22.2 mg, $410 \mu \mathrm{mol})$ was added at room temperature. After $16 \mathrm{~h}$, TLC analysis (EtOAC) of the reaction mixture revealed the absence starting material. Then, the solvent was evaporated under vacuum, $\mathrm{CH}_{2} \mathrm{Cl}_{2}$ $(3 \mathrm{~mL})$ was added and the organic phase was washed with water $(3 \times 3 \mathrm{~mL})$. The combined organic 
extracts were dried over anhydrous $\mathrm{MgSO}_{4}$ and concentrated under reduced pressure to afford 126 (98.6 mg, $189.7 \mu \mathrm{mol}, 93 \%$ yield).

(4S,9R)-4-(((tert-butyldiphenylsilyl)oxy)methyl)-10a-hydroxy-9-methoxyhexahydropyrido[1,2a]azepine-6,10(2H,7H)-dione, 136

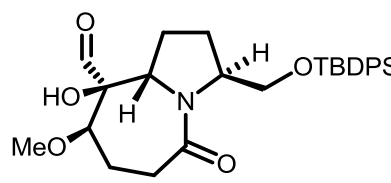

62

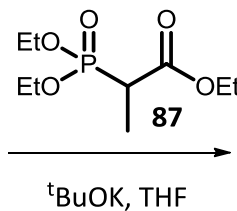

tBuOK, THF

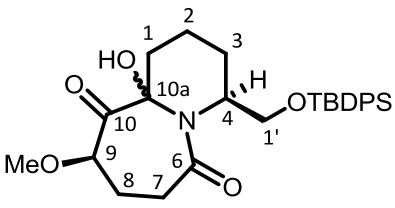

136

To a solution of ethyl ester $87(14 \mathrm{mg}, 58.8 \mu \mathrm{mol})$ in dry THF $(0.5 \mathrm{~mL})$ under $\mathrm{N}_{2}$ atmosphere, ${ }^{\mathrm{t}} \mathrm{BuOK}(7 \mathrm{mg}, 62.3 \mu \mathrm{mol})$ was added at $-78{ }^{\circ} \mathrm{C}$. After stirring $5 \mathrm{~min}$, a solution of hydroxyaldehyde $62(22 \mathrm{mg}, 44.4 \mu \mathrm{mol})$ in dry THF $(0.2 \mathrm{~mL})$ was slowly added. Then, the reaction mixture was slowly warmed up to room temperature and stirred overnight. The solution was washed with $\mathrm{NH}_{4} \mathrm{Cl}$ saturated solution, the two phases were separated and the aqueous one was extracted with $\mathrm{CH}_{2} \mathrm{Cl}_{2}$. The combined organic extracts were dried over anhydrous $\mathrm{MgSO}_{4}$ and concentrated in vacuo. Flash column chromatography on silica gel (EtOAc) provided 136 (6.6 mg, $13.3 \mu \mathrm{mol}, 30 \%$ yield).

\section{Spectroscopic data of 136:}

${ }^{1} \mathrm{H}-\mathrm{NMR}\left(400 \mathrm{MHz}, \mathrm{CDCl}_{3}\right): \delta 7.63\left(\mathrm{~m}, 4 \mathrm{H}_{\mathrm{Ar}}\right), 7.38\left(\mathrm{~m}, 6 \mathrm{H}_{\mathrm{Ar}}\right), 4.15\left(\mathrm{dd}, J=9.9,7.5 \mathrm{~Hz}, 1 \mathrm{H}: \mathrm{H}_{1^{1}}\right), 4.05$ $(\mathrm{s}, 1 \mathrm{H}: \mathrm{OH}), 4.03\left(\mathrm{dd}, J=9.9,5.7 \mathrm{~Hz}, 1 \mathrm{H}: \mathrm{H}_{1}\right), 3.41\left(\mathrm{~m}, 1 \mathrm{H}: \mathrm{H}_{9}\right), 3.22\left(\mathrm{~s}, 3 \mathrm{H}: \mathrm{OCH}_{3}\right), 3.06(\mathrm{ddd}, J=12.9$, 11.9, 3.3 Hz, $\left.1 \mathrm{H}: \mathrm{H}_{7}\right), 2.74$ (dddd, $\left.J=11.1,7.4,5.7,1.5 \mathrm{~Hz}, 1 \mathrm{H}: \mathrm{H}_{4}\right), 2.52\left(\mathrm{~m}, 2 \mathrm{H}: \mathrm{H}_{7}, \mathrm{H}_{1}\right), 2.32(\mathrm{~m}$, $\left.1 \mathrm{H}: \mathrm{H}_{1}\right), 2.05\left(\mathrm{~m}, 4 \mathrm{H}: \mathrm{H}_{3}, \mathrm{H}_{2}, 2 \mathrm{H}_{8}\right), 1.79\left(\mathrm{~m}, 1 \mathrm{H}: \mathrm{H}_{10}\right), 1.51\left(\mathrm{~m}, 1 \mathrm{H}: \mathrm{H}_{9}\right), 1.02\left(\mathrm{~s}, 9 \mathrm{H}: \mathrm{C}\left(\mathrm{CH}_{3}\right)_{3}\right)$.

${ }^{13}$ C-NMR $\left(100 \mathrm{MHz}, \mathrm{CDCl}_{3}\right)$ : $\delta 214.2\left(\mathrm{C}_{10}\right), 169.9\left(\mathrm{C}_{6}\right), 135.8\left(\mathrm{C}_{\mathrm{Ph}}\right), 135.7\left(\mathrm{C}_{\mathrm{Ph}}\right), 133.8\left(\mathrm{C}_{\mathrm{Ph}}\right), 129.7$ $\left(\mathrm{C}_{\mathrm{Ph}}\right), 127.8\left(\mathrm{C}_{\mathrm{Ph}}\right), 89.5\left(\mathrm{C}_{10 \mathrm{a}}\right), 80.6\left(\mathrm{C}_{9}\right), 64.8\left(\mathrm{C}_{1^{1}}\right), 63.4\left(\mathrm{C}_{4}\right), 56.4\left(\mathrm{OCH}_{3}\right), 41.7\left(\mathrm{C}_{7}\right)$,

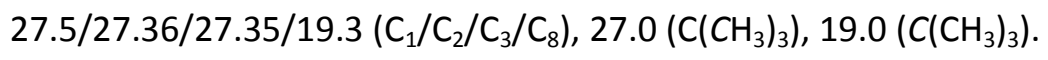

HRMS (ESI+): calcd for $\mathrm{C}_{34} \mathrm{H}_{46} \mathrm{NO}_{8} \mathrm{PSi}: 518.2333\left[\mathrm{M}+\mathrm{Na}^{+}\right]$; found 518.2339. 
(2S,3'S,8'R,9a'S)-3'-tert-Butyldiphenylsilyloxymethyl-8'-methoxy-hexahydro-3H-spiro\{furan-

\section{2,9'-pyrrolo[1,2-a]azepine\}-5,5'(4H,6'H)-dione, 127}

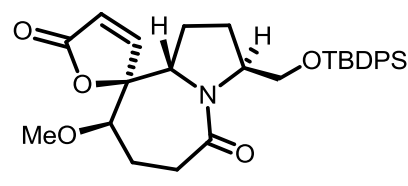

126

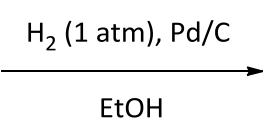

$\mathrm{EtOH}$

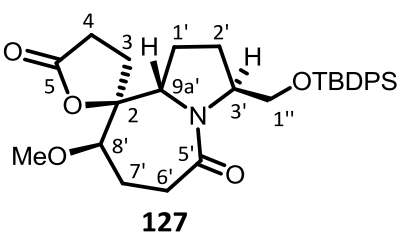

To a solution of compound 126 (62.4 mg, $120 \mu \mathrm{mol}$ ) in EtOH (5 mL), 10\% Pd/C (56 mg, 52.6 $\mu \mathrm{mol}$ ) was added. The reaction mixture was stirred in atmospheric pressure of $\mathrm{H}_{2}$ for $4 \mathrm{~h}$. Then, it was filtered through Celite ${ }^{\circledR}$ and the solvent was evaporated under reduced pressure to provide 127 (58 mg, $111 \mu \mathrm{mol}, 93 \%$ yield).

Physical and spectroscopic data of 127:

$[\alpha]_{\mathrm{D}}{ }^{20}=-54.2\left(c 0.60, \mathrm{CHCl}_{3}\right)$.

IR (ATR): 2930, 2845, 1765, 1645, 1460, 1443, 1178, 1080, $1019 \mathrm{~cm}^{-1}$.

${ }^{1} \mathrm{H}-\mathrm{NMR}\left(400 \mathrm{MHz}, \mathrm{CDCl}_{3}\right): \delta 7.61\left(\mathrm{~m}, 4 \mathrm{H}: 4 \mathrm{H}_{\mathrm{Ar}}\right), 7.38\left(\mathrm{~m}, 6 \mathrm{H}: 6 \mathrm{H}_{\mathrm{Ar}}\right), 4.63\left(\mathrm{~d}, \mathrm{~J}=9.4 \mathrm{~Hz}, 1 \mathrm{H}: \mathrm{H}_{9 \mathrm{a}^{\prime}}\right), 4.33$ $\left(\mathrm{m}, 1 \mathrm{H}: \mathrm{H}_{3^{\prime}}\right), 3.81\left(\mathrm{~m}, 2 \mathrm{H}: 2 \mathrm{H}_{1^{\prime \prime}}\right), 3.46\left(\mathrm{~s}, 3 \mathrm{H}: \mathrm{OCH}_{3}\right), 3.30\left(\mathrm{~d}, J=3.7 \mathrm{~Hz}, 1 \mathrm{H}: \mathrm{H}_{8^{\prime}}\right), 2.82(\mathrm{td}, J=13.5,1.5$ $\left.\mathrm{Hz}, \quad 1 \mathrm{H}: \mathrm{H}_{6^{\prime}}\right), 2.60\left(\mathrm{~m}, 2 \mathrm{H}: 2 \mathrm{H}_{4}\right), 2.32\left(\mathrm{~m}, 1 \mathrm{H}: \mathrm{H}_{1^{\prime}}\right), 2.12\left(\mathrm{~m}, 4 \mathrm{H}: \mathrm{H}_{2^{\prime}}, \mathrm{H}_{6^{\prime}}, \mathrm{H}_{7^{\prime}}, \mathrm{H}_{3}\right), 1.81(\mathrm{~m}$, $\left.4 \mathrm{H}: \mathrm{H}_{1^{\prime}}, \mathrm{H}_{2^{\prime}}, \mathrm{H}_{7^{\prime}}, \mathrm{H}_{3}\right), 1.06\left(\mathrm{~s}, 9 \mathrm{H}: \mathrm{C}\left(\mathrm{CH}_{3}\right)_{3}\right)$.

${ }^{13} \mathrm{C}$-NMR $\left(100 \mathrm{MHz}, \mathrm{CDCl}_{3}\right): \delta 175.8\left(\mathrm{C}_{5}\right), 173.3\left(\mathrm{C}_{5^{\prime}}\right), 135.72\left(\mathrm{C}_{\mathrm{Ph}}\right), 135.70\left(\mathrm{C}_{\mathrm{Ph}}\right), 133.67\left(\mathrm{C}_{\mathrm{Ph}}\right)$, $133.61\left(C_{\mathrm{Ph}}\right), 129.9\left(\mathrm{C}_{\mathrm{Ph}}\right), 127.86\left(\mathrm{C}_{\mathrm{Ph}}\right), 127.85\left(\mathrm{C}_{\mathrm{Ph}}\right), 88.5\left(\mathrm{C}_{2}\right), 83.2\left(\mathrm{C}_{8^{\prime}}\right), 63.2\left(\mathrm{C}_{1^{\prime \prime}}\right), 61.0\left(\mathrm{C}_{3^{\prime}}\right), 58.8$ $\left(\mathrm{OCH}_{3}\right), 57.4\left(\mathrm{C}_{9^{\prime}}\right), 30.5\left(\mathrm{C}_{6^{\prime}}\right), 28.7\left(\mathrm{C}_{4}\right), 27.1\left(\mathrm{C}\left(\mathrm{CH}_{3}\right)_{3}\right), 26.8 / 26.0 / 25.5 / 23.8\left(\mathrm{C}_{3} / \mathrm{C}_{1^{\prime}} / \mathrm{C}_{2^{\prime}} / \mathrm{C}_{7^{\prime}}\right), 19.4$ $\left(\mathrm{C}\left(\mathrm{CH}_{3}\right)_{3}\right)$.

HRMS (ESI+): calcd for $\mathrm{C}_{30} \mathrm{H}_{39} \mathrm{NO}_{5} \mathrm{Si}: 544.2490\left[\mathrm{M}+\mathrm{Na}^{+}\right]$; found 544.2500 . 
(2S,4R,3'S,8'R,9a'S)-3'-tert-Butyldiphenylsilyloxymethyl-8'-methoxy-4-methylhexahydro-3Hspiro\{furan-2,9'-pyrrolo[1,2-a]azepine\}-5,5' $\left(4 H, 6^{\prime} H\right)$-dione, 128

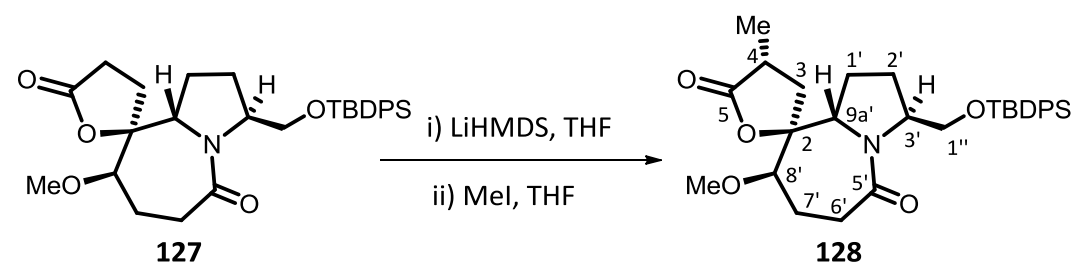

To a stirred solution of 127 (23 mg, $44 \mu \mathrm{mol})$ in dry THF $(0.9 \mathrm{~mL})$ under $\mathrm{N}_{2}$ atmosphere at $78^{\circ} \mathrm{C}$, a THF solution of LiHMDS (1M, $\left.48 \mu \mathrm{Lm}, 48 \mu \mathrm{mol}\right)$ was added. After $45 \mathrm{~min}$, Mel $(41 \mu \mathrm{L}, 658$ umol) was added fast. After $45 \mathrm{~min}, \mathrm{NH}_{4} \mathrm{Cl}(1 \mathrm{~mL})$ was added and the reaction was allowed to warm up to room temperature. The two phases were separated and the aqueous one was extracted with $\mathrm{CH}_{2} \mathrm{Cl}_{2}(3 \times 8 \mathrm{~mL})$. The combined organic extracts were dried over anhydrous $\mathrm{MgSO}_{4}$ and concentrated under reduced pressure. The resulting oil was purified by flash column chromatography on silica gel (EtOAc:hexanes 1:1) to afford 128 (19.5 mg, $36 \mu \mathrm{mol}$, 83\% yield over recovered 127).

Physical and spectroscopic data of 128:

$[\alpha]_{D}^{20}=-36.5\left(c 2.6, \mathrm{CHCl}_{3}\right)$.

IR (ATR): 2930, 2856, 1771, 1643, 1442, 1410, 1229, 1170, $1105 \mathrm{~cm}^{-1}$.

${ }^{1} \mathrm{H}-N M R\left(400 \mathrm{MHz}, \mathrm{C}_{6} \mathrm{D}_{6}\right): \delta 7.75\left(\mathrm{~m}, 4 \mathrm{H}: 4 \mathrm{H}_{\mathrm{Ar}}\right), 7.24\left(\mathrm{~m}, 6 \mathrm{H}: 6 \mathrm{H}_{\mathrm{Ar}}\right), 4.43\left(\mathrm{~d}, J=9.5 \mathrm{~Hz}, 1 \mathrm{H}: \mathrm{H}_{9 \mathrm{a}^{\prime}}\right), 4.34$ $\left(\mathrm{m}, 1 \mathrm{H}: \mathrm{H}_{3^{\prime}}\right), 4.00\left(\mathrm{dd}, J=9.7,2.9 \mathrm{~Hz}, 1 \mathrm{H}: \mathrm{H}_{1^{\prime \prime}}\right), 3.74\left(\mathrm{dd}, J=9.7,6.7 \mathrm{~Hz}, 1 \mathrm{H}: \mathrm{H}_{1^{\prime \prime}}\right), 3.10\left(\mathrm{~s}, 3 \mathrm{H}: \mathrm{OCH}_{3}\right)$, $2.68\left(\mathrm{t}, J=13.1 \mathrm{~Hz}, 1 \mathrm{H}: \mathrm{H}_{6^{\prime}}\right), 2.57\left(\mathrm{~d}, J=4.2 \mathrm{~Hz}, 1 \mathrm{H}: \mathrm{H}_{8^{\prime}}\right), 2.14\left(\mathrm{~m}, 2 \mathrm{H}: \mathrm{H}_{6^{\prime}}, \mathrm{H}_{4}\right), 1.89\left(\mathrm{~m}, 1 \mathrm{H}: \mathrm{H}_{1^{\prime}}\right), 1.71$ $\left(\mathrm{m}, 2 \mathrm{H}: \mathrm{H}_{3}, \mathrm{H}_{1^{\prime}}\right), 1.40\left(\mathrm{~m}, 3 \mathrm{H}: 2 \mathrm{H}_{2^{\prime}}, \mathrm{H}_{7^{\prime}}\right), 1.17\left(\mathrm{~m}, 1 \mathrm{H}: \mathrm{H}_{7^{\prime}}\right), 1.16\left(\mathrm{~s}, 9 \mathrm{H}: \mathrm{C}\left(\mathrm{CH}_{3}\right)_{3}\right), 0.98(\mathrm{~d}, J=7.1 \mathrm{~Hz}$, $\left.3 \mathrm{H}: \mathrm{CH}_{3}\right), 0.58\left(\mathrm{dd}, J=13.7,10.7 \mathrm{~Hz}, 1 \mathrm{H}: \mathrm{H}_{3}\right)$.

${ }^{13}$ C-NMR (100 MHz, $\left.C_{6} D_{6}\right): \delta 178.2\left(C_{5}\right), 172.8\left(C_{5^{\prime}}\right), 136.60\left(C_{\text {Ph }}\right), 136.58\left(C_{\text {Ph }}\right), 134.6\left(C_{\text {Ph }}\right), 134.5$ $\left(C_{\text {Ph }}\right), 130.7\left(C_{P_{p h}}\right), 86.1 / 85.5\left(C_{2} / C_{8^{\prime}}\right), 63.9\left(C_{1^{\prime \prime}}\right), 61.6\left(C_{3^{\prime}}\right), 59.3\left(\mathrm{OCH}_{3}\right), 57.5\left(C_{9 a^{\prime}}\right), 35.4\left(C_{4}\right), 35.0$ $\left(\mathrm{C}_{3}\right), 31.1\left(\mathrm{C}_{6^{\prime}}\right), 27.7\left(\mathrm{C}\left(\mathrm{CH}_{3}\right)_{3}\right), 27.3\left(\mathrm{C}_{2^{\prime}}\right), 26.3\left(\mathrm{C}_{1^{\prime}}\right), 24.2\left(\mathrm{C}_{7^{\prime}}\right), 20.1\left(\mathrm{C}\left(\mathrm{CH}_{3}\right)_{3}\right), 17.6\left(\mathrm{CH}_{3}\right)$.

HRMS (ESI+): calcd for $\mathrm{C}_{31} \mathrm{H}_{41} \mathrm{NO}_{5} \mathrm{Si}: 558.2646\left[\mathrm{M}+\mathrm{Na}^{+}\right]$; found 558.2645 . 
(2S,4S,3'S, 8'R,9a'S)-3'-tert-Butyldiphenylsilyloxymethyl-8'-methoxy-4-methylhexahydro-3Hspiro\{furan-2,9'-pyrrolo[1,2-a]azepine\}-5,5'(4H,6'H)-dione, 135

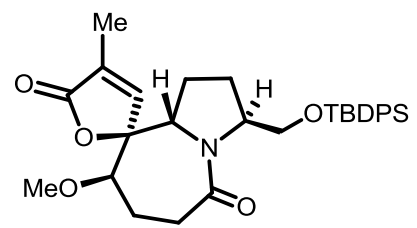

63

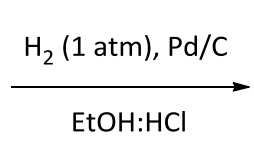

$\mathrm{EtOH}: \mathrm{HCl}$

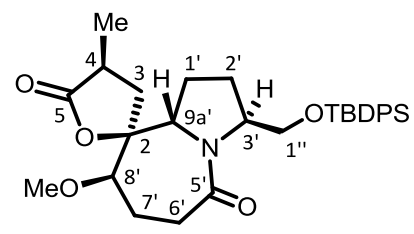

135

To a solution of lactone $63(12.2 \mathrm{mg}, 23 \mu \mathrm{mol})$ in a $1: 1$ mixture of EtOH and $10 \% \mathrm{HCl}(1.4$ $\mathrm{ml}$ ), 10\% Pd/C (11 mg, $10.2 \mu \mathrm{mol}$ ) was added. The reaction mixture was stirred at atmospheric pressure of $\mathrm{H}_{2}$ for $24 \mathrm{~h}$. Then, it was filtered through Celite ${ }^{\circledR}$ and the filtrate was washed with saturated solution of $\mathrm{NaHCO}_{3}$. The aqueous layer was extracted with $\mathrm{CH}_{2} \mathrm{Cl}_{2}(3 \times 2 \mathrm{~mL})$. The combined organic extracts were dried over anhydrous $\mathrm{MgSO}_{4}$ and concentrated under reduced pressure. Purification of the residue by flash column chromatography on silica gel (EtOAc) furnished saturated lactone 135 (11 mg, 20.5 umol, 90\% yield).

Physical and spectroscopic data of 135:

$[\alpha]_{D}^{20}=-71.0\left(c 0.1, \mathrm{CHCl}_{3}\right)$.

IR (ATR): 2929, 2360, 2341, 1773, 1645, 1446, 1412, 1191, 1109, $1010 \mathrm{~cm}^{-1}$.

${ }^{1} \mathrm{H}-\mathrm{NMR}\left(400 \mathrm{MHz}, \mathrm{C}_{6} \mathrm{D}_{6}\right): \delta 7.76\left(\mathrm{~m}, 4 \mathrm{H}: 4 \mathrm{H}_{\mathrm{Ar}}\right), 7.24\left(\mathrm{~m}, 6 \mathrm{H}: 6 \mathrm{H}_{\mathrm{Ar}}\right), 4.56\left(\mathrm{dd}, J=9.8,2.0 \mathrm{~Hz}, 1 \mathrm{H}: \mathrm{H}_{9 \mathrm{a}^{\prime}}\right)$, $4.27\left(\mathrm{~m}, 1 \mathrm{H}: \mathrm{H}_{3^{\prime}}\right), 3.93\left(\mathrm{~m}, 2 \mathrm{H}: 2 \mathrm{H}_{1^{\prime \prime}}\right), 3.07\left(\mathrm{~s}, 3 \mathrm{H}: \mathrm{OCH}_{3}\right), 2.74\left(\mathrm{td}, J=13.5,2.2 \mathrm{~Hz}, 1 \mathrm{H}: \mathrm{H}_{6^{\prime}}\right), 2.63(\mathrm{dd}, J$ $\left.=4.7,1.9 \mathrm{~Hz}, 1 \mathrm{H}: \mathrm{H}_{8^{\prime}}\right), 2.20\left(\mathrm{ddd}, J=13.6,6.7,1.8 \mathrm{~Hz}, 1 \mathrm{H}: \mathrm{H}_{6^{\prime}}\right), 2.00\left(\mathrm{~m}, 1 \mathrm{H}: \mathrm{H}_{1^{\prime}}\right), 1.90\left(1 \mathrm{H}: \mathrm{H}_{4}\right), 1.72$

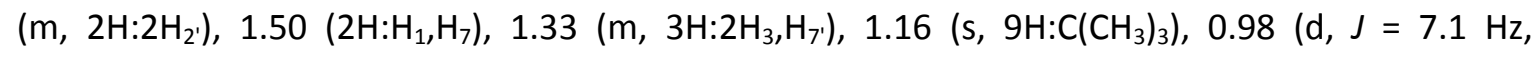
$\left.3 \mathrm{H}: \mathrm{CH}_{3}\right)$.

${ }^{13} \mathrm{C}$-NMR (100 MHz, $\left.\mathrm{C}_{6} \mathrm{D}_{6}\right): \delta 177.1\left(\mathrm{C}_{5}\right), 172.2\left(\mathrm{C}_{5^{\prime}}\right), 136.1\left(\mathrm{C}_{\mathrm{ph}}\right), 134.0\left(\mathrm{C}_{\mathrm{Ph}}\right), 133.9\left(\mathrm{C}_{\mathrm{Ph}}\right), 130.1\left(\mathrm{C}_{\mathrm{ph}}\right)$, $85.9\left(\mathrm{C}_{2}\right), 81.2\left(\mathrm{C}_{8^{\prime}}\right), 63.5\left(\mathrm{C}_{1^{\prime \prime}}\right), 61.0\left(\mathrm{C}_{3^{\prime}}\right), 58.9\left(\mathrm{OCH}_{3}\right), 57.2\left(\mathrm{C}_{9 \mathrm{a}^{\prime}}\right), 34.2\left(\mathrm{C}_{4}\right), 33.3\left(\mathrm{C}_{3}\right), 31.0\left(\mathrm{C}_{6^{\prime}}\right)$, $27.2\left(\mathrm{C}\left(\mathrm{CH}_{3}\right)_{3}\right), 27.0\left(\mathrm{C}_{2^{\prime}}\right), 25.6 / 24.9\left(\mathrm{C}_{1^{\prime}} / \mathrm{C}_{7^{\prime}}\right), 19.5\left(\mathrm{C}^{\prime}\left(\mathrm{CH}_{3}\right)_{3}\right), 15.8\left(\mathrm{CH}_{3}\right)$.

HRMS (ESI+): calcd for $\mathrm{C}_{31} \mathrm{H}_{41} \mathrm{NO}_{5} \mathrm{Si}: 558.2646\left[\mathrm{M}+\mathrm{Na}^{+}\right]$; found 558.2640 . 
$\left(2 S, 4 R, 3^{\prime} S, 8\right.$ ' $R, 9 a$ 'S)-3'-Hydroxymethyl-8'-methoxy-4-methylhexahydro-3H-spiro\{furan-2,9'pyrrolo[1,2-a]azepine\}-5,5'(4H,6'H)-dione, 144

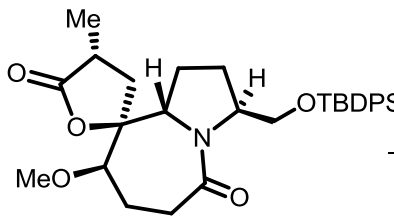

128

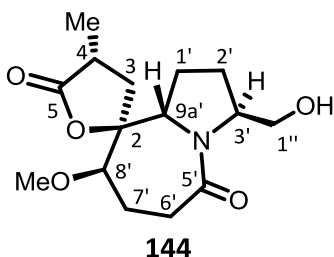

144

$\mathrm{Et}_{3} \mathrm{~N} \cdot 3 \mathrm{HF}(0.2 \mathrm{~mL}, 1.3 \mathrm{mmol}$ ) was added to a stirred solution of 128 ( $35 \mathrm{mg}, 65 \mu \mathrm{mol})$ in THF $(1.4 \mathrm{~mL})$. The reaction mixture was heated at the reflux temperature for $4 \mathrm{~h}$, when TLC analysis showed no starting material. The excess of $\mathrm{Et}_{3} \mathrm{~N} \cdot 3 \mathrm{HF}$ was quenched with $\mathrm{NaHCO}_{3}$ saturated solution. Then, EtOAc was added and the aqueous phase was extracted with $\mathrm{CH}_{2} \mathrm{Cl}_{2}(2 \times 2 \mathrm{~mL})$. The combined organic extracts were dried over anhydrous $\mathrm{MgSO}_{4}$ and concentrated in vacuo. The resulting oil was filtered through silica gel (EtOAc) to furnish alcohol 144 (16.5 mg, $55.5 \mu \mathrm{mol}$, $85 \%$ yield).

Physical and spectroscopic data of 144:

$[\alpha]_{D}^{20}=-44.8\left(c \quad 1.53, \mathrm{CHCl}_{3}\right)$.

IR (ATR): 3392, 2936, 1768, 1622, 1447, 1421, 1226, 1171, $1102 \mathrm{~cm}^{-1}$.

${ }^{1} \mathrm{H}-\mathrm{NMR}\left(400 \mathrm{MHz}, \mathrm{CDCl}_{3}\right): \delta 4.73\left(\mathrm{dd}, J=8.7,4.2 \mathrm{~Hz}, 1 \mathrm{H}: \mathrm{H}_{9 \mathrm{a}^{\prime}}\right), 4.47(\mathrm{~s}, 1 \mathrm{H}: \mathrm{OH}), 4.18\left(\mathrm{~m}, 1 \mathrm{H}: \mathrm{H}_{3^{\prime}}\right)^{\prime}$ ), $3.69\left(\mathrm{~m}, 2 \mathrm{H}: 2 \mathrm{H}_{1^{\prime \prime}}\right), 3.48\left(\mathrm{~s}, 3 \mathrm{H}: \mathrm{OCH}_{3}\right), 3.26\left(\mathrm{~d}, J=3.6 \mathrm{~Hz}, 1 \mathrm{H}: \mathrm{H}_{8^{\prime}}\right), 2.94\left(\mathrm{td}, J=13.7,1.7 \mathrm{~Hz}, 1 \mathrm{H}: \mathrm{H}_{6^{\prime}}\right)$, $2.75\left(m, 1 \mathrm{H}: \mathrm{H}_{4}\right), 2.40\left(\mathrm{~m}, 1 \mathrm{H}: \mathrm{H}_{3}\right), 2.27\left(\mathrm{~m}, 1 \mathrm{H}: \mathrm{H}_{6^{\prime}}\right), 2.19\left(\mathrm{~m}, 1 \mathrm{H}: \mathrm{H}_{1^{\prime}}\right), 2.08\left(\mathrm{~m}, 1 \mathrm{H}: \mathrm{H}_{7^{\prime}}\right), 1.90(\mathrm{~m}$, $\left.1 \mathrm{H}: \mathrm{H}_{2^{\prime}}\right), 1.71\left(\mathrm{~m}, 3 \mathrm{H}: \mathrm{H}_{1^{\prime}}, \mathrm{H}_{2^{\prime}}, \mathrm{H}_{7^{\prime}}\right), 1.41\left(\mathrm{dd}, J=14.1,9.4 \mathrm{~Hz}, 1 \mathrm{H}: \mathrm{H}_{3}\right), 1.32\left(\mathrm{~d}, J=7.2 \mathrm{~Hz}, 3 \mathrm{H}: \mathrm{CH}_{3}\right)$.

${ }^{13}$ C-NMR $\left(100 \mathrm{MHz}, \mathrm{CDCl}_{3}\right): \delta 178.5\left(\mathrm{C}_{5}\right), 175.4\left(\mathrm{C}_{5^{\prime}}\right), 86.3\left(\mathrm{C}_{2}\right), 84.3\left(\mathrm{C}_{8^{\prime}}\right), 66.1\left(\mathrm{C}_{1^{\prime \prime}}\right), 64.6\left(\mathrm{C}_{3^{\prime}}\right), 58.8$ $\left(\mathrm{OCH}_{3}\right), 58.0\left(\mathrm{C}_{9 \mathrm{a}^{\prime}}\right), 35.4\left(\mathrm{C}_{4}\right), 34.3\left(\mathrm{C}_{3}\right), 30.5\left(\mathrm{C}_{6^{\prime}}\right), 27.8\left(\mathrm{C}_{2^{\prime}}\right), 26.1\left(\mathrm{C}_{1^{\prime}}\right), 23.3\left(\mathrm{C}_{7^{\prime}}\right), 17.7\left(\mathrm{CH}_{3}\right)$.

HRMS (ESI+): calcd for $\mathrm{C}_{15} \mathrm{H}_{23} \mathrm{NO}_{5}: 320.1468\left[\mathrm{M}+\mathrm{Na}^{+}\right]$; found 320.1472 . 
(2S,4R,3'S,8'R,9a'S)-8'-Methoxy-4-methyl-5,5'-dioxodecahydro-3H-spiro\{furan-2,9'-pyrrolo[1,2a]azepine\}-3'-carbaldehyde, 145
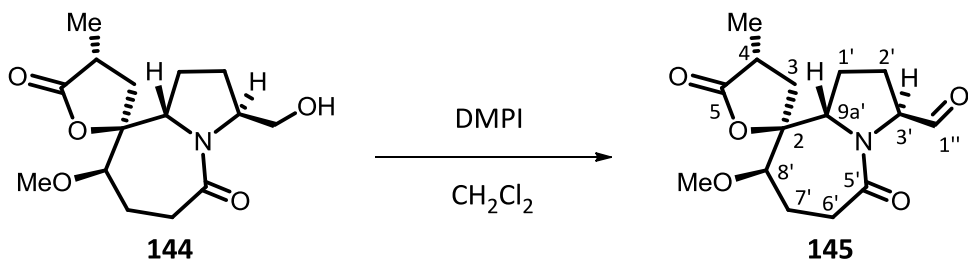

A commercially available solution of Dess-Martin periodinane in $\mathrm{CH}_{2} \mathrm{Cl}_{2}(15 \% \mathrm{wt}, 285 \mu \mathrm{L}$, $137.3 \mu \mathrm{mol}$ ) was added via syringe to a solution of alcohol $144(32 \mathrm{mg}, 107.6 \mu \mathrm{mol})$ in dry $\mathrm{CH}_{2} \mathrm{Cl}_{2}$ $(0.9 \mathrm{~mL})$. After $2 \mathrm{~h}$ of stirring at room temperature, TLC analysis indicated the complete consumption of the starting material. The solution was washed with $\mathrm{NaHCO}_{3}$ saturated solution containing a sevenfold excess of $\mathrm{Na}_{2} \mathrm{~S}_{2} \mathrm{O}_{3}$, the aqueous phase was extracted with $\mathrm{CH}_{2} \mathrm{Cl}_{2}(2 \times 2 \mathrm{~mL})$ and the combined organic extracts were dried over anhydrous $\mathrm{MgSO}_{4}$ and concentrated under vacuum. Flash column chromatography of the residue on silica gel (EtOAc) provided aldehyde 145 (26.4 mg, $89.4 \mu \mathrm{mol}, 83 \%$ yield).

\section{Physical and spectroscopic data of $145:$}

$[\alpha]_{\mathrm{D}}^{20}=-126.5\left(\mathrm{c} 0.54, \mathrm{CHCl}_{3}\right)$.

IR (ATR): 2936, 1752, 1714, 1622, 1422, 1236, 1197, 1100, $1011 \mathrm{~cm}^{-1}$.

${ }^{1} \mathrm{H}-\mathrm{NMR}\left(400 \mathrm{MHz}, \mathrm{CDCl}_{3}\right): \delta 9.45\left(\mathrm{~d}, J=2.1 \mathrm{~Hz}, 1 \mathrm{H}: \mathrm{H}_{1^{\prime \prime}}\right), 4.81\left(\mathrm{dd}, J=8.9,4.4 \mathrm{~Hz}, 1 \mathrm{H}: \mathrm{H}_{9 \mathrm{a}^{\prime}}\right), 4.51(\mathrm{t}, J$ $\left.=6.7 \mathrm{~Hz}, 1 \mathrm{H}: \mathrm{H}_{3^{\prime}}\right), 3.49\left(\mathrm{~s}, 3 \mathrm{H}: \mathrm{OCH}_{3}\right), 3.29\left(\mathrm{~d}, J=4.8 \mathrm{~Hz}, 1 \mathrm{H}: \mathrm{H}_{8^{\prime}}\right), 3.00\left(\mathrm{t}, J=13.8 \mathrm{~Hz}, 1 \mathrm{H}: \mathrm{H}_{6^{\prime}}\right), 2.74$ $\left(\mathrm{m}, 1 \mathrm{H}: \mathrm{H}_{4}\right), 2.41\left(\mathrm{dd}, J=14.2,10.8 \mathrm{~Hz}, 1 \mathrm{H}: \mathrm{H}_{3}\right), 2.31\left(\mathrm{dd}, J=14.5,6.9 \mathrm{~Hz}, 1 \mathrm{H}: \mathrm{H}_{6^{\prime}}\right), 2.19\left(\mathrm{~m}, 1 \mathrm{H}: \mathrm{H}_{1^{\prime}}\right)$, $2.10\left(\mathrm{~m}, 1 \mathrm{H}: \mathrm{H}_{7^{\prime}}\right), 1.94\left(\mathrm{~m}, 2 \mathrm{H}: 2 \mathrm{H}_{2^{\prime}}\right), 1.79\left(\mathrm{~m}, 2 \mathrm{H}: \mathrm{H}_{1^{\prime}}, \mathrm{H}_{7^{\prime}}\right), 1.44\left(\mathrm{dd}, J=14.2,9.4 \mathrm{~Hz}, 1 \mathrm{H}: \mathrm{H}_{3}\right), 1.33(\mathrm{~d}, J$ $\left.=7.2 \mathrm{~Hz}, 3 \mathrm{H}: \mathrm{CH}_{3}\right)$.

${ }^{13} \mathrm{C}$-NMR $\left(100 \mathrm{MHz}, \mathrm{CDCl}_{3}\right): \delta 197.2\left(\mathrm{C}_{1^{\prime \prime}}\right), 178.3\left(\mathrm{C}_{5}\right), 173.8\left(\mathrm{C}_{5^{\prime}}\right), 86.2\left(\mathrm{C}_{2}\right), 84.1\left(\mathrm{C}_{8^{\prime}}\right), 67.2\left(\mathrm{C}_{3^{\prime}}\right)$, $58.8\left(\mathrm{OCH}_{3}\right), 57.1\left(\mathrm{C}_{\mathrm{a}^{\prime}}\right), 35.4\left(\mathrm{C}_{4}\right), 34.2\left(\mathrm{C}_{3}\right), 29.2\left(\mathrm{C}_{6^{\prime}}\right), 26.8\left(\mathrm{C}_{1^{\prime}}\right), 24.8\left(\mathrm{C}_{2^{\prime}}\right), 23.1\left(\mathrm{C}_{7^{\prime}}\right), 17.7\left(\mathrm{CH}_{3}\right)$. HRMS (ESI+): calcd for $\mathrm{C}_{15} \mathrm{H}_{21} \mathrm{NO}_{5}: 318.1317\left[\mathrm{M}+\mathrm{Na}^{+}\right]$; found 318.1312 . 
$\left(2 S, 4 R, 3^{\prime} S, 8^{\prime} R, 9 a^{\prime} S, 2^{\prime \prime} S\right)-, \quad 146, \quad$ and $\quad\left(2 S, 4 R, 3^{\prime} S, 8^{\prime} R, 9 a^{\prime} S, 2^{\prime \prime} R\right)-8^{\prime}-$ Methoxy-4-methyl-3'-(4methylene-5-oxotetrahydrofuran-2-yl)hexahydro-3H-spiro\{furan-2,9'-pyrrolo[1,2-a]azep-ine\}5,5'(4H,6'H)-dione, 147<smiles>COC1CCC(=O)N2C(C=O)CC[C@@]23C[C@@H](C)C(=O)O[C@]13C</smiles>

145

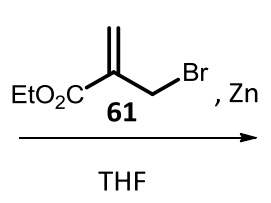

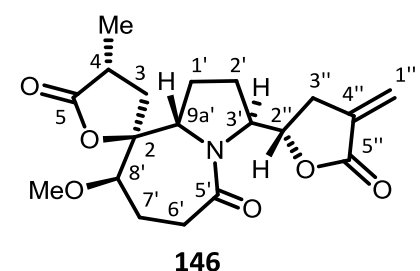

146

To a stirred solution of aldehyde $145(18.1 \mathrm{mg}, 61.3 \mu \mathrm{mol})$ in dry THF $(0.6 \mathrm{~mL})$ under $\mathrm{N}_{2}$ atmosphere, activated $\mathrm{Zn}^{51}$ (14.1 mg, $0.22 \mathrm{mmol}$ ) was added. The solution was heated up and, when reflux started, a solution of ethyl 2-(bromomethyl)acrylate, $61(9.3 \mu \mathrm{L}, 67.3 \mu \mathrm{mol})$, in dry THF $(0.38 \mathrm{~mL}$ ) was added. After $1 \mathrm{~h}$, TLC analysis of the reaction mixture (EtOAc) revealed the absence of the starting aldehyde. The reaction mixture was filtered through Celite ${ }^{\circledR}$ and the organic solvent was evaporated under vacuum to afford a mixture of diastereoisomers 146 and 147 ( $20.3 \mathrm{mg}, 55.9 \mu \mathrm{mol}, 91 \%$ yield), as a colorless oil. This residue was purified by flash column chromatography on Florisil ${ }^{\circledR}$ (EtOAc) to provide the following fractions: i) threo-bislactone 146 (7.9 mg, $21.7 \mu \mathrm{mol}, 36 \%$ yield); ii) a mixture of bislactones 146 and 147 (4 mg, $11.0 \mu \mathrm{mol}, 18 \%$ yield); iii) erythro-bislactone 147 ( $8.3 \mathrm{mg}, 22.8 \mu \mathrm{mol}, 37 \%$ yield).

Physical and spectroscopic data of 146 (threo):

$[\alpha]_{D}^{20}=-33.2\left(c 0.79, \mathrm{CHCl}_{3}\right)$.

IR (ATR): 2934, 1761, 1641, 1445, 1408, 1232, 1164, 1103, $1014 \mathrm{~cm}^{-1}$.

${ }^{1} \mathrm{H}-N M R\left(400 \mathrm{MHz}, \mathrm{CDCl}_{3}\right): \delta 6.21\left(\mathrm{~m}, 1 \mathrm{H}: \mathrm{H}_{1^{\prime \prime \prime}}\right), 5.64\left(\mathrm{~m}, 1 \mathrm{H}: \mathrm{H}_{1^{\prime \prime}}\right), 5.17\left(\mathrm{~m}, 1 \mathrm{H}: \mathrm{H}_{2^{\prime \prime}}\right), 4.77(\mathrm{dd}, J=$ 9.1, $\left.2.8 \mathrm{~Hz}, 1 \mathrm{H}: \mathrm{H}_{9^{\prime}}\right), 4.61\left(\mathrm{~m}, 1 \mathrm{H}: \mathrm{H}_{3^{\prime}}\right), 3.48\left(\mathrm{~s}, 3 \mathrm{H}: \mathrm{OCH}_{3}\right), 3.26\left(\mathrm{~d}, J=4.0 \mathrm{~Hz}, 1 \mathrm{H}: \mathrm{H}_{8^{\prime}}\right), 2.89(\mathrm{~m}$, $\left.3 \mathrm{H}: 2 \mathrm{H}_{3^{\prime \prime}}, \mathrm{H}_{6^{\prime}}\right), 2.76\left(\mathrm{~m}, 1 \mathrm{H}: \mathrm{H}_{4}\right), 2.31\left(\mathrm{~m}, 3 \mathrm{H}: \mathrm{H}_{1^{\prime}}, \mathrm{H}_{6^{\prime}}, \mathrm{H}_{3}\right), 2.08\left(\mathrm{~m}, 1 \mathrm{H}: \mathrm{H}_{7^{\prime}}\right), 1.82\left(\mathrm{~m}, 4 \mathrm{H}: 2 \mathrm{H}_{2^{\prime}}, \mathrm{H}_{1^{\prime}}, \mathrm{H}_{7^{\prime}}\right)$, $1.42\left(\mathrm{dd}, J=14.2,9.6 \mathrm{~Hz}, 1 \mathrm{H}: \mathrm{H}_{3}\right), 1.32\left(\mathrm{~d}, J=7.2 \mathrm{~Hz}, 3 \mathrm{H}: \mathrm{CH}_{3}\right)$.

${ }^{13} \mathrm{C}-\mathrm{NMR}\left(100 \mathrm{MHz}, \mathrm{CDCl}_{3}\right): \delta 178.4\left(\mathrm{C}_{5}\right), 175.5\left(\mathrm{C}_{5^{\prime}}\right), 170.0\left(\mathrm{C}_{5^{\prime \prime}}\right), 134.0\left(\mathrm{C}_{1^{\prime \prime \prime}}\right), 122.5\left(\mathrm{C}_{4^{\prime \prime}}\right), 86.1\left(\mathrm{C}_{2}\right)$, $84.3\left(C_{8^{\prime}}\right), 76.5\left(C_{2^{\prime \prime}}\right), 61.9\left(C_{3^{\prime}}\right), 58.8\left(\mathrm{OCH}_{3}\right), 58.2\left(C_{9 a^{\prime}}\right), 35.4\left(C_{4}\right), 34.3\left(C_{3}\right), 30.3\left(C_{6^{\prime}}\right), 29.7\left(C_{3^{\prime \prime}}\right)$, $26.3\left(\mathrm{C}_{1^{\prime}}\right), 25.6\left(\mathrm{C}_{2^{\prime}}\right), 23.2\left(\mathrm{C}_{7^{\prime}}\right), 17.6\left(\mathrm{CH}_{3}\right)$.

HRMS (ESI+): calcd for $\mathrm{C}_{19} \mathrm{H}_{25} \mathrm{NO}_{6}$ : $386.1574\left[\mathrm{M}+\mathrm{Na}^{+}\right]$; found 386.1573 . 
Physical and spectroscopic data of 147 (erythro):

$[\alpha]_{D}^{20}=-78.0\left(c 0.83, \mathrm{CHCl}_{3}\right)$.

IR (ATR): 2935, 1763, 1638, 1444, 1412, 1257, 1166, $1105 \mathrm{~cm}^{-1}$.

${ }^{1} \mathrm{H}-\mathrm{NMR}\left(400 \mathrm{MHz}, \mathrm{CDCl}_{3}\right): \delta 6.27\left(\mathrm{t}, J=2.7 \mathrm{~Hz}, 1 \mathrm{H}: \mathrm{H}_{1^{\prime \prime \prime}}\right), 5.68\left(\mathrm{t}, J=2.7 \mathrm{~Hz}, 1 \mathrm{H}: \mathrm{H}_{1^{\prime \prime \prime}}\right), 5.26(\mathrm{dd}, J=$ $\left.8.2,6.5 \mathrm{~Hz}, 1 \mathrm{H}: \mathrm{H}_{2^{\prime \prime}}\right), 4.85\left(\mathrm{~d}, J=9.9 \mathrm{~Hz}, 1 \mathrm{H}: \mathrm{H}_{9 \mathrm{a}^{\prime}}\right), 4.38\left(\mathrm{~m}, 1 \mathrm{H}: \mathrm{H}_{3^{\prime}}\right), 3.48\left(\mathrm{~s}, 3 \mathrm{H}: \mathrm{OCH}_{3}\right), 3.25(\mathrm{~d}, J=4.4$ $\left.\mathrm{Hz}, 1 \mathrm{H}: \mathrm{H}_{8^{\prime}}\right), 3.11\left(\mathrm{ddt}, J=17.7,8.4,2.6 \mathrm{~Hz}, 1 \mathrm{H}: \mathrm{H}_{3^{\prime \prime}}\right), 3.00\left(\mathrm{t}, J=12.9 \mathrm{~Hz}, 1 \mathrm{H}: \mathrm{H}_{6^{\prime}}\right), 2.67\left(\mathrm{~m}, 1 \mathrm{H}: \mathrm{H}_{4}\right)$, $2.54\left(\mathrm{ddt}, J=17.7,6.2,3.0 \mathrm{~Hz}, 1 \mathrm{H}: \mathrm{H}_{3^{\prime \prime}}\right), 2.33\left(\mathrm{~m}, 3 \mathrm{H}: \mathrm{H}_{1^{\prime}}, \mathrm{H}_{6^{\prime}}, \mathrm{H}_{3}\right), 2.08\left(\mathrm{~m}, 1 \mathrm{H}: \mathrm{H}_{7^{\prime}}\right), 1.79(\mathrm{~m}$, $\left.4 \mathrm{H}: \mathrm{H}_{1^{\prime}}, 2 \mathrm{H}_{2^{\prime}}, \mathrm{H}_{7^{\prime}}\right), 1.40$ (dd, J=14.0,10.4 Hz, $1 \mathrm{H}: \mathrm{H}_{3}$ ), 1.30 (d, J= 7.1 Hz, 3H: $\mathrm{CH}_{3}$ ).

${ }^{13} \mathrm{C}$-NMR $\left(63 \mathrm{MHz}, \mathrm{CDCl}_{3}\right)$ : $\delta 178.4\left(\mathrm{C}_{5}\right), 174.6\left(\mathrm{C}_{5^{\prime}}\right), 170.0\left(\mathrm{C}_{5^{\prime \prime}}\right), 133.6\left(\mathrm{C}_{4^{\prime \prime}}\right), 123.3\left(\mathrm{C}_{1^{\prime \prime \prime}}\right), 85.7\left(\mathrm{C}_{2}\right)$, $84.5\left(C_{8^{\prime}}\right), 75.5\left(C_{2^{\prime \prime}}\right), 63.2\left(C_{3^{\prime}}\right), 58.9\left(\mathrm{OCH}_{3}\right), 57.4\left(C_{9 a^{\prime}}\right), 35.2 / 34.7\left(C_{4} / C_{3}\right), 30.5 / 30.4\left(C_{3^{\prime \prime}} / C_{6^{\prime}}\right)$, 26.4/23.5 $\left(\mathrm{C}_{1^{\prime}} / \mathrm{C}_{2^{\prime}}\right), 23.4\left(\mathrm{C}_{7^{\prime}}\right), 17.3\left(\mathrm{CH}_{3}\right)$.

HRMS (ESI+): calcd for $\mathrm{C}_{19} \mathrm{H}_{25} \mathrm{NO}_{6}$ : $386.1574\left[\mathrm{M}+\mathrm{Na}^{+}\right]$; found 386.1569 .

(2S,4R,3'S, 8'R,9a'S,2"S,4"S)-8'-Methoxy-4-methyl-3'-(4-methyl-5-oxotetrahydrofuran-2yl)hexahydro-3H-spiro\{furan-2,9'-pyrrolo[1,2-a]azepine\}-5,5'(4H,6'H)-dione, 114

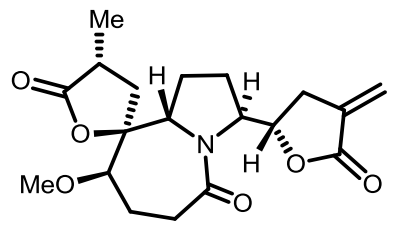

146
$\mathrm{EtOH}$
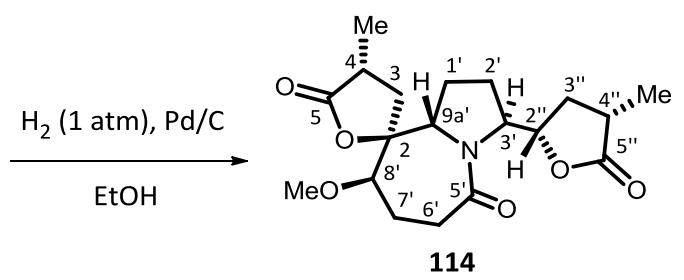

To a solution of bislactone $146(8.0 \mathrm{mg}, 21.7 \mu \mathrm{mol})$ in a $\mathrm{EtOH}(1 \mathrm{ml}), 10 \% \mathrm{Pd} / \mathrm{C}(9.2 \mathrm{mg}, 8.6$ $\mu \mathrm{mol}$ ) was added. The reaction mixture was stirred at atmospheric pressure of $\mathrm{H}_{2}$ for $4 \mathrm{~h}$. Then, it was filtered through Celite ${ }^{\circledR}$ and concentrated under reduced pressure to furnish bislactone $\mathbf{1 1 4}$ (8.0 mg, $21.6 \mu \mathrm{mol}$, quantitative yield).

Physical and spectroscopic data of 114:

$[\alpha]_{D}^{20}=-31.6\left(c 0.82, \mathrm{CHCl}_{3}\right)$.

IR (ATR): 2937, 1769, 1645, 1448, 1412, 1380, 1169, 1103, $1012 \mathrm{~cm}^{-1}$. 
${ }^{1} \mathrm{H}-\mathrm{NMR}\left(400 \mathrm{MHz}, \mathrm{CDCl}_{3}\right): \delta 5.05$ (ddd, $\left.J=11.0,5.3,4.6 \mathrm{~Hz}, 1 \mathrm{H}: \mathrm{H}_{2^{\prime \prime}}\right), 4.74\left(\mathrm{~m}, 1 \mathrm{H}_{9 \mathrm{a}^{\prime}}\right), 4.65(\mathrm{~m}$, $\left.1 \mathrm{H}: \mathrm{H}_{3^{\prime}}\right), 3.48\left(\mathrm{~s}, 3 \mathrm{H}: \mathrm{OCH}_{3}\right), 3.26\left(\mathrm{~d}, J=3.7 \mathrm{~Hz}, 1 \mathrm{H}: \mathrm{H}_{8^{\prime}}\right), 2.88\left(\mathrm{~m}, 1 \mathrm{H}: \mathrm{H}_{6^{\prime}}\right), 2.73\left(\mathrm{~m}, 1 \mathrm{H}: \mathrm{H}_{4}\right), 2.61(\mathrm{~m}$, $\left.1 \mathrm{H}: \mathrm{H}_{4^{\prime \prime}}\right), 2.34\left(\mathrm{dd}, J=14.1,10.7 \mathrm{~Hz}, 1 \mathrm{H}: \mathrm{H}_{3}\right), 2.25\left(\mathrm{~m}, 3 \mathrm{H}: \mathrm{H}_{1^{\prime}}, \mathrm{H}_{6^{\prime}}, \mathrm{H}_{3^{\prime \prime}}\right), 2.08\left(\mathrm{~m}, 1 \mathrm{H}: \mathrm{H}_{7^{\prime}}\right), 1.86(\mathrm{~m}$, $\left.3 \mathrm{H}: 2 \mathrm{H}_{2^{\prime}}, \mathrm{H}_{1^{\prime}}\right), 1.74\left(\mathrm{~m}, 1 \mathrm{H}: \mathrm{H}_{7^{\prime}}\right), 1.52\left(\mathrm{q}, J=12.0 \mathrm{~Hz}, 1 \mathrm{H}: \mathrm{H}_{3^{\prime \prime}}\right), 1.40\left(\mathrm{dd}, J=14.1,9.9 \mathrm{~Hz}, 1 \mathrm{H}: \mathrm{H}_{3}\right), 1.32$ $\left(\mathrm{d}, J=7.2 \mathrm{~Hz}, 3 \mathrm{H}: \mathrm{CH}_{3}\right), 1.25\left(\mathrm{~d}, J=7.0 \mathrm{~Hz}, 3 \mathrm{H}: \mathrm{CH}_{3}\right)$.

${ }^{13}$ C-NMR $\left(100 \mathrm{MHz}, \mathrm{CDCl}_{3}\right)$ : $\delta 178.8\left(\mathrm{C}_{5}\right), 178.4\left(\mathrm{C}_{5^{\prime \prime}}\right), 174.0\left(\mathrm{C}_{5^{\prime}}\right), 86.2\left(\mathrm{C}_{2}\right), 84.5\left(\mathrm{C}_{8^{\prime}}\right), 76.8\left(\mathrm{C}_{2^{\prime \prime}}\right)$, $60.1\left(\mathrm{C}_{3^{\prime}}\right), 58.8\left(\mathrm{OCH}_{3}\right), 57.7\left(\mathrm{C}_{9 \mathrm{a}^{\prime}}\right), 35.9\left(\mathrm{C}_{4^{\prime \prime}}\right), 35.3\left(\mathrm{C}_{4}\right), 34.3\left(\mathrm{C}_{3}\right), 32.6\left(\mathrm{C}_{3^{\prime \prime}}\right), 30.5\left(\mathrm{C}_{6^{\prime}}\right), 26.6\left(\mathrm{C}_{1^{\prime}}\right)$, $25.0\left(\mathrm{C}_{2^{\prime}}\right), 23.4\left(\mathrm{C}_{7^{\prime}}\right), 17.5\left(\mathrm{CH}_{3}\right), 15.0\left(\mathrm{CH}_{3}\right)$.

HRMS (ESI+): calcd for $\mathrm{C}_{19} \mathrm{H}_{27} \mathrm{NO}_{6}: 388.1731\left[\mathrm{M}+\mathrm{Na}^{+}\right]$; found 388.1734 .

(2S,4R,3'S,8'R,9a'S,2"S,4"S)-8'-Methoxy-4-methyl-3'-(4-methyl-5-oxotetrahydrofuran-2-yl)-5'thioxooctahydro-3H-spiro[furan-2,9'-pyrrolo[1,2-a]azepin]-5(4H)-one, 148

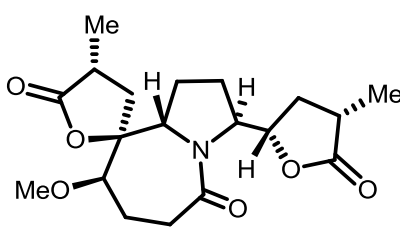

114

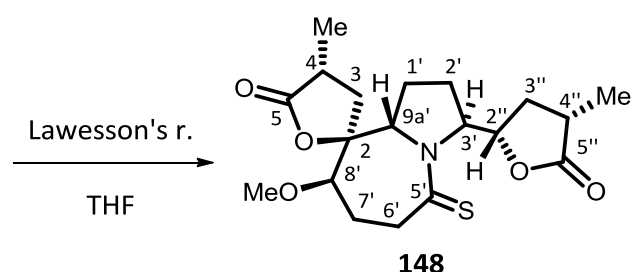

148

Lawesson's reagent $(5.7 \mathrm{mg}, 14.1 \mu \mathrm{mol})$ was added to a solution of $114(8.2 \mathrm{mg}, 22.4 \mu \mathrm{mol})$ in dry THF ( $1 \mathrm{~mL})$ and the mixture was heated at the reflux temperature for $45 \mathrm{~min}$. The solvent was removed under vacuum and the residue was filtered through $\mathrm{Al}_{2} \mathrm{O}_{3}$ Brockman I using EtOAc as eluent. Evaporation of the solvent under reduced pressure afforded a residue, which was identified as the thiolactam 148.

Spectroscopic data of 148:

IR (ATR): 2926, 1769, 1428, 1376, 1333, 1260, 1222, 1193, 1166, 1088, 1059, $1023 \mathrm{~cm}^{-1}$.

${ }^{1} \mathrm{H}-\mathrm{NMR}\left(400 \mathrm{MHz}, \mathrm{CDCl}_{3}\right): \delta 5.47\left(\mathrm{dt}, J=11.3,4.9 \mathrm{~Hz}, 1 \mathrm{H}: \mathrm{H}_{2^{\prime \prime}}\right), 5.37\left(\mathrm{~m}, 1 \mathrm{H}: \mathrm{H}_{3^{\prime}}\right), 5.04(\mathrm{~d}, J=9.3 \mathrm{~Hz}$, $\left.1 \mathrm{H}: \mathrm{H}_{9 \mathrm{a}^{\prime}}\right), 3.48\left(\mathrm{~s}, 3 \mathrm{H}: \mathrm{OCH}_{3}\right), 3.26\left(\mathrm{~d}, J=2.6 \mathrm{~Hz}, 1 \mathrm{H}: \mathrm{H}_{8^{\prime}}\right), 3.18\left(\mathrm{td}, J=12.7,1.5 \mathrm{~Hz}, 1 \mathrm{H}: \mathrm{H}_{6^{\prime}}\right), 3.06(\mathrm{~m}$, $\left.1 \mathrm{H}: \mathrm{H}_{6^{\prime}}\right), 2.75\left(\mathrm{~m}, 1 \mathrm{H}: \mathrm{H}_{4}\right), 2.63\left(\mathrm{~m}, 1 \mathrm{H}: \mathrm{H}_{4^{\prime \prime}}\right), 2.27\left(\mathrm{~m}, 3 \mathrm{H}: \mathrm{H}_{2^{\prime}}, \mathrm{H}_{3}, \mathrm{H}_{3^{\prime \prime}}\right), 2.07$ (m, 4H:2 $\left.\mathrm{H}_{1^{\prime}}, \mathrm{H}_{2^{\prime}}, \mathrm{H}_{7^{\prime}}\right), 1.85$ $\left(\mathrm{m}, 1 \mathrm{H}: \mathrm{H}_{7^{\prime}}\right), 1.57\left(\mathrm{~m}, 1 \mathrm{H}: \mathrm{H}_{3^{\prime \prime}}\right), 1.45\left(\mathrm{dd}, J=14.3,10.1 \mathrm{~Hz}, 1 \mathrm{H}: \mathrm{H}_{3}\right), 1.32\left(\mathrm{~d}, J=7.2 \mathrm{~Hz}, 3 \mathrm{H}: \mathrm{CH}_{3}\right), 1.27$ $\left(\mathrm{d}, J=7.0 \mathrm{~Hz}, 3 \mathrm{H}: \mathrm{CH}_{3}\right)$. 
${ }^{13} \mathrm{C}-\mathrm{NMR}\left(63 \mathrm{MHz}, \mathrm{CDCl}_{3}\right): \delta 207.0\left(\mathrm{C}_{5^{\prime}}\right), 178.3 / 178.2\left(\mathrm{C}_{5} / \mathrm{C}_{5^{\prime \prime}}\right), 85.3 / 84.6\left(\mathrm{C}_{2} / \mathrm{C}_{8^{\prime}}\right), 74.3\left(\mathrm{C}_{2^{\prime \prime}}\right), 65.0$ $\left(\mathrm{C}_{3^{\prime}}\right), 62.3\left(\mathrm{C}_{9 \mathrm{a}^{\prime}}\right), 58.9\left(\mathrm{OCH}_{3}\right), 40.9,36.1,35.1,33.0,29.9,27.1,25.5,25.1,17.4\left(\mathrm{CH}_{3}\right), 15.0\left(\mathrm{CH}_{3}\right)$.

(2S,4R,3'S,8'R,9a'S,2"S,4"S)-8'-Methoxy-4-methyl-3'-(4-methyl-5-oxotetrahydrofuran-2yl)octahydro-3H-spiro\{furan-2,9'-pyrrolo[1,2-a]azepine\}-5(4H)-one, stemospironine

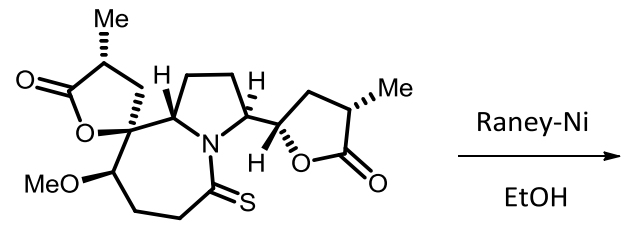

148

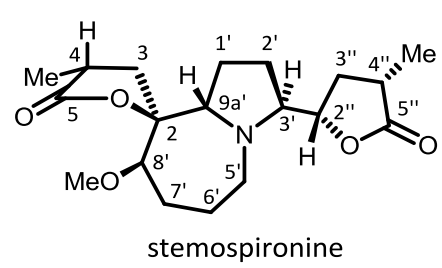

stemospironine

Thiolactam 148 was dissolved in EtOH (1 mL), Raney-Ni (aprox. $50 \mathrm{mg}$ ) was added and the reaction mixture was heated at the reflux temperature for $1 \mathrm{~h}$. Then, it was filtered through Celite ${ }^{\circledR}$ and the solvent was evaporated in vacuo to provide stemospirone $(4.1 \mathrm{mg}, 11.8 \mu \mathrm{mol}$, $54 \%$ yield from 114 , two steps).

Physical and spectroscopic data of stemospironine:

$[\alpha]_{D}^{20}=-8.6\left(c 0.46, \mathrm{CHCl}_{3}\right) .\left(\mathrm{lit}^{11}[\alpha]_{\mathrm{D}}{ }^{27}=-8.2\left(\mathrm{c} 0.92, \mathrm{CHCl}_{3}\right)\right)$.

${ }^{1} \mathrm{H}-\mathrm{NMR}\left(600 \mathrm{MHz}, \mathrm{CDCl}_{3}\right): \delta 4.36\left(\mathrm{~m}, 1 \mathrm{H}: \mathrm{H}_{2^{\prime \prime}}\right), 3.78\left(\mathrm{~m}, 1 \mathrm{H}: \mathrm{H}_{9 \mathrm{a}^{\prime}}\right), 3.40\left(\mathrm{~s}, 3 \mathrm{H}: \mathrm{OCH}_{3}\right), 3.30(\mathrm{~m}$, $\left.1 \mathrm{H}: \mathrm{H}_{3^{\prime}}\right), 3.22\left(\mathrm{~d}, J=5.6 \mathrm{~Hz}, 1 \mathrm{H}: \mathrm{H}_{8^{\prime}}\right), 3.11\left(\mathrm{~m}, 2 \mathrm{H}: 2 \mathrm{H}_{5^{\prime}}\right), 2.70(\mathrm{~m}, 1 \mathrm{H}) / 2.61(\mathrm{~m}, 1 \mathrm{H}) / 2.47(\mathrm{~m}, 1 \mathrm{H}) / 2.38$ $(\mathrm{m}, 1 \mathrm{H})\left(\mathrm{H}_{4} / \mathrm{H}_{4^{\prime \prime}} / \mathrm{H}_{3} / \mathrm{H}_{3^{\prime \prime}}\right), 1.95(\mathrm{~m}, 2 \mathrm{H}) / 1.83(\mathrm{~m}, 2 \mathrm{H}) / 1.62(\mathrm{~m}, 6 \mathrm{H})\left(2 \mathrm{H}_{1^{\prime}} / 2 \mathrm{H}_{2^{\prime}} / 2 \mathrm{H}_{6^{\prime}} / 2 \mathrm{H}_{7^{\prime}} / \mathrm{H}_{3} / \mathrm{H}_{3^{\prime \prime}}\right), 1.31$ (d, $\left.J=7.3 \mathrm{~Hz}, 3 \mathrm{H}: \mathrm{CH}_{3}\right), 1.26\left(\mathrm{~d}, J=7.1 \mathrm{~Hz}, 3 \mathrm{H}: \mathrm{CH}_{3}\right)$.

${ }^{13} \mathrm{C}$-NMR $\left(150 \mathrm{MHz}, \mathrm{CDCl}_{3}\right)$ ): $179.5\left(\mathrm{C}_{5}+\mathrm{C}_{5^{\prime \prime}}\right)$, $90.6\left(\mathrm{C}_{2}\right), 85.4\left(\mathrm{C}_{8^{\prime}}\right), 80.1\left(\mathrm{C}_{2^{\prime \prime}}\right), 67.9\left(\mathrm{C}_{9 \mathrm{a}^{\prime}}\right), 63.2\left(\mathrm{C}_{3^{\prime}}\right)$, $58.2\left(\mathrm{OCH}_{3}\right), 49.0\left(\mathrm{C}_{5^{\prime}}\right), 35.8 / 35.3 / 35.1 / 34.7\left(\mathrm{C}_{4} / \mathrm{C}_{4^{\prime \prime}} / \mathrm{C}_{3} / \mathrm{C}_{3^{\prime \prime}}\right), 27.2 / 26.7 / 25.8 / 22.4\left(\mathrm{C}_{1^{\prime}} / \mathrm{C}_{2^{\prime}} / \mathrm{C}_{6^{\prime}} / \mathrm{C}_{7^{\prime}}\right)$, $17.7\left(\mathrm{CH}_{3}\right), 15.0\left(\mathrm{CH}_{3}\right)$. 
(2S,4R,3'S,8'R,9a'S,2"R,4" $R)-8$ '-Methoxy-4-methyl-3'-(4-methyl-5-oxotetrahydrofuran-2-

yl)hexahydro-3H-spiro\{furan-2,9'-pyrrolo[1,2-a]azepine\}-5,5'(4H,6'H)-dione, 117

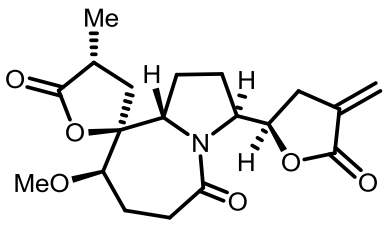

147

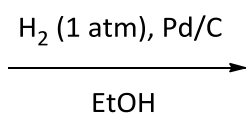

$\mathrm{EtOH}$

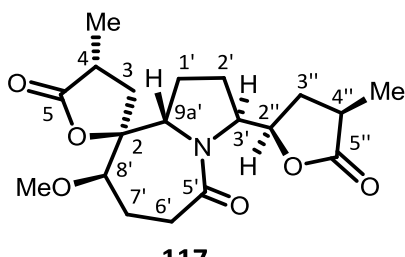

117

To a solution of bislactone $147(8.3 \mathrm{mg}, 22.8 \mu \mathrm{mol})$ in EtOH $(1 \mathrm{~mL}), 10 \% \mathrm{Pd} / \mathrm{C}(10.9 \mathrm{mg}$, $10.2 \mu \mathrm{mol}$ ) was added. The reaction mixture was stirred at atmospheric pressure of $\mathrm{H}_{2}$ for $4 \mathrm{~h}$. Then, it was filtered through Celite ${ }^{\circledR}$ and concentrated under reduced pressure to furnish bislactone 117 (7.8 mg, $21.3 \mu \mathrm{mol}, 94 \%$ yield).

Physical and spectroscopic data of 117:

$[\alpha]_{\mathrm{D}}{ }^{20}=-41.4\left(c 0.73, \mathrm{CHCl}_{3}\right)$.

IR (ATR): 2935, 1768, 1639, 1444, 1412, 1232, 1173, 1103, $1021 \mathrm{~cm}^{-1}$.

${ }^{1} \mathrm{H}-\mathrm{NMR}\left(400 \mathrm{MHz}, \mathrm{CDCl}_{3}\right.$ ): $\delta 5.02$ (ddd, $\left.J=11.0,5.6,1.6 \mathrm{~Hz}, 1 \mathrm{H}: \mathrm{H}_{2^{\prime \prime}}\right), 4.80$ (d, $J=9.7 \mathrm{~Hz}, 1 \mathrm{H}: \mathrm{H}_{9 \mathrm{a}^{\prime}}$ ), $4.35\left(\mathrm{brd}, J=9.1 \mathrm{~Hz}, 1 \mathrm{H}: \mathrm{H}_{3^{\prime}}\right), 3.48\left(\mathrm{~s}, 3 \mathrm{H}: \mathrm{OCH}_{3}\right), 3.24\left(\mathrm{~d}, J=4.1 \mathrm{~Hz}, 1 \mathrm{H}: \mathrm{H}_{8^{\prime}}\right), 2.95(\mathrm{td}, J=13.7,1.6$ $\left.\mathrm{Hz}, 1 \mathrm{H}: \mathrm{H}_{6^{\prime}}\right), 2.67\left(\mathrm{~m}, 2 \mathrm{H}: \mathrm{H}_{4}, \mathrm{H}_{4^{\prime \prime}}\right), 2.47\left(\mathrm{~m}, 2 \mathrm{H}: \mathrm{H}_{3^{\prime \prime}}, \mathrm{H}_{1^{\prime}}\right), 2.34\left(\mathrm{dd}, J=14.0,10.5 \mathrm{~Hz}, 1 \mathrm{H}: \mathrm{H}_{3}\right), 2.24(\mathrm{dd}, J$ $\left.=13.7,6.0 \mathrm{~Hz}, 1 \mathrm{H}: \mathrm{H}_{6^{\prime}}\right), 2.07\left(\mathrm{~m}, 1 \mathrm{H}: \mathrm{H}_{7^{\prime}}\right), 1.80\left(\mathrm{~m}, 4 \mathrm{H}: \mathrm{H}_{1^{\prime}}, 2 \mathrm{H}_{2^{\prime}}, \mathrm{H}_{7^{\prime}}\right), 1.47\left(\mathrm{q}, J=12.0 \mathrm{~Hz}, 1 \mathrm{H}: \mathrm{H}_{3^{\prime \prime}}\right), 1.38$ (dd, $\left.J=13.9,10.4 \mathrm{~Hz}, 1 \mathrm{H}: \mathrm{H}_{3}\right), 1.31$ (d, J = 7.2 Hz, 3H: $\left.\mathrm{CH}_{3}\right), 1.27$ (d, J = 7.0 Hz, $3 \mathrm{H}: \mathrm{CH}_{3}$ ).

${ }^{13} \mathrm{C}-\mathrm{NMR}\left(63 \mathrm{MHz}, \mathrm{CDCl}_{3}\right): \delta 179.0\left(\mathrm{C}_{5}\right), 178.4\left(\mathrm{C}_{5^{\prime \prime}}\right), 174.0\left(\mathrm{C}_{5^{\prime}}\right), 85.9\left(\mathrm{C}_{2}\right), 84.6\left(\mathrm{C}_{8^{\prime}}\right), 77.2\left(\mathrm{C}_{2^{\prime \prime}}\right), 61.8$ $\left(\mathrm{C}_{3^{\prime}}\right), 58.8\left(\mathrm{OCH}_{3}\right), 57.1\left(\mathrm{C}_{9 \mathrm{a}^{\prime}}\right), 35.7 / 35.2 / 34.7 / 34.4\left(\mathrm{C}_{3} / \mathrm{C}_{3^{\prime \prime}} / \mathrm{C}_{4} / \mathrm{C}_{4^{\prime \prime}}\right), 30.5\left(\mathrm{C}_{6^{\prime}}\right), 26.5 / 23.8 / 23.5$ $\left(\mathrm{C}_{1^{\prime}} / \mathrm{C}_{2^{\prime}} / \mathrm{C}_{7^{\prime}}\right), 17.3\left(\mathrm{CH}_{3}\right), 15.1\left(\mathrm{CH}_{3}\right)$.

HRMS (ESI+): calcd for $\mathrm{C}_{19} \mathrm{H}_{27} \mathrm{NO}_{6}: 388.1731\left[\mathrm{M}+\mathrm{Na}^{+}\right]$; found 388.1727. 
(2S,4R,3'S,8'R,9a'S,2"R,4"R)-8'-Methoxy-4-methyl-3'-(4-methyl-5-oxotetrahydrofuran-2-

yl)octahydro-3H-spiro\{furan-2,9'-pyrrolo[1,2-a]azepine\}-5(4H)-one, 119

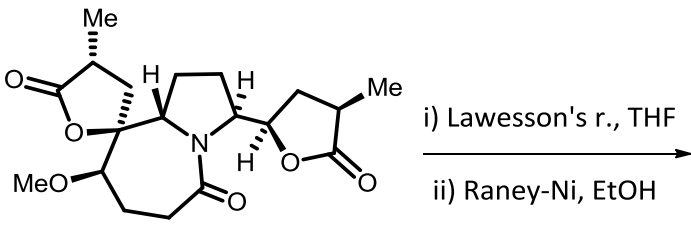

117

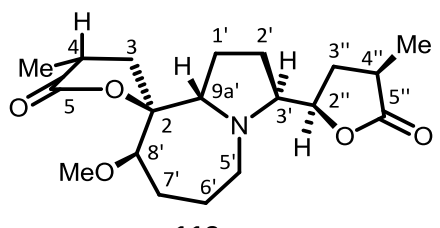

119

Lawesson's reagent $(6.3 \mathrm{mg}, 15.6 \mu \mathrm{mol})$ was added to a solution of $117(7.8 \mathrm{mg}, 21.3 \mu \mathrm{mol})$ in dry THF ( $1 \mathrm{~mL}$ ) and the mixture was heated at the reflux temperature for $45 \mathrm{~min}$. The solvent was removed under vacuum and the residue was filtered through $\mathrm{Al}_{2} \mathrm{O}_{3}$ Brockman I, using EtOAc as eluent. After evaporation of the solvent under reduced pressure, the resulting solid was dissolved in $\mathrm{EtOH}(1 \mathrm{~mL})$. Next, Raney-Ni $(50 \mathrm{mg}$ ) was added to the solution and the reaction mixture was heated at the reflux temperature for $1 \mathrm{~h}$. Then, it was filtered through Celite ${ }^{\circledR}$ and the solvent was evaporated in vacuo to furnish amine 119 ( $2.8 \mathrm{mg}, 8.1 \mu \mathrm{mol}, 52 \%$ yield).

Physical and spectroscopic data of 119:

$[\alpha]_{D}^{20}=-28.2\left(c 0.28, \mathrm{CHCl}_{3}\right)$.

IR (ATR): 2935, 2877, 1764, 1456, 1376, 1335, 1264, 1198, 1173, 1106, $1014 \mathrm{~cm}^{-1}$.

${ }^{1} \mathrm{H}-\mathrm{NMR}\left(400 \mathrm{MHz}, \mathrm{CDCl}_{3}\right.$ ): $\delta 4.52$ (ddd, $J=10.5,5.8,3.1 \mathrm{~Hz}, 1 \mathrm{H}: \mathrm{H}_{2^{\prime \prime}}$ ), 3.77 (dd, $J=8.1,5.4 \mathrm{~Hz}$, $\left.1 \mathrm{H}: \mathrm{H}_{9^{\prime}}\right), 3.40\left(\mathrm{~s}, 3 \mathrm{H}: \mathrm{OCH}_{3}\right), 3.38\left(\mathrm{~m}, 1 \mathrm{H}: \mathrm{H}_{3^{\prime}}\right), 3.20\left(\mathrm{dd}, J=7.1,2.1 \mathrm{~Hz}, 1 \mathrm{H}: \mathrm{H}_{8^{\prime}}\right), 3.03$ (ddd, $J=12.0$, 8.0, 3.7 Hz, $1 \mathrm{H}: \mathrm{H}_{5^{\prime}}$ ), 2.88 (ddd, $\left.J=12.0,7.5,4.3 \mathrm{~Hz}, 1 \mathrm{H}: \mathrm{H}_{5^{\prime}}\right), 2.68\left(\mathrm{~m}, 2 \mathrm{H}: \mathrm{H}_{4}, \mathrm{H}_{4^{\prime \prime}}\right), 2.45$ (dd, $J=13.6$, $10.9 \mathrm{~Hz}, 1 \mathrm{H}: \mathrm{H}_{3}$ ), 2.37 (ddd, $J=12.5,8.8,5.8 \mathrm{~Hz}, 1 \mathrm{H}: \mathrm{H}_{3^{\prime \prime}}$ ), 2.05 (ddd, $J=16.2,13.0,8.2 \mathrm{~Hz}, 1 \mathrm{H}: \mathrm{H}_{1^{\prime}}$ ), $1.88\left(\mathrm{~m}, 3 \mathrm{H}: \mathrm{H}_{2^{\prime}}, \mathrm{H}_{6^{\prime}}, \mathrm{H}_{7^{\prime}}\right), 1.60\left(\mathrm{~m}, 6 \mathrm{H}: \mathrm{H}_{1^{\prime}}, \mathrm{H}_{2^{\prime}}, \mathrm{H}_{6^{\prime}}, \mathrm{H}_{7^{\prime}}, \mathrm{H}_{3}, \mathrm{H}_{3^{\prime \prime}}\right), 1.29\left(\mathrm{t}, J=7.2 \mathrm{~Hz}, 6 \mathrm{H}: 2 \mathrm{CH}_{3}\right)$.

${ }^{13}$ C-NMR $\left(100 \mathrm{MHz}, \mathrm{CDCl}_{3}\right): \delta$ 179.5/179.3 $\left(\mathrm{C}_{5} / \mathrm{C}_{5^{\prime \prime}}\right), 90.4\left(\mathrm{C}_{2}\right), 85.5\left(\mathrm{C}_{8^{\prime}}\right), 78.6\left(\mathrm{C}_{2^{\prime \prime}}\right), 66.1\left(\mathrm{C}_{\mathrm{a}^{\prime}}\right), 63.6$ $\left(\mathrm{C}_{3^{\prime}}\right), \quad 58.2 \quad\left(\mathrm{OCH}_{3}\right), \quad 49.1 \quad\left(\mathrm{C}_{5^{\prime}}\right), \quad 35.8 / 35.7 / 35.1 / 33.9 \quad\left(\mathrm{C}_{4} / \mathrm{C}_{4^{\prime \prime}} / \mathrm{C}_{3} / \mathrm{C}_{3^{\prime \prime}}\right), \quad 27.1 / 26.2 / 25.9 / 22.9$ $\left(\mathrm{C}_{6^{\prime}} / \mathrm{C}_{1^{\prime}} / \mathrm{C}_{2^{\prime}} / \mathrm{C}_{7^{\prime}}\right), 17.5\left(\mathrm{CH}_{3}\right), 15.3\left(\mathrm{CH}_{3}\right)$.

HRMS (ESI+): calcd for $\mathrm{C}_{19} \mathrm{H}_{29} \mathrm{NO}_{5}: 352.2118\left[\mathrm{M}+\mathrm{H}^{+}\right]$; found 352.2120 . 

5. Annex Spectra 


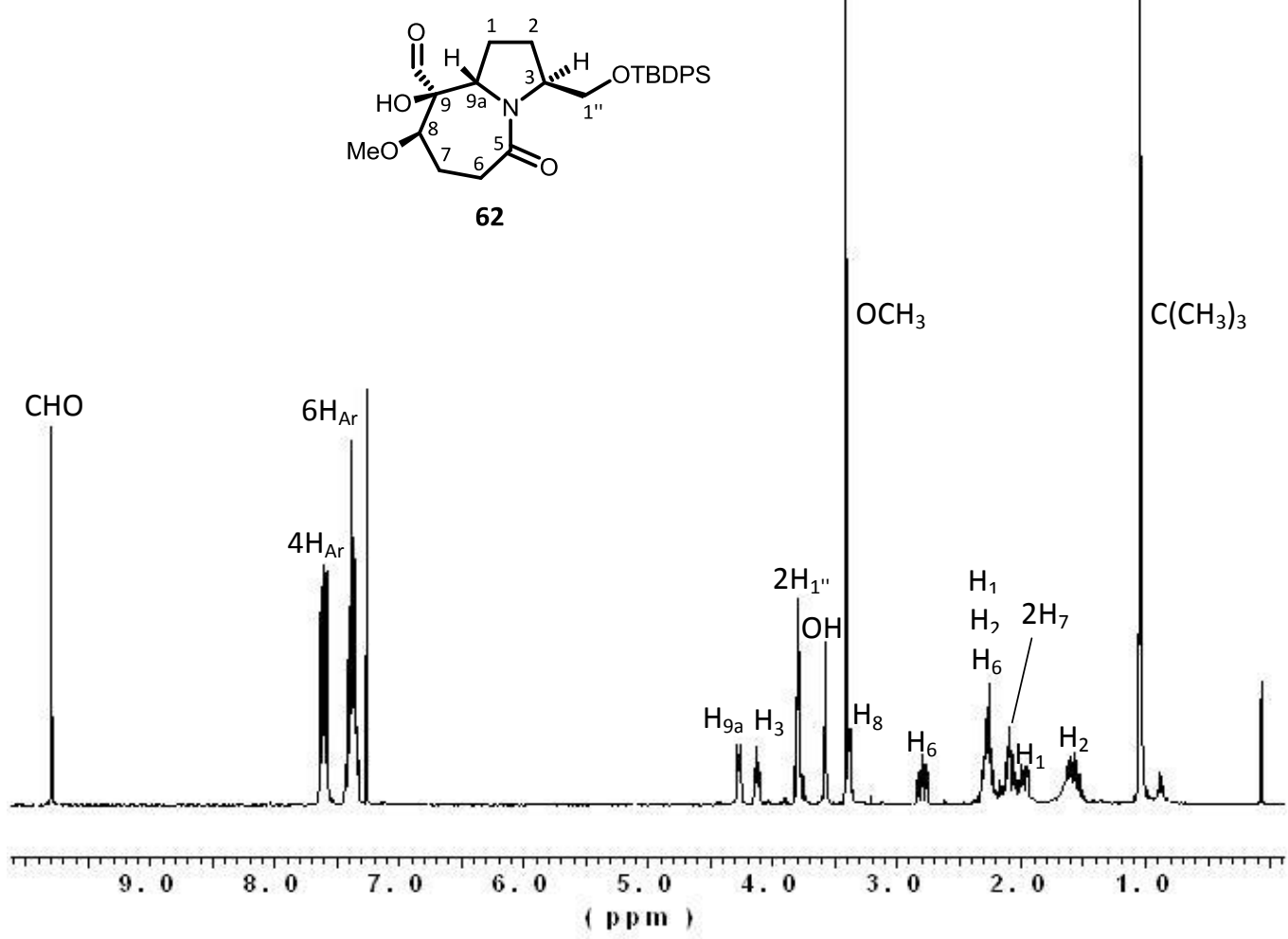

${ }^{1}$ H-NMR $\left(250 \mathrm{MHz}, \mathrm{CDCl}_{3}\right)$

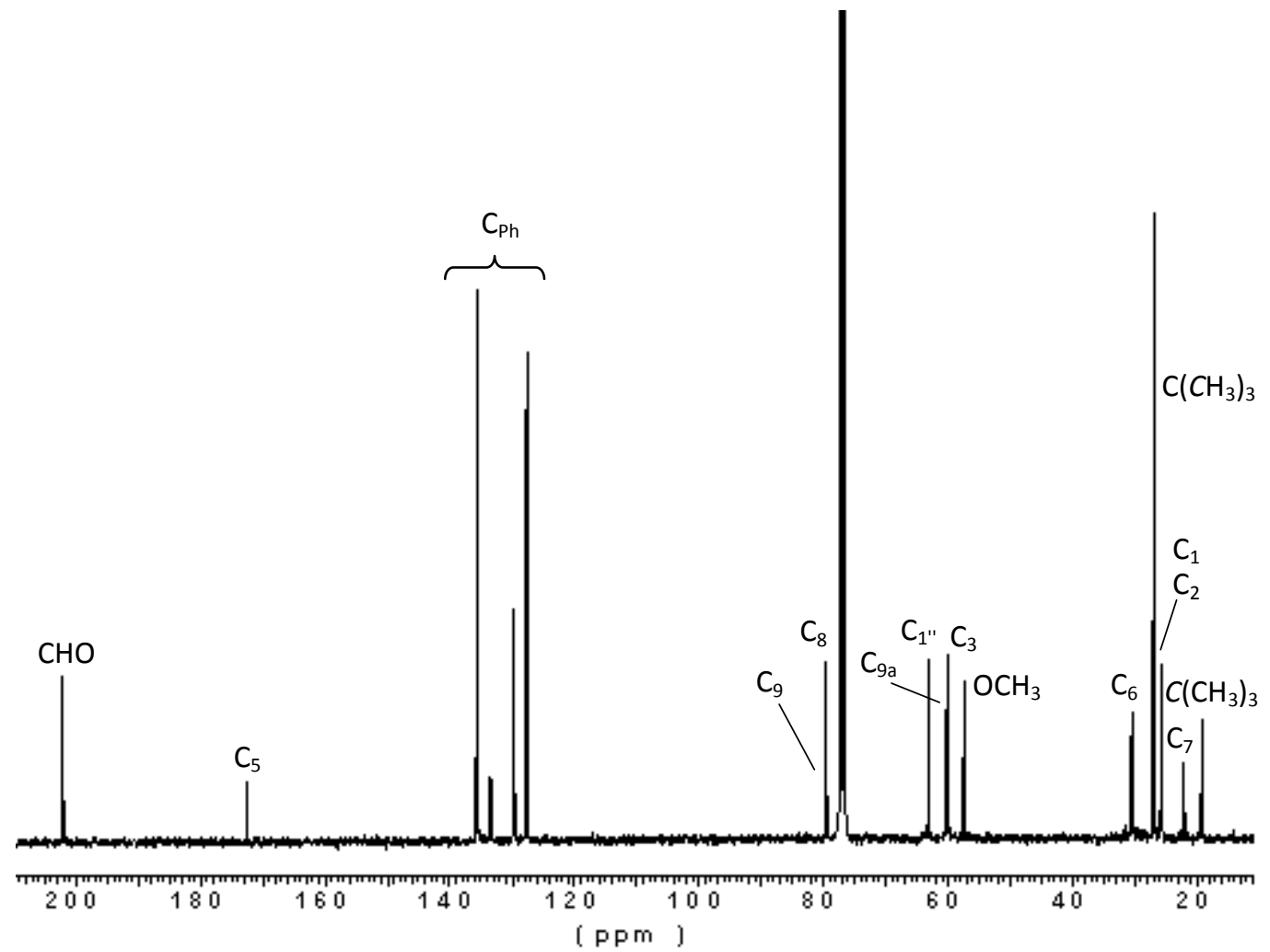

${ }^{13}$ C-NMR (63 MHz, $\mathrm{CDCl}_{3}$ ) 


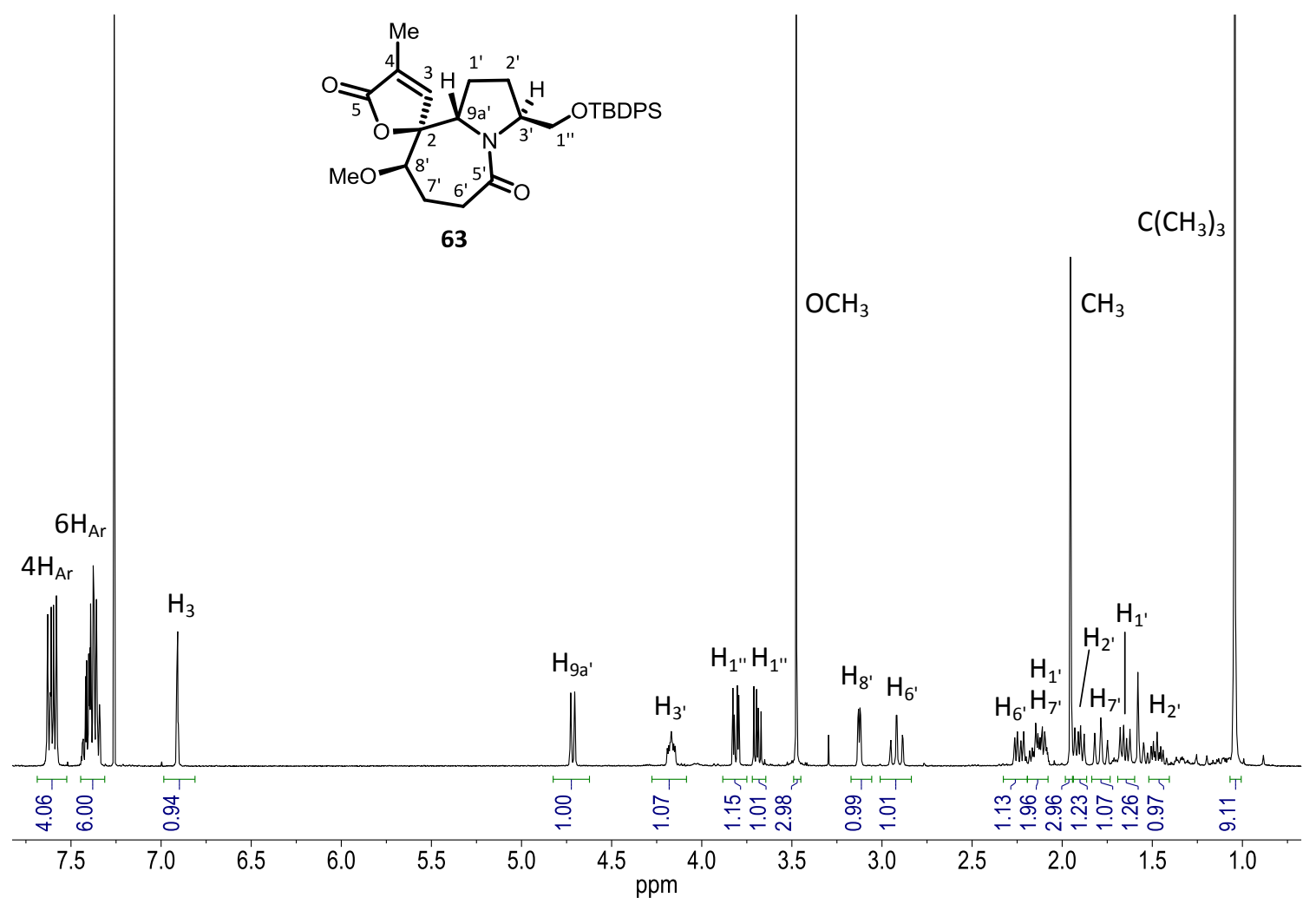

${ }^{1} \mathrm{H}-\mathrm{NMR}\left(400 \mathrm{MHz}, \mathrm{CDCl}_{3}\right.$ )

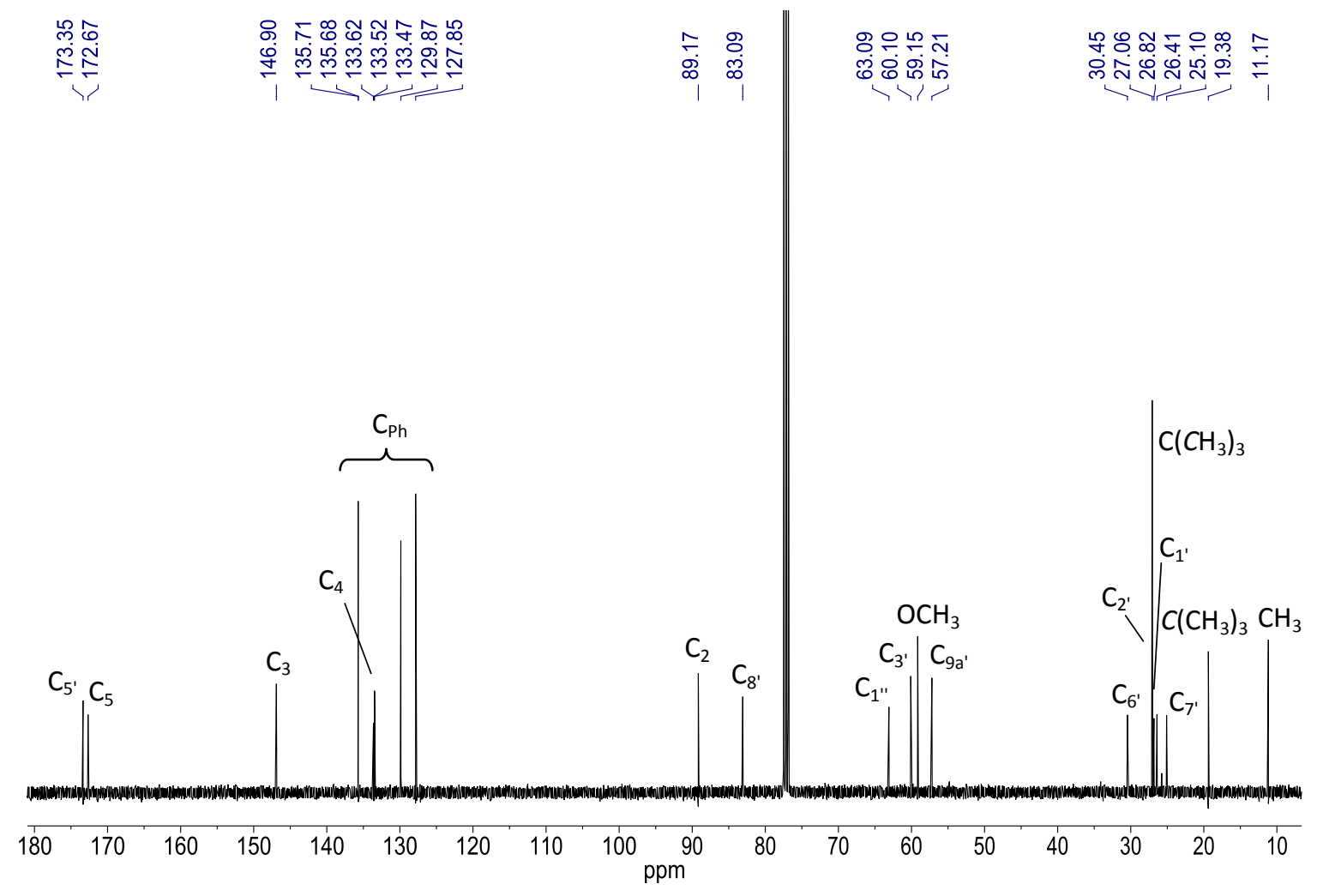

${ }^{13}$ C-NMR $\left(100 \mathrm{MHz}, \mathrm{CDCl}_{3}\right)$ 


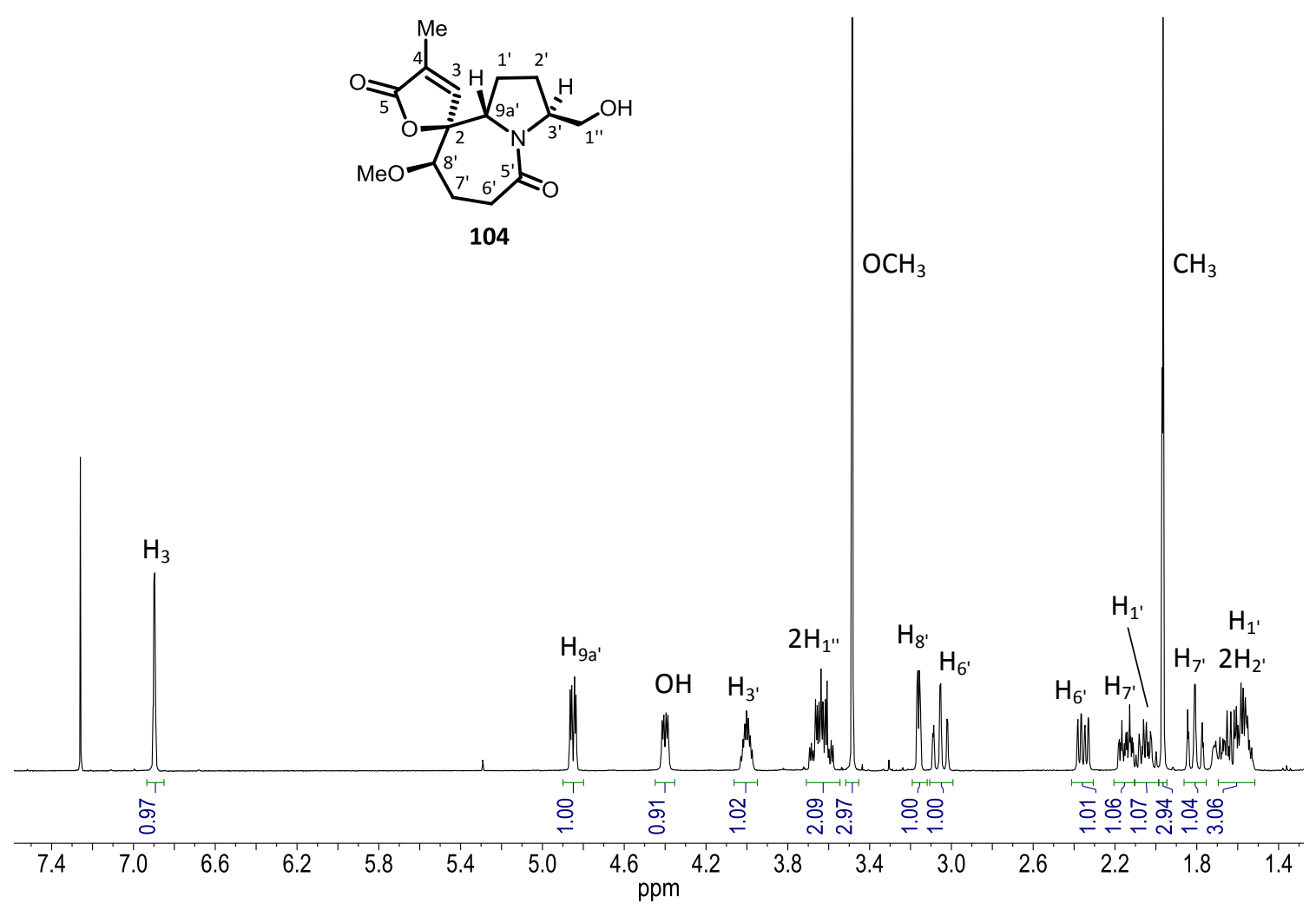

${ }^{1}$ H-NMR (400 MHz, $\mathrm{CDCl}_{3}$ )

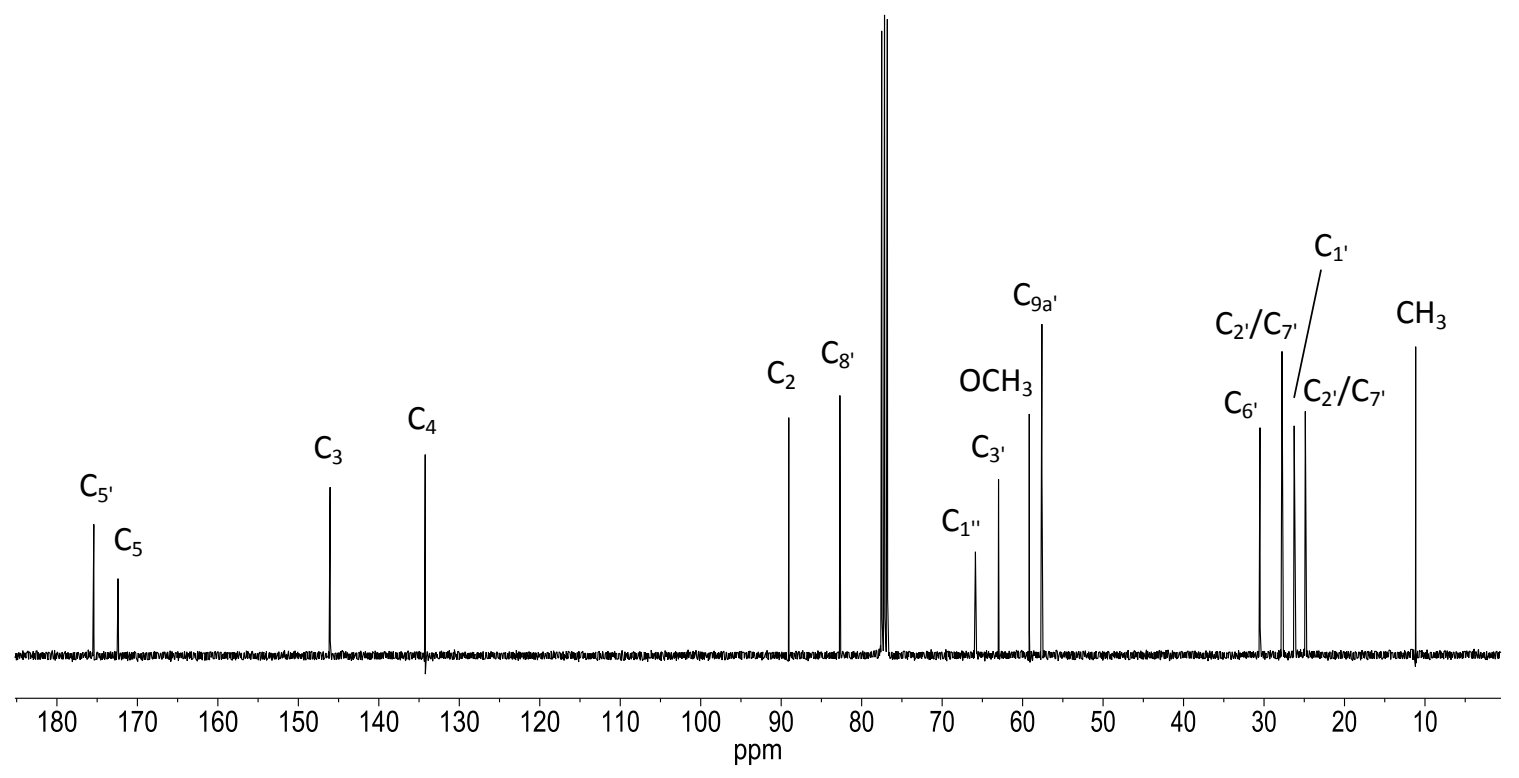

${ }^{13}$ C-NMR (100 MHz, $\left.\mathrm{CDCl}_{3}\right)$ 


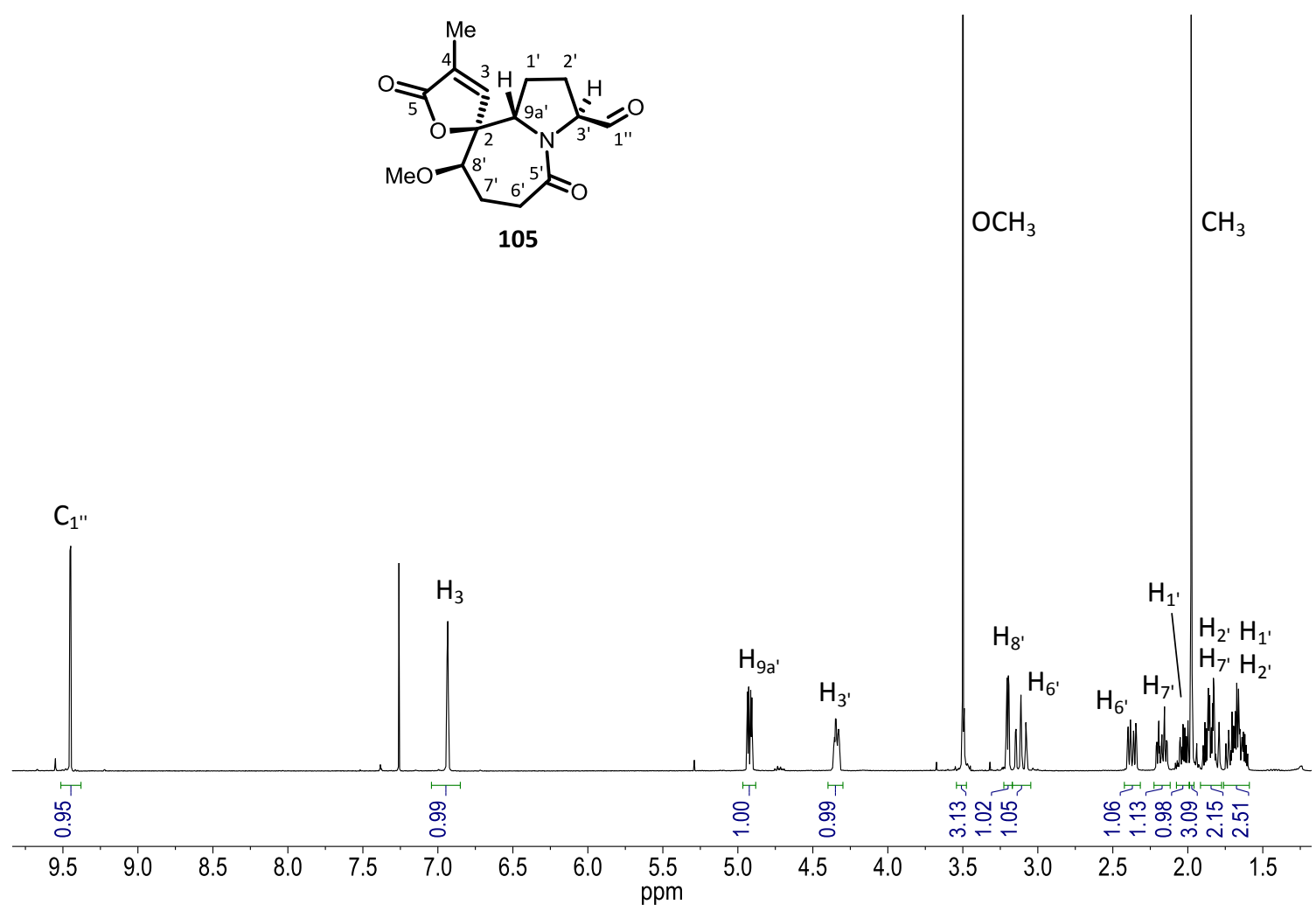

${ }^{1}$ H-NMR (400 MHz, $\mathrm{CDCl}_{3}$ )

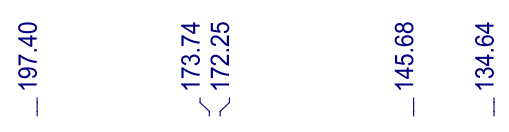

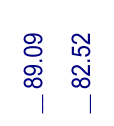

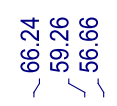

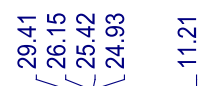

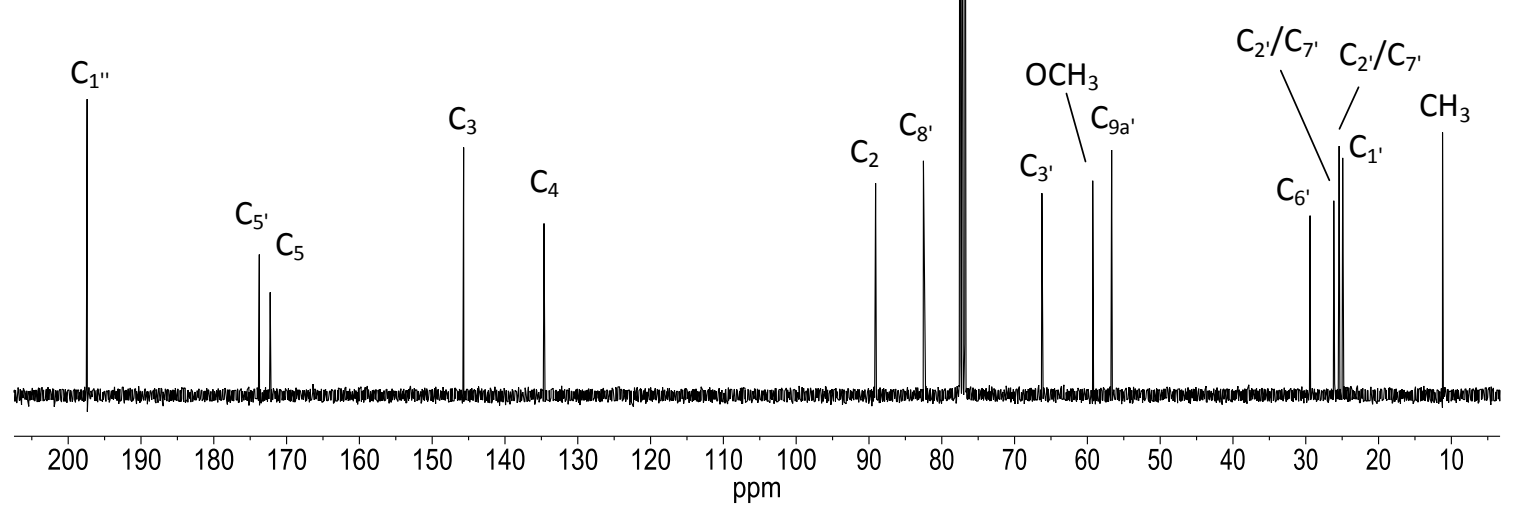

${ }^{13}$ C-NMR $\left(100 \mathrm{MHz}, \mathrm{CDCl}_{3}\right)$ 


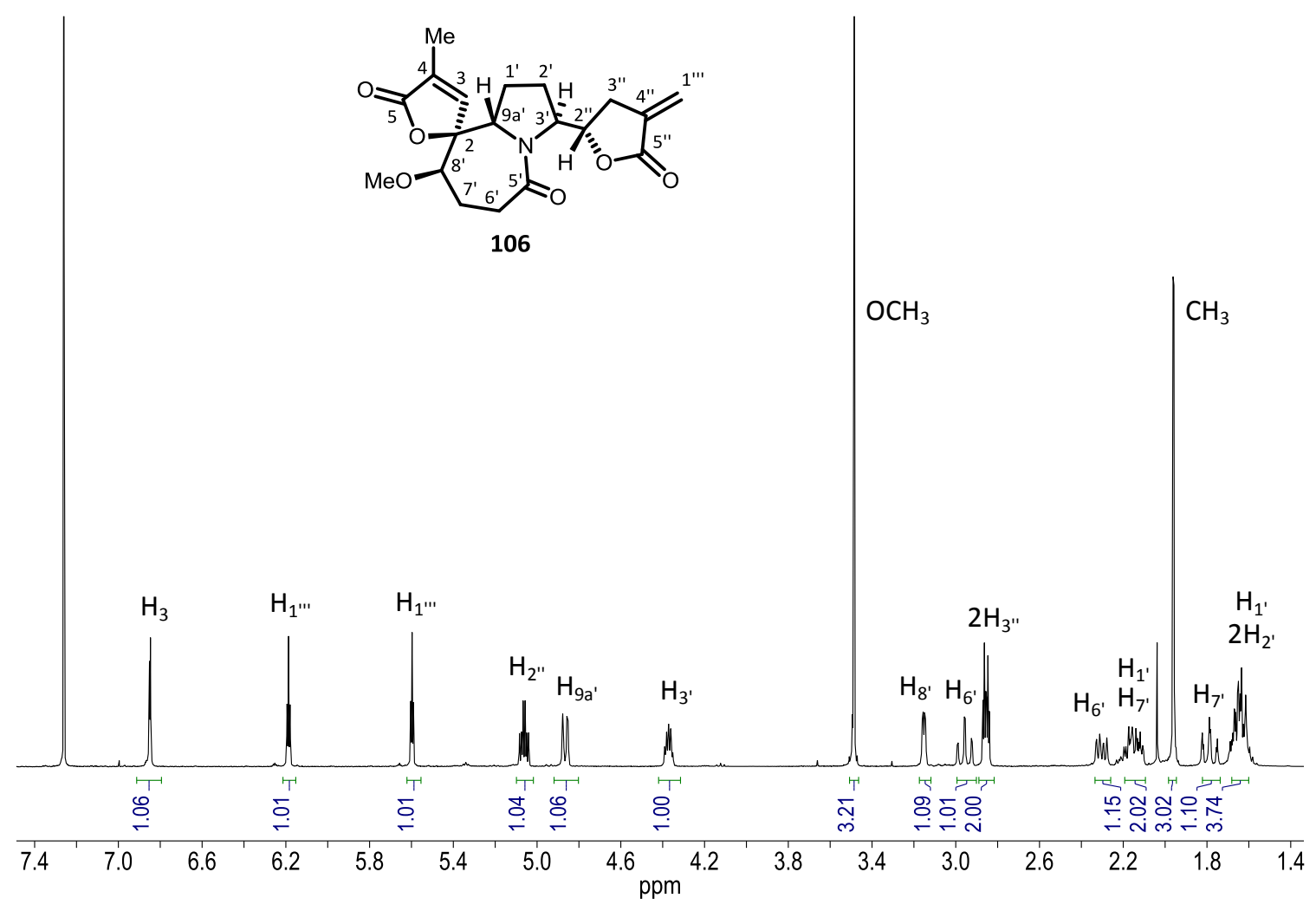

${ }^{1} \mathrm{H}-\mathrm{NMR}\left(400 \mathrm{MHz}, \mathrm{CDCl}_{3}\right)$

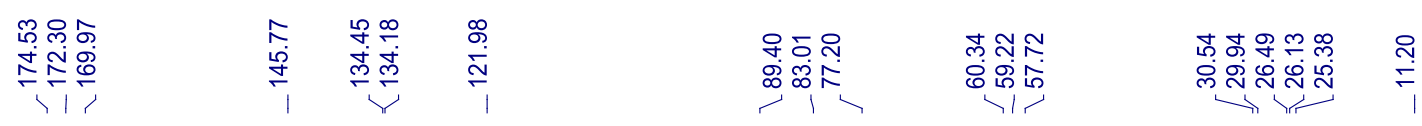

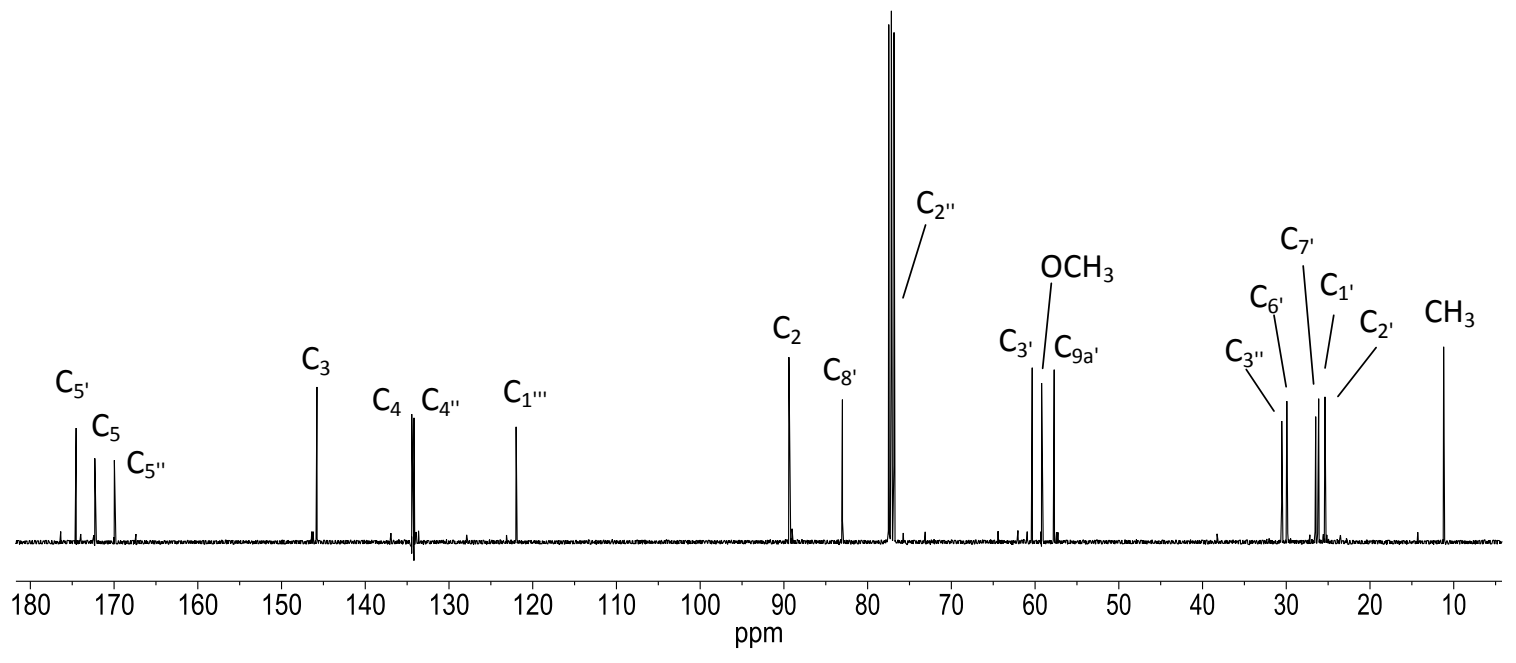

${ }^{13}$ C-NMR (100 MHz, $\left.\mathrm{CDCl}_{3}\right)$ 


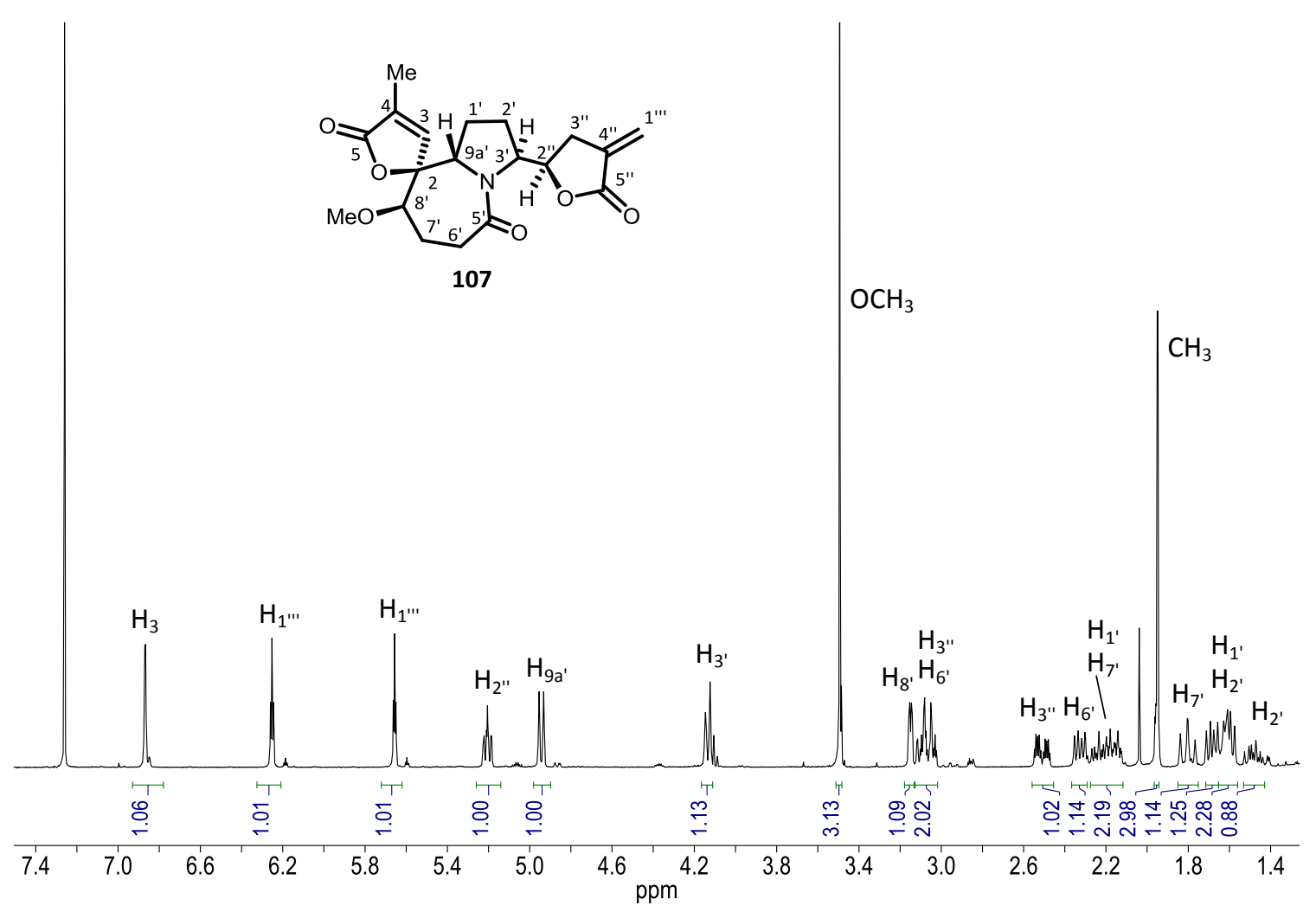

${ }^{1} \mathrm{H}-\mathrm{NMR}\left(400 \mathrm{MHz}, \mathrm{CDCl}_{3}\right.$ )

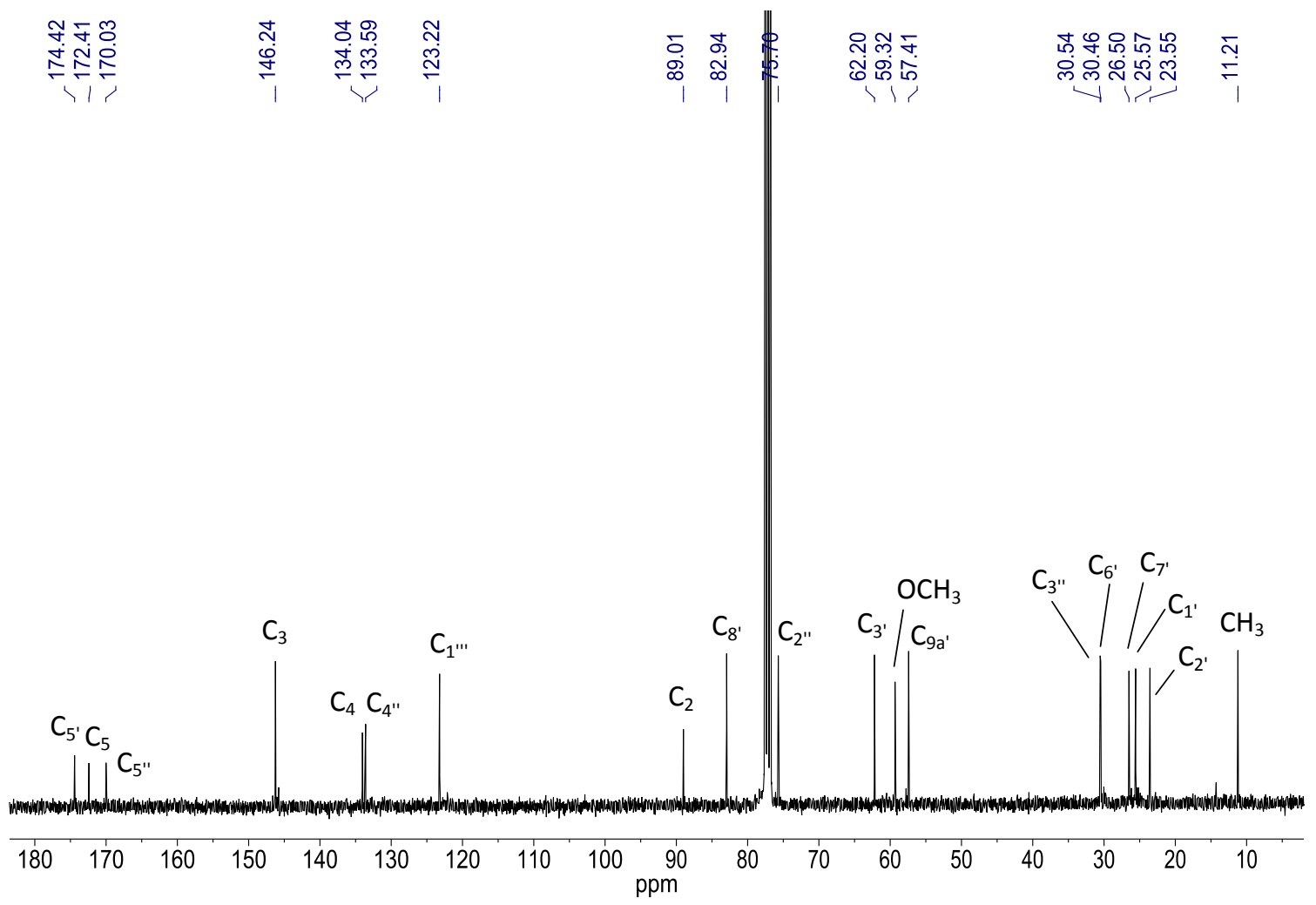

${ }^{13}$ C-NMR $\left(100 \mathrm{MHz}, \mathrm{CDCl}_{3}\right)$ 


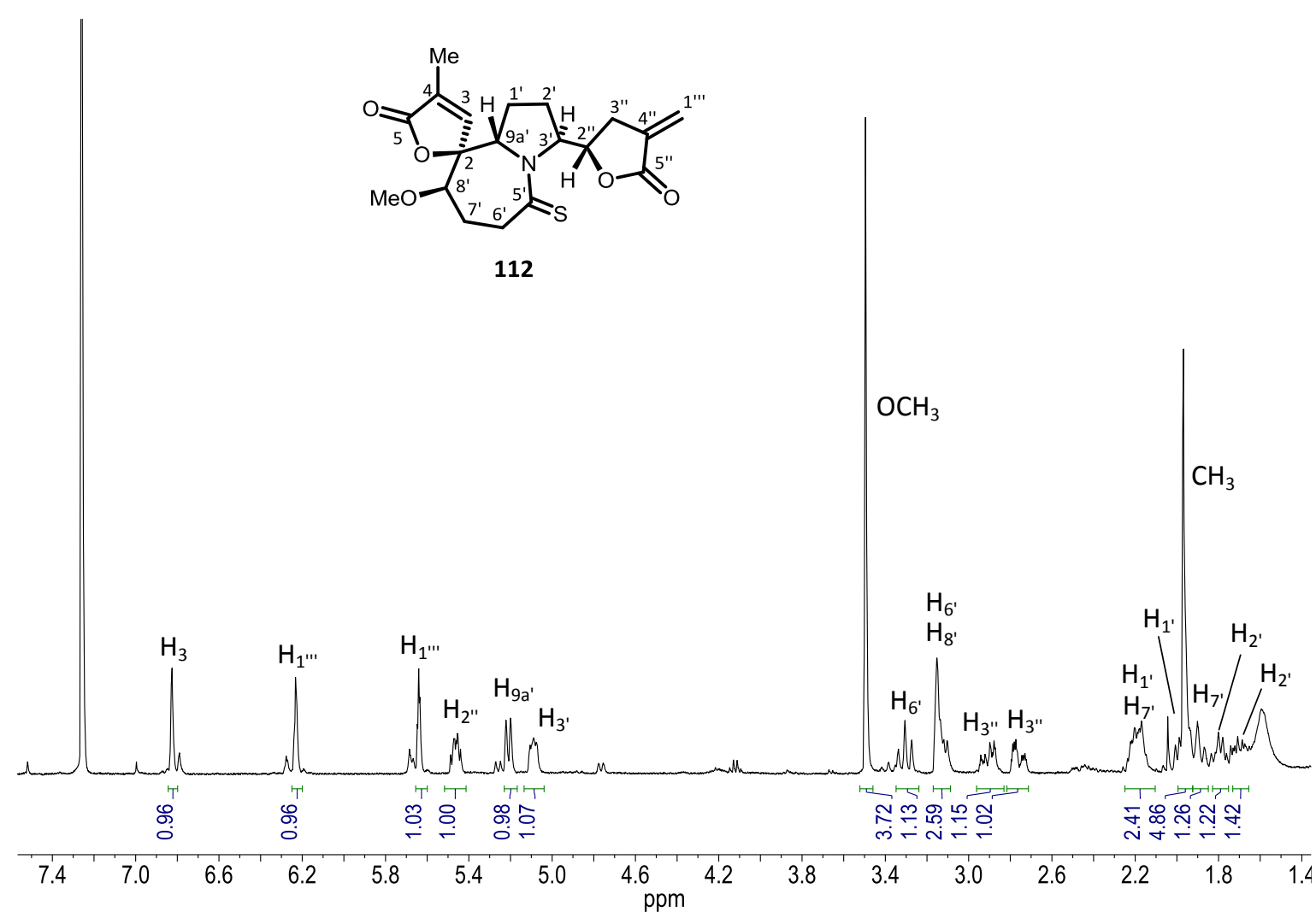

${ }^{1}$ H-NMR (400 MHz, $\mathrm{CDCl}_{3}$ )

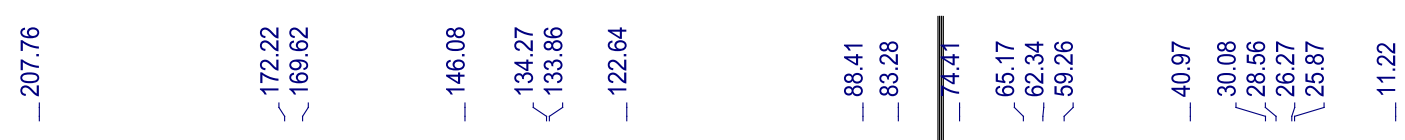
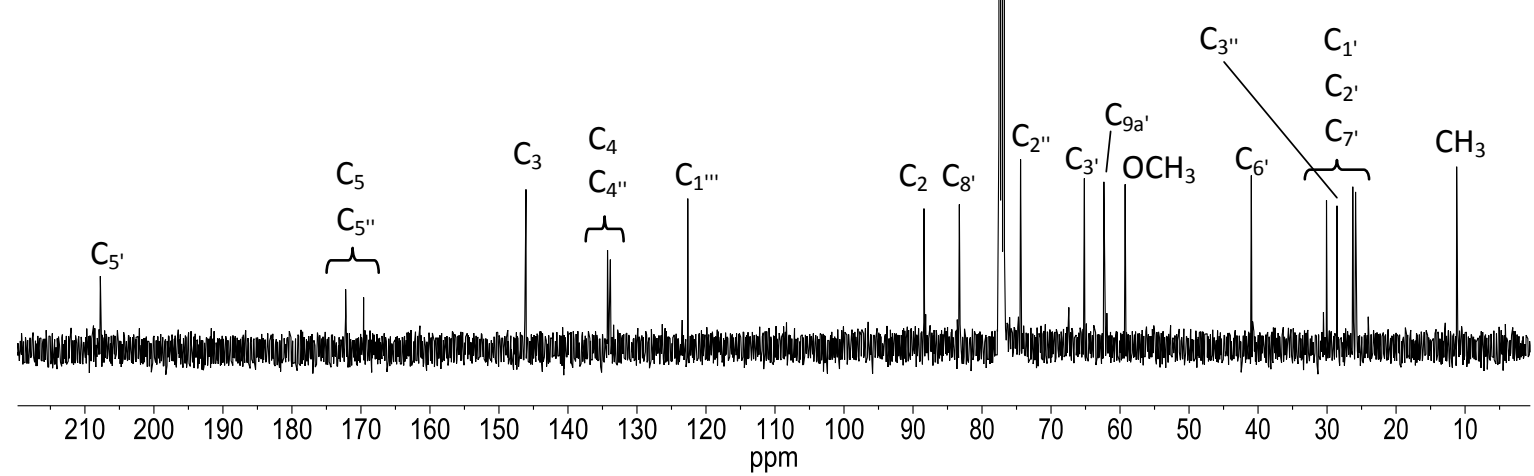

${ }^{13}$ C-NMR (100 MHz, $\mathrm{CDCl}_{3}$ ) 


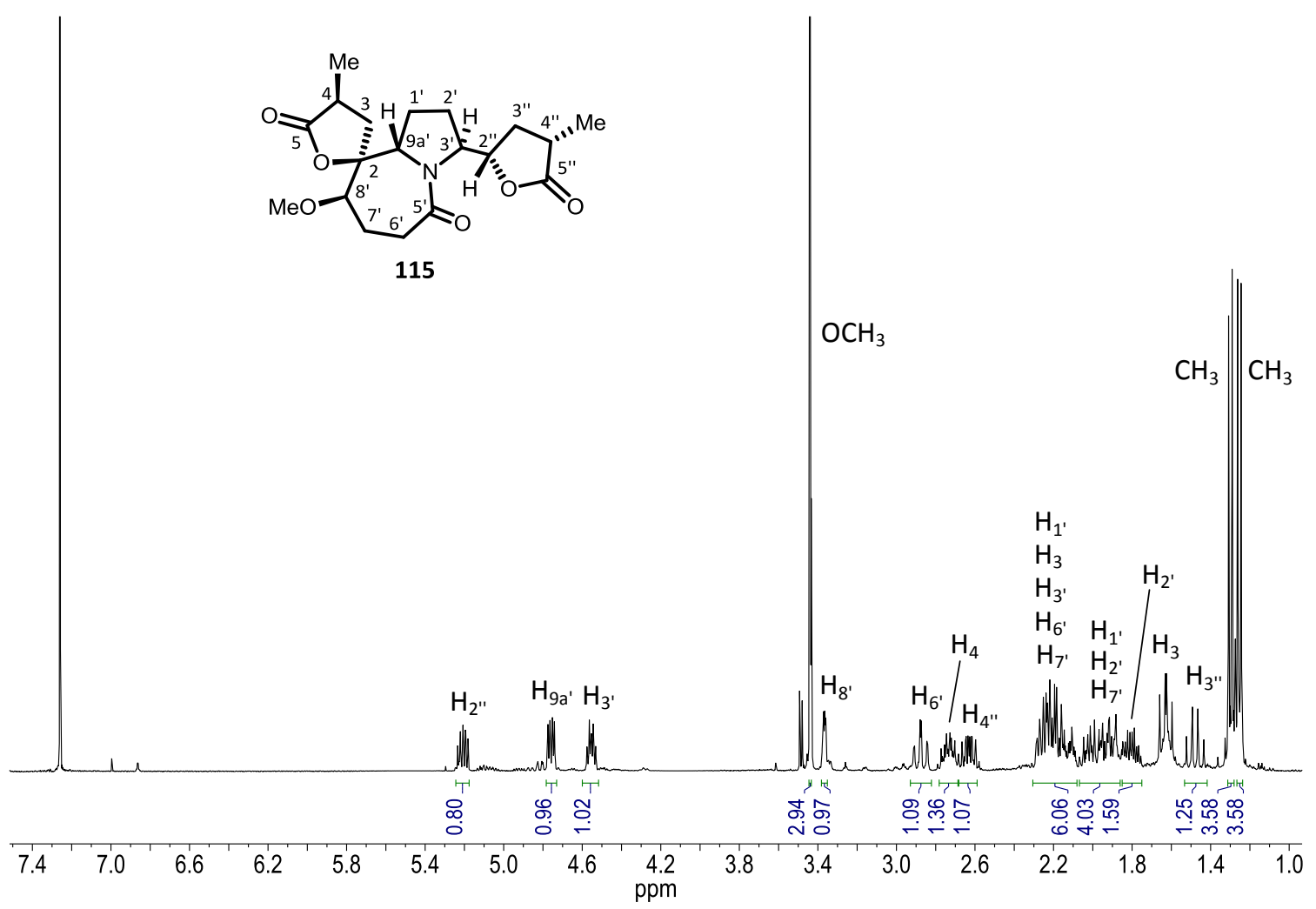

${ }^{1} \mathrm{H}-\mathrm{NMR}\left(400 \mathrm{MHz}, \mathrm{CDCl}_{3}\right.$ )

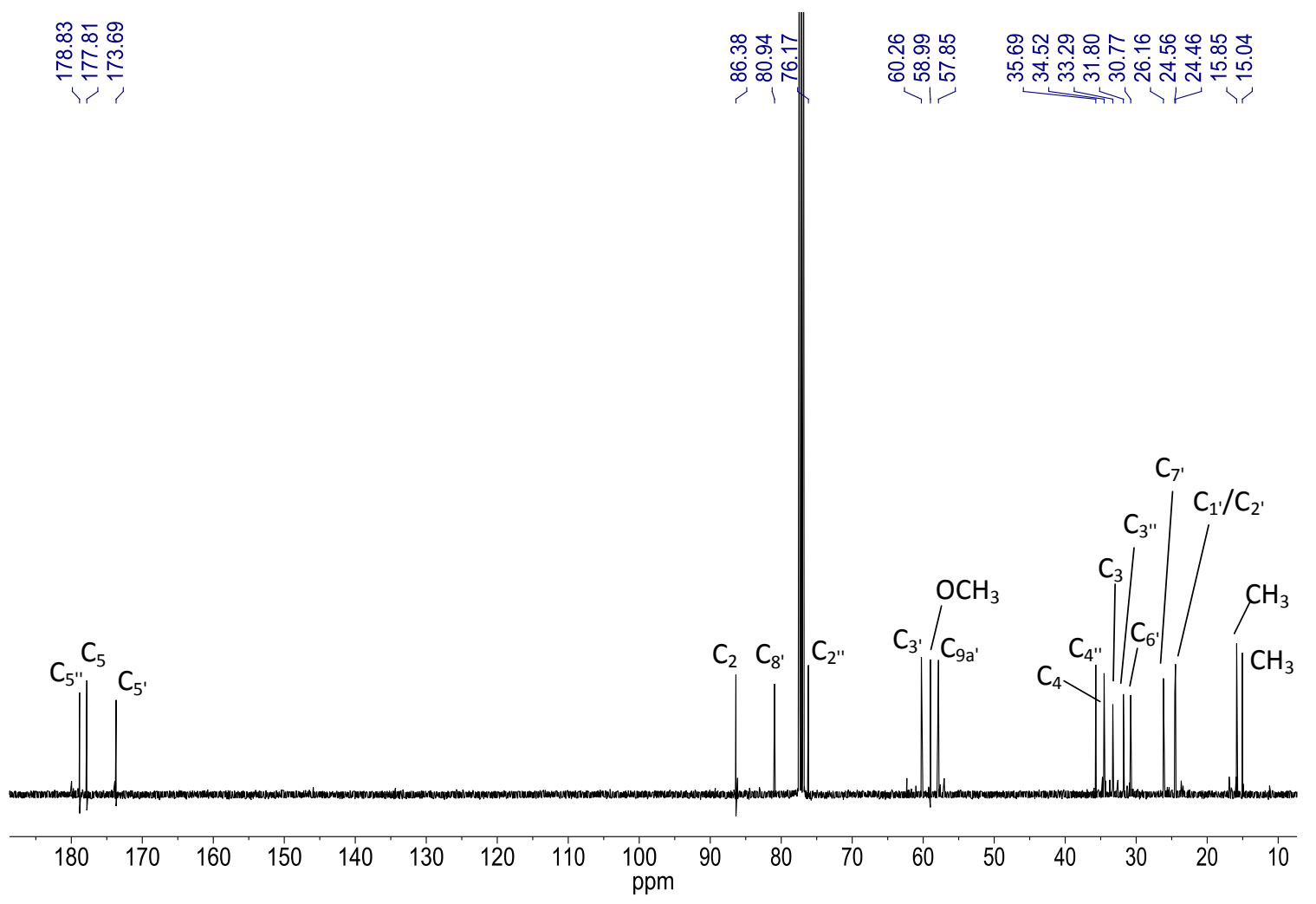

${ }^{13}$ C-NMR $\left(100 \mathrm{MHz}, \mathrm{CDCl}_{3}\right)$ 


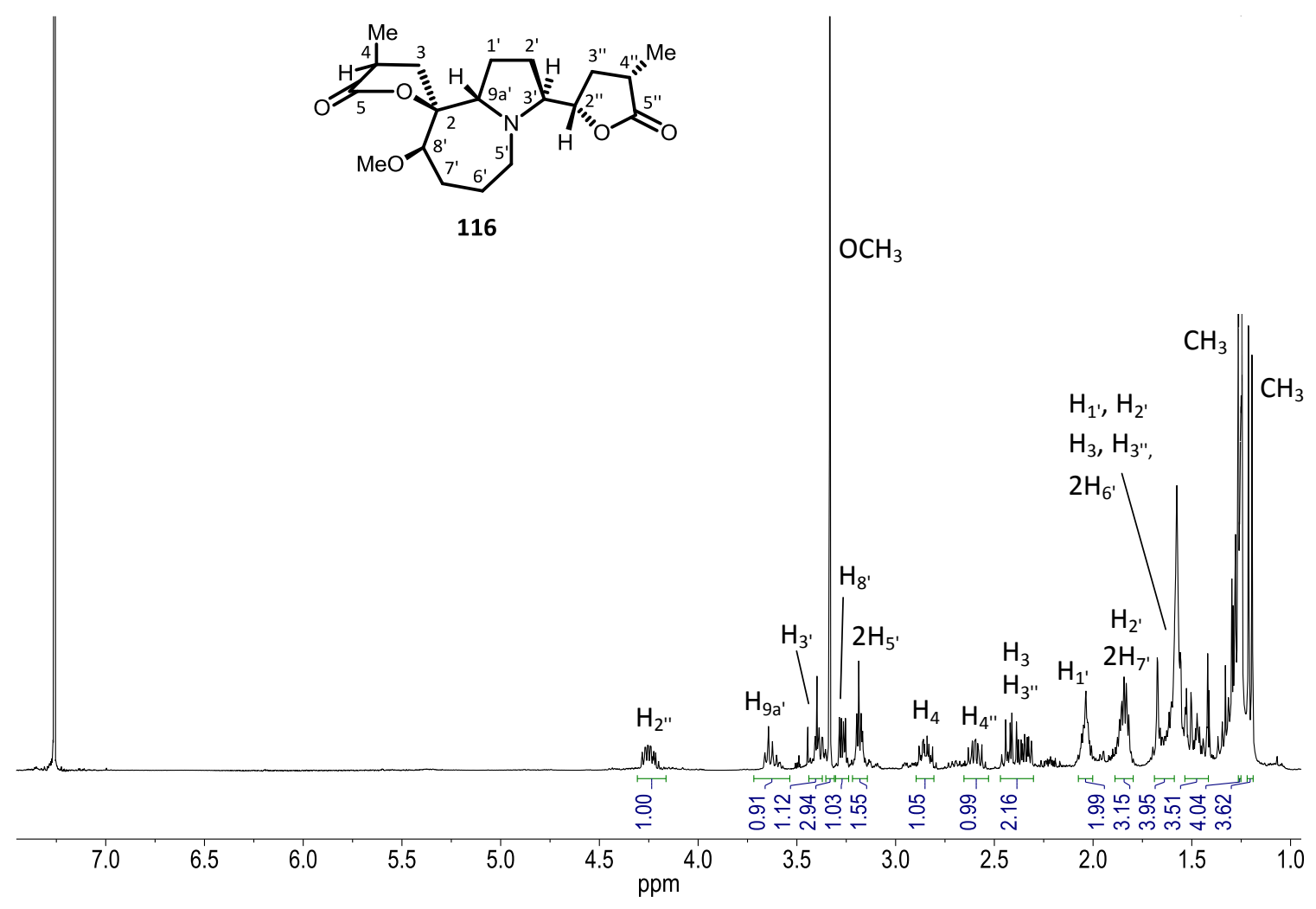

${ }^{1}$ H-NMR (400 MHz, $\mathrm{CDCl}_{3}$ )

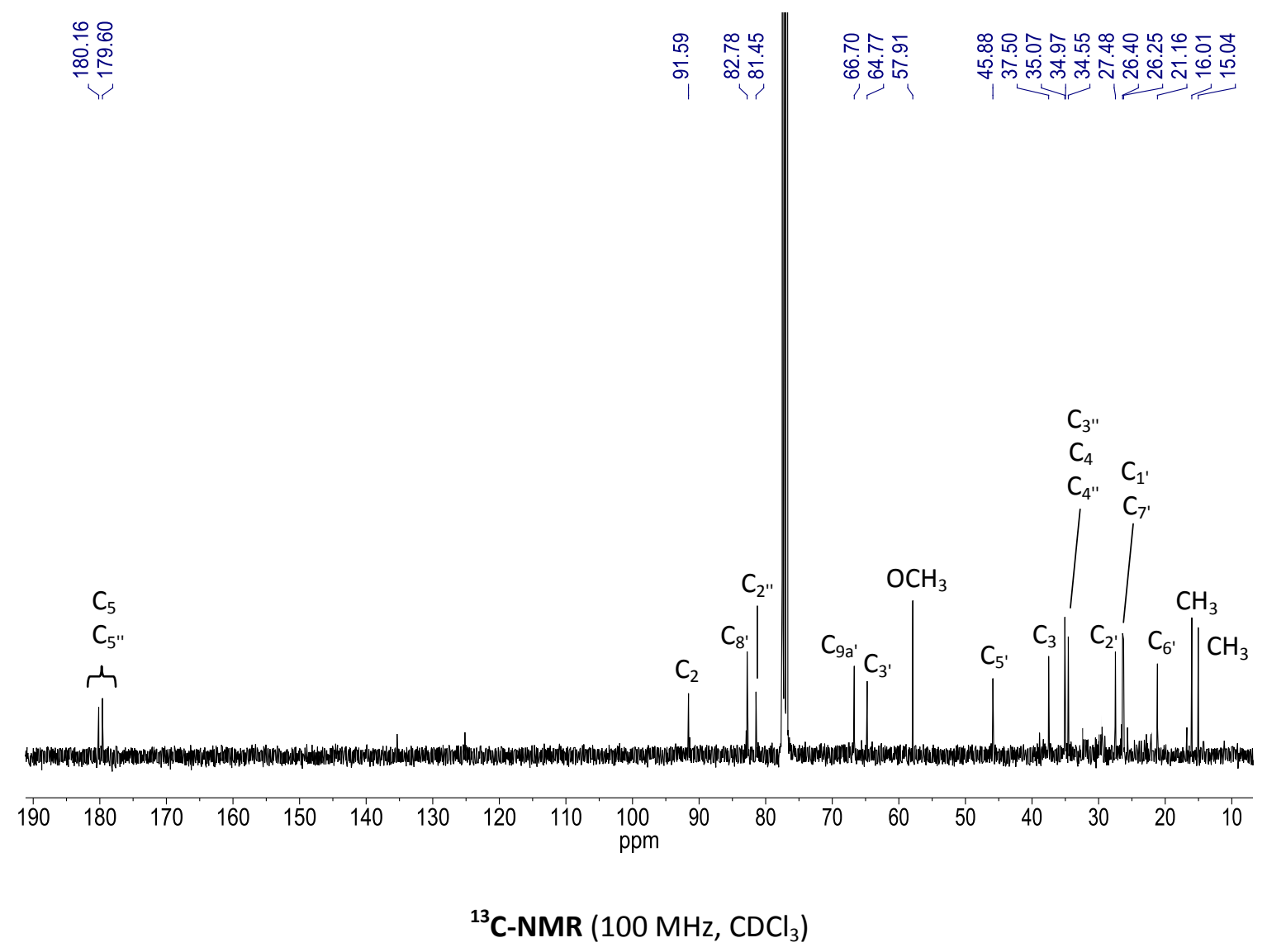




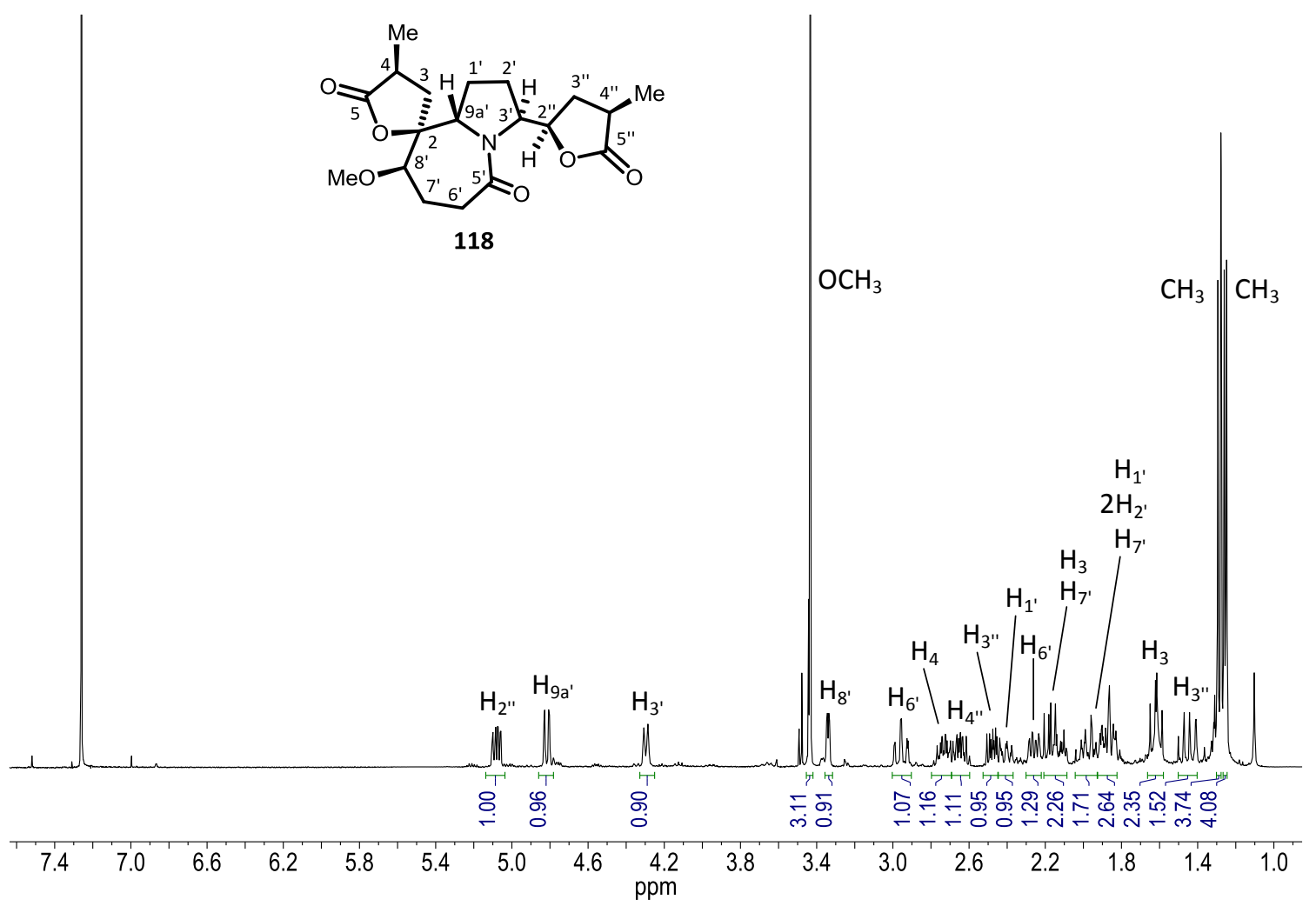

${ }^{1} \mathrm{H}-\mathrm{NMR}\left(400 \mathrm{MHz}, \mathrm{CDCl}_{3}\right.$ )

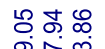

단.5

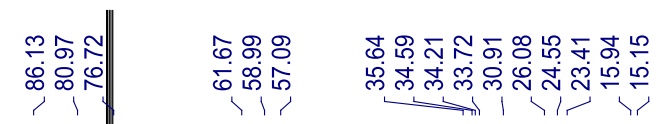

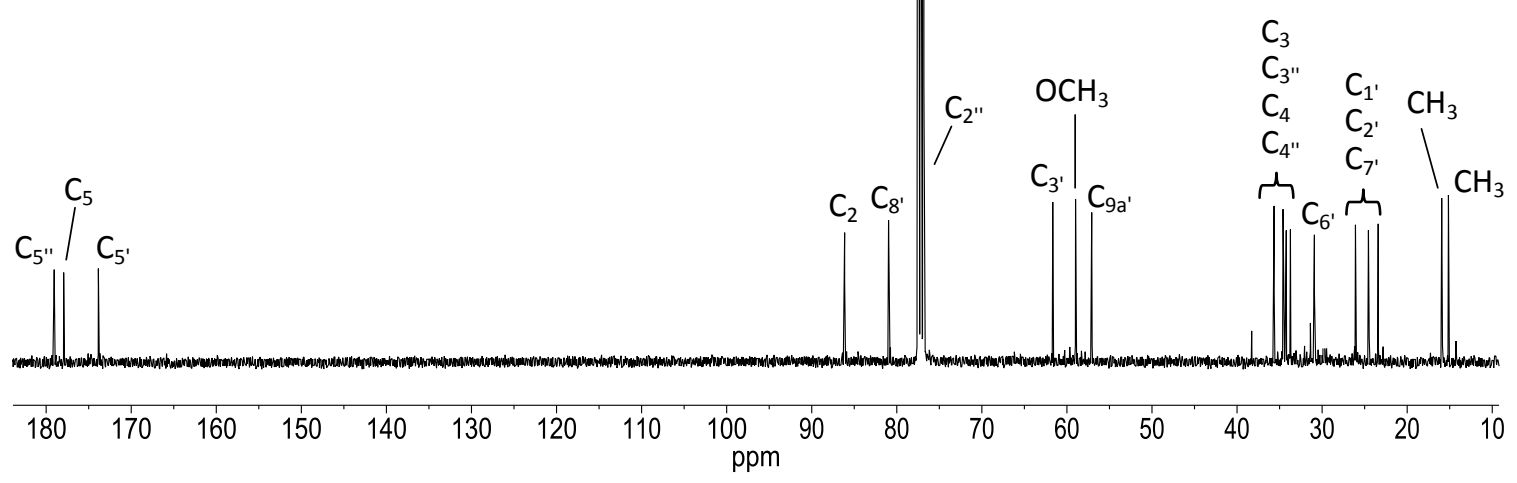

${ }^{13}$ C-NMR $\left(100 \mathrm{MHz}, \mathrm{CDCl}_{3}\right)$ 


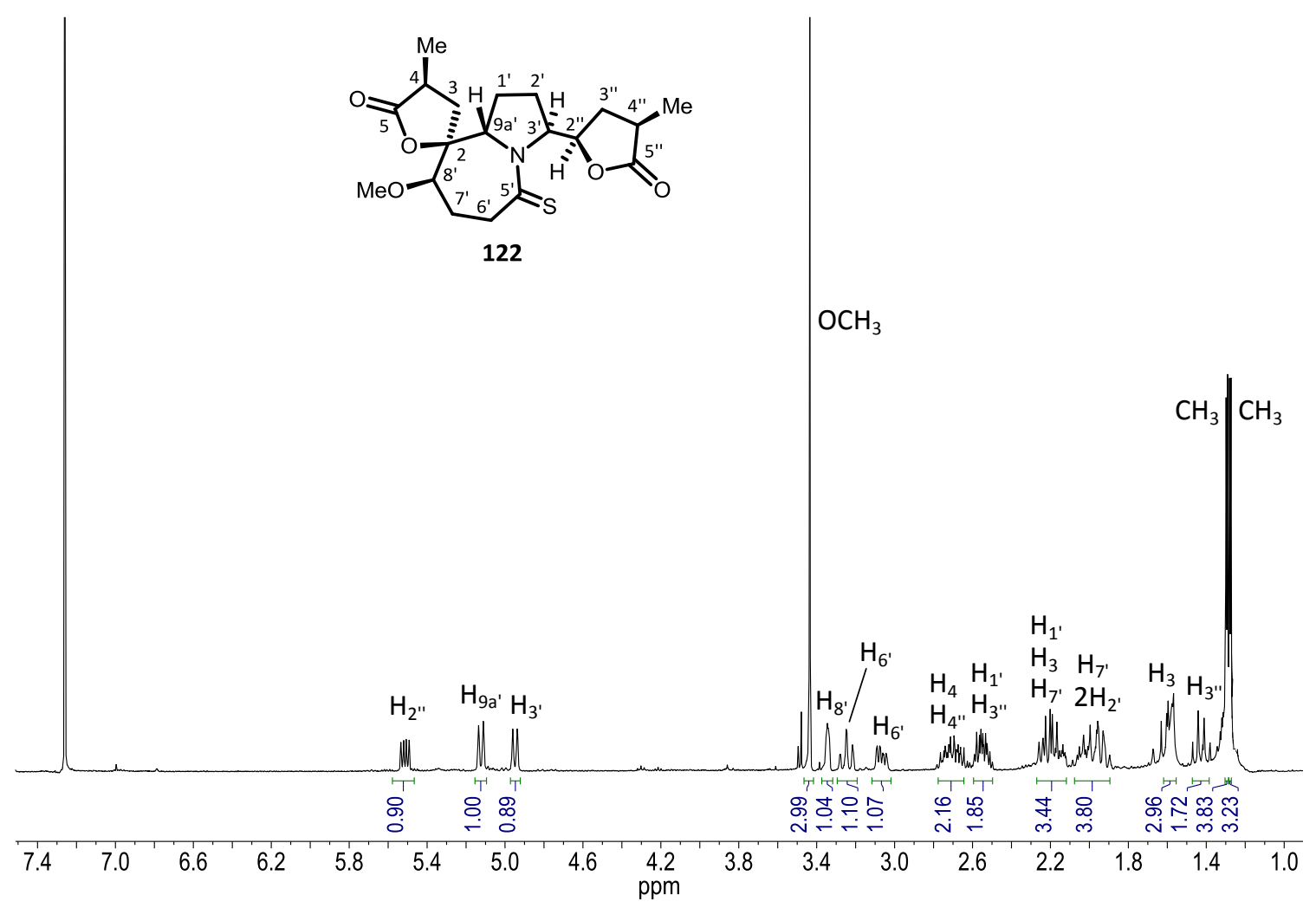

${ }^{1}$ H-NMR (400 MHz, $\mathrm{CDCl}_{3}$ )

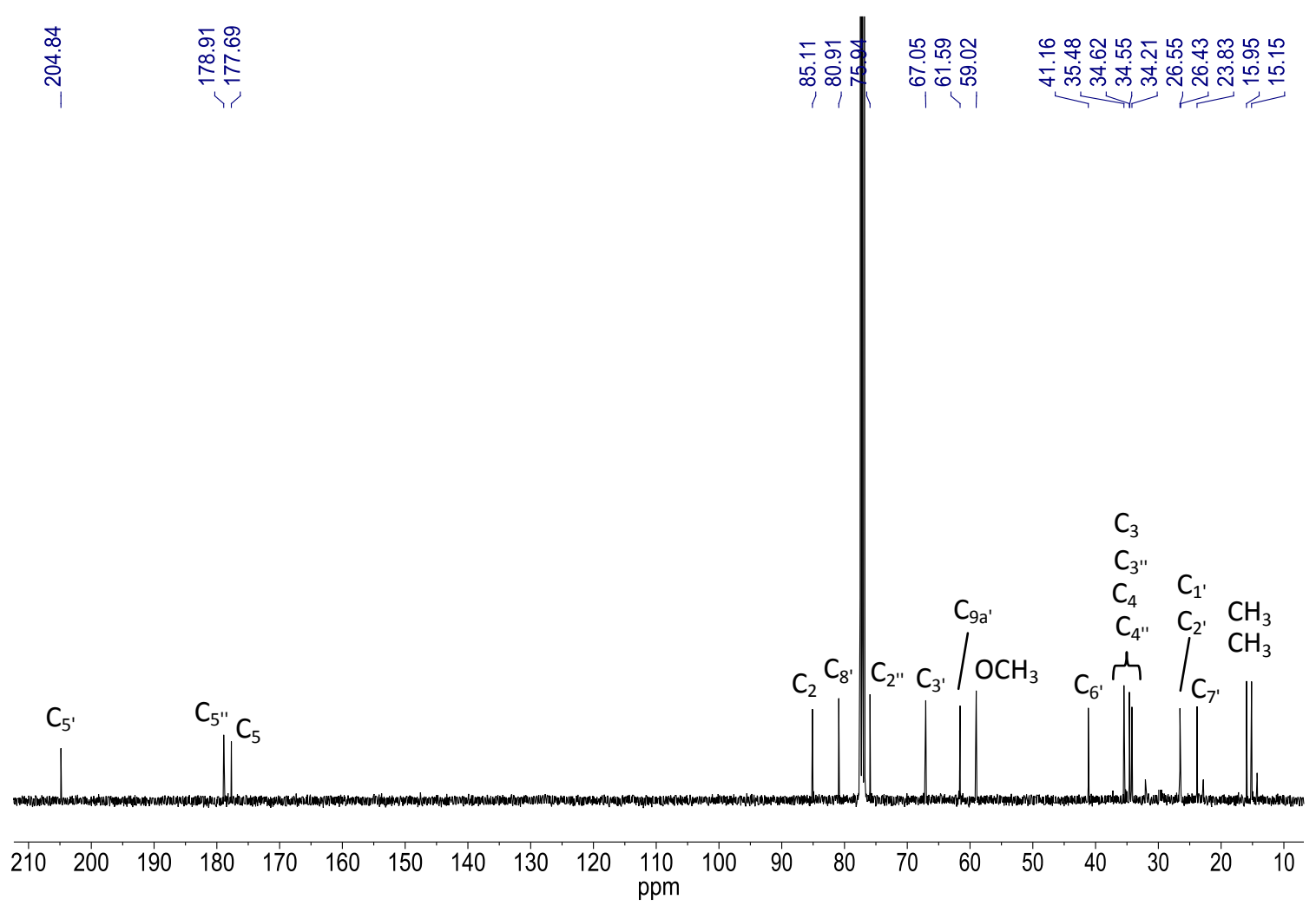

${ }^{13}$ C-NMR $\left(100 \mathrm{MHz}, \mathrm{CDCl}_{3}\right)$ 


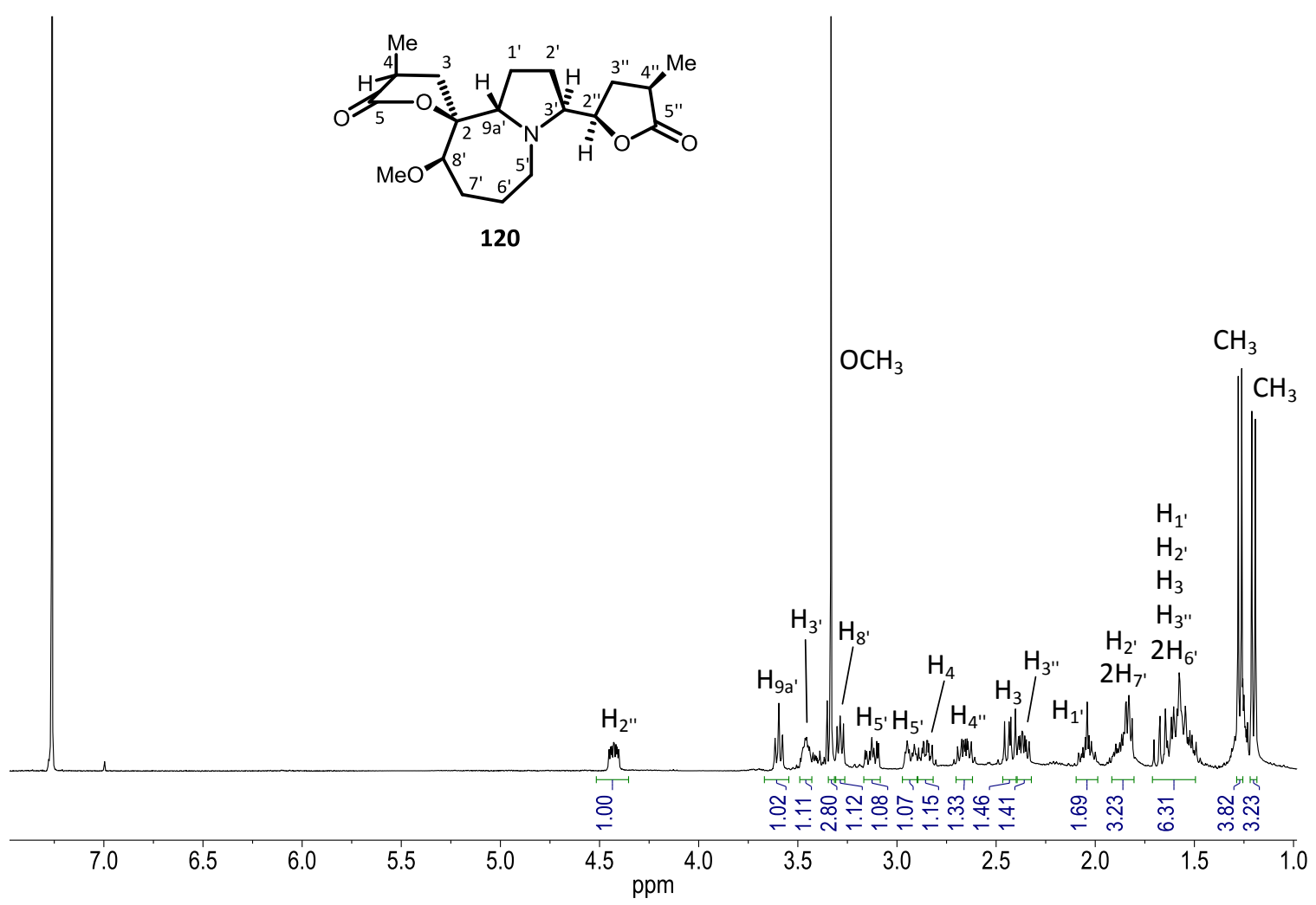

${ }^{1} \mathbf{H}-\mathbf{N M R}\left(400 \mathrm{MHz}, \mathrm{CDCl}_{3}\right.$ )

乐

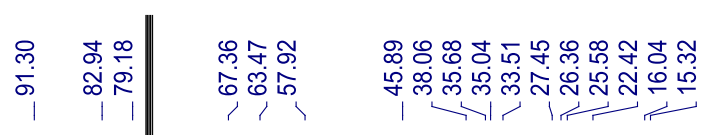

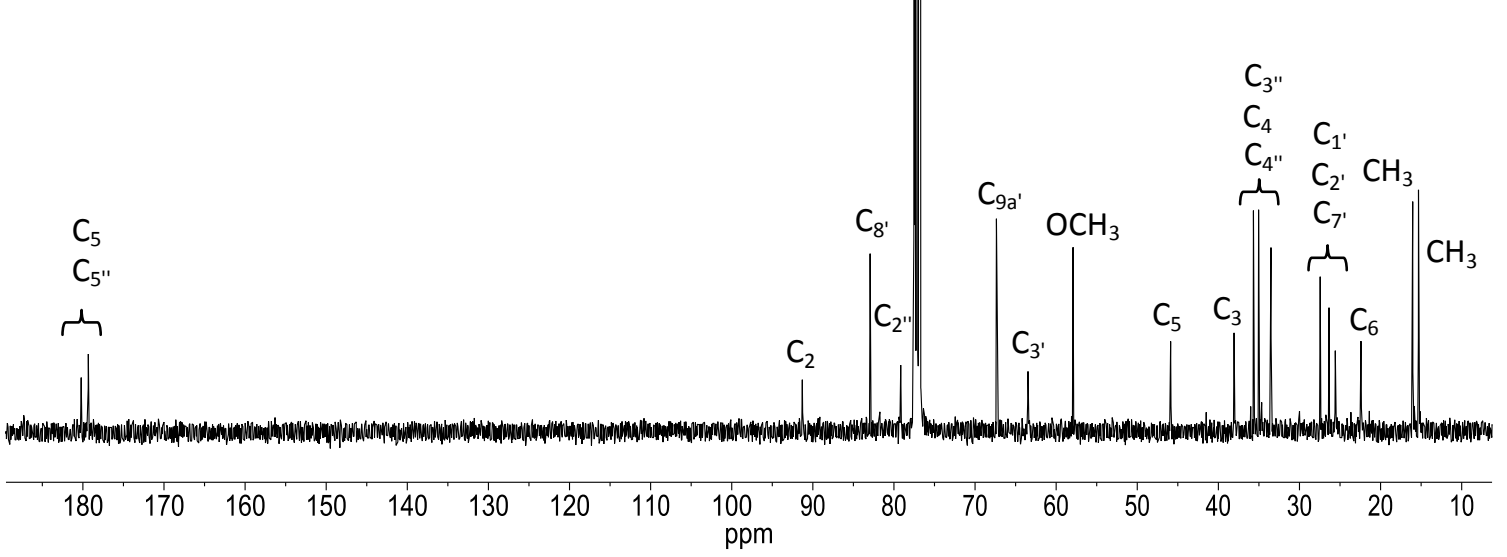

${ }^{13}$ C-NMR (100 MHz, $\left.\mathrm{CDCl}_{3}\right)$ 


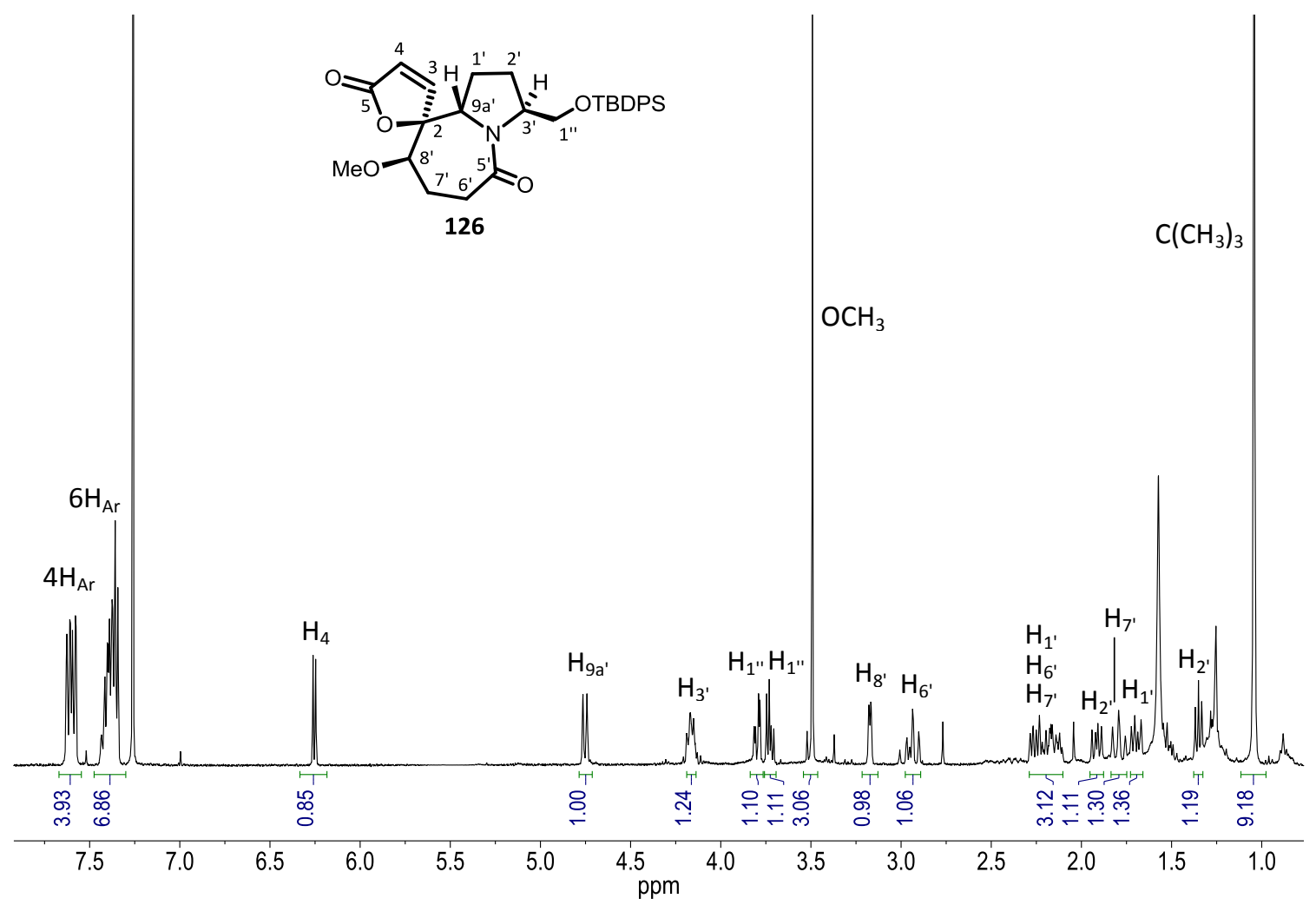

${ }^{1}$ H-NMR (400 MHz, $\mathrm{CDCl}_{3}$ )

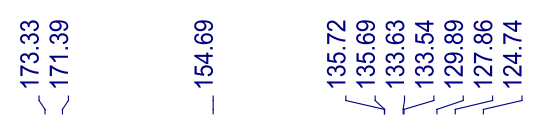

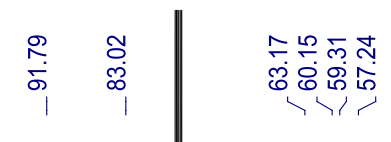

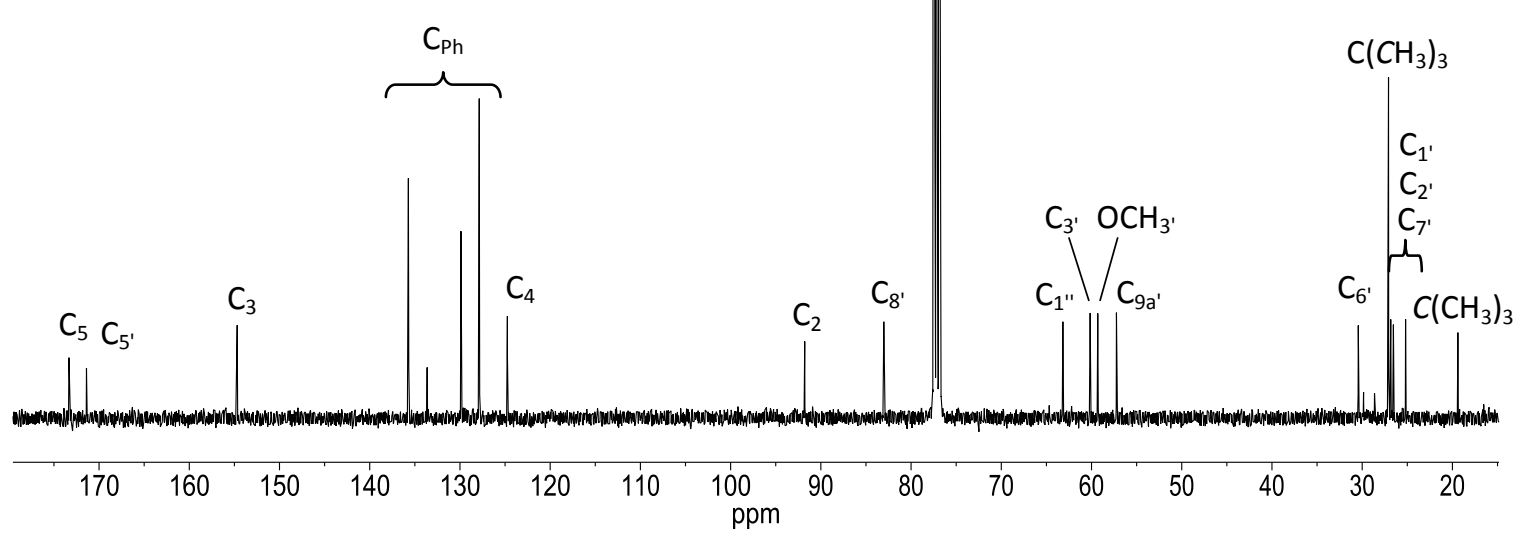

${ }^{13}$ C-NMR (100 MHz, $\left.\mathrm{CDCl}_{3}\right)$ 


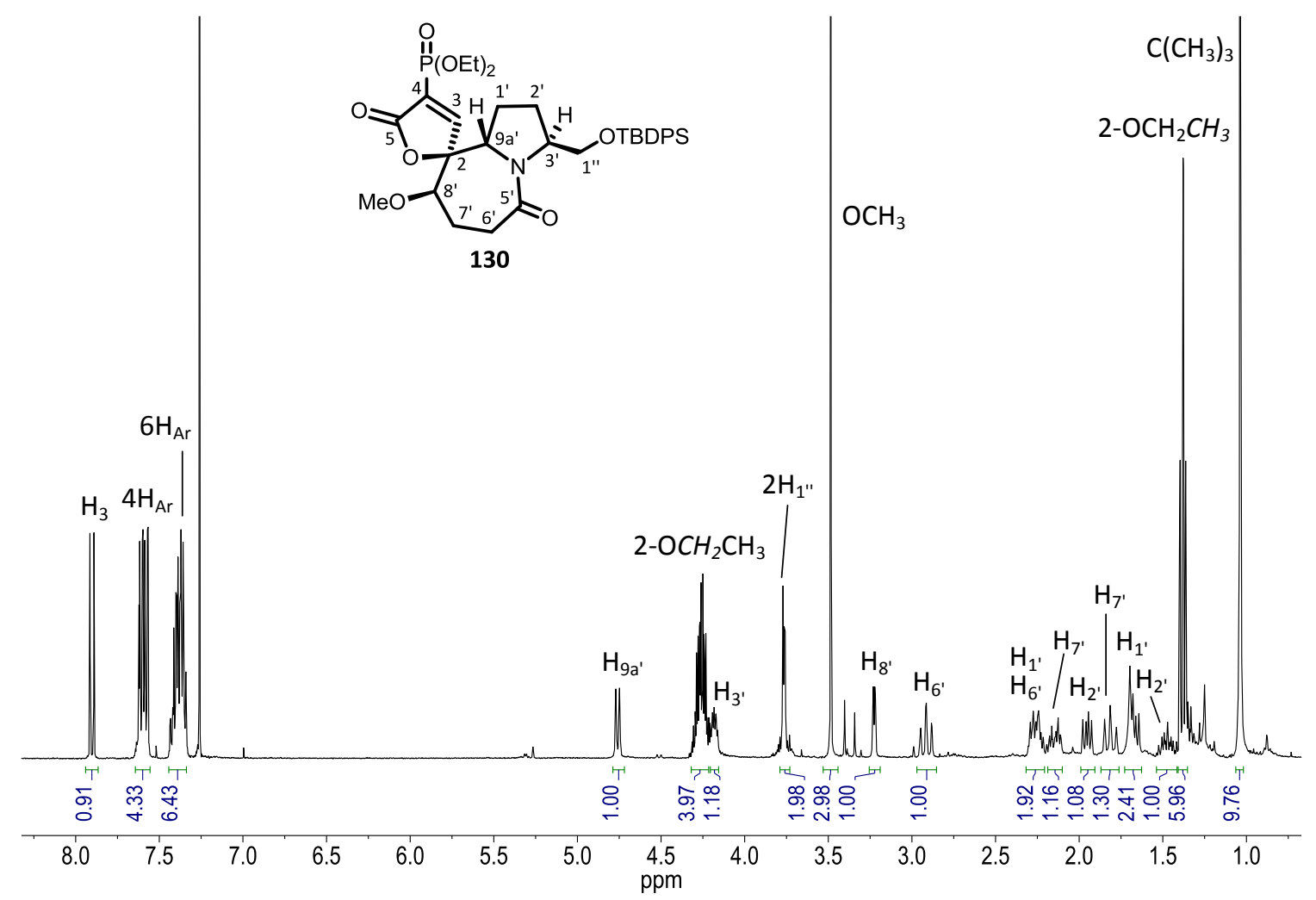

${ }^{1}$ H-NMR (400 MHz, $\mathrm{CDCl}_{3}$ )

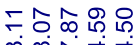

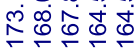

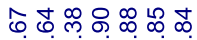

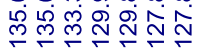

马诲

ऽ

ivi

îj

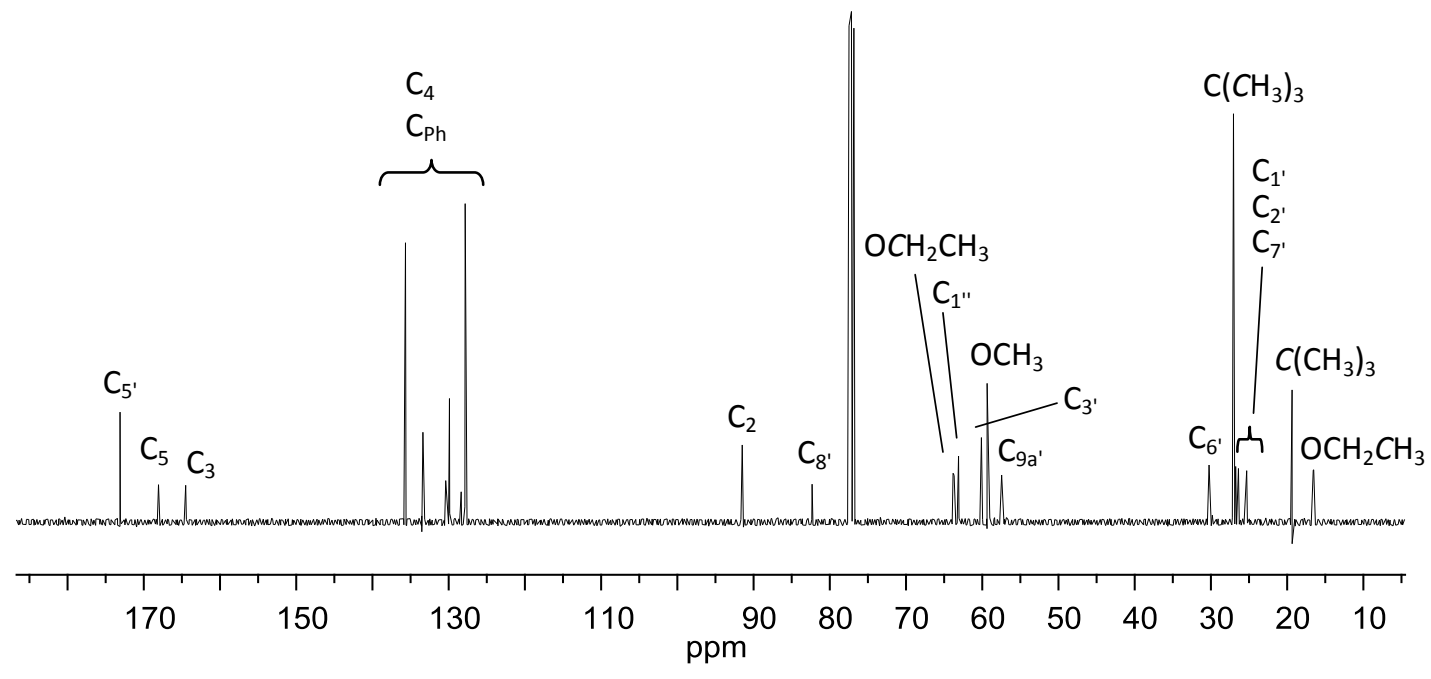

${ }^{13}$ C-NMR (100 MHz, $\left.\mathrm{CDCl}_{3}\right)$ 


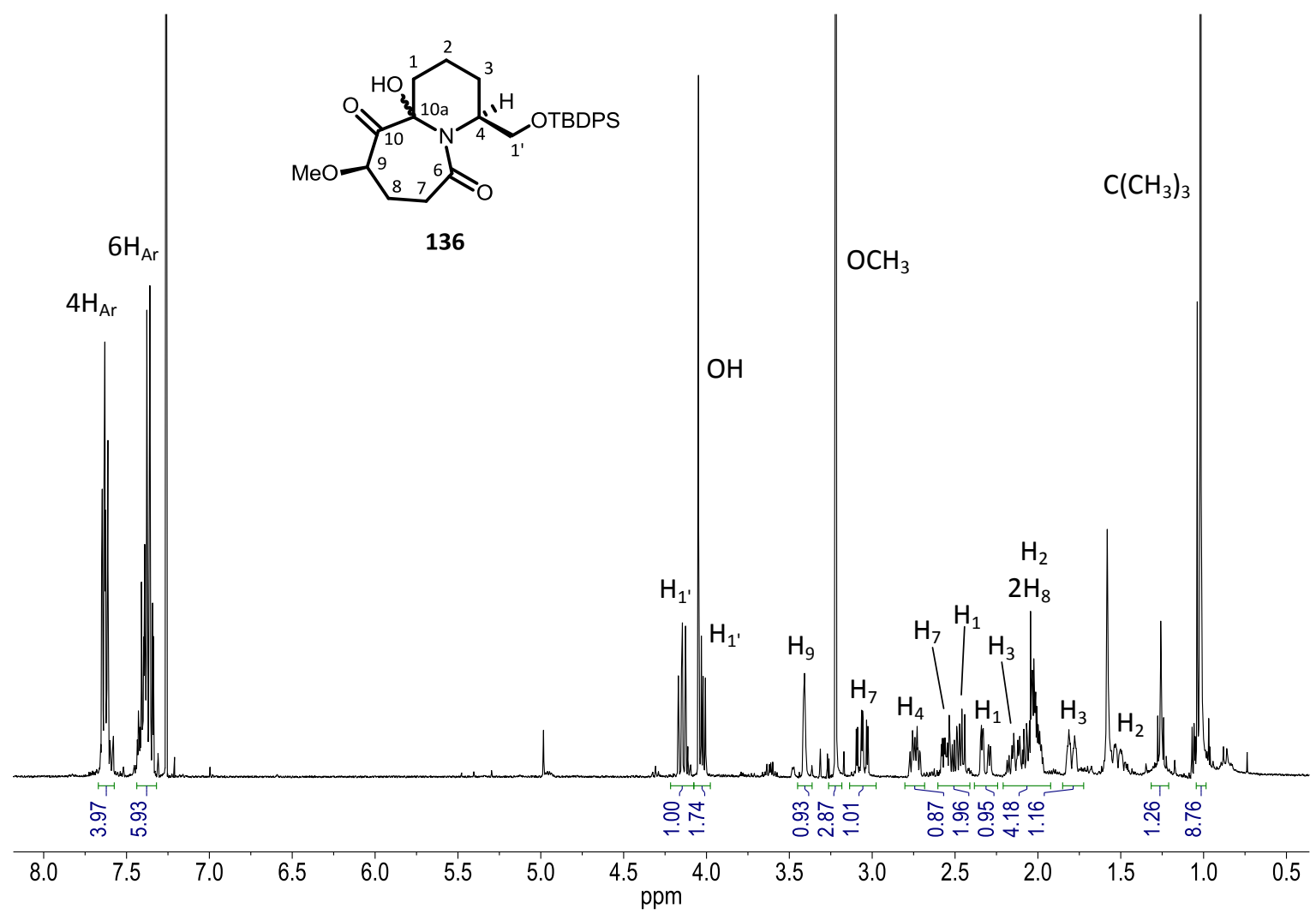

${ }^{1}$ H-NMR (400 MHz, $\mathrm{CDCl}_{3}$ )

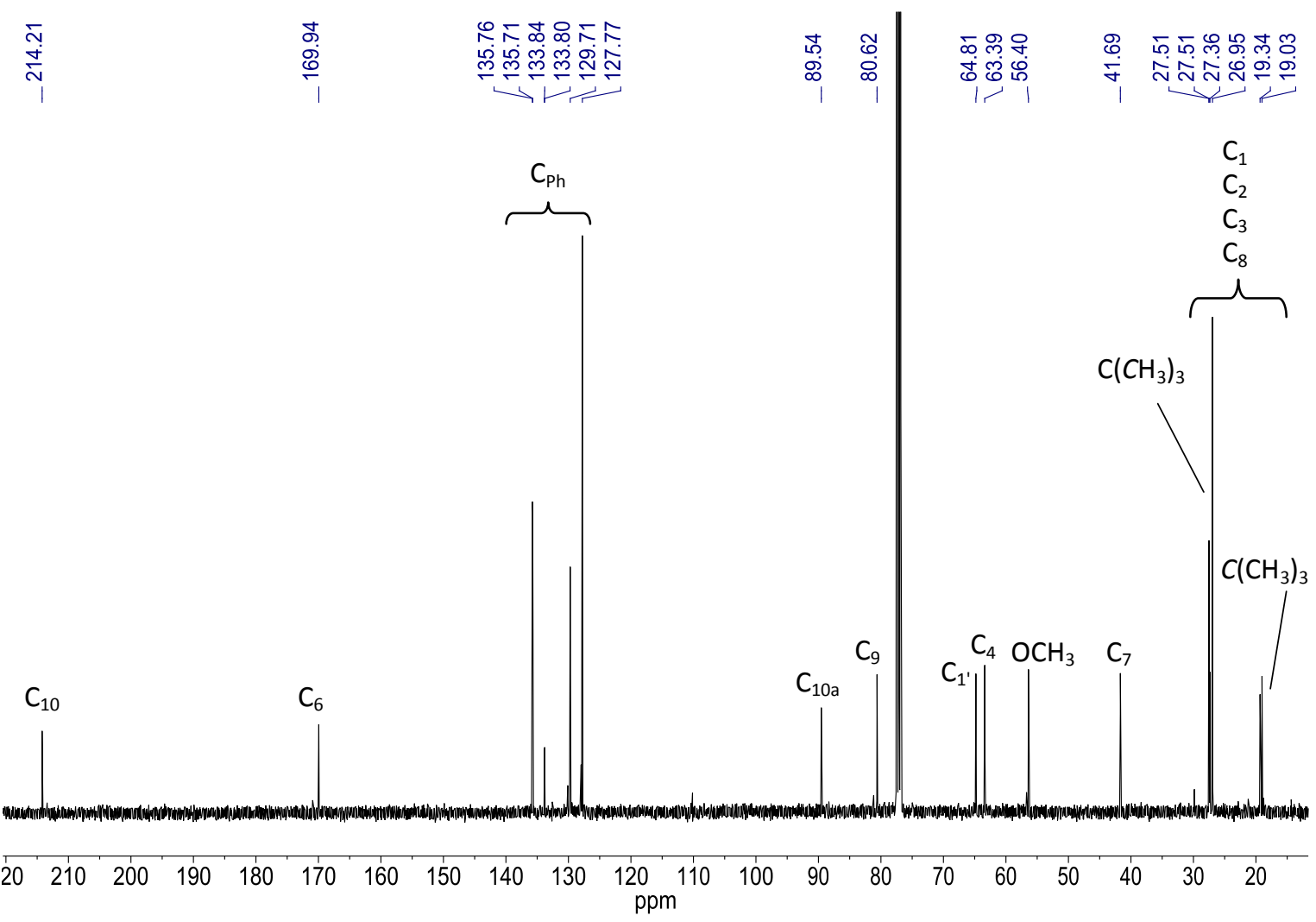

${ }^{13}$ C-NMR (100 MHz, $\left.\mathrm{CDCl}_{3}\right)$ 


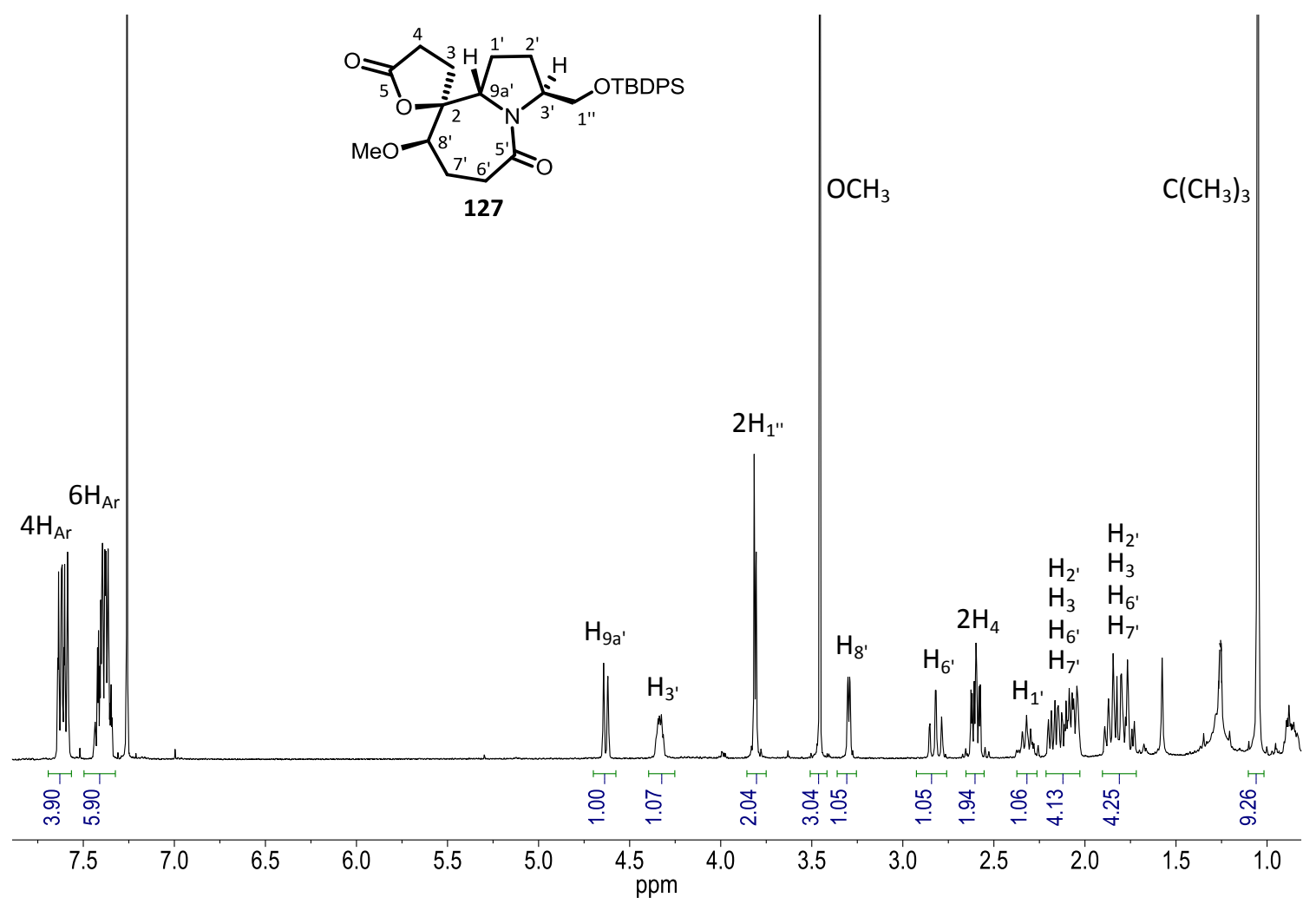

${ }^{1}$ H-NMR (400 MHz, $\mathrm{CDCl}_{3}$ )

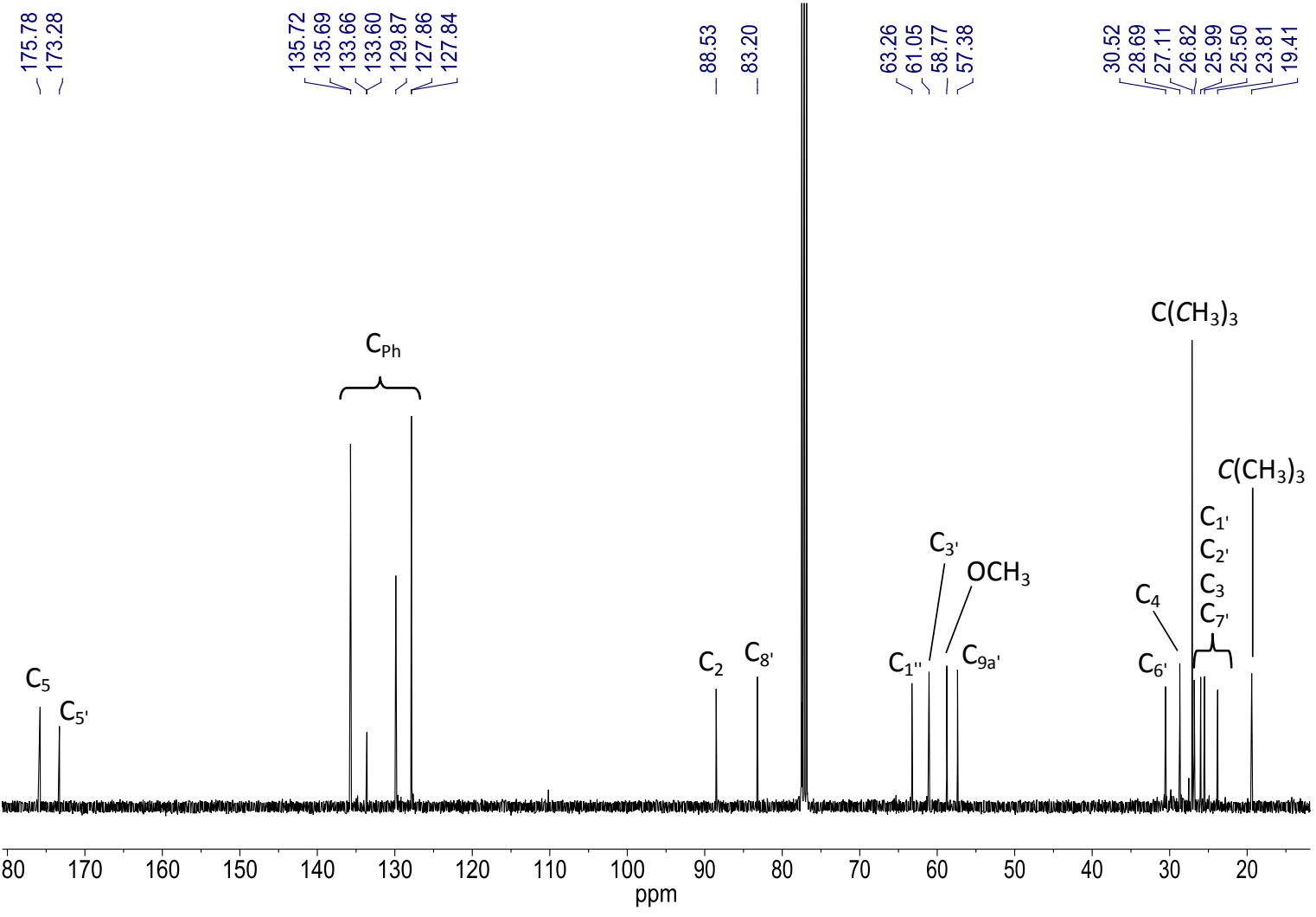

${ }^{13}$ C-NMR $\left(100 \mathrm{MHz}, \mathrm{CDCl}_{3}\right)$ 


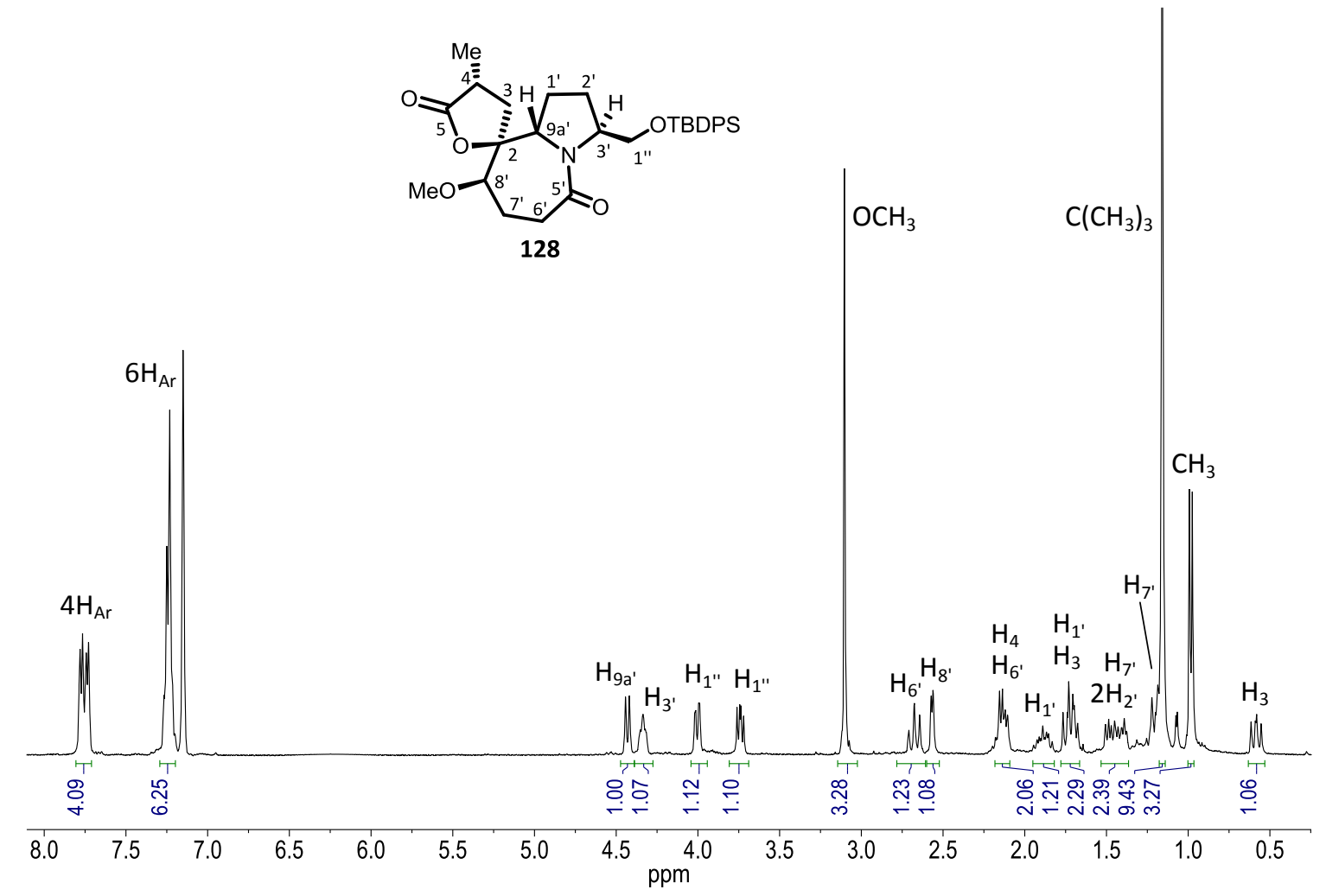

${ }^{1}$ H-NMR (400 MHz, $\left.C_{6} D_{6}\right)$

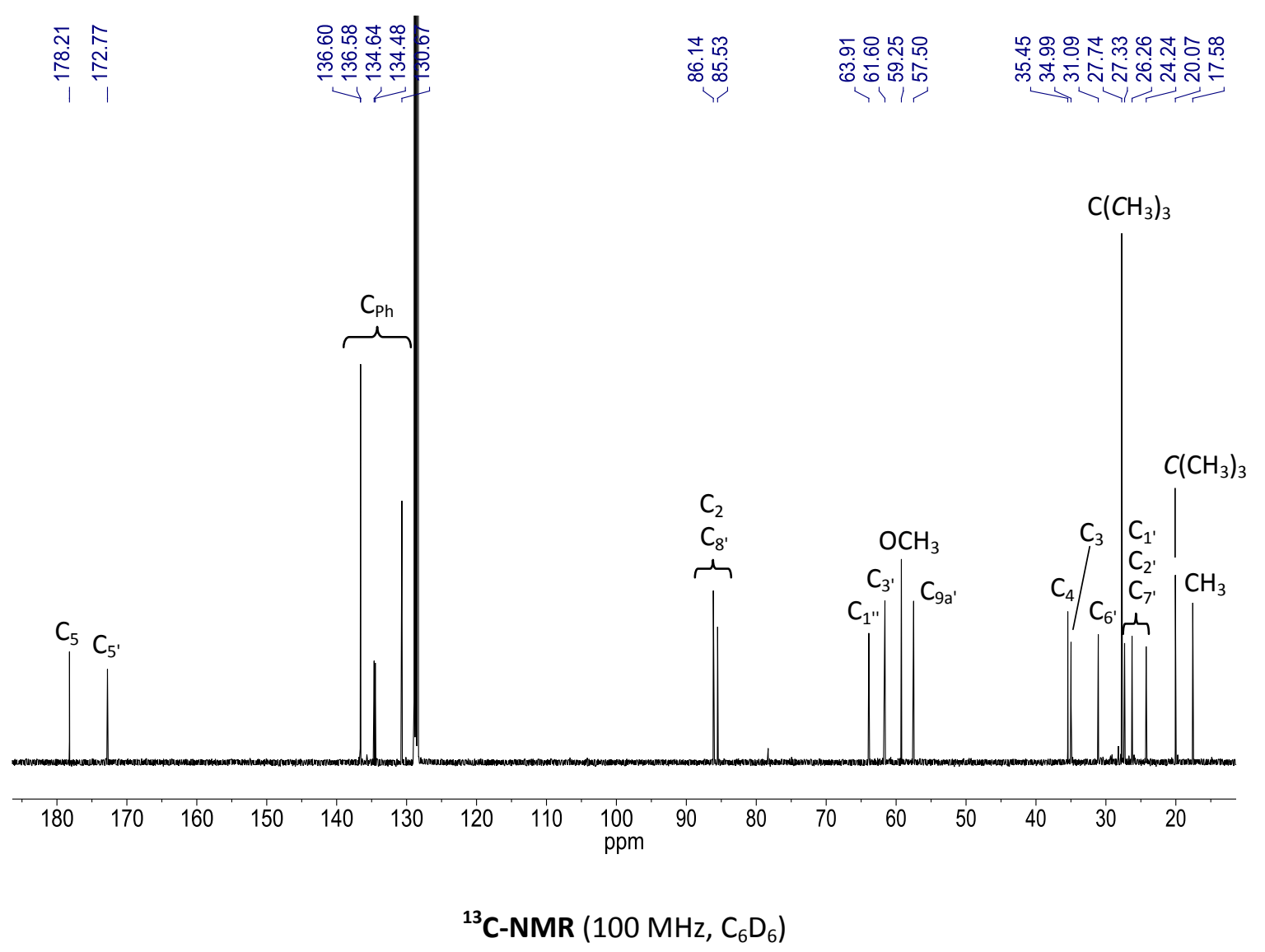




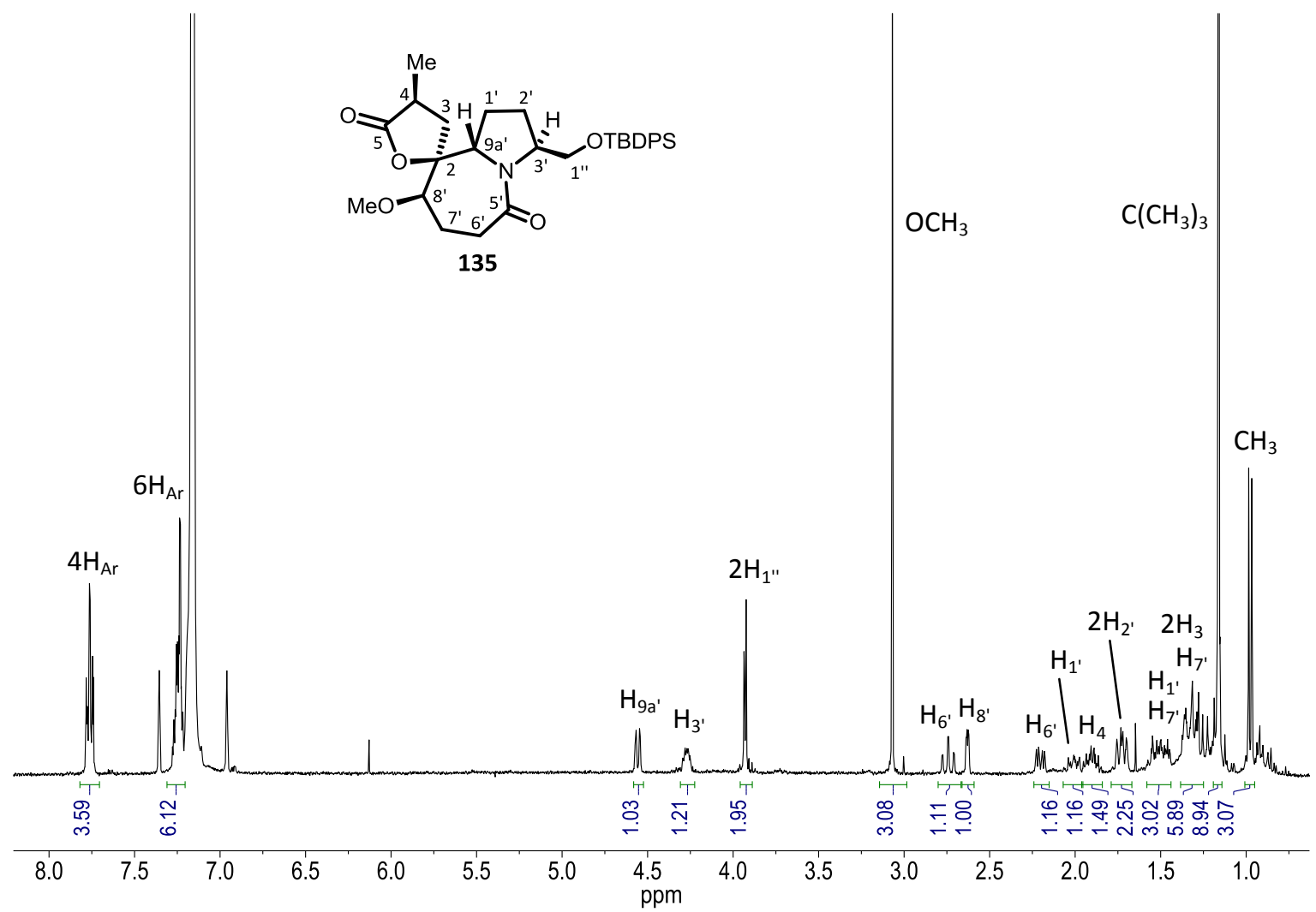

${ }^{1}$ H-NMR (400 MHz, $\left.\mathrm{C}_{6} \mathrm{D}_{6}\right)$

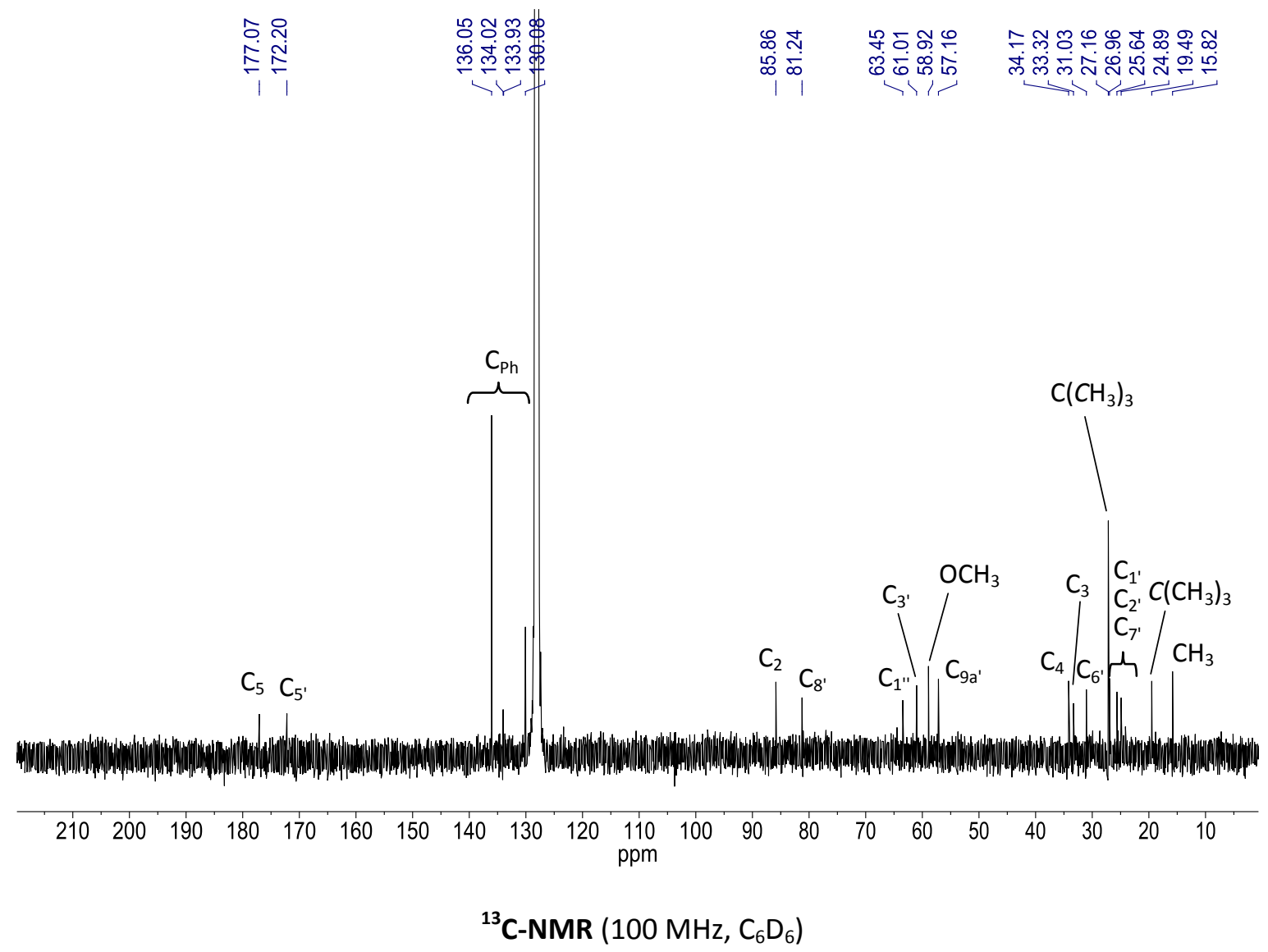




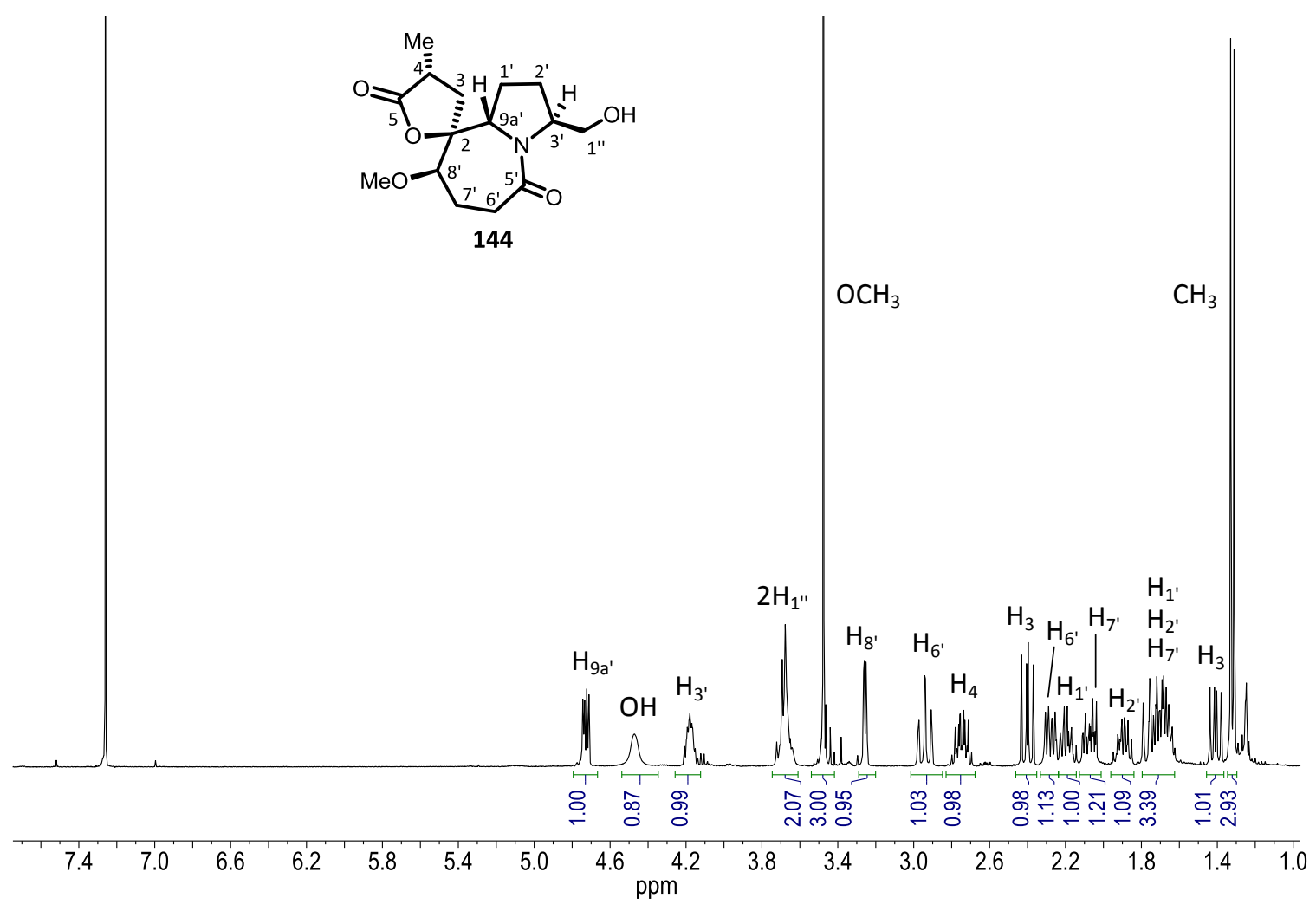

${ }^{1}$ H-NMR (400 MHz, $\mathrm{CDCl}_{3}$ )

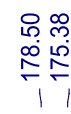

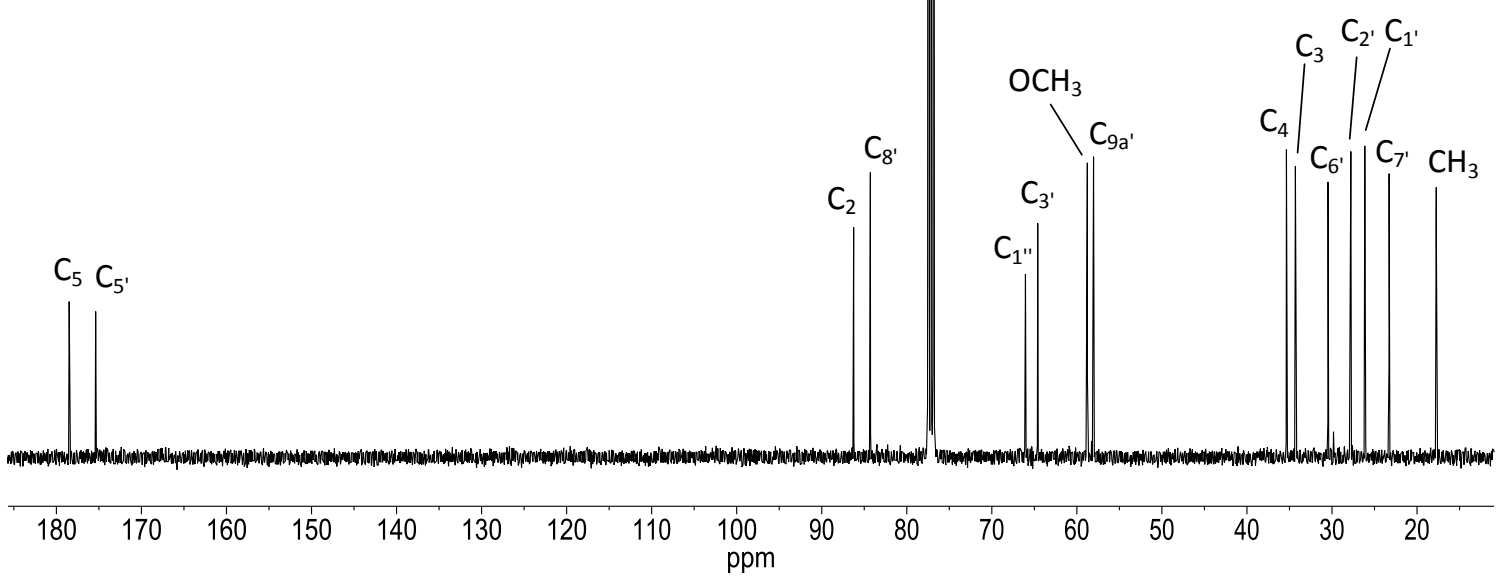

${ }^{13}$ C-NMR (100 MHz, $\left.\mathrm{CDCl}_{3}\right)$ 


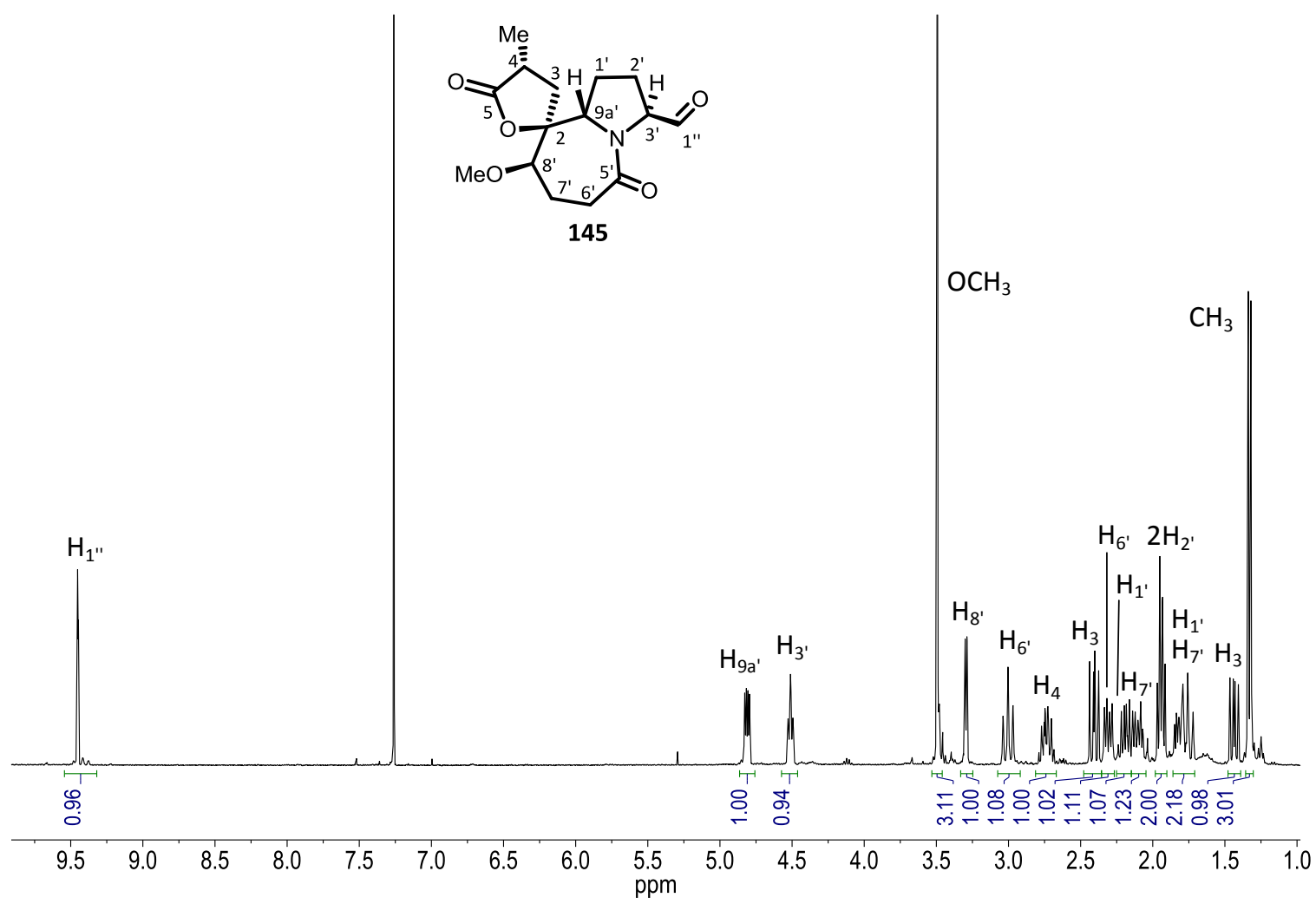

${ }^{1} \mathrm{H}-\mathrm{NMR}\left(400 \mathrm{MHz}, \mathrm{CDCl}_{3}\right)$

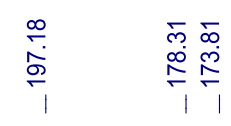

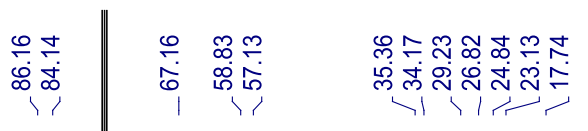

$\mathrm{C}^{\prime \prime \prime}$

$\mathrm{C}_{5} \mathrm{C}_{5^{\prime}}$

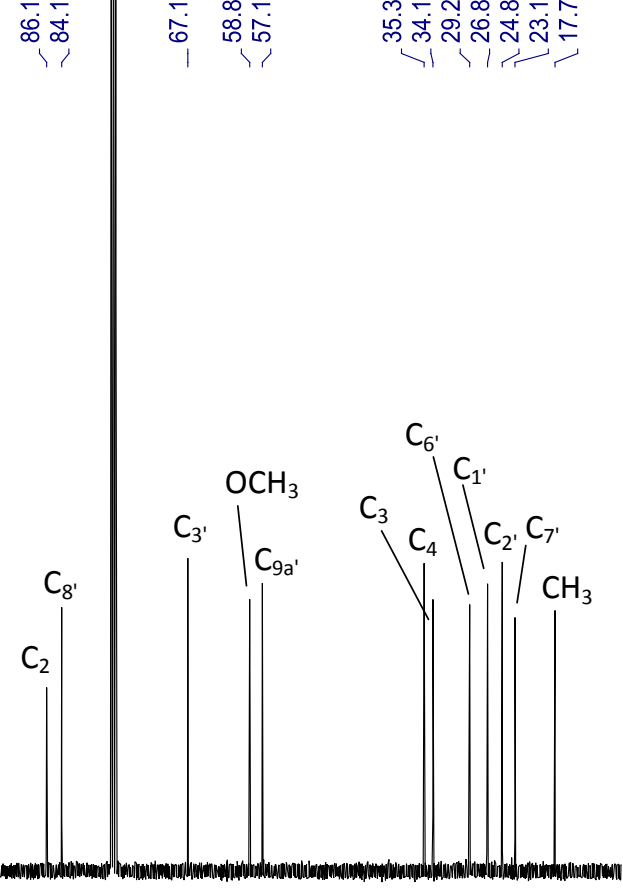

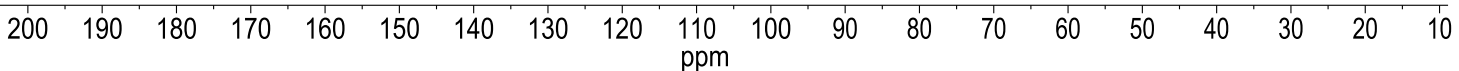

${ }^{13}$ C-NMR $\left(100 \mathrm{MHz}, \mathrm{CDCl}_{3}\right)$ 


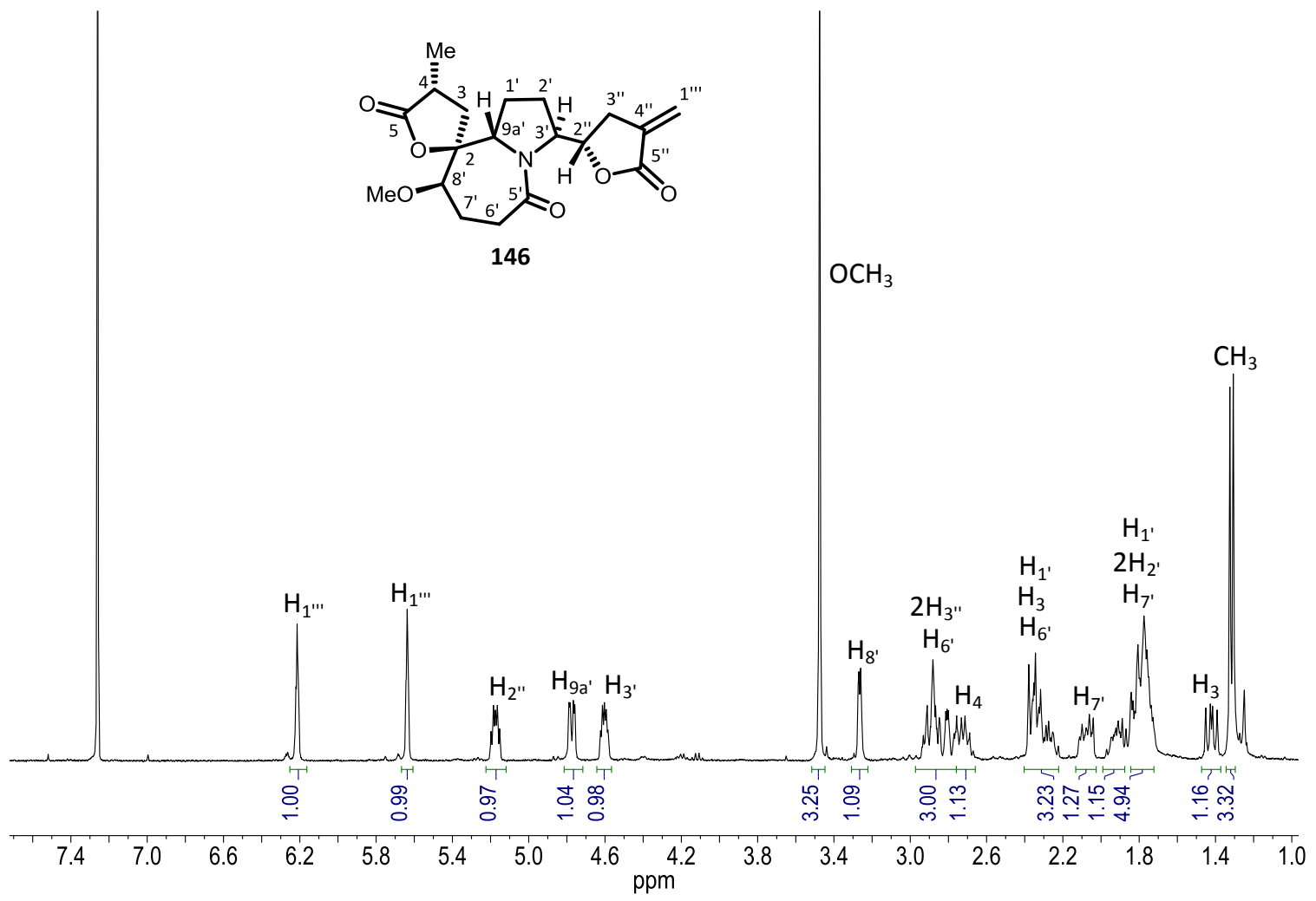

${ }^{1}$ H-NMR (400 MHz, $\mathrm{CDCl}_{3}$ )

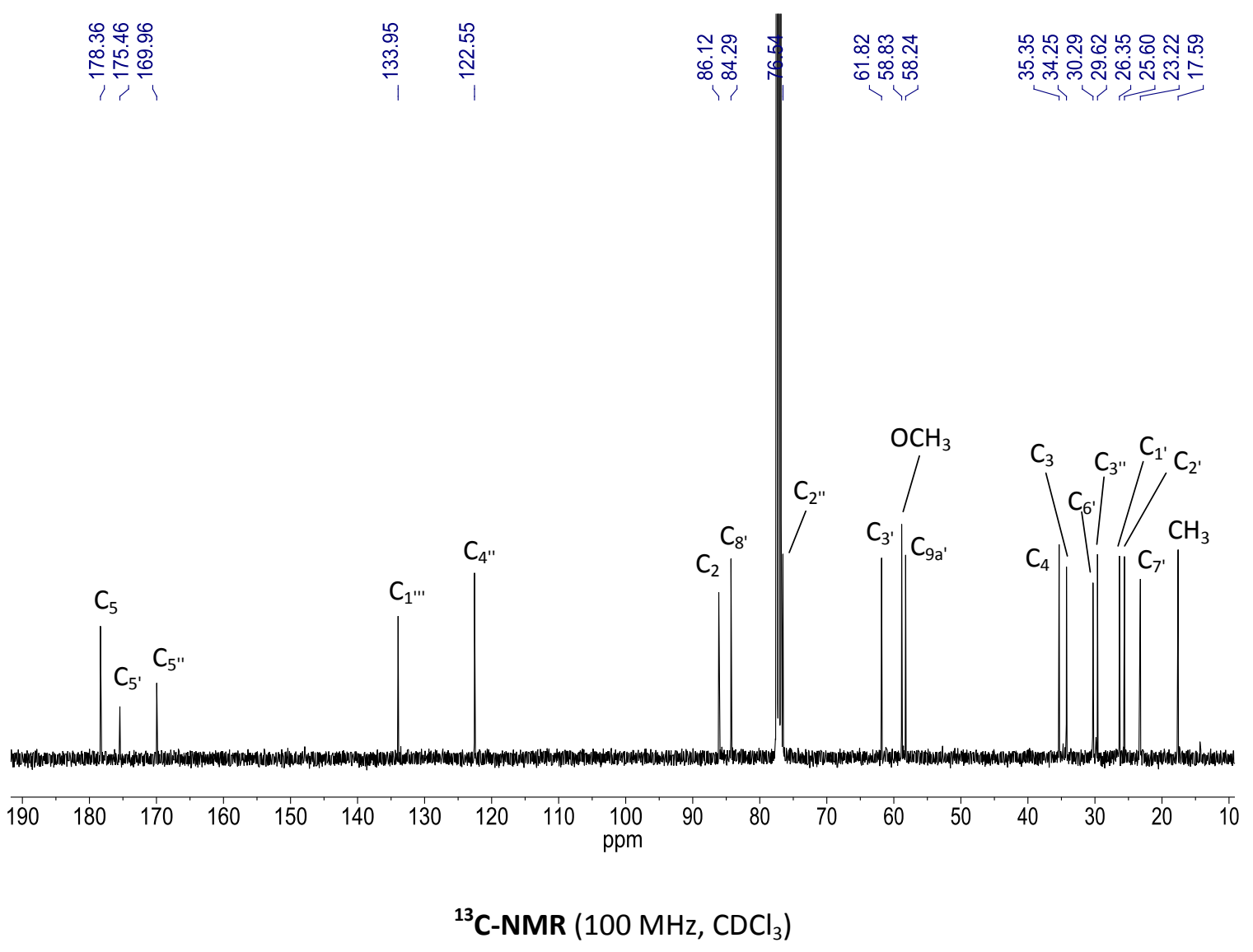




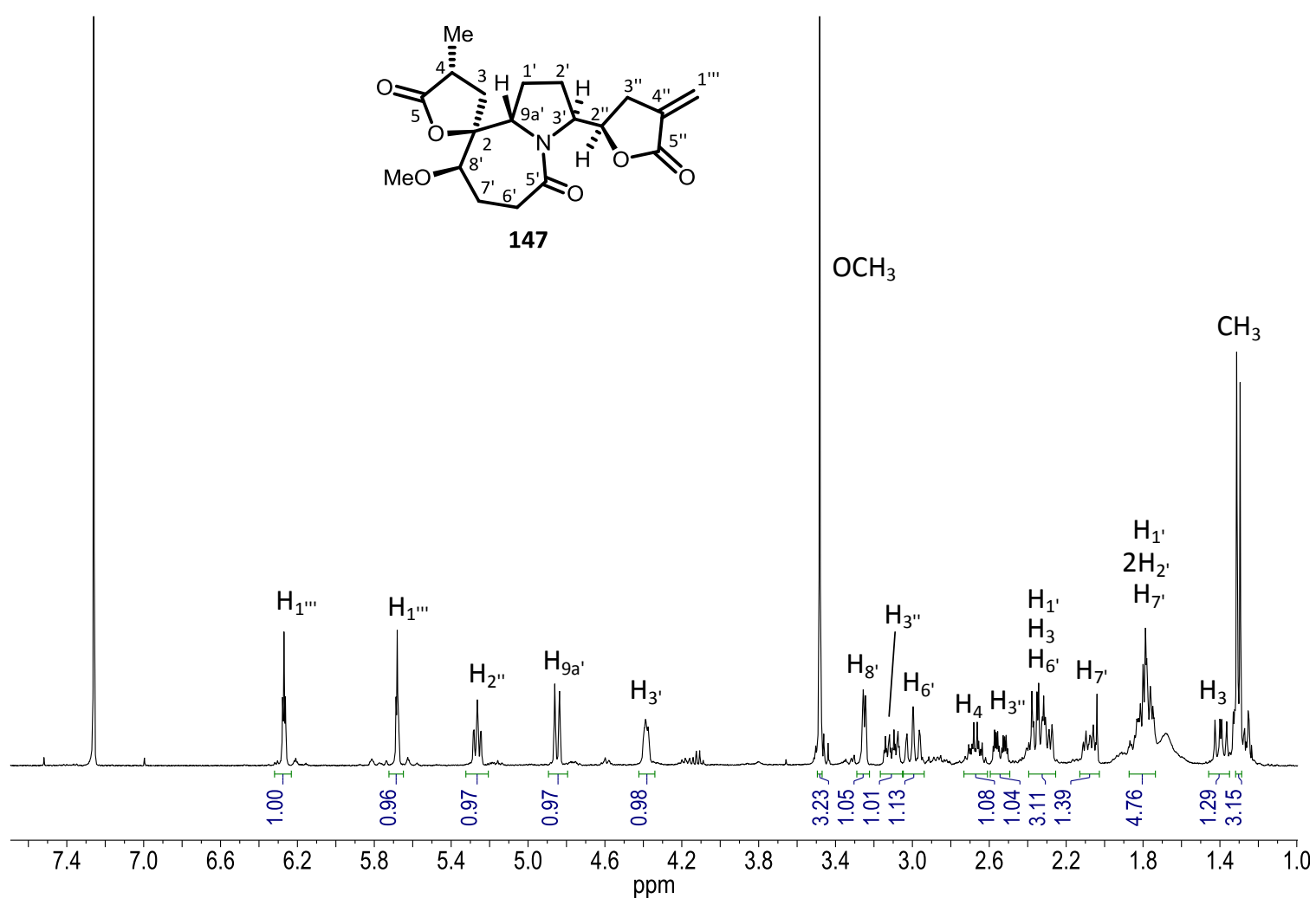

${ }^{1} \mathrm{H}-\mathrm{NMR}\left(400 \mathrm{MHz}, \mathrm{CDCl}_{3}\right.$ )

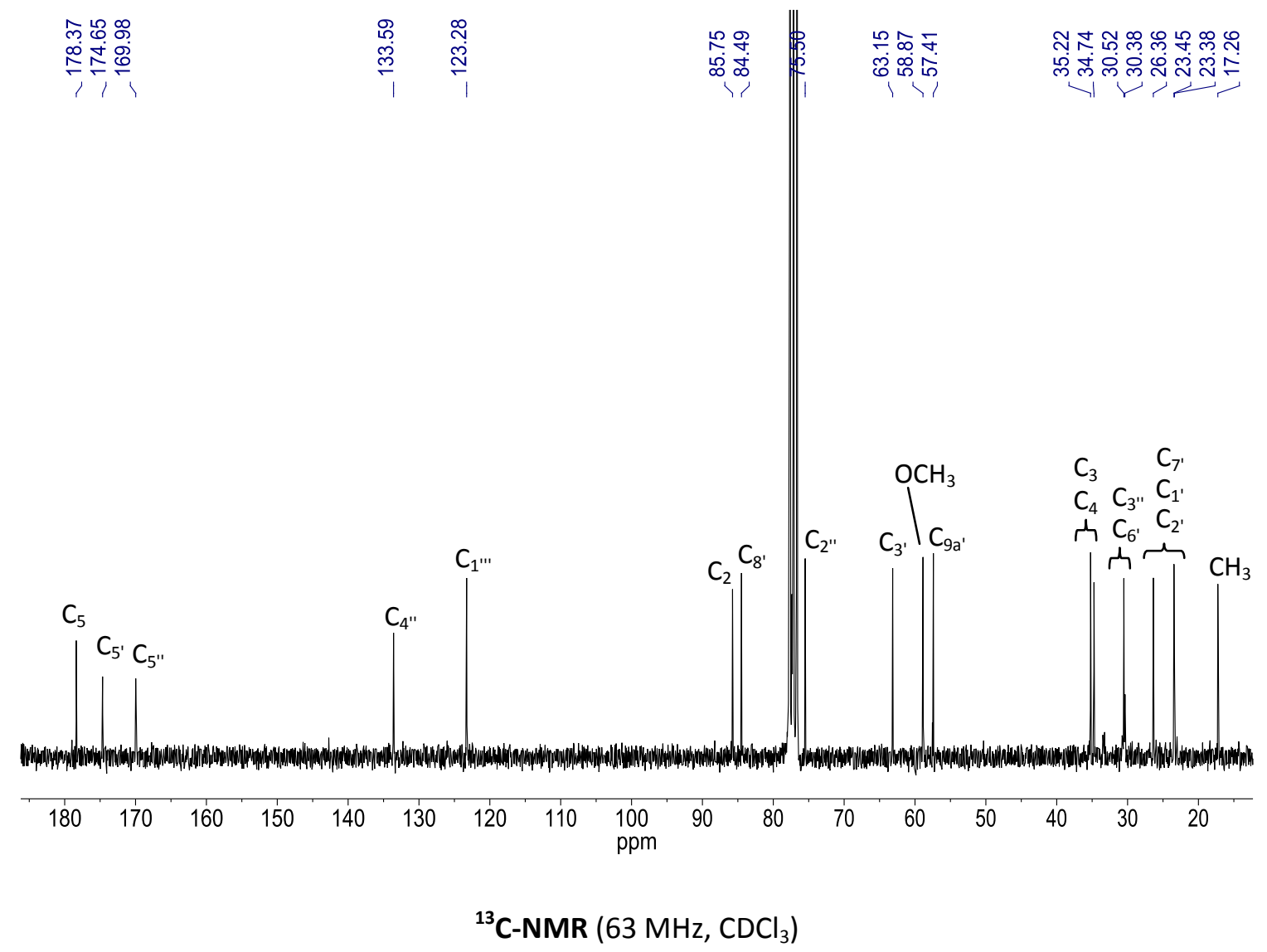




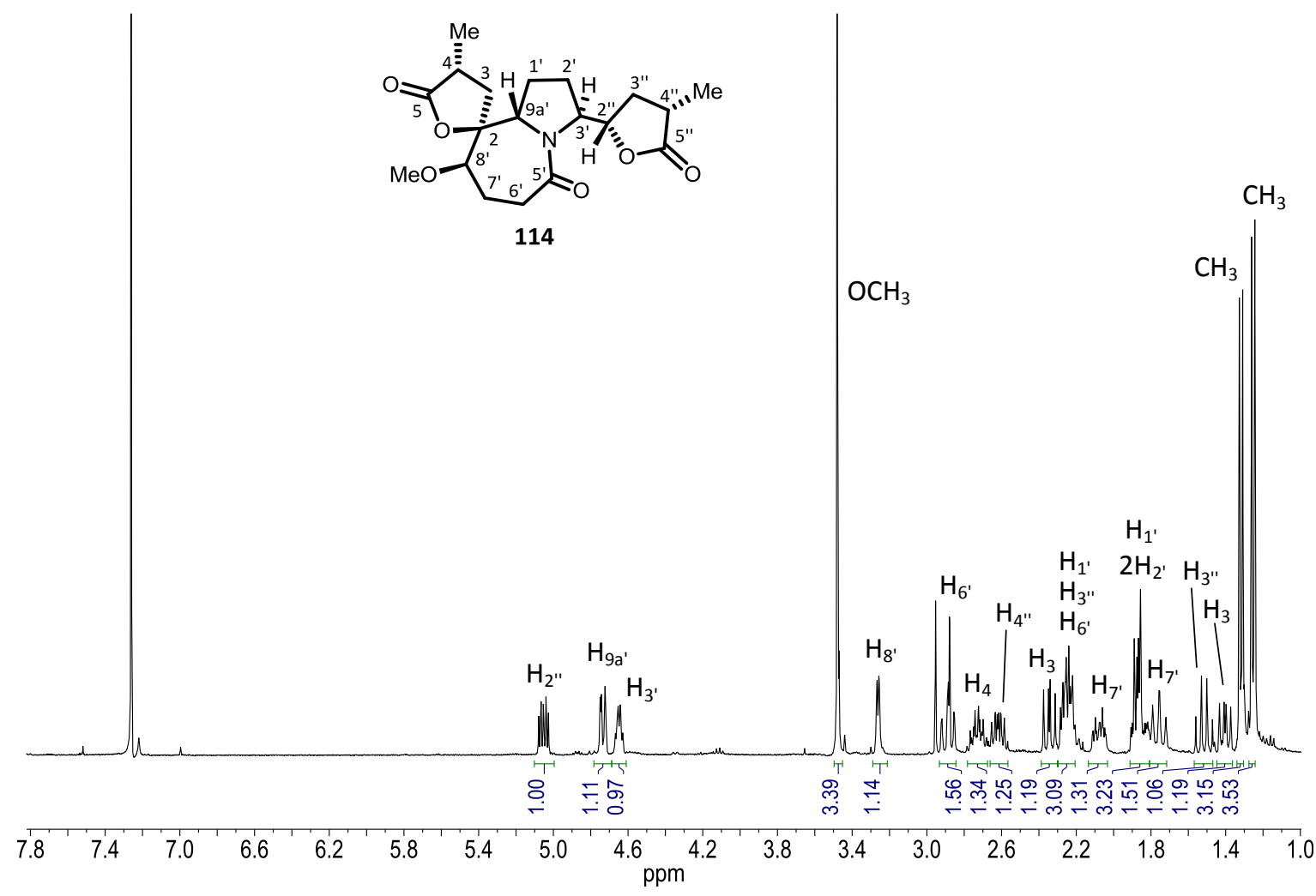

${ }^{1}$ H-NMR (400 MHz, $\mathrm{CDCl}_{3}$ )

$\sqrt{n-5}$
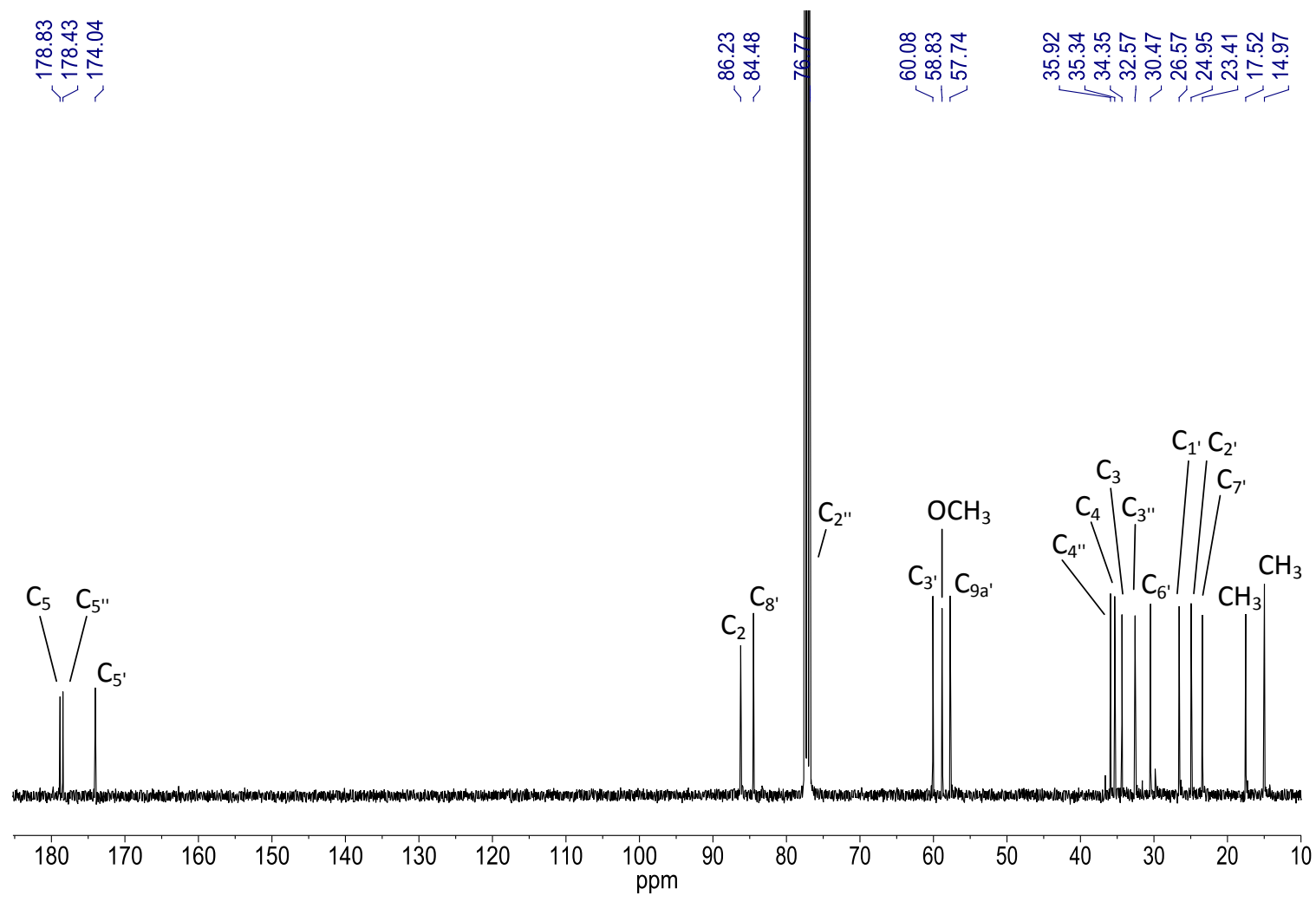

${ }^{13}$ C-NMR (100 MHz, $\left.\mathrm{CDCl}_{3}\right)$ 


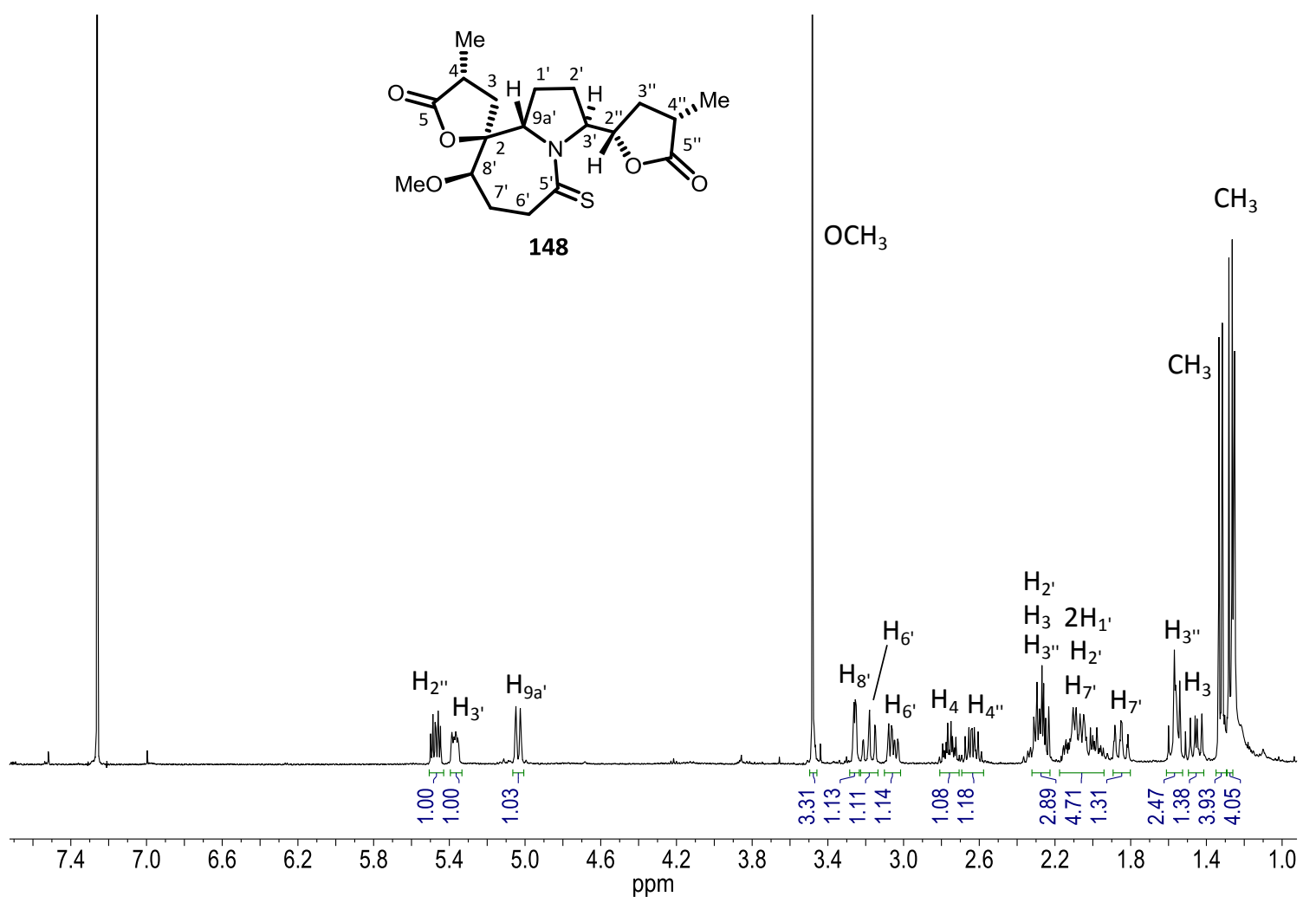

${ }^{1} \mathrm{H}-\mathrm{NMR}\left(400 \mathrm{MHz}, \mathrm{CDCl}_{3}\right.$ )

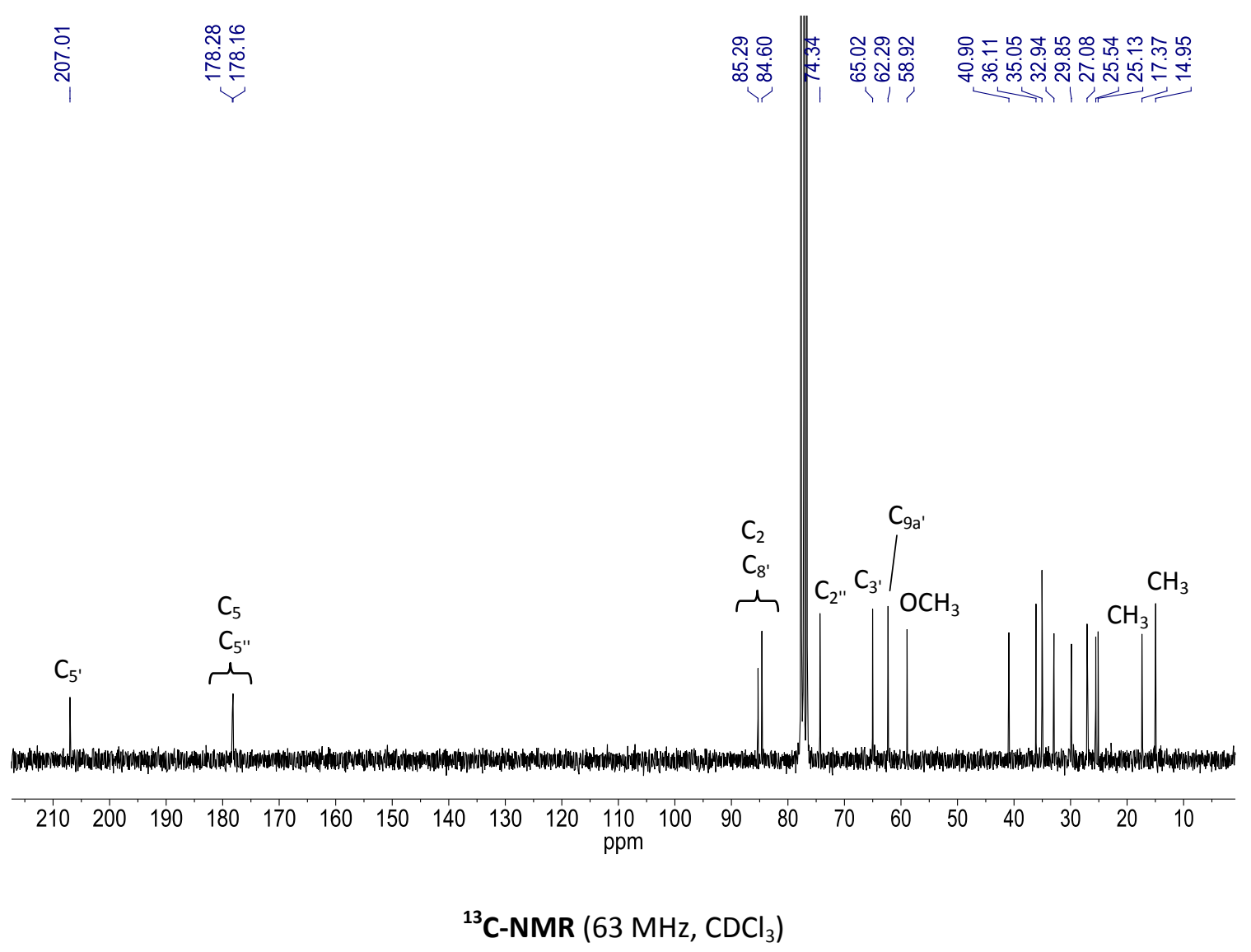




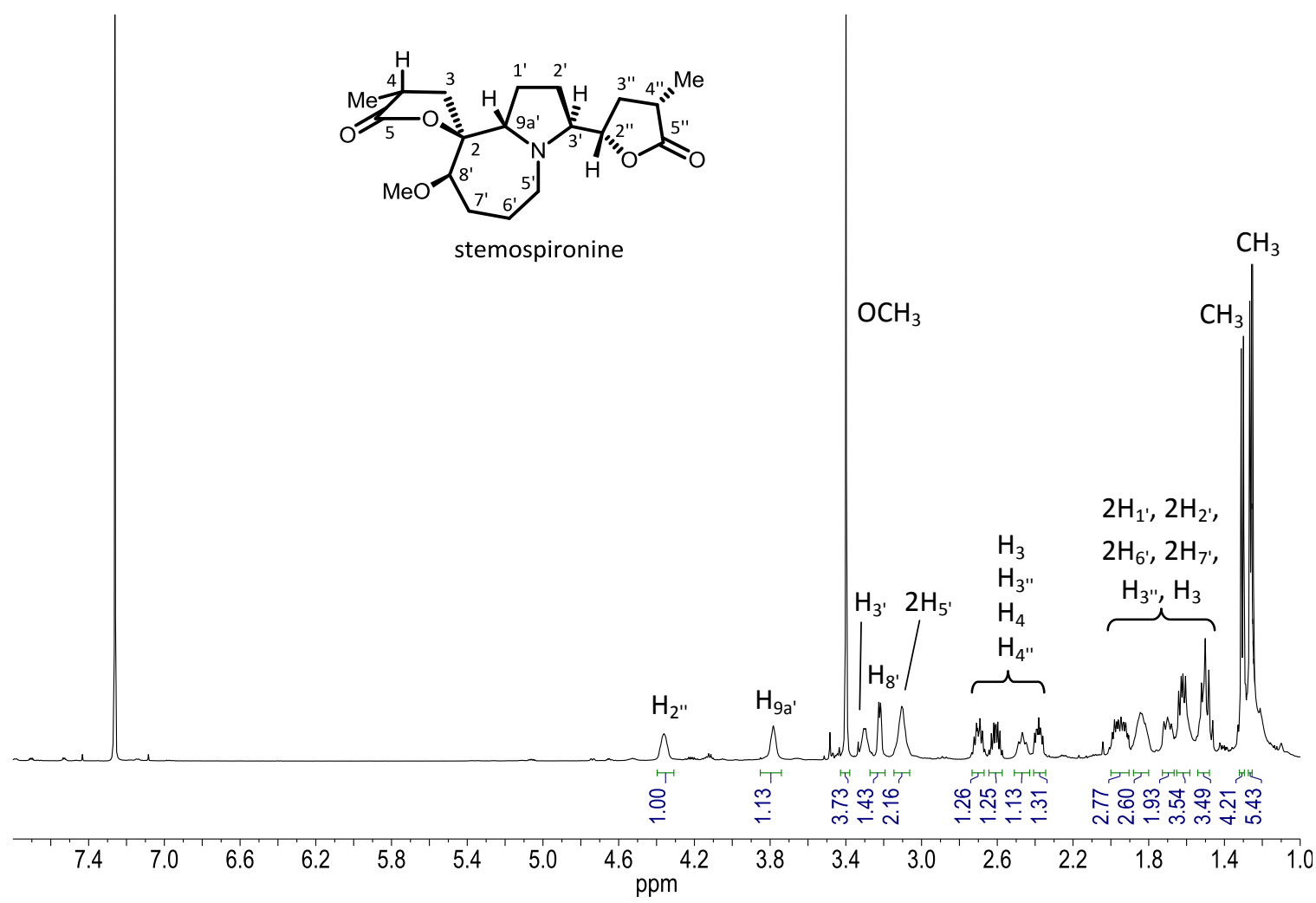

${ }^{1}$ H-NMR (600 MHz, $\mathrm{CDCl}_{3}$ )

웅

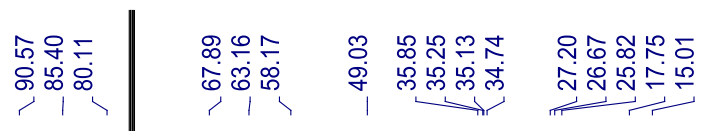

$\mathrm{C}_{5}$

$\mathrm{C}_{5}$

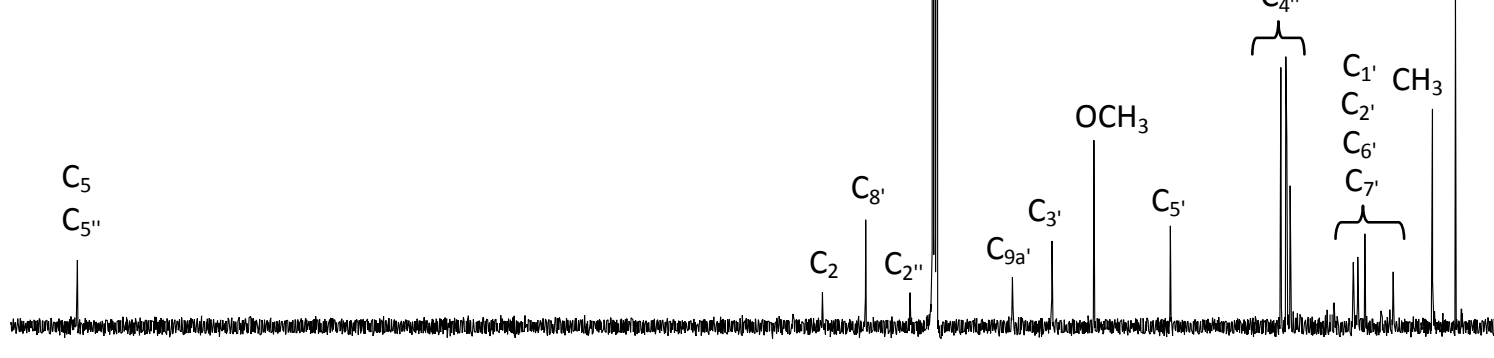

$\mathrm{C}_{3}$

$\mathrm{C}_{3 "}$

$\mathrm{C}_{4}$

$\quad \mathrm{CH}_{3}$

$\begin{array}{lllllllllllllllll}180 & 170 & 160 & 150 & 140 & 130 & 120 & 110 & \begin{array}{c}100 \\ \mathrm{ppm}\end{array} & 90 & 80 & 70 & 60 & 50 & 40 & 30 & 20\end{array}$

${ }^{13}$ C-NMR (150 MHz, $\left.\mathrm{CDCl}_{3}\right)$ 


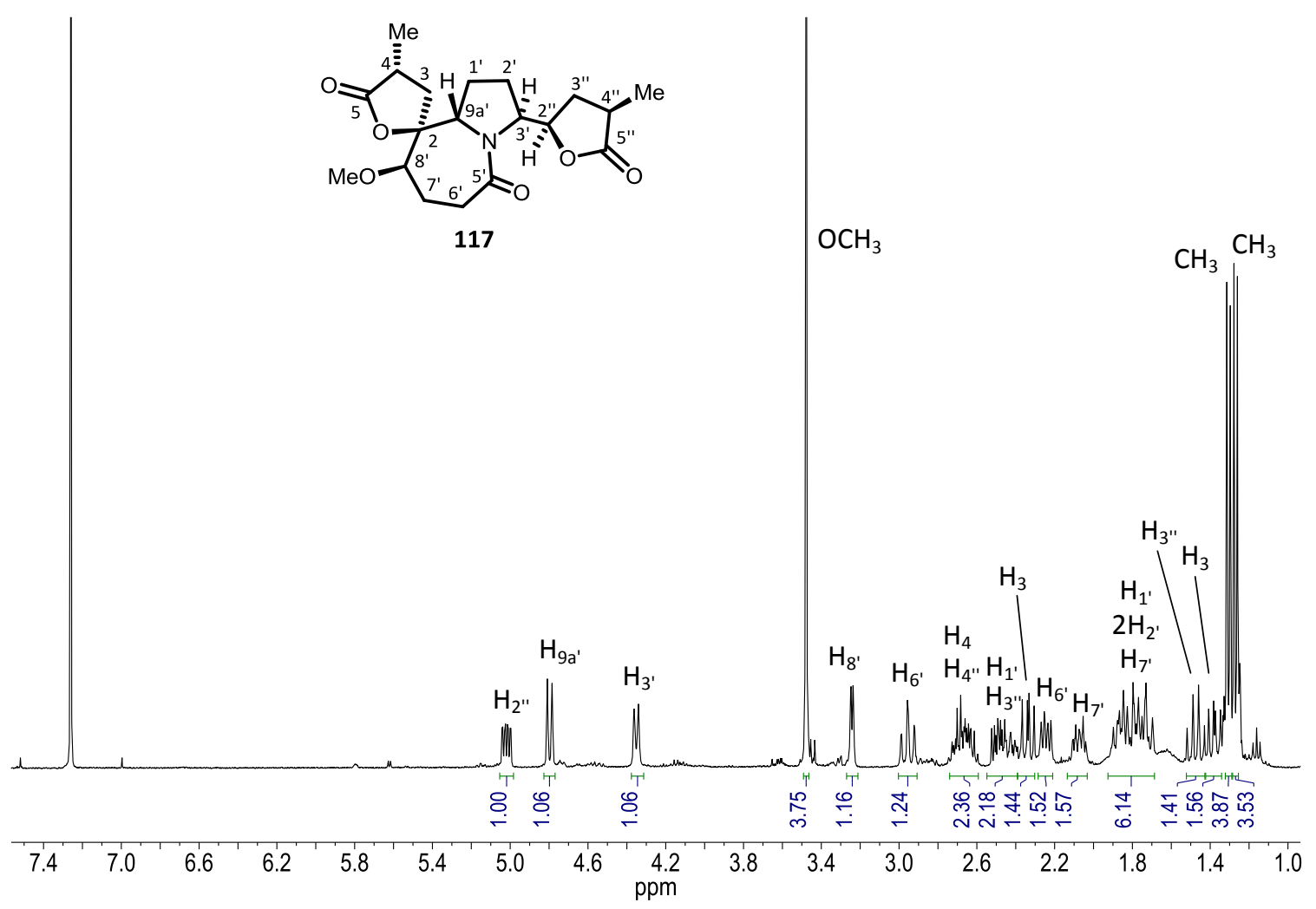

${ }^{1} \mathrm{H}-\mathrm{NMR}\left(400 \mathrm{MHz}, \mathrm{CDCl}_{3}\right.$ )

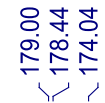

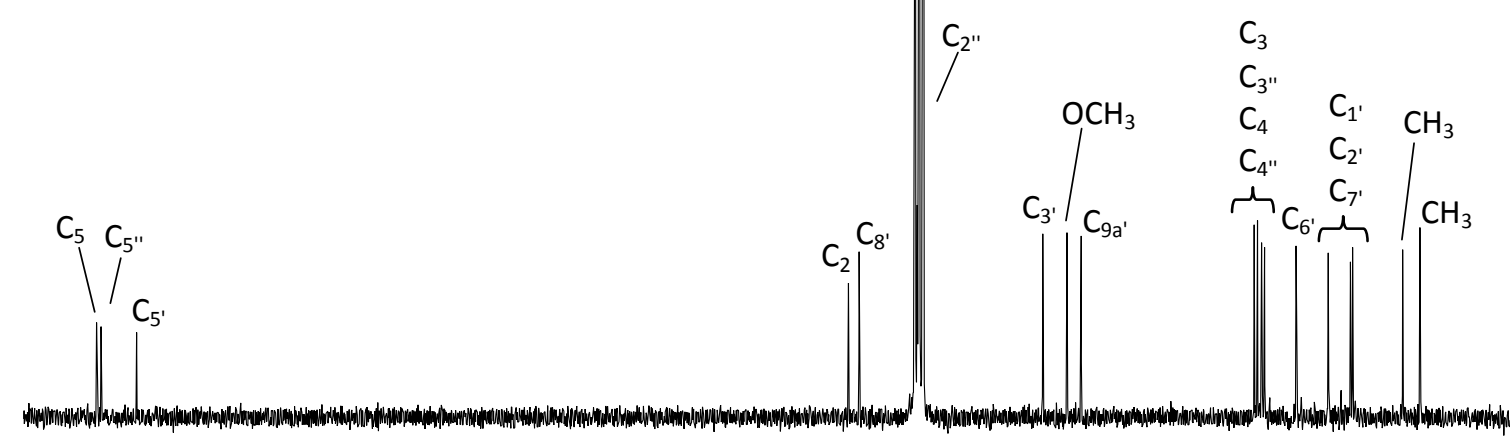

$\mathrm{C}_{2 "}$

$\mathrm{C}_{3}$

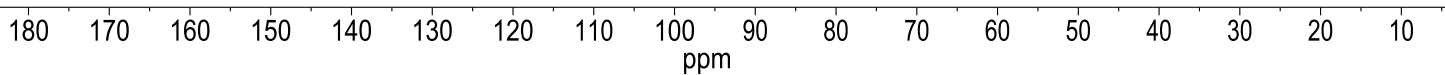

${ }^{13} \mathrm{C}-\mathrm{NMR}\left(63 \mathrm{MHz}, \mathrm{CDCl}_{3}\right)$ 


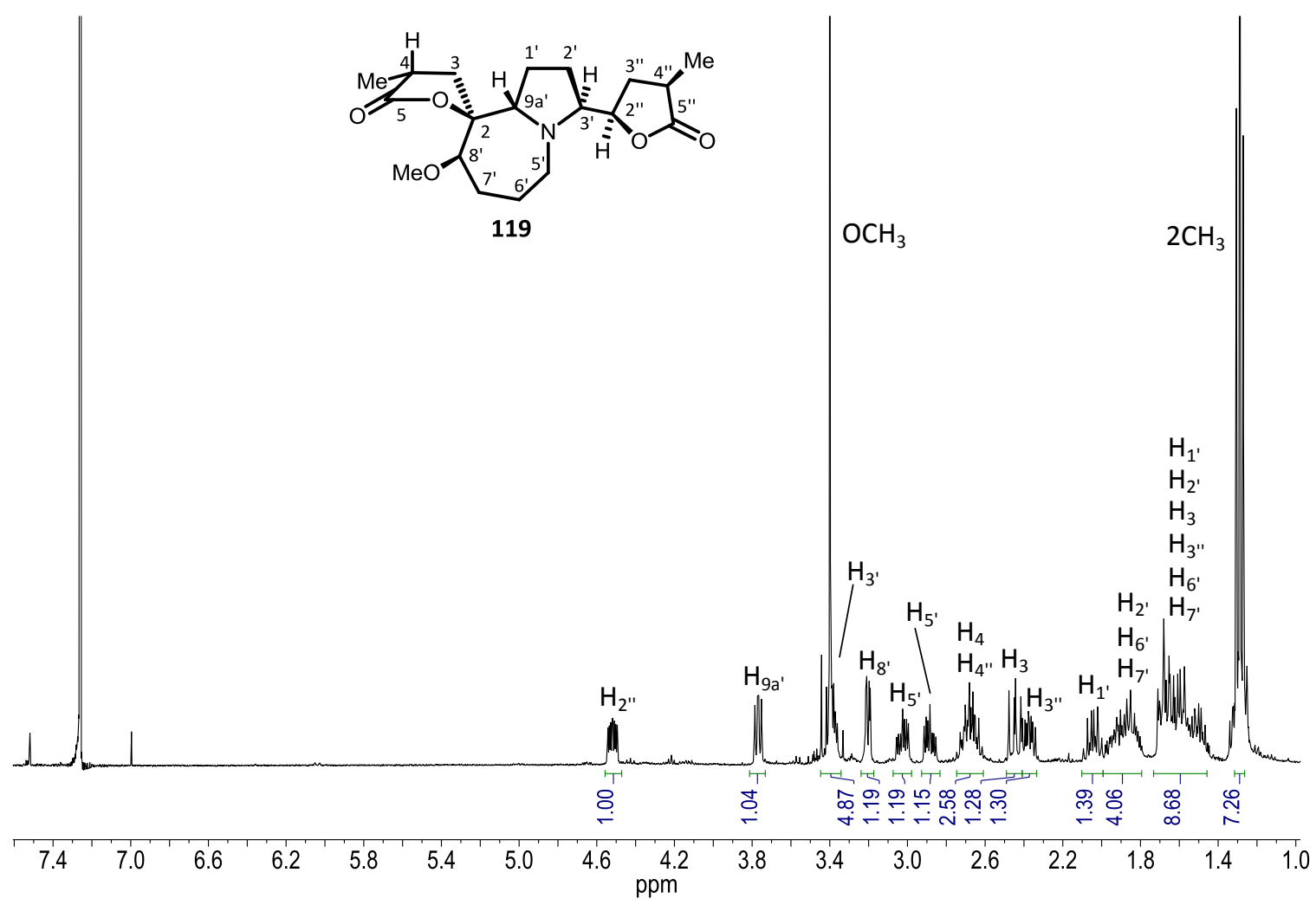

${ }^{1}$ H-NMR (400 MHz, $\mathrm{CDCl}_{3}$ )

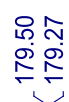

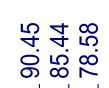
舟

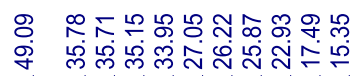

$\mathrm{C}_{4}$

$\begin{array}{ll}\mathrm{C}_{4^{\prime \prime}} & \mathrm{C}_{1} \\ \mathrm{C}_{3} & \end{array}$

$\begin{array}{lll}\mathrm{C}_{3} & \mathrm{C}_{2} \mathrm{C}^{\prime} & \mathrm{CH}_{3}\end{array}$

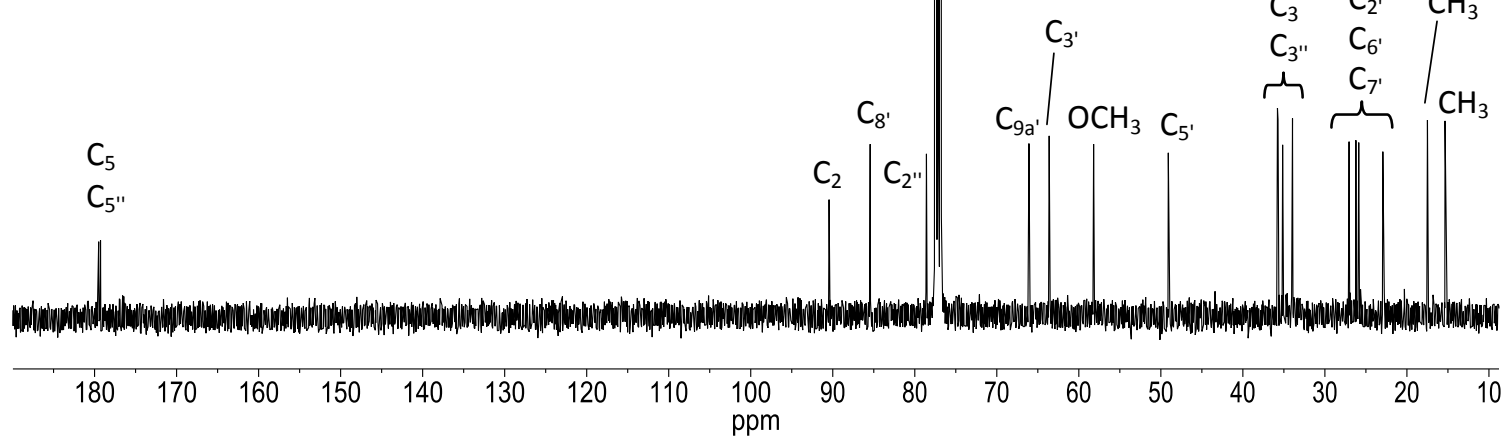

${ }^{13}$ C-NMR (100 MHz, $\mathrm{CDCl}_{3}$ ) 

6. Index of References 

${ }^{1}$ (a) Pilli, R. A.; de Oliveira, M. C. F. Nat. Prod. Rep. 2000, 17, 117-127; (b) Pilli, R. A.; Rosso, G. B.; de Oliveira, M. C. F.; in: The Alkaloids (Ed.: G.A. Cordell), Elsevier, New York, 2005, 62, 77-173; (c) Greger, H.; Planta Med. 2006, 72, 99-113; (d) Pilli, R. A.; Rosso, G. B.; de Oliveira, M. C. F.; Nat. Prod. Rep. 2010, 27, 1908-1937.

${ }^{2}$ Figueredo, M.; Alibés, R. Eur. J. Org. Chem. 2009, 2421-2435.

${ }^{3}$ There are several webpages where the use and marketing of products containing extracts of these plants are described.

${ }^{4}$ Shenging, F.Z. CN 102643134 A 20120822; Liren, Z.; Yuebin, Z. CN 1054349 A 19910111; (c) Maoxuan, L.; Guangyu, Y. CN 1308871 A 20010822; (d) Changan, W.; Zhaoming, W. CN 1120890 A 19960424.

${ }^{5}$ Ahaoli, C. CN 1129733 A 19960828.

${ }^{6}$ (a) Xianliang, H. CN 1247893 A 20000322; (b) Minqui, D.; Jihua, X.; Chengjing, W. CN 1301533 A 20010704.

${ }^{7}$ (a) Shenging, Z. CN 102640765 A 20120822; (b) Shuili, X. CN 1186604 A 19980708.

${ }^{8}$ (a) Shenging, F. Z. CN 102614434 A 20120801; (b) Quingyun, M.; Yingchun, C. CN 102552773 A 20120711; (c) Hongbo, Z.; Xiaming, Z. CN 102526662 A 20120704.

${ }^{9}$ (a) Junrui, M. CN 1265315 A 20000906; (b) Lisheng, S. CN 102579928 A 20120718; (c) Yanke, L. CN 102166304 B 20120425.

${ }^{10}$ Shinozaki, H.; Ishida, M. Brain Res. 1985, 334, 33-40.

${ }^{11}$ Sakata, K.; Aoki, K.; Chang, C.-F.; Sakurai, A.; Tamura, S.; Murakoshi, S. Agric. Biol. Chem. 1978, 42, 457-463.

${ }^{12}$ Brem, B.; Seger, C.; Pacher, T.; Hofer, O.; Vajrodaya, S.; Greger. H. J. Agric. Food Chem. 2002, $50,6383-6388$.

${ }^{13}$ (a) Sekine, T.; Ikegami, F.; Fukasawa, N.; Kashiwagi, Y.; Aizawa, T.; Fujii, Y.; Ruangrungsi, N.; Murakoshi, I. J. Chem. Soc. Perkin Trans. 1, 1995, 391-393; (b) Tip-Pyang, S.; Tangpraprutgul, P.; Wiboonpun, N.; Veerachato, G.; Phuwapraisirisan, P.; Sup-Udompol, B. ACGC Chem. Res. Commun. 2000, 12, 31-35.

${ }^{14}$ (a) Chung, H.-S.; Hon, P.-M.; Lin, G.; But, P. P.-H.; Dong, H. Planta Med. 2003, 69, 914; (b) Xu, Y. T.; Shaw, P. C.; Jiang, R. W.; Hon, P. M.; Chan, Y. M.; But, P. P. J. Ethnopharmacol. 2010, 128, 679684; (c) Yang, X. Z.; Zhu, J. Y.; Tang, C. P.; Ke, C. Q.; Lin, G.; Cheng, T. Y.; Rudd, J. A.; Ye, Y. Planta Med. 2009, 75, 174-177; (d) Wang, W.; Wang, X.; Sun, H.; Dong, W.; Zhang, A. Fitoterapia, 2012, 
83, 1699-1705; (e) Lin, L.-G.; Leung, H. P.-H.; Zhu, J.-Y.; Tang, C.-P.; Ke, C.-Q.; Rudd, J. A.; Ye, Y. Tetrahedron, 2008, 64, 10155-10161; (f) But, P. P.-H; Shaw, P.-C.; Jiang, R.-W.; Xu, Y.-T. Adv. Bot. Res. 2012, 62, 1-33.

${ }^{15}$ Rinner, B.; Siegl, V.; Pürstner, P.; Efferth, T.; Brem, B.; Greger, H.; Pfragner, R. Anticancer Res. 2004, 24, 495-500.

${ }^{16}$ (a) Xiang, L.; Kozikowski, A. P. Synlett 1990, 279-281; (b) Wipf, P.; Kim, Y. Tetrahedron Lett. 1992, 33, 5477-5480; (c) Beddoes, R. L.; Davies, M. P. H.; Thomas, E. J. J. Chem. Soc., Chem. Commun. 1992, 538-540; (d) Martin, S. F.; Corbett, J. W. Synthesis 1992, 01/02, 55-57; (e) Morimoto, Y.; Nishida, K.; Hayashi, Y.; Shirahama, H. Tetrahedron Lett. 1993, 34, 5773-5776; (f) Morimoto, Y.; Iwahashi, M. Synlett 1995, 1221-1222; (g) Wipf, P.; Goldstein, D. M. Tetrahedron Lett. 1996, 37, 739-742; (h) Martin, S. F.; Bur, S. K. Tetrahedron Lett. 1997, 38, 7641-7644; (i) Rigby, J. H.; Laurent, S.; Cavezza, A.; Heeg, M. J. J. Org. Chem. 1998, 63, 5587-5591; (j) Wipf, P.; Li, W. J. Org. Chem. 1999, 64, 4576-4577; (k) Pearson, W. H.; Hutta, D. A.; Fang, W.-K. J. Org. Chem. 2000, 65, 8326-8332; (I) Jung, S. H.; Lee, J. E.; Joo, H. J.; Kim, S. H.; Koh, H. Y. Bull. Korean Chem. Soc. 2000, 21, 159-160; (m) Pearson, W. H.; Walavalkar, R. Tetrahedron 2001, 57, 50815089; (n) Hinmnan, M. M.; Heathcock, C. H. J. Org. Chem. 2001, 66, 7751-7756; (o) Velázquez, F.; Olivo, H. F. Org. Lett. 2002, 4, 3175-3178; (p) Booker-Milburn, K. I.; Hirst, P.; Charamant, J. P. H.; Taylor, L. H. J. Angew. Chem. Int. Ed. 2003, 42, 1642-1644; (q) Lindsay, K. B.; Pyne, S. G. Synlett 2004, 779-782; (r) Cid, P.; Closa, M.; de March, P.; Figueredo, M.; Font, J.; Sanfeliu, E.; Soria, A. Eur. J. Org. Chem. 2004, 4215-4233; (s) Roberts, E.; Samçon, J. P.; Sweeney, J. B. Org. Lett. 2005, 7, 2075-2078; (t) Alibés, R.; Blanco, P.; Casas, E.; Closa, M.; de March, P.; Figueredo, M.; Font, J.; Sanfeliu, E.; Álvarez-Larena, A. J. Org. Chem. 2005, 70, 3157-3167; (u) Gu, P.; Zhao Y.-M.; Tu, Y. Q.; Ma, Y.; Zhang, F. Org. Lett. 2006, 8, 5271-5273; (v) Antoline, J. E.; Hsung, R. P.; Huang, J.; Song, Z.; Li, G. Org. Lett. 2007, 9, 1275-1278; (w) Zhu, L.; Lauchli, R.; Loo, M.; Shea, K. J. Org. Lett. 2007, 9, 2269-2271; (x) Frankowski, K. J.; Neuenswander, B.; Aubé, J. J. Comb. Chem. 2008, 10, 721-725; (y) Yaji, K.; Shindo, M. Tetrahedron Lett. 2010, 51, 5469-5472; (z) Burrell, A.; Watson, L.; Martin, N. G.; Oram, N.; Coldham, I. Org. Biomol. Chem. 2010, 8, 4530-4532; (aa) Dietz, J.; Martin, S. F. Tetrahedron Lett. 2011, 52, 2048-2050; (ab) Bates, R. W.; Sridhar, S. J. Org. Chem. 2011, 76, 50265035.

\section{${ }^{17-38}$ Total syntheses:}

${ }^{17}$ (+)-Croomine: (a) Williams, D. R.; Brown, D. L.; Benbow, J. W. J. Am. Chem. Soc. 1989, 111, 1923-1925; (b) Martin, S. F.; Barr, K. J. J. Am. Chem. Soc. 1996, 118, 3299-3300; (c) Martin, S. F.; Barr, K. J.; Smith, D. W.; Bur, S. K. J. Am. Chem. Soc. 1999, 121, 6990-6997. 
${ }^{18}$ ( \pm )-Stenine: (a) Chen, C. Y.; Hart, D. J. J. Org. Chem. 1990, 55, 6236-6240; (b) Chen, C. Y.; Hart, D. J. J. Org. Chem. 1993, 58, 3840-3849; (c) Ginn, J. D.; Padwa, A. Org. Lett. 2002, 4, 1515-1517; (d) Golden, J. E.; Aubé, J. Angew. Chem. Int. Ed. 2002, 41, 4316-4318; (e) Zeng, Y.; Aubé, J. J. Am. Chem. Soc. 2005, 127, 15712-15713; (f) Frankowski, K. J.; Golden, J. E.; Zeng, Y.; Lei, Y.; Aubé, J. J. Am. Chem. Soc. 2008, 130, 6018-6024.

${ }^{19}$ (-)-Stenine: (a) Wipf, P.; Kim, Y.; Goldstein, D. M. J. Am. Chem. Soc. 1995, 117, 11106-11112;(b) Morimoto, Y.; Iwahashi, M.; Nishida, K.; Hayashi, Y.; Shirahama, H. Angew. Chem. Int. Ed. Engl. 1996, 35, 904-906; (c) Morimoto, Y.; Iwahashi, M.; Kinoshita, T.; Nishida, K. Chem. Eur. J. 2001, 7, 4107-4116; (d) Chen, J.; Chen, J.; Xie, Y.; Zhang, H. Angew. Chem. Int. Ed. 2012, 51, 1024-1027; (e) Fujioka, H.; Nakahara, K.; Kotoku, N.; Ohba, Y.; Nagatomi, Y.; Wang, T.-L.; Sawama, Y.; Murai, K.; Hirano, K.; Oki, T.; Wakamatsu, S.; Kita, Y. Chem. Eur. J. 2012, 18, 13861-13870.

${ }^{20}$ (士)-Stemoamide: (a) Kohno, Y.; Narasaka, K. Bull. Chem. Soc. Jpn. 1996, 69, 2063-2070; (b) Jacobi, P. A.; Lee, K. J. Am. Chem. Soc. 1997, 119, 3409-3410; (c) Jacobi, P. A.; Lee, K. J. Am. Chem. Soc. 2000, 122, 4295-4303; (d) Bogliotti, N.; Dalko, P. I.; Cossy, J. J. Org. Chem. 2006, 71, 95289531; (e) Bates, R. W.; Sridhar, S. Synlett. 2009, 12, 1979-1981; (f) Wang, Y.; Zhu, L.; Zhang, Y.; Hong, R. Angew. Chem. Int. Ed. 2011, 50, 2787-2790.

${ }^{21}$ (-)-Stemoamide: (a) Williams, D. R.; Reddy, J. P.; Amato, G. S. Tetrahedron Lett. 1994, 35, 64176420; (b) Kinoshita, A.; Mori, M. J. Org. Chem. 1996, 61, 8356-8357; (c) Kinoshita, A.; Mori, M. Heterocycles 1997, 46, 287-299; (d) see ref. 20c; (e) Gurjar, M. K.; Reddy, D. S. Tetrahedron Lett. 2002, 43, 295-298; (f) Sibi, M. P.; Subramanian, T. Synlett 2004, 1211-1214; (g) Olivo, H. F.; TovarMiranda, R.; Barragán, E. J. Org. Chem. 2006, 71, 3287-3290; (h) Torssell, S.; Wanngren, E.; Somfai, P.; J. Org. Chem. 2007, 72, 4246-4249; (i) Honda, T.; Matsukawa, T.; Takahashi, K. Org. Biomol. Chem. 2011, 9, 673-675.

${ }^{22}$ (+)-Stemoamide: Bogliotti, N.; Dalko, P. I.; Cossy, J. Synlett. 2006, 2664-2666.

${ }^{23}$ (-)-9,10-epi-Stemoamide: Khim, S.-K.; Schultz, A. G. J. Org. Chem. 2004, 69, 7734-7736.

${ }^{24}$ (士)-9,10-epi-Stemoamide: see ref. $20 \mathrm{~d}$.

${ }^{25}$ (士)-Isostemofoline: Kende, A. S.; Smalley, Jr T. L.; Huang, H. J. Am. Chem. Soc. 1999, 121, 74317432.

${ }^{26}( \pm)$-Stemonamide and ( \pm )-isostemonamide: (a) Kende, A. S.; Hernando, J. I. M.; Milbank, J. B. J. Org. Lett. 2001, 3, 2505-2508; (b) Kende, A. S.; Hernando, J. I. M.; Milbank, J. B. J. Tetrahedron 2002, 58, 61-74; (c) Taniguchi, T.; Tanabe, O.; Muraoka, O.; Ishibashi, H. Org. Lett. 2008, 10, 197199; (d) Taniguchi, T.; Ishibashi, H. Tetrahedron 2008, 64, 8773-8779; (e) Chen, Z.-H.; Zhang, Y.; 
Chen, Z; Tu, Y.; Zhang, F. Chem. Comm. 2011, 47, 1836-1838; (f) Chen, Z.; Chen, Z.; Zhang, Y.-Q.; Tu, Y.-Q.; Zhang, F.-M. J. Org. Chem. 2011, 76, 10173-10186.

${ }^{27}$ (-)-Stemospironine: (a) Williams, D. R.; Fromhold, M. G.; Earley, J. D. Org. Lett. 2001, 3, 2721 2724; (b) Bardají, N.; Sánchez-Izquierdo, F.; Alibés, R.; Font, J.; Busqué, F.; Figueredo, M. Org. Lett. 2012, 14, 4854-4857.

${ }^{28}$ (-)-Tuberostemonine: (a) Wipf, P.; Rector, S. R.; Takahashi, H. J. Am. Chem. Soc. 2002, 124, 14848-14849; (b) Wipf, P.; Spencer, S. R. J. Am. Chem. Soc. 2005, 127, 225-235.

${ }^{29}$ (-)-Stemonine: Williams, D. R.; Shamim, K.; Reddy, J. P.; Amato, G. S.; Shaw, S. M. Org. Lett. 2003, 5, 3361-3364.

${ }^{30}( \pm)$-Didehidrostemofoline (asparagamine $A$ ) and ( \pm )-isodidehidrostemofoline: Brüggemann, M.; McDonald, A. I.; Overman, L. E.; Rosen, M. D.; Schwink, L.; Scott, J. P. J. Am. Chem. Soc. 2003, $125,15284-15285$.

${ }^{31}$ (-)-Didehidrotuberostemonine: see ref. 28b.

${ }^{32}$ ( \pm )-Neostenine: (a) Lainchbury, M. D.; Medley, M. I.; Taylor, P. M.; Hirst, P.; Dohle, W.; BookerMilburn, K. I. J. Org. Chem; 2008, 73, 6497-6505; (b) see ref. $18 f$.

${ }^{33}$ ( \pm )-Stemonamine and ( \pm )-isostemonamine: (a) see ref. 26d; (b) Zhao, Y.-M.; Gu, P.; Tu, Y.-Q.; Fan, C.-A.; Zhang, Q. Org. Lett. 2008, 10, 1763-1766; (c) Zhao, Y.-M.; Gu, P.; Zhang, H.-J.; Zhang, Q.-W.; Fan, C.-A.; Tu, Y.-Q.; Zhang, F.-M. J. Org. Chem. 2009, 74, 3211-3213; (d) Chen, Z.-H.; Tu, Y.-Q.; Zhang, S.-Y.; Zhang, F.-M. Org. Lett. 2011, 13, 724-727.

${ }^{34}$ (-)-Sessilifoliamide J: (a) Liu, X.-K.; Ye, J.-L.; Ruan, Y.-P.; Li, Y.-X.; Huang, P.-Q. J. Org. Chem. 2013, 78, 35-41, (b) Tuo, S.; Liu, X.; Huang, P. Chin. J. Chem. 2013, 31, 55-62.

${ }^{35}$ (-)-9-epi-sessilifoliamide J: Tuo, S.-C.; Ye, J.-L.; Wang, A.-E; Huang, S.-Y.; Huang, P.-Q. Org. Lett. 2011, 13, 5270-5273.

${ }^{36}$ (-)-Sessilifoliamide C and (-)-8-epi-stemoamide: Hoye, A. T.; Wipf, P. Org. Lett. 2011, 13, 26342637.

${ }^{37}( \pm)$-Maistemonine: see ref. 26e-f.

${ }^{38}$ Stemonidine (putative structure): Sánchez-Izquierdo, F.; Blanco, P.; Busqué, F.; Alibés, R.; de March, P.; Figueredo, M.; Font, J.; Parella, T. Org. Lett. 2007, 9, 1769-1772.

${ }^{39}$ Williams, D. R.; Osterhout, M. H.; McGill, J. M. Tetrahedron Lett. 1989, 30, 1331-1334.

${ }^{40}$ Closa, M.; de March, P.; Figueredo, M.; Font, J. Tetrahedron Assymetry 1997, 8, 1031-1037. 
${ }^{41}$ Busqué, F.; de March, P.; Figueredo, M.; Font, J.; Gallagher, T.; Milán, S. Tetrahedron: Assymetry 2002, 13, 437-445.

${ }^{42}$ Alibés, R.; Blanco, P.; de March, P.; Figueredo, M.; Font, J.; Álvarez-Larena, A.; Piniella, J.F. Tetrahedron Lett. 2003, 44, 523-525.

${ }^{43}$ Gella, C.; Ferrer, E.; Alibés, R.; Busqué, F.; de March, P.; Figueredo, M.; Font, J. J. Org. Chem. 2009, 74, 6365-6367.

${ }^{44}$ Xu, R.; Lu, Y.; Chu, J.; Iwashita, T.; Naoki, H.; Naya, Y.; Nakanishi, K. Tetrahedron 1982, 38, $2667-$ 2670; He, X.; Lin, W.; Xu, R. Huaxue Xuebao 1990, 48, 694.

${ }^{45}$ Houk, K. N.; Firestone, R. A.; Münchausen, L. L.; Mueller, P. H.; Arison, B. H.; García, L. A. J. Am. Chem. Soc. 1985, 107, 7227-7228.

${ }^{46}$ (a) Tufariello, J. J. 1,3-Dipolar Cycloaddition Chemistry, Padwa, A. Ed., John Wiley and Sons, New York, 1984, Vol. 2, Chapter 9; (b) Torsell, K. B. G. Nitrile Oxides, Nitrones, and Nitronates in Organic Synthesis, H. Feuer Ed., V. C. H. Publishers, Inc., New York, 1988; (c) Little, R. C. Comprehensive Organic Chemistry, Trost, B. M. and Fleming, I. Ed., Pergamon Press 1991, Vol. 5, Chapter 3.

${ }^{47}$ Sustmann, R. Pure Appl. Chem. 1974, 40, 569-593.

${ }^{48}$ (a) Plate, R.; Hermkens, P. H. H.; Simits, J. M. M.; Ottenheijm, H. C. J. J. Org. Chem. 1986, 51, 309-314; (b) Burdisso, M.; Gandolfi, R.; Grünanger, P. Tetrahedron 1989, 45, 5579-5594; (c) Ali, Sk. A.; Khan, J. H.; Wazeer, M. I. M.; Perzanowski, H. P. Tetrahedron 1989, 45, 5979-5986.

${ }^{49}$ (a) Cid, P.; de March, P.; Figueredo, M.; Font, J.; Milán, S.; Soria, A.; Virgili, A. Tetrahedron 1993, 49, 3857-3870; (b) Alonso-Perarnau, D.; de March, P.; Figueredo, M.; Font, J.; Soria, A. Tetrahedron 1993, 49, 4267-4274; (c) Busqué, F.; de March, P.; Figueredo, M.; Font, J.; Montsalvatje, M.; Álvarez-Larena, A.; Piniella, J. F. J. Org. Chem. 1996, 61, 8578-8585, (d) de March, P.; Figueredo, M.; Font, J.; Heterocycles 1999, 50, 1213-1226.

${ }^{50}$ Raghavan, S.; Reddy, S. R.; Tony, K.A.; Kumar, C. N.; Varma, A. K.; Nangia, A. J. Org. Chem. 2002, $67,5838-5841$.

${ }^{51}$ Newman, M. S.; Evans, F. J. J. Am. Chem. Soc. 1955, 77, 946-497.

${ }^{52}$ Mitsunobu, O. Synthesis, 1981, 1-28.

${ }^{53}$ (a) Wagner, D.; Verheyden, J. P. H.; Moffat, J. G. J. Org. Chem. 1974, 39, 24-29; (b) Busqué, F.; Hopkins, S. A.; Konopelski, J. P. J. Org. Chem. 2002, 67, 6097-6103.

${ }^{54}$ Jones, S. B.; Simmons, B.; Mastracchio, A.; MacMillan, D. W. Nature 2011, 475, 183-188. 
55 Rauter, A. P.; Figueiredo, J.; Ismael, M.; Canda, T.; Font, J.; Figueredo, M. Tetrahedron: Asymmetry 2001, 12, 1131-1146.

${ }^{56}$ Corey, E. J.; Li, W.; Reichard, G. A. J. Am. Chem. Soc. 1998, 120, 2330-2336.

${ }^{57}$ Patel, P.; Lee, G.-J.; Kim, S.; Grant, G. E.; Powell, W.S.; Rokach, J. J. Org. Chem. 2008, 73, 72137218.

${ }^{58}$ Veitch, G. E.; Beckmann, E.; Burke, B. J.; Boyer, A.; Maslen, S. L.; Ley, S. V. Angew. Chem. Int. Ed. $2007,46,7629-2632$.

${ }^{59}$ Einhorn, J.; Einhorn, C.; Ratajczak, F.; Pierre, J.-L. J. Org. Chem. 1996, 61, 7452-7454.

${ }^{60}$ Luke, G. P.; Seekamp, C. K.; Wang, Z.-Q.; Chenard, B. L. J. Org. Chem. 2008, 73, 6397-6400.

61 (a) Nahmany, M.; Melman, A. Org. Lett. 2001, 3, 3733-3735; (b) Shelkov, R.; Nahmany, M.; Melman, A. J. Org. Chem. 2002, 67, 8975-8982; (c) Shelkov, R.; Nahmany, M.; Melman, A. Org. Biomol. Chem. 2004, 2, 397-401.

62 Blanco Merinero, P. Ph.D. Thesis, Universitat Autònoma de Barcelona, 2004.

${ }^{63}$ (a) Figueredo, M.; Font, J.; Virgili, A. Tetrahedron 1987, 43, 1881-1886; (b) Busqué, F.; de March, P.; Figueredo, M.; Font, J.; Sanfeliu, E. Tetrahedron Lett. 2002, 43, 5583-5585; (c) Blanco, P.; Busqué, F.; de March, P.; Figueredo, M.; Font, L.; Sanfeliu, E. Eur. J. Org. Chem. 2004, 48-53.

${ }^{64}$ González, D. Ph.D. Thesis, Universitat Autònoma de Barcelona, 2009.

${ }^{65}$ Keinan, E.; Greenspoon, N. J. Am. Chem. Soc. 1986, 108, 7314-7325.

${ }^{66}$ Khurana, J.M.; Sharma, P. Bull. Chem. Soc. Jpn. 2004, 77, 549-552.

67 (a) Kling, A.; Backfish, G.; Delzer, J.; Geneste, H.; Graef, C. Hornberger, W.; Lange, U. E. W.; Lauterbach, A.; Seitz, W.; Subkowski, T. Bioorg. Med. Chem. 2003, 11, 1319-1341; ; (b) Garrido, N. M.; Sánchez, M. R.; Díez, D.; Sanz, F.; Urones, J. G. Tetrahedron: Assymetry 2011, 872-880; (c) Dupont, C.; Guénard, D.; Tchertanov, L.; Thoret, S.; Guéritte, F. Bioorg. Med. Chem. 1999, 7, 2961-2969.

${ }^{68}$ González-Gálvez, D.; García-García, E.; Alibés, R.; Bayón, P.; de March, P.; Figueredo, M.; Font, J. J. Org. Chem. 2009, 74, 6199-6211.

${ }^{69}$ Brown, H. C.; Yoon, N. M. J. Am. Soc. Chem. 1966, 88, 1464-1472.

${ }^{70}$ Giraud, L.; Huber, V.; Jenny, T. Tetrahedron 1998, 54, 11899-11906.

${ }^{71}$ Yan, B.; Spilling, C. D. J. Org. Chem. 2008, 73, 5385-5396. 
72 (a) Carson, C. A.; Kerr, M. A. Angew. Chem. Int. Ed.. 2006, 45, 6560-6563; (b) Krawczyk, E.; Koprowski, M.; Luczak, J. Tetrahedron: Assymetry 2007, 18, 1780-1787.

${ }^{73}$ Medeiros, M. R.; Wood, J. L. Tetrahedron 2010, 66, 4701-4709.

${ }^{74}$ Leduc, A. B.; Kerr, M.A. Angew. Chem. Int. Ed. 2008, 47, 7945-7948.

${ }^{75}$ (a) Meyers, Spohn, R. F.; Linderman, R. J. J. Org. Chem. 1985, 50, 3633-3635, (b) Hicks, D. R.; Fraser-Reid, B. Chem. Comm. 1976, 869-870; (c) Olejniczak, K.; Frank, R. W.; J. Org. Chem. 1982, 47, 380-381; (d) Bonadies, F.; Cardilli, A.; Lattanzi, A.; Pesci, S.; Scettri, A. Tetrahedron Lett. 1995, $36,2839-2840$.

${ }^{76}$ (a) Kitazume, T.; Kobayashi, T.; Yamamoto, T.; Yamazaki, T. J. Org. Chem. 1987, 52, 3218-3223; (b) Ishihara, K.; Kawaguchi, T.; Matsuya, Y.; Sakurai, H.; Saiki, I.; Nemoto, H. Eur. J. Org. Chem. 2004, 3973-3978; (c) Ensch, C.; Hesse, M. Helv. Chim. Acta 2003, 86, 233-246; (d) Suenaga, K.; Mutou, T.; Shibata, T.; Itoh, T.; Fujita, T.; Takada, N.; Hayamizu, K.; Takagi, M.; Irifune, T.; Kigoshi, H.; Yamada, K. Tetrahedron 2004, 60, 8509-8527.

${ }^{77}$ Crisóstomo, F. R.; Lledó, A.; Shenoy, S. R.; Iwasawa, T.; Rebek, J. J. Am. Chem. Soc. 2009, 131, 7402-7410.

${ }^{78}$ D'Annibale, A.; Ciaralli, L. J. Org. Chem. 2007, 72, 6067-6074.

${ }^{79}$ Janecki, T.; Blaszczyk, E. Synthesis 2001, 3, 403-408. 


